

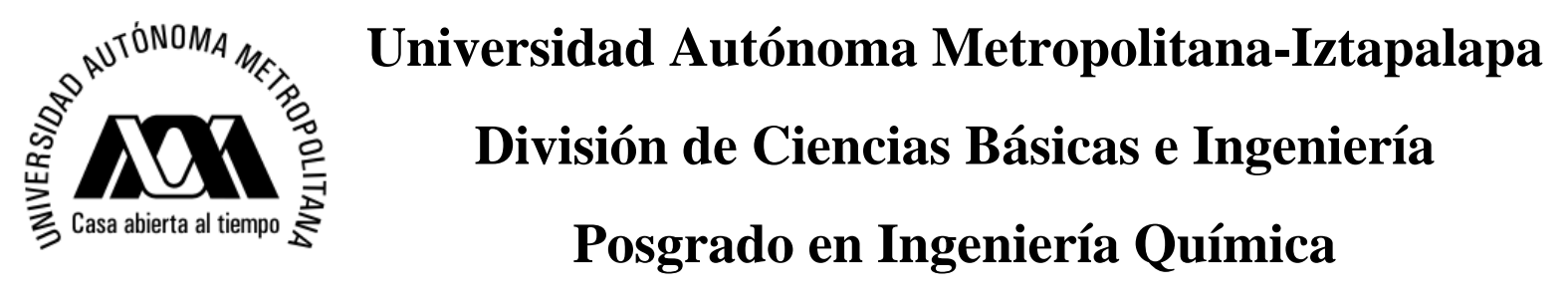

\title{
DISEÑO CONCEPTUAL DE UN PROCESO DE REACCIÓN-SEPARACIÓN PARA LA PRODUCCIÓN DE BIODIESEL
}

\author{
Tesis que presenta: \\ María Gloria Aca Aca \\ Para obtener el Grado de \\ Maestro en Ciencias en Ingeniería Química \\ Asesor: \\ Dr. Eduardo S. Pérez Cisneros \\ Jurado Calificador: \\ Presidente: Dr. Rosendo Monroy Loperena \\ Secretario: Dr. Eduardo S. Pérez Cisneros \\ Vocal: Dr. Juan Gabriel Segovia Hernández
}

México, D.F., Junio 2012 


\section{Agradecimientos}

Expreso mi más sincero agradecimiento a Dios por haberme dado la vida, a mis padres Federico y Hortencia por todo el amor, la confianza y apoyo que siempre me han brindado y que me han ayudado a seguir creciendo y formándome como persona A cada uno de los miembros de mi familia a los que amo y contribuyeron a concluir una etapa más de mi vida.

También agradezco a mi asesor el Dr. Eduardo S. Pérez Cisneros por cada una de las accesorias que me dio, en las que se trasmitieron su conocimiento, por todo el apoyo y paciencia en la elaboración de este trabajo, así como por todos los consejos brindados los cuales ayudaron a enriquecer mi formación.

Agradezco a mis sinodales el Dr, Juan Gabriel Segovia Hernández y el Dr. Rosendo Monroy Loperena, por sus comentarios y observaciones acertadas que ayudaron a la mejora de este trabajo.

Esta fue una etapa fructífera y enriquecedora que tuvo bajas y altas, que me ha dejado muchas enseñanzas y aprendizajes, y en la que no puede faltar agradecer a cada uno de mis amigos por estar cerca de mi siempre, por brindarme su brazo para sostenerme y palabras de aliento para seguir adelante, a los que estuvieron cerca y no tan cerca pero siempre al pendiente de lo que pasaba conmigo.

Agradezco a cada uno de mis compañeros de la maestría que me acompañaron e hicieron más placentera mi estancia en la misma.

Agradezco a la vida por la vida misma y por permitirme conocer a Sergio una de las personas más maravillosa y especiales de mi vida en estos momentos.

Agradezco el apoyo económico otorgado por el Consejo Nacional de Ciencia y Tecnología CONACyT para la realización de este trabajo. 


\section{Resumen}

En el presente trabajo se ha desarrollado un proceso integrado de reacción-separación novedoso para la producción de biodiesel. El proceso consiste de dos columnas de destilación reactiva acopladas. El sistema reactivo considera las reacciones cinéticamente controladas de esterificación del ácido oleico y la transesterificación de la trioleína como compuestos representativos de los aceites vegetales. Se realizó el diseño conceptual de cada una de las columnas de destilación reactiva a través del cálculo de los mapas de curvas residuales reactivas. El sistema reactivo es representado utilizando el concepto de elemento. El diseño conceptual de la columna de destilación reactiva correspondiente a la esterificación consiste de una sola zona reactiva cargada con catalizador heterogéneo de Amberlyst 15 y para la columna de transesterificación que consiste de dos zonas reactivas las cuales son cargadas con catalizador heterogéneo de Zirconia Alumina dopada con Tungstato (WZA) permitiendo la obtención de biodiesel con alta pureza. Se llevó a cabo simulación intensiva del proceso en el simulador comercial ASPEN PLUS. Los resultados muestran que el proceso es estable con materia prima que contenga impurezas, es decir, un aceite con cantidades significativas de ácido graso y agua. El diseño final del proceso integrado consiste de una columna de destilación reactiva para la esterificación con 19 etapas totales, de las cuales 15 son reactivas, operando a una relación de reflujo de $0.1 \mathrm{y}$

una relación del rehervidor de 0.8 conectada a una segunda columna de destilación reactiva para la transesterificación que considera 25 etapas totales, de las cuales 21 son reactivas, distribuidas en dos zonas reactivas. La segunda columna opera a una relación de reflujo de 2.5 y una relación del rehervidor de 3. Finalmente, el proceso de separación-reacción integrado demostró su flexibilidad operacional para diferentes cargas y tipos de aceites vegetales. 


\section{Nomenclatura}

\begin{tabular}{|c|c|}
\hline $\mathrm{R}$ & Longitud de la cadena del alcohol \\
\hline $\mathrm{R}_{1}, \mathrm{R}_{2}, \mathrm{R}_{3}$ & Cadenas de ácidos grasos \\
\hline$r_{i}$ & Velocidad de reacción de la reacción $i$ \\
\hline$k_{i}, k_{-i}$ & $\begin{array}{l}\text { Constantes cinéticas de la reacción } i \text { hacia adelante y hacia atrás } \\
\text { spectivamente }\end{array}$ \\
\hline$E_{A i,} E_{A-i}$ & $\begin{array}{l}\text { Energía de activación de la reacción } i \text { hacia adelante y hacia atrás } \\
\text { respectivamente }\end{array}$ \\
\hline$H_{A o}$ & $\begin{array}{l}\text { constante de equilibrio de intercambio iónico para la reacción del metanol } \\
\text { protonado con el ácido oleico }\end{array}$ \\
\hline$H_{w}$ & $\begin{array}{l}\text { Constante de equilibrio de intercambio iónico para la reacción del metanol } \\
\text { protonado con el agua }\end{array}$ \\
\hline$H_{M E}$ & $\begin{array}{l}\text { Constante de equilibrio de intercambio iónico para la reacción del metanol } \\
\text { protonado con el metil oleato }\end{array}$ \\
\hline$C_{i}^{R}$ & Concentración del componente $i$ en la fase líquida del interior de la resina \\
\hline$T^{r e f}$ & Temperatura de referencia \\
\hline$k^{r e f}$ & Constante cinética de referencia a la $\mathrm{T}$ de referencia \\
\hline$k_{\mathrm{MeOH}}$ & Constante de adsorción del metanol \\
\hline$C_{i}$ & Concentración del componente $i$ \\
\hline$k_{e q, \mathrm{i}}$ & Coeficiente de equilibrio de la reacción $i$ \\
\hline$K_{A}$ & Constante de equilibrio de adsorción del alcohol \\
\hline$a_{i}$ & Actividad del componente $i$ en cada reacción \\
\hline$A_{i}$ & Factor pre-exponencial de la reacción $i$ \\
\hline$R$ & Constante de los gases ideales \\
\hline$T$ & Temperatura del sistema \\
\hline$T c$ & Temperatura crítica \\
\hline $\mathrm{Vc}$ & Volumen crítico \\
\hline
\end{tabular}




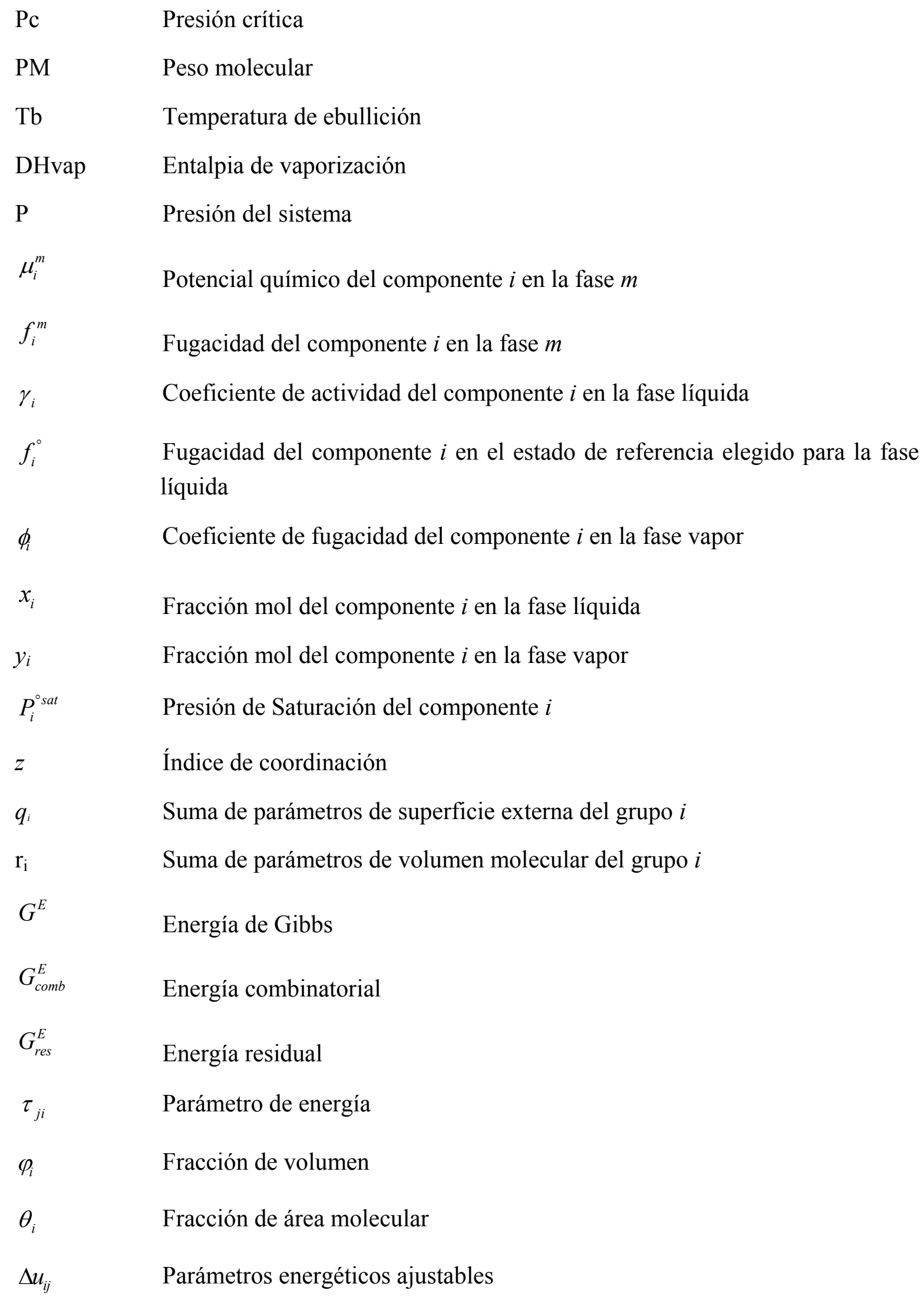


$l_{i} \quad$ Una función de la superficie externa de la molécula

$R_{k} \quad$ Parámetro de volumen de grupo $k$

$Q_{k} \quad$ Parámetro de superficie de grupo $k$

$N_{k i} \quad$ Número de grupos de tipo $k$ en la molécula $i$

$V_{W k} \quad$ Volumen de Van der Waals

$A_{W k} \quad$ Superficie de Van der Waals

$\Gamma_{k} \quad$ Coeficiente de actividad residual del grupo $k$

$\Gamma_{k i} \quad$ Coeficiente de actividad residual del grupo $k$ para una mezcla de referencia que solamente contenga las moléculas del tipo $i$.

$\Theta_{m} \quad$ Fracción de superficie del grupo $k$

$X_{m} \quad$ Fracción molar del grupo $m$ en la mezcla

$\Psi_{m n} \quad$ Parámetro de interacción

$U_{\mathrm{mn}} \quad$ Energía de interacción entre los grupos $m$ y $n$

$\alpha_{m n} \quad$ Parámetros de interacción entre los grupos $m$ y $n$

$H_{0} \quad$ Mezcla modelo molar líquida

$Q \quad$ Suministro de calor

$H(t) \quad$ Variación de la cantidad de líquido retenido en el destilador

$V(t) \quad$ Flujo molar de vapor

$M_{c a t}^{0} \quad$ Masa de catalizador que se encuentra en el destilador

$v_{T, j} \quad$ Suma algebraica de todos los coeficientes estequiométricos que intervienen en la reacción $j$

$t_{\max } \quad$ Tiempo máximo

$v_{i, j} \quad$ Coeficiente estequiométrico del compuesto $i$ en la reacción $j$

$\xi \quad$ Tiempo deformado

$r_{0} \quad$ Rapidez de reacción característica

$\alpha \quad$ Parámetro de reacción-separación

F $\quad$ Grados de libertad en tal sistema 
NF Número de fases

M Número mínimo de sustancias que deben estar presentes

NC Número de especies

S Número de restricciones

$E_{j} \quad$ Cantidad en que se encuentra presente el elemento $j$

$E_{T} \quad$ Suma total de $E_{j}$ para todos los M elementos presentes

L Cantidad del líquido

$A_{j, i} \quad$ Número de elementos químicos naturales $j$ presentes en el compuesto $i$

$W_{j} \quad$ Fracción mol elemento del elemento $j$

\section{Subíndices}

$\mathrm{AO}$

Ácido Oleico

MEOH Metanol

MO Metil Oleato

W Agua

TG Triglicérido

DG Diglicérido

MG Monoglicérido

GLY Glicerol

ME Metil Ester

Superíndices

m Estado físico de la materia: liquido, vapor ó solido 


\section{Contenido}

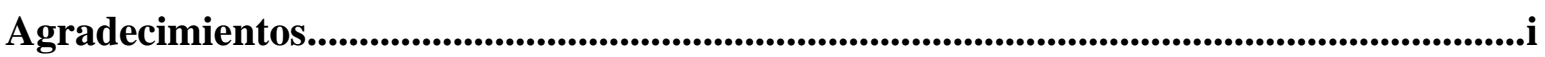

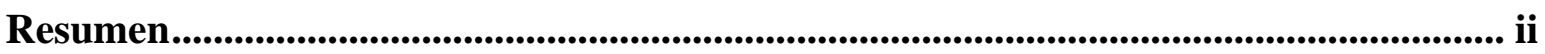

Nomenclatura ................................................................................................................................... iii

Capítulo 1. Introducción ...................................................................................................................1

Capítulo 2. El Sistema Reactivo..........................................................................................9

2.1 Reacciones Presentes en la Producción de Biodiesel ..................................................9

2.2 Procesos de Obtención de Biodiesel ......................................................................12

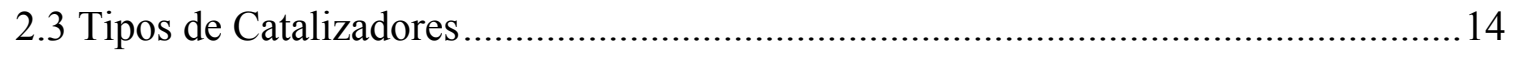

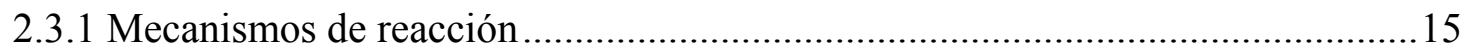

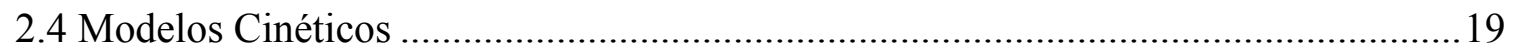

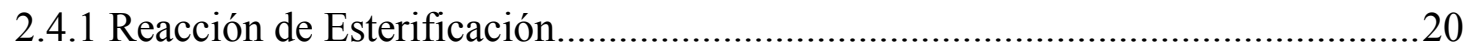

2.4.2 Reacciones de Transesterificación.................................................................21

2.5 Propiedades Termodinámicas de los Compuestos Puros...............................................24

2.6 Modelos Termodinámicos para el Cálculo de Equilibrio de Fases ..............................25

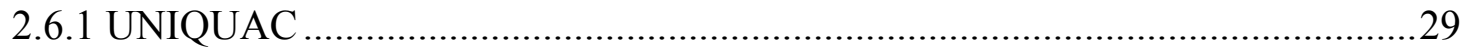

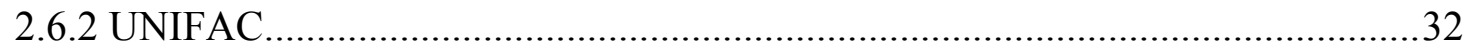

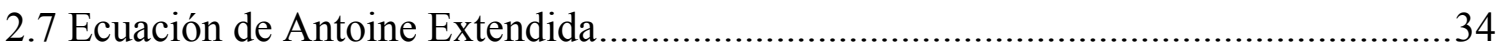

Capítulo 3. Diseño Conceptual ........................................................................................................35

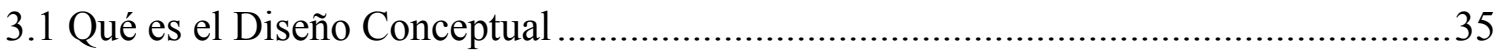

3.2 Formulación del Modelo: Destilación Reactiva por Lotes ...........................................40

3.3 Representación del Sistema en Términos de Elementos ..............................................44

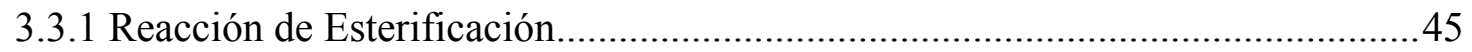

3.3.2 Reacciones de Transesterificación..................................................................46 
3.4.1 Reacción de Esterificación.

3.4.2 Reacciones de Transesterificación.

3.5 Construcción de los Mapas de Curvas Residuales Reactivos 53

3.5.1 Mapas de Curvas Residuales para la Reacción de Esterificación...... .57

3.5.2 Mapas de Curvas Residuales para las Reacciones de Transesterificación

3.6 Diseño Conceptual del Proceso Integrado

Capítulo 4. Simulación Intensiva.........................................................................70

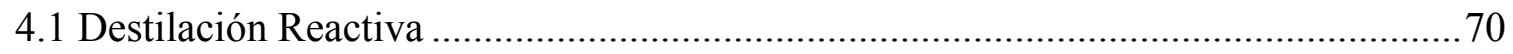

4.2 Determinación de las Condiciones de Operación de la Columna para la Reacción de Esterificación 75

4.3 Determinación de las Condiciones de Operación de la Columna para las Reacciones de Transesterificación

Capítulo 5. Proceso de Reacción-Separación Integrado

5.1 Proceso integrado.

Capítulo 6. Conclusiones 125

Bibliografía

Apéndice A: Columna de Destilación Reactiva con Condensador Total (CDR-CT), para la reacción de esterificación.

Apéndice C. Columna de Destilación Reactiva sin Condensador (CDR-SC), para la reacción de esterificación.

Apéndice D. Columna de Destilación Reactiva con Condensador Total y una sola corriente de metanol (CDR-CT1), para la reacción de transesterificación. 144 Apéndice E. Columna de Destilación Reactiva con Condensador Total y dos corrientes de metanol (CDR-CT2), para la reacción de transesterificación. .151 


\section{Capítulo 1}

\section{Introducción}

La problemática mundial ambiental causada principalmente por la utilización inadecuada que ha hecho el ser humano del territorio y de sus recursos naturales, ha conducido a una crisis que pone de manifiesto la necesidad urgente de reorientar la interacción hombrenaturaleza, como medio para garantizar su supervivencia en el planeta.

Según estudios científicos, en las pasadas cinco décadas el ser humano ha cambiado de forma rápida y extensa su entorno, debido a dos razones principales: a) el cambio en el estilo de vida y b) el significante crecimiento de la población que supone un gasto de recursos naturales y energéticos cada vez más creciente e insostenible. De ahí que los dos más grades consumidores de energía son el sector transporte y el sector industrial (Nigam y Singh, 2011), por otro lado, es reportado que el 80.3\% de la energía primaria consumida en el mundo es obtenida del uso de combustibles fósiles y el $57.7 \%$ de esta cantidad es usada por el sector transporte (International Energy Agency I, 2006). Por otra parte, el consumo global de combustible diesel fósil se estima es de 934 millones de toneladas por año. De ahí, que tan sólo las plantas de generación de energía a base de carbón emiten 2,500 millones de toneladas de bióxido de carbono $\left(\mathrm{CO}_{2}\right)$ al año y los automóviles emiten casi 1,500 millones de toneladas de $\mathrm{CO}_{2}$ anualmente. Además, el Foro de Energía Mundial predijo que los aceites fósiles podrían escasear en menos de 10 décadas, si nuevos aceites no son encontrados (Lam, Lee et al., 2010).

Lo mencionado ha provocado que algunos efectos de la crisis ecológica sean claramente perceptibles: como el aumento de las temperaturas, la desertificación, la acumulación de residuos radiactivos, la acidificación, la deforestación, el agotamiento de la capa de ozono, el agotamiento de los recursos renovables y no renovables, entre otros (Gaya y Patel, 2002). Además el despilfarro de unas sociedades repercute directamente en la pobreza de otras y contribuye al deterioro ambiental general. Es sabido que con sólo el 23\% de la población 
mundial, los países industrializados consumen el $80 \%$ de la producción mundial de energía comercial, el $79 \%$ del acero, el $85 \%$ del papel y el $86 \%$ de los metales no ferrosos.

A esta problemática mundial no se escapa México, en donde la crisis ambiental ha tomado una connotación dramática, reflejada especialmente en la explotación inadecuada de algunos recursos. Como puede observarse en la Figura (1.1a) conforme pasa cada año se hace más notorio la disminución de las reservas, donde ya para el año 2000 las reservas probadas eran menos de la mitad del total que se estimaba se poseía, seguida por las reservas probables y posibles, no olvidando que parte de esta última se encuentra en las profundidades del mar del golfo de México, lo cual dificultara su obtención. Con el paso de los años se observa que la tendencia de las reservas probadas tiende a disminuir hasta el grado que en la actualidad está por debajo de las líneas de reservas probables y posibles. Además, si comparamos con las reservas probadas que poseen otros países del mundo, México ocupa el lugar 17 con una reserva de 10420 millones de barriles de petróleo crudo, probado hasta el 1 de enero de 2010 (Anuario estadístico de Pemex 2011), por lo que es urgente generar alternativas energéticas que ayuden a retardar la escasez de dicho producto.
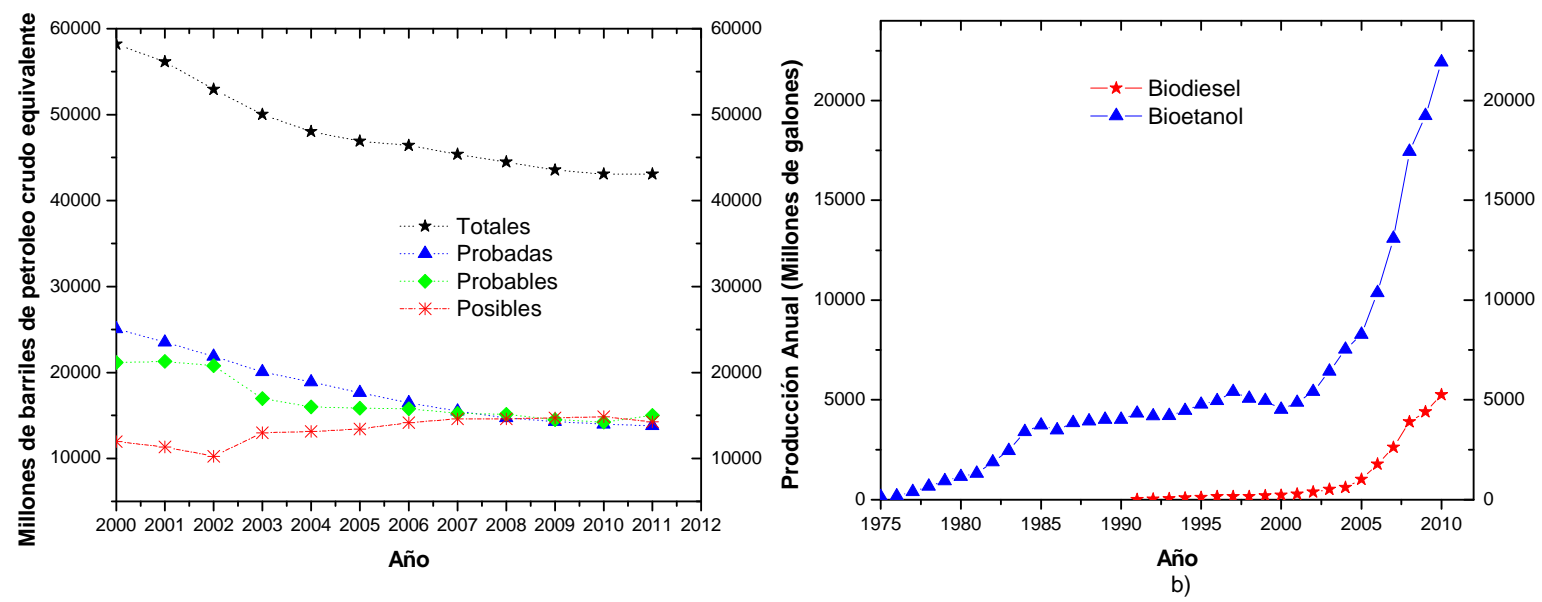

Figura 1.1 a) Reservas de petróleo crudo que se estima posee México. Fuente: Anuario Estadístico 2011 de Pemex. b) Producción mundial anual de biodiesel y bioetanol. Fuentes: F. O. Licht, World Ethanol and Biofuels Report, Vol. 8, no. 13 y 162010.

Las energías renovables representan una respuesta importante a la demanda generalizada de un modelo sustentable de progreso que no afecte a las generaciones futuras. Estas se encuentran disponibles globalmente en forma de biomasa o desechos, los cuales pueden ser 
transformados en biocombustibles líquidos. Sin embargo, el proceso de conversión o transformación química podría ser muy caro y no valdría la pena económicamente usarlo a una gran escala comercial. De ahí que son necesarias muchas investigaciones que permitan una efectividad económica y un proceso de conversión efíciente. Así mismo, su eficaz aprovechamiento contribuirá a la conservación y uso eficiente de los recursos energéticos no renovables. La principal ventaja de la utilización de fuentes renovables para la producción de biocombustibles es la utilización de los recursos biológicos naturales (que están geográficamente más repartidos que los combustibles fósiles), y la producción de bioenergía, proporciona independencia y seguridad del suministro de energía, sin embargo, la economía de cada combustible varía con la localización de la materia prima y otros actores. Además, las economías de escala alcanzadas como resultado del mayor aprovechamiento de las mismas, junto con el notable incremento en los precios de los combustibles fósiles observado durante la presente década, han mejorado la posición competitiva de los biocombustibles, abriéndoles mayores posibilidades (Gaya y Patel, 2002). Tan sólo entre 1980 y 2005, la producción mundial de biocombustibles aumentó en un orden de magnitud de 4.4 a 50.1 billones de litros, con aumentos aún más dramáticos en el futuro (Nigam y Singh, 2011). Esto se muestra en la Figura 1.1b, donde el incremento de la producción mundial anual de bioetanol y biodiesel en los últimos 10 años es considerable. Es interesante notar que el $75 \%$ de la producción del biodiesel total proviene de países Europeos. Esto se mantiene debido principalmente al soporte substancial de los gobiernos Europeos, en incentivos de consumo (reducción en el impuesto del combustible) e incentivos de producción (incentivos de impuestos y prestamos avalados) lo cual podría catalizar el crecimiento del mercado de biodiesel en los próximos diez años (Lam et al., 2010).

Hoy en día existe un fuerte debate sobre la sustentabilidad de los biocombustibles, donde se platea que sólo serán beneficiosos si son cultivados de forma sustentable con la biodiversidad y no existe competencia con los alimentos. Siendo que a veces los granos que podrían ser consumidos por los seres humanos, son ahora destinados a la producción de biocombustibles lo que envía señales de alerta en algunos lugares del mundo. 
Entre los métodos para la producción de biocombustibles se encuentra la transesterificación de aceites y grasas naturales para obtener biodiesel, donde este depende de la materia prima existente en cada localidad.

El biodiesel es obtenido mediante una reacción química (catalizada o no) entre un aceite vegetal ó una grasa animal y un alcohol de cadena corta. Los componentes principales de los aceites vegetales y de las grasas animales son los triglicéridos, los cuales consisten en tres cadenas largas de ácidos grasos esterificados que están integradas a la estructura del glicerol. Cuando los triglicéridos reaccionan con el alcohol, las tres cadenas de ácidos grasos son liberadas de la estructura del glicerol y se combinan con el alcohol para formar ésteres alquílicos de ácidos grasos, obteniéndose glicerina como subproducto (Clements, 1996).

Desde el 2006 se presentó a la secretaria de energía en México (SENER, 2006) un estudio sobre las posibilidades y viabilidad del uso del bioetanol y del biodiesel como combustibles para el transporte en México. En dicho reporte se menciona que para llegar a sustituir un 5\% del diesel de petróleo en el país será necesario instalar 10 plantas industriales con capacidad de 100,000 ton/año cada una o más de 140 plantas pequeñas con capacidad de 5,000 ton/año cada una. Se reconoce que la producción a gran escala de biodiesel en México requiere de un esfuerzo importante en investigación y desarrollo. Y se recomienda que la producción y procesamiento de este combustible se haga con tecnología diseñada y construida localmente y evitarse la importación directa de las plantas. Asimismo, se debe evitar la competencia por el uso de la tierra para fines de alimentación, o evitar la contaminación por el uso intensivo de fertilizantes químicos y pesticidas, enfatizar un enfoque agroecológico e impulsar los cultivos perennes - como la Higuerilla o la Jatropha que permitan el uso de tierras de temporal y/o marginales- $y$ aseguren una mayor cobertura del suelo para control de erosión. No obstante, el Doctor Albert Sasson (Terra-noticias, 2011), presidente del organismo promotor de biotecnología BioEuroLatina, durante su visita realizada en los primeros días de abril del año pasado a México, menciona que muchos países, incluso latinoamericanos, ya tienen identificados hacia dónde dirigir sus esfuerzos en materia de bioenergéticos; sin embargo, se dijo sorprendido de que México aún no haya definido su estrategia, a pesar de que tenga los recursos humanos y las 
condiciones geográficas para contar con más de una opción. Para el doctor Sasson, la indecisión de México por entrar a la 'carrera' de los biocombustibles, a pesar de tener grupos de investigación que trabajan al respecto, puede ser un punto a favor si aprovecha los nuevos conocimientos y comienza a trabajar a partir de las tendencias más recientes, como el uso de celulosa o microalgas en la producción de biodiesel.

El biodiesel comercial es actualmente producido por transesterificación usando soluciones catalíticas homogéneas ya sea acidas o alcalinas. Sin embargo, estos requieren una alta pureza de la materia prima (MP) y la separación del catalizador del producto final. Ambos implican un aumento en los costos de producción, tan sólo el $80 \%$ del costo de producción del biodiesel es atribuido al refinado de los aceites vegetales (Lam et al., 2009). Las principales impurezas presentes son los ácidos grasos libres (FFA) y agua, pero también pueden existir fosfolípidos u otros contaminantes. Por ejemplo, para obtener una alta pureza de la materia prima, se recomienda un pretratamiento como el desgomado para obtener grasas y aceites refinados con la menor cantidad de impurezas. La otra dificultad presente en los procesos catalizados es la separación post-reacción del catalizador, el subproducto y el producto, ya que al final de la reacción existen dos fases líquidas y mucho del catalizador se queda en la película de glicerol, así que este debe ser removido para producir glicerol puro. Y para remover el catalizador que queda en la película de éster se le realiza un lavado lo cual puede generar grandes volúmenes de agua contaminada que requerirá posteriormente ser tratada, lo que implica un gasto energético extra (Pinnarat y Savage, 2008).

La destilación reactiva (DR) es una combinación de un rector y una columna de destilación en una sola unidad en la cual ocurre simultáneamente reacción química y separación de los productos lo que ofrece distintas ventajas sobre el proceso convencional. Tan solo una de las aplicaciones más famosas es el proceso químico Eastman Co's para la producción de Metil Acetato, donde una sola columna de DR reemplazo 11 unidades de proceso que se utilizaban en el proceso convencional. En esta se incluye sistemas en los que un catalizador (homogéneo o heterogéneo) acelera la reacción. Como resultado, en una columna de destilación reactiva (CDR) se encuentran interactuando de manera compleja el equilibrio físico, la transferencia de masa entre el líquido y vapor, la difusión dentro del catalizador 
(cuando el proceso es catalizado de forma heterogénea) y la cinética química. En la Figura 1.2 se puede observar como en fase líquida sobre los platos o el empaque de una etapa reactiva se está llevando a cabo reacción y destilación simultáneamente. Esta técnica es especialmente útil para reacciones limitadas por el equilibrio tales como las reacciones de transesterificación y la esterificación. La conversión puede incrementarse más allá de lo esperado por el equilibrio debido a la continua remoción de los productos de la reacción de la zona reactiva, lo que ayuda a que la reacción proceda hacia adelante. La DR es vista como una opción atractiva por ambas razones económicas y ambientales. Pues en algunos casos una columna de destilación reactiva, es decir un solo equipo puede reemplazar el trabajo de un conjunto de equipos (como son reactores, dispositivos de separación de distinto tipo, bombas, etc.) que son indispensables en un proceso químico de producción tradicional, por ello, el interés de usar destilación reactiva para la producción de biodiesel.

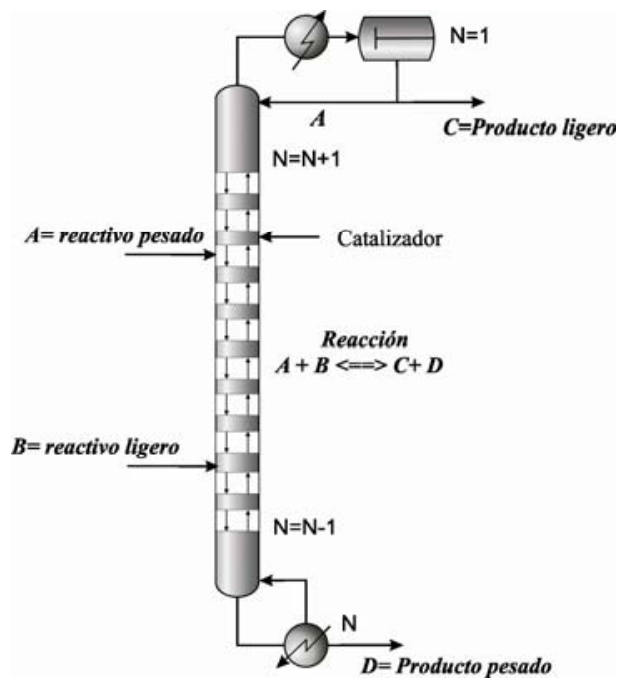

Figura 1.2 Columna completa de destilación reactiva

Considerando lo anterior, se puede establecer como objetivo general del presente trabajo el desarrollo de un proceso de reacción-separación (Destilación Reactiva) para la producción de biodiesel con la capacidad de tratar una materia prima con impurezas, es decir, con cantidades representativas de ácidos grasos libres y agua. Para alcanzar dicho objetivo general se establecen los siguientes objetivos específicos:

a) Estudio y evaluación del sistema reactivo en términos de las rutas de reacción implicados, las cinéticas de reacción y los catalizadores utilizados. Además, es 
necesario determinar las propiedades termodinámicas de los componentes puros y establecer los modelos termodinámicos para el cálculo del equilibrio de fases.

b) Realizar el diseño conceptual del proceso de reacción-separación a través de la construcción de mapas de curvas residuales reactivos.

c) Realizar simulación intensiva para identificar las principales variables que afectan al proceso y determinar las condiciones de operación óptimas para el manejo de un aceite que contenga altos porcentajes de impurezas.

En este sentido, el presente trabajo de tesis se organizó considerando 6 capítulos que a continuación se describen brevemente.

En este primer capítulo se plantea brevemente los antecedentes y objetivos del presente trabajo.

En el segundo capítulo se explican brevemente las diferentes reacciones presentes en la producción de biodiesel, los mecanismos generales al usar diferentes catalizadores así como los modelos cinéticos de las reacciones involucradas que se utilizan en este trabajo. Además, se presentan las propiedades termodinámicas de los componentes puros, así como también se describe la teoría que hay detrás de los modelos termodinámicos usados en este trabajo para predecir el equilibrio de fases de las mezclas reactivas.

En el tercer capítulo se realiza la construcción de los mapas de curvas residuales reactivos en términos de elemento propuesto por Pérez-Cisneros (1997) para los dos sistemas reactivos estudiados en este trabajo que son: la reacción de esterificación y la reacción de transesterificación.

En el cuarto capítulo se realizan simulaciones por separado de cada sistema (reacción de esterificación y transesterificación). Se presentan los resultados de las simulaciones realizadas en Aspen Plus para diferentes configuraciones de columnas. Se analiza la influencia de los parámetros de operación de cada columna, eligiendo las columnas con condiciones de reacción más convenientes para cada sistema en estudio. 
En el quinto capítulo se integran las dos columnas elegidas en el capítulo anterior, para poder manejar diferentes tipos de aceites (con diferentes grados de impurezas) y así obtener el mejor rendimiento del biodiesel.

Por último se presentan las conclusiones de este trabajo, donde se resumen las contribuciones principales de esta tesis y posible trabajo futuro. 


\section{Capítulo 2}

\section{El Sistema Reactivo}

En este capítulo se describe brevemente las reacciones principales que ocurren durante la producción de biodiesel, así como también un bosquejo general de los procesos de producción de biodiesel, ventajas y desventajas de su uso, los tipos de catalizadores existentes. La descripción de modelos cinéticos que se utilizan en este trabajo. Y el principio básico que hay detrás de los modelos termodinámicos que se usaron.

\subsection{Reacciones Presentes en la Producción de Biodiesel}

Los aceites vegetales o las grasas animales son ésteres de ácidos monocarboxílicos saturados o insaturados unidos a una molécula de glicerol. Estos ésteres son llamados triglicéridos los cuales pueden reaccionar con algún alcohol en presencia de un catalizador, esta reacción es conocida como transesterificación. La forma simplificada de esta reacción química se presenta a continuación:

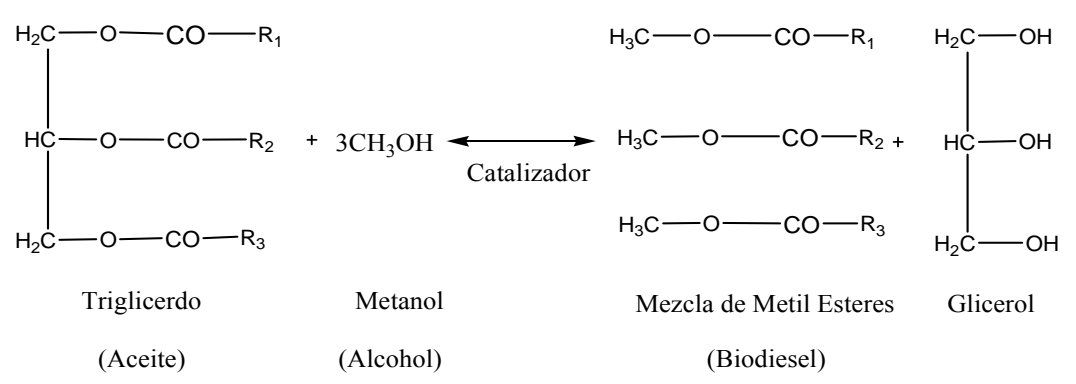

Figura 2.1 Esquema de la reacción global de transesterificación.

Donde $\mathrm{R}_{1}, \mathrm{R}_{2} \mathrm{y} \mathrm{R}_{3}$ son diferentes cadenas largas de ácidos grasos esterificados en la molécula de glicerol. Cuando los triglicéridos son convertidos paso a paso a diglicérido, 
monoglicérido y finalmente glicerol, $1 \mathrm{~mol}$ de éster es liberado en cada paso. Usualmente el metanol es preferido como alcohol para producir biodiesel debido a su bajo costo (Leung et al., 2010).

También los aceites vegetales y grasas pueden contener pequeñas cantidades de agua y ácidos grasos libres como impurezas. Cuando la transesterificación es catalizada alcalinamente, el catalizador alcalino que es usado puede reaccionar con los ácidos grasos libres y formar jabón, como se ve en la Figura 2.2. Esta reacción es indeseable porque el jabón disminuye la producción de biodiesel e inhibe la separación del éster del glicerol. Esto puede vincularse con la necesidad de una mayor cantidad de catalizador, y por tanto que el proceso incremente su costo.

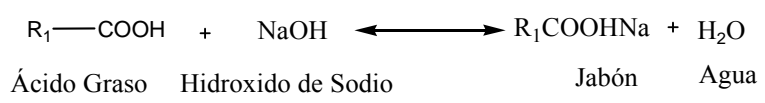

Figura 2.2. Reacción de saponificación.

Por otro lado, el agua originaria ya sea de los aceites, grasas o formada durante la reacción de saponificación, retarda la reacción de transesterificación debido a la reacción de hidrolisis que se presentaría entre el triglicérido y el agua como se muestra en la Figura 2.3.

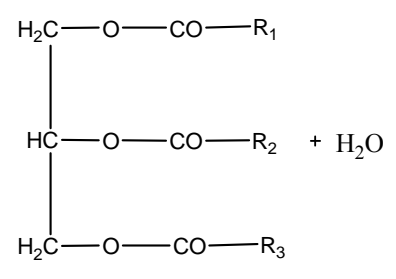

Triglicerdo

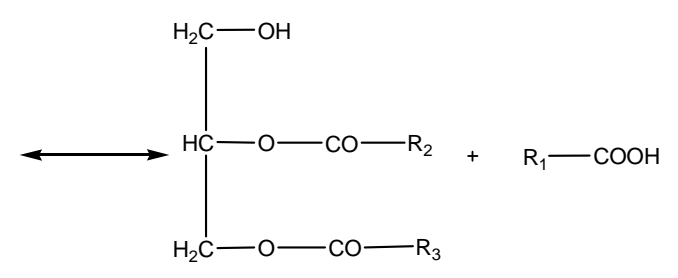

Diglicérido

FFA

\section{Figura 2.3. Hidrolisis de triglicéridos, donde $R_{1}, R_{2}$ y $R_{3}$ representan las cadenas de Ácidos} Grasos.

Sin embargo, los ácidos grasos libres en presencia de catalizadores ácidos podrían reaccionar con alcohol para formar éster (biodiesel) (Leung et al., 2010). Esta reacción es muy útil al manejar aceites o grasas con un alto contenido de ácidos grasos (Figura 2.4). 


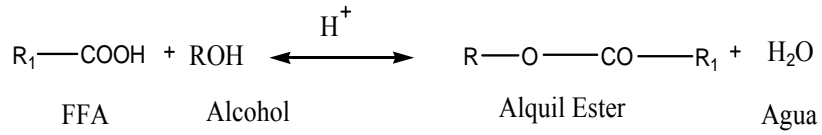

Figura 2.4. Reacción de Esterificación, donde $R_{1}$ representa al ácido graso.

Como ya se mencionó los aceites están compuestos principalmente de triglicéridos y estos a su vez de ácidos grasos, en general estos últimos definen las características de la molécula y proporcionan las diversas propiedades de los aceites, por lo que es fundamental conocer la composición de cada aceite. Normalmente, hay cinco tipos de cadenas de ácidos grasos en los aceites vegetales y grasas animales que son: ácido palmítico, ácido esteárico, ácido oleico, ácido linoleico y ácido linolenico, como puede observarse en la Tabla 2.1 donde se muestra la composición en ácidos grasos de algunos aceites que son utilizados para la producción de biodiesel.

Tabla 2.1. Composiciones químicas en \% peso de aceites vegetales. Fuente: Chang and Liu, 2010; Achten et al., 2008.

\begin{tabular}{llrrrrrr}
\hline & $\begin{array}{c}\text { Carbono } \\
\text { con }\end{array}$ & $\begin{array}{c}\text { Aceite de } \\
\text { Má́z }\end{array}$ & $\begin{array}{c}\text { Aceite de } \\
\text { Canola }\end{array}$ & $\begin{array}{c}\text { Aceite de } \\
\text { Soya }\end{array}$ & $\begin{array}{c}\text { Aceite de } \\
\text { Oliva }\end{array}$ & $\begin{array}{c}\text { Aceite de } \\
\text { Jatropha }\end{array}$ & $\begin{array}{c}\text { Aceite de } \\
\text { Palma }\end{array}$ \\
\hline Componente & (=) enlace & \multicolumn{1}{c}{ \% Peso } & \% Peso & \% Peso & \% Peso & \% Peso & \% Peso \\
\hline Ácido Mirístico & C14:0 & 0.0 & 0.0 & 0.0 & 0.0 & 0.0 & 0.7 \\
Ácido Palmitoleico & C16:1 & 0.6 & 0.0 & 0.1 & 1 & 0.0 & 0.1 \\
\hline Ácido Palmítico & C16:0 & 6.5 & 4.9 & 11.3 & 11.6 & 14.54 & 36.7 \\
Ácido Esteárico & C18:0 & 1.4 & 1.6 & 3.6 & 3.1 & 6.30 & 6.6 \\
Ácido Oleico & C18:1 & $\mathbf{6 5 . 6}$ & $\mathbf{3 3}$ & $\mathbf{2 4 . 9}$ & $\mathbf{7 5}$ & $\mathbf{4 2 . 0 2}$ & $\mathbf{4 6 . 1}$ \\
Ácido Linoleico & C18:2 & 25.2 & 20.4 & 53 & 7.8 & 35.38 & 8.6 \\
Ácido Linolenico & C18:3 & 0.1 & 7.9 & 6.1 & 0.6 & & 0.3 \\
\hline Ácido Araquídico & C20:0 & 0.1 & 0.0 & 0.3 & 0.3 & & 0.4 \\
\hline
\end{tabular}

Como puede notarse en la Tabla 2.1 el compuesto que está presente en mayor proporción en muchos de los aceites es el ácido oleico con su respectiva trioleína como triglicérido. 


\subsection{Procesos de Obtención de Biodiesel}

Dependiendo del tipo y la calidad de la materia prima (MP) existen diferentes procesos para obtener el biodiesel vía transesterificación estos pueden ser procesos convencionales o no convencionales. Los procesos convencionales (uso de equipos por separado para cada etapa) se pueden clasificar de acuerdo al tipo de catalizador con que se lleva a cabo: si ocupan catalizadores ácidos, catalizadores alcalinos o catalizadores enzimáticos (Leung et al, 2010). Los procesos no convencionales están en proceso de estudio y aun no existen como procesos a nivel industrial, entre ellos están el proceso en condiciones supercríticas no catalizada y la destilación reactiva (Pinnarat y Savage, 2008; Omota et al., 2003). En la Tabla 2.2 y 2.3 se presentan las diferentes tecnologías para obtener biodiesel, haciéndose la comparación de las principales características de estas y presentando las ventajas y desventajas de cada proceso.

Tabla 2.2. Comparación de diferentes tecnologías para producir biodiesel. Fuente: Leung et al, 2010; Marchetti et al., 2007; Pinnarat y Savage, 2008; Kiss et al., 2007; Omota et al., 2003.

\begin{tabular}{|c|c|c|c|c|c|}
\hline Variable & $\begin{array}{l}\text { Catalizador } \\
\text { Alcalino }\end{array}$ & Catalizador Ácido & $\begin{array}{l}\text { Catalizado con } \\
\text { Lipasa }\end{array}$ & Destilación reactiva & $\begin{array}{c}\text { Alcohol } \\
\text { Supercrítico }\end{array}$ \\
\hline $\begin{array}{l}\text { Temperatura de } \\
\text { reacción }\left({ }^{\circ} \mathrm{C}\right)\end{array}$ & $60-70$ & $55-80$ & $30-40$ & $130-450$ & $239-385$ \\
\hline $\begin{array}{c}\text { Presencia de } \\
\text { Ácidos grasos } \\
\text { libres en la MP }\end{array}$ & $\begin{array}{c}\text { Productos } \\
\text { saponificados }\end{array}$ & Ésteres & Metil ésteres & Metil ésteres & Ésteres \\
\hline $\begin{array}{l}\text { Presencia de Agua } \\
\text { en la materia prima } \\
(\mathrm{MP})\end{array}$ & $\begin{array}{l}\text { Interferencia con } \\
\text { la reacción }\end{array}$ & $\begin{array}{l}\text { Interferencia con } \\
\text { reacción }\end{array}$ & No influye & $\begin{array}{l}\text { Interferencia en la } \\
\text { separación y con el } \\
\text { catalizador }\end{array}$ & No influye \\
\hline $\begin{array}{l}\text { Producción de } \\
\text { Metil Ésteres }\end{array}$ & Normal & Normal & Muy alta & Alta & Buena \\
\hline $\begin{array}{l}\text { Recuperación del } \\
\text { glicerol }\end{array}$ & Difícil & Difícil & Muy fácil & Fácil & Fácil \\
\hline $\begin{array}{l}\text { Purificación de } \\
\text { Metil ésteres }\end{array}$ & Varios lavados & Varios lavados & Nada & En el mismo equipo & Nada \\
\hline $\begin{array}{l}\text { Relación molar } \\
\text { alcohol-aceite }\end{array}$ & $6: 1$ & $30: 1$ & & $25: 1$ & $>40: 1$ \\
\hline $\begin{array}{c}\text { Reacciones } \\
\text { presentes }\end{array}$ & Transesterificación & $\begin{array}{c}\text { Transesterificación } \\
\text { Esterificación }\end{array}$ & Transesterificación & $\begin{array}{c}\text { Transesterificación } \\
\text { Esterificación }\end{array}$ & $\begin{array}{c}\text { Transesterificación } \\
\text { Esterificación } \\
\text { Hidrólisis }\end{array}$ \\
\hline $\begin{array}{l}\text { Cantidad de } \\
\text { catalizador }\end{array}$ & $1 \%$ peso & $1-5 \%$ peso & & $3 \%$ peso & \\
\hline Tiempo de reacción & $1 \mathrm{~h}$ & $3-20 \mathrm{~h}$ & & & $4 \mathrm{~min}$ \\
\hline
\end{tabular}

Analizando la tabla anterior se puede decir que el proceso catalizado con Lipasas es el mejor de todos en varios aspectos, sin embargo, el mayor inconveniente al utilizar este catalizador es que es difícil de obtener las cantidades necesarias para un proceso a nivel 
industrial y es muy caro en comparación con los otros catalizadores, además de que a altas temperaturas la enzimas tienden a desnaturalizarse fácilmente (ver Tabla 2.3).

Tabla 2.3. Ventajas y desventajas en cada proceso de producción de biodiesel. Fuente: Leung et al, 2010; Kiss et al., 2007, Omota et al., 2003.

\begin{tabular}{|c|c|c|c|}
\hline Tipo & Ejemplo & Ventajas & Desventajas \\
\hline \multicolumn{4}{|c|}{ Proceso convencional usando catalizadores alcalinos } \\
\hline Homogéneo & $\mathrm{NaOH}, \mathrm{KOH}$ & $\begin{array}{l}\text { Al usar estos catalizadores hay alta actividad } \\
\text { catalítica, bajo costo, cinética favorable y } \\
\text { condiciones de operación modesta }\end{array}$ & $\begin{array}{l}\text { Pero se requiere bajas cantidades de FFAs, } \\
\text { condiciones anhidras, puede presentarse } \\
\text { saponificación y más agua de desecho en la } \\
\text { purificación }\end{array}$ \\
\hline Heterogéneo & $\begin{array}{l}\mathrm{CaO}, \mathrm{CaTiO} 3, \mathrm{CaZ} \\
\mathrm{rO3}, \quad \text { alúmina } \\
\text { soportada en } \\
\text { silica, AlO3/KI }\end{array}$ & $\begin{array}{l}\text { El uso del catalizador es no corrosivo, } \\
\text { ambientalmente benigno, reciclable, menos } \\
\text { problemas eliminación, fácil separación, alta } \\
\text { selectividad, tiempo de vida del catalizador } \\
\text { grandes }\end{array}$ & $\begin{array}{l}\text { Requiere bajos requerimientos de FFAs, } \\
\text { condiciones anhidras, agua de desecho por la } \\
\text { purificación, requiere de una alta relación molar } \\
\text { de alcohol aceite, alta temperatura y presión de } \\
\text { reacción, y hay limitación de difusión, alto costo }\end{array}$ \\
\hline \multicolumn{4}{|c|}{ Proceso convencional usando catalizadores ácidos } \\
\hline Homogéneo & $\begin{array}{l}\text { Ácido sulfúrico } \\
\text { concentrado }\end{array}$ & $\begin{array}{l}\text { El catalizador esterifica y transesterifica } \\
\text { simultáneamente, evita la formación de } \\
\text { jabón }\end{array}$ & $\begin{array}{l}\text { Este catalizador genera corrosión del equipo, } \\
\text { desecho por neutralización, difícil para reciclar, } \\
\text { alta temperatura de reacción, largos tiempos de } \\
\text { reacción, débil actividad catalítica }\end{array}$ \\
\hline Heterogéneo & $\begin{array}{l}\mathrm{ZnO} / \mathrm{I} 2 \text {, } \\
\text { catalizador acido } \\
\text { basado en carbón, } \\
\text { Zirconia sulfatada }\end{array}$ & $\begin{array}{l}\text { El catalizador esterifica y transesterifica } \\
\text { simultáneamente, reciclable, eco amigable }\end{array}$ & $\begin{array}{l}\text { Concentración del sitio bajo, baja micro } \\
\text { porosidad, limitación de difusión, alto costo del } \\
\text { proceso }\end{array}$ \\
\hline \multicolumn{4}{|c|}{ Proceso convencional usando catalizadores enzimáticos } \\
\hline Enzimas & $\begin{array}{l}\text { Fracción B lipasa } \\
\text { Candida antartica, } \\
\text { Lipasa mieher } \\
\text { Rhizomucor }\end{array}$ & $\begin{array}{l}\text { El uso de estos catalizadores evita la } \\
\text { formación de jabón, no contaminante, fácil } \\
\text { purificación, alta producción }\end{array}$ & $\begin{array}{l}\text { El mayor inconveniente es el costo del } \\
\text { catalizador y que se desnaturaliza la enzima }\end{array}$ \\
\hline \multicolumn{4}{|c|}{ Procesos no convencionales } \\
\hline $\begin{array}{l}\text { Destilación } \\
\text { Reactiva }\end{array}$ & $\begin{array}{l}\text { Catalizador solido } \\
\text { súper ácido: } \\
\text { Zirconia (SZr) } \\
\text { Metanol }\end{array}$ & $\begin{array}{l}\text { Este proceso reduce el costo de operación, } \\
\text { debido a reducción de unidades de operación } \\
\text { y uso de energía. } \\
\text { No necesita neutralizar al catalizador. } \\
\text { Alta conversión ya que se puede desplazar } \\
\text { hacia el consumo de los reactivos } \\
\text { Al retirar los productos de la zona reactiva } \\
\text { no se afecta la actividad del catalizador }\end{array}$ & $\begin{array}{l}\text { Costosa recuperación del alcohol en exceso } \\
\text { Formación de azeótropos en algunos casos }\end{array}$ \\
\hline $\begin{array}{l}\text { Proceso no } \\
\text { catalizado en } \\
\text { condiciones } \\
\text { supercríticas }\end{array}$ & $\begin{array}{l}\text { Metanol, Etanol, } \\
\text { Butanol }\end{array}$ & $\begin{array}{l}\text { Se lleva cabo una hidrolisis, esterificación y } \\
\text { transesterificación simultáneamente, no } \\
\text { limitación por difusión, cortos tiempos de } \\
\text { reacción, El alcohol no solamente es un } \\
\text { reactivo sino también un catalizador ácido } \\
\text { Las impurezas no afectan el rendimiento }\end{array}$ & $\begin{array}{l}\text { Altas temperaturas y presión de operación, } \\
\text { requiere una mayor relación molar de alcohol } \\
\text { aceite }\end{array}$ \\
\hline
\end{tabular}


Entonces analizando las tablas anteriores, vemos que el proceso que se lleva a cabo en condiciones supercríticas parece ser también un proceso muy prometedor, sin embargo, su principal inconveniente es el alto costo de los equipos ya que este debe soportar altas temperaturas y presiones lo que incrementa su costo considerablemente.

Otro proceso viable es el de destilación reactiva, la ventaja es que este permite procesar materia prima de baja calidad sin tener muchas dificultades, no obstante, presenta algunos inconvenientes, siendo este el reto para muchos investigadores encontrar como superarlos, entre ellos la motivación de este trabajo.

\subsection{Tipos de Catalizadores}

Hay dos factores principales que definen el costo del biodiesel: el costo de la materia prima y el costo del procesamiento del mismo. Los costos de procesamiento pueden ser reducidos por medio de operaciones simplificadas y eliminación de corrientes de desecho. Una solución a este problema podría ser a través de la transesterificación no catalizada en metanol supercrítico, aunque ya se ha mencionado su inconveniente. Otra alternativa es el uso de catalizadores heterogéneos donde los productos de reacción y las condiciones de reacción pueden ser menos drásticos que las de metanol supercrítico.

La gran cantidad de investigaciones enfocadas en producir un catalizador heterogéneo para la producción de biodiesel se ha incrementado enormemente en los últimos años. En particular, se busca que el catalizador tenga diversas cualidades- que catalice tanto la transesterificación como la esterificación, no se desactive por el agua, que sea estable, que sea activo a altas y bajas temperaturas y que tenga una alta selectividad- dichos resultados positivos podrían ser obtenidos en los próximos años si los esfuerzos en investigación continúan a la misma velocidad como hasta la fecha.

Hasta ahora existen métodos combinados donde se lleva a cabo primero la esterificación de los ácidos grasos utilizando catalizadores ácidos y posteriormente se lleva a cabo la 
transesterificación de los triglicéridos usando catalizadores alcalinos. Este método es la base del presente trabajo pero implementado en columnas de destilación reactiva. Aunque también existen catalizadores ácidos que pueden promover la esterificación y la transesterificación en un solo paso, pero la investigación en esta área aun es escasa.

\subsubsection{Mecanismos de reacción}

Desde un punto de vista general los catalizadores ácidos y básicos pueden ser clasificados como Brönsted o Lewis, además en muchos casos ambos tipos de sitios están presentes y no es fácil de evaluar la importancia relativa de los dos tipos de sitios en la reacción.

La transesterificación con catalizador básico es comúnmente usado en producciones comerciales a gran escala porque la velocidad de reacción es más rápida y es menos corrosivo que cuando se usan procesos con catalizador ácido. El mecanismo de reacción en forma general para este caso se presenta en la Figura 2.5 y se describe a continuación (Payawan et al., 2010):

1) El primer paso es la reacción del catalizador básico con el alcohol produciendo un alcóxido y el catalizador protonado.

2) En el segundo paso el triglicérido podría someterse a una reacción nucleofílica, el grupo alcóxido ataca al grupo carbonilo del triglicérido formando un intermedio tetraédrico

3) Este ultimo compuesto forma un anión diglicérido y un alquil éster en el tercer paso

4) Este alquil éster resultante podría deprotonar al catalizador en el cuarto paso

5) Por último en el quinto paso hay un rearreglo de las especies activas y es entonces que vuelve a empezar otro ciclo catalítico con otra molécula de alcohol

El mecanismo de reacción de transesterificación con catalizadores heterogéneos básicos difiere ligeramente de los catalizadores homogéneos básicos. Lo mismo que con los catalizadores homogéneos la base orgánica inmovilizada sobre la superficie del catalizador 
convierte al alcohol en un alcóxido el cual reaccionaria con el grupo carbonilo del triglicérido y sigue la misma ruta descrita anteriormente.

$$
\begin{array}{cll}
\mathrm{ROH}+\mathrm{B} & \mathrm{RO}^{-}+\mathrm{BH}^{+} \\
\text {Alcohol Catalizador básico } & \text { Alcóxido } & \text { Catalizador protonado }
\end{array}
$$
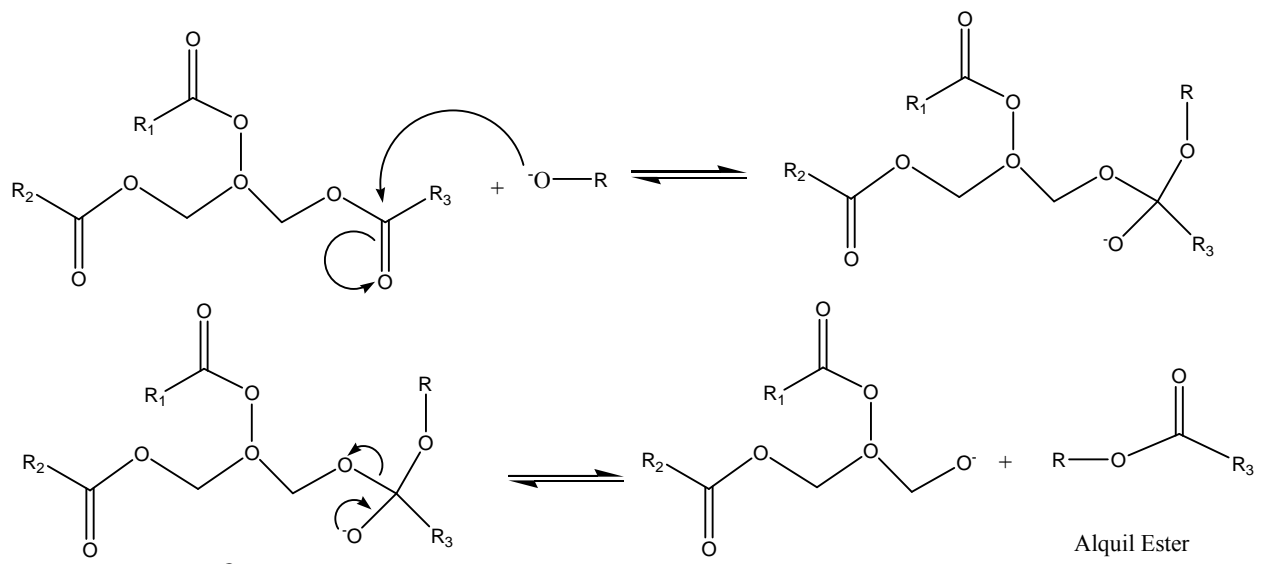

(3)<smiles>[R]O[OH+]CC[O+](COC([R])=O)OC([R])=CC=C</smiles>

(4)

Figura 2.5. Esquema de reacción de transesterificación con catalizador básico de un triglicérido y el metanol

Los catalizadores líquidos fuertemente ácidos son menos sensitivos a los ácidos grasos libres y pueden promover la transesterificación y esterificación simultáneamente, aunque ellos promueven las velocidades de reacción más lentas y necesitan mayores temperaturas de reacción. Sin embargo, si los catalizadores ácidos heterogéneos pueden remplazar a los catalizadores líquidos, los problemas ambientales y de corrosión que estos provocan se podrían evitar, así como también los procesos de purificación de los productos podrían reducirse, haciendo posible que los costos de producción del biodiesel disminuyan. 
El mecanismo de reacción en forma general de este caso se presenta en la Figura 2.6 y se describe a continuación (Lotero et al., 2005):

1) El primer paso es la protonación del oxigeno del grupo carbonilo por el catalizador ácido.

2) En el segundo paso el ataque necleófilico del alcohol genera un intermedio tetraédrico

3) En el último paso hay una migración del protón y por tanto la formación del producto intermedio, en este caso el diglicérido y la liberación de un alquil éster. Esta secuencia es repetida dos veces.<smiles>[R]C(=O)OCOC(COC([R9])=O)OCOC(=O)[B]C#C</smiles>

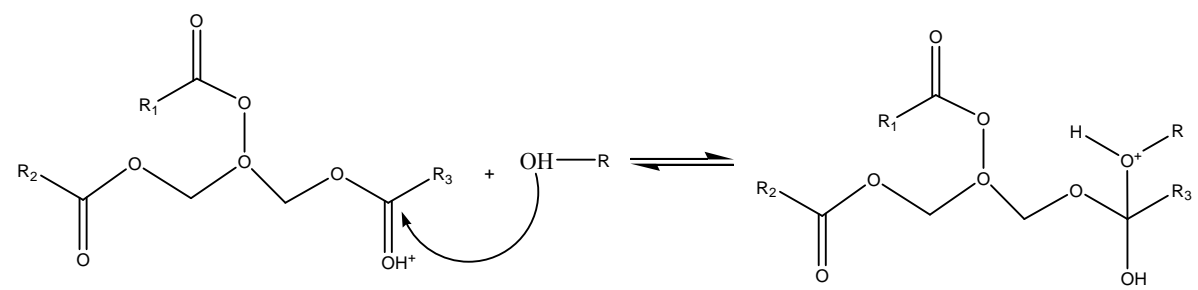

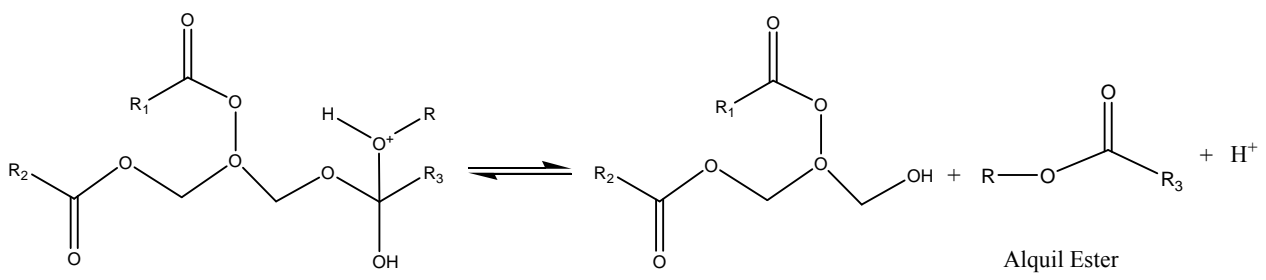

(3)

\section{Figura 2.6. Esquema de reacción de transesterificación con catalizador ácido de un triglicérido y el metanol}

La ruta química mostrada anteriormente para la reacción catalizada con ácidos indica que en la interacción catalizador triglicérido el paso clave es la protonación del oxigeno del grupo carbonilo. Ya que esto incrementa la electrofilicidad del átomo de carbono adjunto, haciendo al carbono más susceptible al ataque necleófilico. Por otro lado, el catalizador básico lleva a cabo una ruta más directa, creando primero al ion alcóxido el cual actúa directamente como un necleófilico fuerte dando diferentes rutas químicas 
para la reacción. Esta diferencia crucial, la formación de más especies electrofilicas (catalizador ácido) versus especies nucleofilicas fuertes (catalizador básico) es la principalmente responsable para observar las diferencias en la actividad.

La esterificación catalizada con ácidos sigue un mecanismo similar a la transesterificación. Sólo que en vez de empezar con una molécula de triglicérido como en la transesterificación (Figura 2.6), se empieza con una molécula de ácido graso. Otra vez el punto clave entre la interacción catalizador ácido graso es la protonación del carbonilo en el ácido graso.

Furuta et al, (2004 y 2006) reportan diferentes estudios de la transesterificación del aceite de soya con metanol de $200-300^{\circ} \mathrm{C}$ y la esterificación del ácido n-octanoico con metanol de $175-200^{\circ} \mathrm{C}$, usando un reactor de lecho empacado a presión atmosférica. Los catalizadores probados son: Zirconia-Alumina dopada con Tungstato (WZA), Zirconia-Alumina dopada con Sulfato (SZA), Oxido de Tin Sulfatado (STO), ZirconiaAlumina dopada con Titanio (TiO2/ZrO2) y Zirconia-Alumina dopada con Aluminio (A12O3/ZrO2). En la Figura 2.7 se presentan las conversiones obtenidas con cada catalizador a $200^{\circ} \mathrm{C}$ en el caso de la esterificación y $250^{\circ} \mathrm{C}$ para la transesterificación.

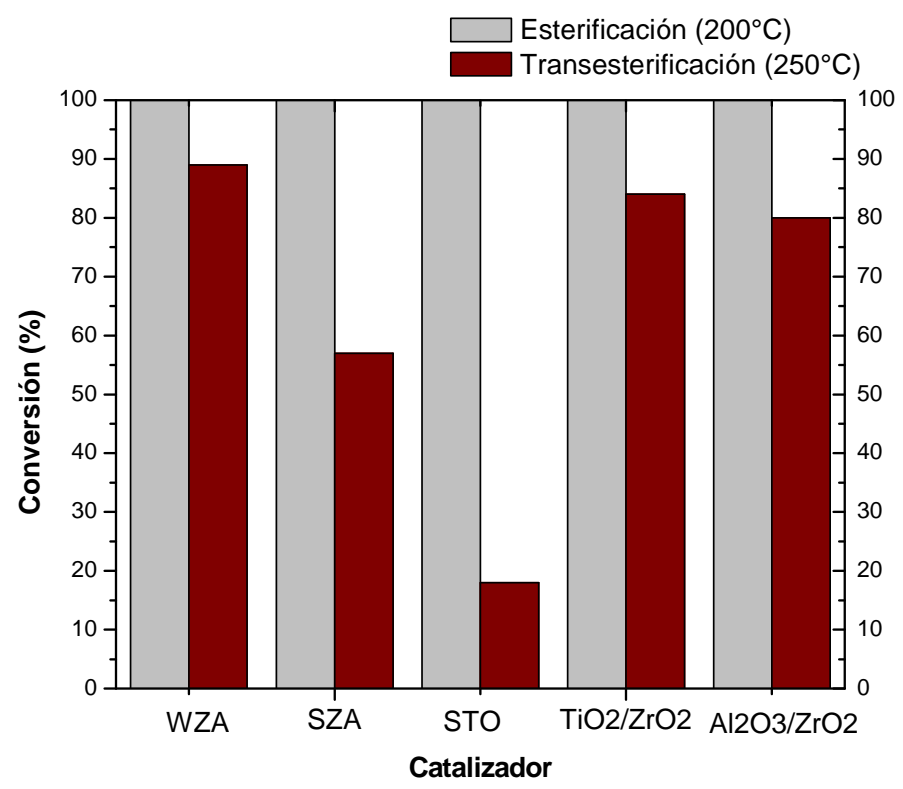

Figura 2.7. Transesterificación del aceite de soya y esterificación del ácido n-octanoico con catalizador ácido y metanol 
Se puede proponer que en la columna de destilación reactiva donde se lleva a cabo la esterificación podríamos usar cualquiera de los catalizadores presentados, no obstante, nos convendría usar el Oxido de Tin Sulfatado (STO), ya que este es más selectivo lo cual permitiría asegurar que se lleve a cabo completamente sólo la esterificación y muy ligeramente la transesterificación. Para la columna donde se lleva a cabo la transesterificación podríamos proponer usar un catalizador heterogéneo básico o un catalizador ácido de los ya presentados, ya que los ácidos grasos libres se habrán esterificado en la primera columna y sólo se pensaría en la transesterificación. La ZirconiaAlumina dopada con Tungstato (WZA), es vista como un catalizador prometedor ya que da altas conversiones y es estable dentro de las condiciones de reacción (Di Serio et al., 2008). El inconveniente hasta el momento de estos catalizadores es que como aun están en estudio los modelos cinéticos que describan la reacción no se han desarrollado. No obstante, en cuanto se desarrollen podrían sustituir a los utilizados en el presente trabajo.

\subsection{Modelos Cinéticos}

En este trabajo consideramos que nuestra materia prima al inicio está libre de agua lo que suprime la reacción de hidrolisis de los triglicéridos, además se plantea el uso de un catalizador heterogéneo lo que evita la reacción de saponificación. Por tanto, sólo estamos interesados en la reacción de esterificación de los ácidos grasos libres (en este caso del ácido oleico como componente representativo) y la transesterificación de los triglicéridos (para este caso de la trioleína como componente representativo). Es por ello que a continuación se presentan los modelos cinéticos que se utilizaron en este trabajo para dichas reacciones. 


\subsubsection{Reacción de Esterificación}

El modelo cinético empleado para la esterificación del ácido oleico es reportado por Tesser et al. (2010) que propone el estudio experimental de la esterificación con un reactor Bach usando dos diferentes tipos de sustratos para dicha esterificación: una mezcla modelo de aceite de soya acidificado artificialmente con ácido oleico y una mezcla comercial de aceites y ácidos grasos libres (oleínas) donde la concentración de los ácidos grasos libres contiene $>95 \%$ peso de ácido oleico, cada una de las mezclas en presencia de metanol y usando resina de intercambio ácido como catalizador (Amberlyst 15). Así la reacción de esterificación se representa en la figura siguiente:

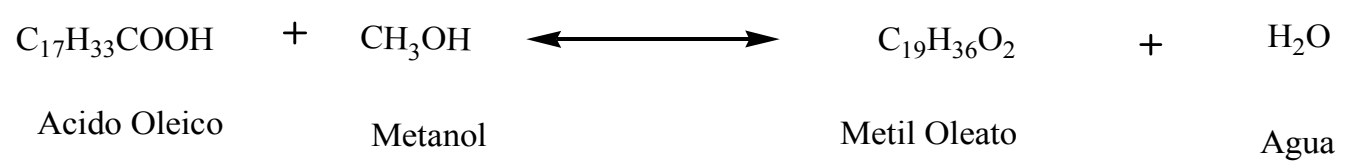

Figura 2.8. Reacción de Esterificación del ácido Oleico.

El modelo cinético desarrollado toma en cuenta los siguientes fenómenos: 1) equilibrio de fase físico (equilibrio de partición) de los componentes entre la fase líquida absorbida dentro de la resina y la fase líquida externa; 2) equilibrio de intercambio iónico entre el metanol protonado y otras moléculas, 3) un mecanismo de reacción de superficie EleyRideal, en el cual un ácido graso protonado reacciona con el metanol proveniente de la fase líquida absorbida por las partículas. Dicho modelo fue capaz de describir bien el comportamiento cinético de sus datos experimentales en particular para corridas desarrolladas a diferentes temperaturas y concentraciones de catalizador.

Entonces de acuerdo con el desarrollo de este modelo, la velocidad de reacción de esterificación es dada por:

$$
r=\frac{k_{1} H_{A O} C_{A O}^{R}-k_{-1} \frac{H_{M O} C_{M O}^{R} C_{W}^{R}}{C_{M E O H}^{R}}}{1+\frac{H_{A O} C_{A O}^{R}}{C_{M E O H}^{R}}+\frac{H_{M O} C_{M O}^{R}}{C_{M E O H}^{R}}+\frac{H_{W} C_{W}^{R}}{C_{M E O H}^{R}}}
$$




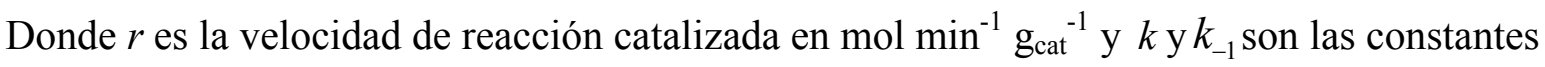
cinéticas de reacción hacia adelante y hacia atrás, con valores 9.01 y $5.5 \mathrm{~cm}^{3} \mathrm{~g}_{\mathrm{cat}}{ }^{1} \mathrm{~min}^{-1}$ respectivamente. De acuerdo a la ecuación de Arrhenius modificada, la constante de velocidad de reacción puede ser expresada como una función de la temperatura en la siguiente forma:

$$
k=k^{r e f} \exp \left[\frac{E_{A}}{R}\left(\frac{1}{T^{r e f}}-\frac{1}{T}\right)\right]
$$

Donde $T^{\text {ref }}=273.15 \mathrm{~K}, E_{A}=17.46 \mathrm{Kcal} \mathrm{mol}^{-1}$ y $E_{-A}=8.78 \mathrm{Kcal} \mathrm{mol}^{-1} . H_{A o}, H_{w}$ y $H_{M E}$ son las constantes de equilibrio de intercambio iónico para la reacción del metanol protonado con el ácido oleico, agua y metil oleato respectivamente, asumiéndose que estas contantes son independientes de la temperatura; $C_{i}^{R}$ es la concentración de varios componentes en la fase líquida absorbida en el interior de la resina. Dicho modelo fue utilizado en la construcción de los mapas de curvas residuales reactivos y para llevar a cabo la simulación rigurosa en Aspen plus.

\subsubsection{Reacciones de Transesterificación}

\section{Catalizador Heterogéneo}

Para el caso de la cinética de la reacción de transesterificación existen pocos trabajos reportados en la literatura, principalmente para la reacción catalizada con catalizador heterogéneo considerando la trioleína y el metanol como reactivos. Uno de los trabajos reportados es el de Dossin et al. (2006), quien propone la transesterificación de la trioleína con metanol usando un catalizador heterogéneo de óxido de magnesio. El modelo cinético está basado en el mecanismo tipo Eley- Rideal de tres pasos en la fase líquida, asumiendo a la velocidad de adsorción del metanol como el paso determinante. En este trabajo estudian la transesterificación de la trioleína con metanol para formar metil oleato para simular la producción del biodiesel de aceite de colza en un reactor de lecho continuo. Y sus 
resultados los campara con procesos que utilizan catalizadores homogéneos. La transesterificación ocurre entre el metanol adsorbido sobre el sitio básico libre del óxido de magnesio y el glicérido de la fase líquida. En general el esquema que representa la reacción de transesterificación de la trioleína paso a paso, incluyendo los intermediarios como son diglicéridos, monoglicéridos y metil ésteres en presencia de metanol se presenta a continuación:

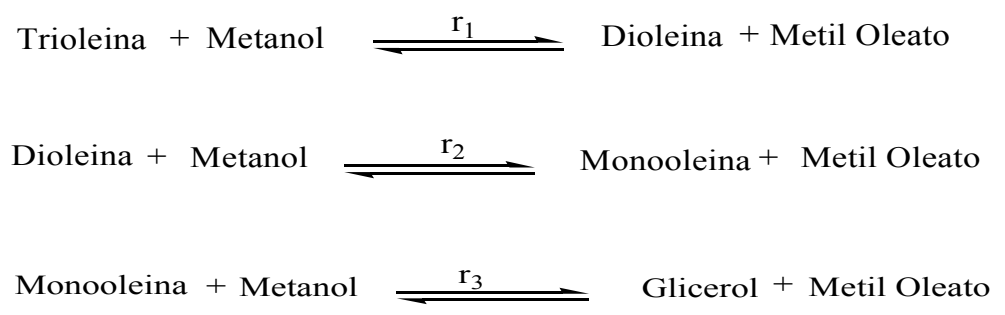

Figura 2.9. Reacciones consecutiva de la transesterificación de la trioleína.

En dicho trabajo se asume que los valores de la energía de activación y el factor preexponencial para cada reacción de transesterificación son iguales a los valores para la transesterificación de etil acetato con metanol.

Entonces de acuerdo con este modelo, las ecuaciones de velocidad de reacción de transesterificación de los glicéridos son:

$$
\begin{gathered}
r_{T G}=\frac{k_{M e O H}\left(C_{M e O H}-\frac{1}{k_{e q, 1}} \frac{a_{M E} a_{D G}}{a_{T G}}\right)}{1+\frac{K_{A}}{k_{e q, 1}} \frac{a_{M E} a_{D G}}{a_{T G}}+K_{A} C_{D G}+K_{A} C_{M G}+K_{A} C_{G L Y}} \\
r_{D G}=\frac{k_{M e O H}\left(C_{M e O H}-\frac{1}{k_{e q, 2}} \frac{a_{M E} a_{M G}}{a_{D G}}\right)}{1+\frac{K_{A}}{k_{e q, 2}} \frac{a_{M E} a_{M G}}{a_{D G}}+K_{A} C_{D G}+K_{A} C_{M G}+K_{A} C_{G L Y}} \\
r_{M G}=\frac{k_{M e O H}\left(C_{M e O H}-\frac{1}{k_{e q, 3}} \frac{a_{M E} a_{G L Y}}{a_{M G}}\right)}{1+\frac{K_{A}}{k_{e q, 3}} \frac{a_{M E} a_{G}}{a_{M G}}+K_{A} C_{D G}+K_{A} C_{M G}+K_{A} C_{G L Y}}
\end{gathered}
$$

Figura 2.10. Expresiones cinéticas de la transesterificación, reportadas por Dossin et al. 
Donde, $r$ es la velocidad de reacción $\left(\mathrm{mol} \mathrm{kg}_{\mathrm{cat}}{ }^{-1} \mathrm{~s}^{-1}\right), k_{\mathrm{MeOH}}\left(\mathrm{m}^{3} \mathrm{~kg}_{\mathrm{cat}}{ }^{-1} \mathrm{~s}^{-1}\right)$ es la constante de adsorción del metanol que es igual para las tres reacciones, $a_{i}$ las actividades de cada componente presente en cada reacción, $C_{i}\left(\mathrm{~mol} \mathrm{~m}^{-3}\right)$ es la concentración de cada componente presente en cada reacción, $k_{e q}$, es el coeficiente de equilibrio de la reacción de transesterificación global y $K_{A}$ es la constante de equilibrio de adsorción del alcohol presente con valor de $0.00529 \mathrm{~m}^{3} \mathrm{~mol}^{-1}$. De acuerdo a la ecuación de Arrhenius, la constante de velocidad de reacción puede ser expresada como una función de la temperatura en la siguiente forma:

$$
K_{\text {MeOH }}=A e^{E_{A} / R T}
$$

Donde $A$ es el factor pre-exponencial con valor de $0.148 \mathrm{~m}^{3} \mathrm{~kg}_{\mathrm{cat}}{ }^{-1} \mathrm{~s}^{-1}, \mathrm{y} E_{A}$ es la energía de activación con valor de $20100 \mathrm{~J} \mathrm{~mol}^{-1}$ para este caso. El modelo ya descrito fue utilizado sólo en la construcción del mapa de curvas residuales reactivo.

\section{Catalizador Homogéneo}

Existen una mayor cantidad de trabajos reportados que desarrollan modelos cinéticos que permiten simular el comportamiento cinético de los aceites, pero utilizando catalizadores homogéneos alcalinos. Uno de ellos es reportado por Narváez et al. (2007), donde realiza un estudio cinético de la transesterificación del aceite de palma. Los datos cinéticos se reproducen con un modelo de cinética de segundo orden para las tres reacciones consecutivas usando $\mathrm{NaOH}$ como catalizador.

Aquí se describe que la reacción toma lugar a través de tres etapas: 1) etapa de lenta transferencia de masa; 2) etapa de rápida cinética; y 3) etapa de lento equilibrio químico. La etapa de una lenta transferencia de masa al inicio es resultado de la inmisibilidad entre el aceite y el metanol. La velocidad de reacción es limitada por la transferencia de masa del triglicérido (TG) al metanol y fase de aceite. La rápida cinética ocurre cuando las reacciones intermediarias de diglicéridos y monoglicéridos actúan como surfactantes y estabilizan al metanol que cae en la fase aceitosa continua. El área interfacial incrementa entre la fase del aceite y el metanol haciendo que la transferencia de masa del TG al metanol y la fase aceitosa no sea larga limitando la velocidad de reacción. En la última 
etapa, la reacción se aproxima al equilibrio químico y la velocidad de reacción se relentiza. Además que puede ocurrir la saponificación de los ácidos grasos libres y el triglicérido con el ion $\mathrm{OH}^{-}$(Chang y Liu, 2010). Entonces de acuerdo con este modelo, la velocidad de reacción de transesterificación es dada por:

$$
\begin{aligned}
& r_{1}=k_{1} C_{T G} C_{M e O H} \rightleftarrows k_{-1} C_{D G} C_{M E} \\
& r_{2}=k_{2} C_{D G} C_{M e O H} \rightleftarrows k_{-2} C_{M G} C_{M E} \\
& r_{3}=k_{3} C_{M G} C_{M e O H} \rightleftarrows k_{-3} C_{G L Y} C_{M E}
\end{aligned}
$$

Donde la $r$ es la velocidad de reacción $\left(\mathrm{mol} \mathrm{L}^{-1} \min ^{-1}\right)$ y $k_{i}$ y $k_{-i}$ son las contantes cinéticas hacia adelante y hacia atrás en cada reacción $\left(\mathrm{L} \mathrm{mol}^{-1} \mathrm{~min}^{-1}\right)$. De acuerdo a la ecuación de Arrhenius, la constante de velocidad de reacción puede ser expresada como una función de la temperatura en la siguiente forma:

$$
k_{i}=A_{i} e^{E_{A i} / R T}
$$

Donde $\operatorname{los} A_{i}$ es el factor pre-exponencial y $E_{A i}$ es la energía de activación para cada reacción y los valores que tienen son:

\begin{tabular}{clcl}
\hline$A_{i}\left(\mathrm{~L} \mathrm{~mol}^{-1} \mathrm{~min}^{-1}\right)$ & Valor & $E_{A i}\left(\mathrm{cal} \mathrm{mol}^{-1}\right)$ & Valor \\
\hline$A_{1}$ & $1.102 \times 10^{6}$ & $E_{A I}$ & 13500 \\
$A_{-I}$ & $1.726 \times 10^{4}$ & $E_{A-I}$ & 10300 \\
$A_{2}$ & $2.206 \times 10^{9}$ & $E_{A 2}$ & 17400 \\
$A_{-2}$ & $2.003 \times 10^{8}$ & $E_{A-2}$ & 16200 \\
$A_{3}$ & 31.714 & $E_{A 3}$ & 6200 \\
$A_{-3}$ & $2.978 \times 10^{4}$ & $E_{A-3}$ & 11900 \\
\hline
\end{tabular}

\subsection{Propiedades Termodinámicas de los Compuestos Puros}

Una propiedad es cualquier característica evaluable de un sistema, cuyo valor depende de las condiciones de éste. Las propiedades de un sistema definen su "estado". La lista de estas propiedades se puede reducir, si se considera que no todas son significativas para un análisis determinado. Por ello se agrupan las propiedades en clases significativas según los 
tipos de análisis, por tanto se proponen diferentes tipos de estados. Por otra parte algunos procesos nuevos requieren del conocimiento de las propiedades termodinámicas de los compuestos puros o de las mezclas que serán sometidos a transformación, en particular de las propiedades críticas del sistema. Por tanto, el análisis termodinámico constituye un aspecto de gran trascendencia en el diseño de procesos, desde contar con las propiedades termodinámicas de los compuestos presentes en la mezcla reactiva como la caracterización apropiada de su comportamiento en el equilibrio de fases para determinar la viabilidad de la separación.

Por tanto se presentan las propiedades termodinámicas más importantes de todos los componentes puros, obtenidas con métodos de contribución de grupos que reporta Aspen Plus, dichas propiedades ayudaran a analizar el estado termodinámico en el cual se está trabajando y serán utilizadas en capítulos posteriores:

Tabla 2.4. Propiedades de los componentes puros presentes en la producción de biodiesel.

\begin{tabular}{|c|c|c|c|c|c|c|c|c|}
\hline Propiedad & Trioleína & Metanol & $\begin{array}{l}\text { Metil } \\
\text { Oleato }\end{array}$ & Dioleína & Monoleína & Glicerol & $\begin{array}{l}\text { Ácido } \\
\text { Oleico }\end{array}$ & Agua \\
\hline Tc (k) & 1639.95 & 512.5 & 764 & 1025.0 & 885 & 850 & 781 & 647.13 \\
\hline $\begin{array}{l}\text { Vc } \\
\left(\mathrm{cm}^{3} / \mathrm{mol}\right)\end{array}$ & 3090 & 117 & 1060 & 2150 & 1210 & 264 & 1000 & 55.948 \\
\hline Pc (Bar) & 4.7 & 80.84 & 12.8 & 7.92 & 12.40 & 75 & 13.9 & 220.55 \\
\hline PM & 885.45 & 32.042 & 296.49 & 621 & 356.55 & 92.095 & 282.47 & 18.015 \\
\hline Tb (K) & 1120 & 337.85 & 617 & 920 & 714 & 561 & 633 & 373.15 \\
\hline $\begin{array}{l}\text { DHvap } \\
\text { (Kcal/ mol) }\end{array}$ & 7.1319 & 8.3932 & 15.197 & 25.556 & 16.322 & 15.695 & 16.562 & 9.7447 \\
\hline
\end{tabular}

\subsection{Modelos Termodinámicos para el Cálculo de Equilibrio de Fases}

Los modelos para calcular el equilibrio de fase son una herramienta útil en la ingeniería de diseño de procesos químicos ya que los métodos de diseño requieren estimados cuantitativos del equilibrio de fase de los fluidos, para el diseño de columnas de destilación, extracción y operaciones similares. 
Uno de los objetivos de la termodinámica es el desarrollo de expresiones que establezcan las condiciones del equilibrio de un sistema. De manera rigurosa, el equilibrio se puede establecer en función de propiedades termodinámicas extensivas como la energía interna, la entalpia, la energía de Helmholtz y la energía de Gibbs. Sin embargo, resulta más práctico expresar el equilibrio utilizando magnitudes intensivas como la presión, la temperatura y los potenciales químicos. Existe un criterio general de equilibrio entre fases, a presión y temperatura constante que se puede formular del modo siguiente:

$$
\mu_{i}^{1}=\mu_{i}^{2}=\ldots \ldots=\mu_{i}^{m} \quad(i=1,2, \ldots, n)
$$

Donde $\mu_{i}^{1}, \mu_{i}^{2}, \mu_{i}^{m}$ son los potenciales químicos del componente $i$ en las fases $1,2, . ., m$ y $n$ el número de componentes de la mezcla.

Es decir, para un sistema de $\mathrm{m}$ fases que se encuentran a la misma $T$ y $P$, la condición de equilibrio se satisface cuando el potencial químico es el mismo en todas las fases. Pero la ecuación anterior no puede aplicarse de forma directa, por lo que, se expresa en términos de alguna función termodinámica relacionada con las magnitudes medibles experimentalmente como la fugacidad.

La fugacidad del componente $i$ en una fase $\alpha, f_{i}^{m}$, está directamente relacionada con su potencial químico mediante la siguiente ecuación:

$$
\mu_{i}^{m}=R T^{m} \ln f_{i}^{m}+c
$$

Siendo $R$ la constante de los gases; $T$, la temperatura absoluta $\mathrm{y}, c$, el parámetro dependiente de la temperatura y la naturaleza del componente.

A partir de las ecuaciones anteriores y admitiendo el equilibrio térmico, se reduce una nueva formulación del criterio de equilibrio en función de las fugacidades.

$$
f_{i}^{1}=f_{i}^{2}=\ldots .=f_{i}^{m} \quad(i=1,2, \ldots n)
$$

Este último criterio del equilibrio de fases requiere que, para que un sistema de $\mathrm{m}$ fases a la misma $T$ y $P$, se encuentren en equilibrio, la fugacidad de cada componente debe ser la misma en todas las fases. Para un sistema formado por una fase líquida y una fase vapor, el estado del equilibrio se puede expresar como: 


$$
f_{i}^{l}=f_{i}^{v}
$$

Para sistemas no ideales, la igualdad de las fugacidades puede escribirse bajo la forma:

$$
y_{i} \phi_{i} P=\gamma_{i} x_{i} f_{i}^{\circ}
$$

Siendo $\gamma_{i}$, el coeficiente de actividad del componente $i$ en la fase líquida; $f_{i}^{\circ}$, la fugacidad del componente $i$ en el estado de referencia elegido para la fase líquida y $\phi_{i}$, el coeficiente de fugacidad del componente $i$ en la fase vapor.

La desviación con respecto a la idealidad de la fase líquida se caracteriza por el coeficiente de actividad de una especie $i$ en disolución definido como:

$$
\gamma_{i}=\frac{f_{i}^{l}}{x_{i} f_{i}^{\circ}}
$$

Es decir, la fugacidad de un componente en una fase líquida está relacionada con la fracción molar de ese componente en dicha fase por medio del coeficiente de actividad y de la fugacidad de referencia. Para un componente $i$ en una fase líquida, la fugacidad de referencia es la fugacidad de ese componente a la temperatura de la disolución, aún cuando su presión y composición sean elegidas de modo arbitrario. Normalmente, se adopta como estado de referencia el correspondiente al líquido $i$ puro, a la temperatura de equilibrio y a la presión del sistema. En una primera aproximación, la fugacidad del líquido puro se puede considerar igual a la presión de saturación de dicho componente $P_{i}^{\circ}$ sat , a la misma temperatura.

Esto significa que una buena aproximación de dicha ecuación es:

$$
y_{i} \phi_{i} P=\gamma_{i} x_{i} P_{i}^{\circ} \text { sat }
$$

El modelo es conocido como Gama-Phi

Considerando que la fase vapor se comporta de forma ideal a bajas presiones tenemos que $\phi_{i}=1$, teniendo por tanto:

$$
y_{i} P=\gamma_{i} x_{i} P_{i}^{\circ} \text { sat }
$$


De este último se puede partir para predecir el comportamiento no ideal de la mezcla en solución.

El estudio teórico del comportamiento termodinámico de las mezclas líquidas es un campo interesante por cuanto su objetivo es crear modelos teóricos que permitan predecir, lo más fielmente posible, los valores de determinadas propiedades termodinámicas de mezclas líquidas sin necesidad de medirlas experimentalmente. Sin embargo, de los tres estados de la materia, sólido, líquido y gaseoso, el estado líquido es el menos conocido y el más difícil de caracterizar por la mecánica estadística.

Por otra parte, las moléculas orgánicas presentan tal complejidad en su estructura que es muy difícil que sus mezclas puedan ser estudiadas termodinámicamente basándose en estudios teóricos fundamentales. Por lo tanto, para esclarecer el comportamiento de las mezclas líquidas, se plantean modelos simplificados que permitan conocer algunas características generales del potencial y de las fuerzas intermoleculares que de otra manera no podrían calcularse, puesto que la aplicación práctica de los tratamientos ecanoestadísticos a un sistema de partículas interactuantes llevaría a resultados demasiado complejos.

Debe tenerse en cuenta, además, la dificultad que entraña el estudio de las interacciones entre las moléculas, concretamente en el estado líquido, sobre todo cuando éstas presentan estructuras tan complejas como son las correspondientes a las moléculas orgánicas. Las fuerzas intermoleculares tienen origen electromagnético, siendo repulsivas a corto alcance $\mathrm{y}$ atractivas a largo alcance.

Los modelos teóricos surgen para tratar de dar respuesta al comportamiento de la materia. Pero, en la actualidad no existe ningún modelo teórico capaz de dar respuestas satisfactorias, de manera absoluta, al comportamiento experimental de la materia, y menos aún del estado líquido, debido a la dificultad de establecer una teoría que prediga el comportamiento experimental en función de su estructura molecular. Por ello, el estudio termodinámico de las mezclas se plantea basándose en los modelos elementales que traten de explicar el comportamiento de ciertas sustancias, modificándolos paulatinamente para aumentar su campo de aplicación. 
En estos modelos moleculares simples propuestos, las moléculas, o parte de ellas, se consideran como estructuras geométricas simples y regulares en las que sus interacciones se analizan introduciendo los parámetros ajustables que dan cuenta de las propiedades de las mezclas. Tales propiedades se predicen una vez ajustados los parámetros.

En la actualidad, se utilizan cuatro grandes grupos de modelos, dependiendo de las consideraciones estructurales que se hagan sobre el fluido, que se clasifican en: a) Modelos de red; b) Modelos de celda; c) Modelos de disoluciones asociadas; d) Modelos de composición local.

En nuestro caso se utilizaron sólo modelos de composición local entre ellos específicamente UNIQUAC y UNIFAC para predecir los coeficientes de actividad y por ende las propiedades termodinámicas de nuestras mezclas de estudio debido a la alta polaridad de los componentes presentes como es el caso del metanol, agua y glicerol principalmente lo que genera una alta no idealidad de la fase líquida.

Los modelos de composición local se basan en la teoría propuesta por Wilson (1964) que introduce el término de fracción de volumen local expresada en función de los factores de Boltzmann. Estos modelos se deducen a partir del modelo fenomenológico de dos fluidos de Scott (1956), el cual supone que las propiedades de una mezcla binaria son equivalentes a las promediadas con dos líquidos puros hipotéticos, constituidos por celdas, en cuyos centros se encuentran las moléculas de cada uno de los componentes puros.

\subsubsection{UNIQUAC}

La ecuación UNIQUAC (Universal Quasi-Chemical), formulada originalmente por Abrams y Prausnitz (1975), permite obtener una expresión semiteórica para la energía molar de Gibbs de exceso, mediante una generalización de la teoría de Guggenheim (1952) a mezclas que contienen moléculas de diferente tamaño y forma haciendo uso del concepto de composición local, en la que consideró que un líquido puede ser representado mediante 
una red de índice de coordinación $z$ y con nudos equidistantes. Cada molécula está constituida por segmentos iguales enlazados ocupando, cada uno de ellos, una celda de la red. Una molécula puede, por tanto, ocupar uno o más nudos de la red y, los $z$ nudos próximos a un segmento de la molécula pueden estar ocupados por otros segmentos de la misma. En consecuencia, los contactos pueden ser tanto internos como externos.

Una molécula de componente $i$ está formada por $r_{i}$, segmentos enlazados, iguales por definición, pero diferenciándose en su área externa de contacto. El número de contactos externos a una molécula viene dado por $q_{i} z$, donde $q_{i}$, es un parámetro proporcional a la superficie externa de la molécula.

Para una molécula lineal $i$, el número de vecinos viene dado por la siguiente expresión:

$$
q_{i}=2(z-1)+\left(s_{i}-z\right)(z-2)
$$

Abrams y Prausnitz muestran que la ecuación de UNIQUAC proporciona una buena representación de los equilibrios líquido-líquido y líquido-vapor para las mezclas binarias y multicomponente, líquidos polares o no polares formadas por una gran variedad de no electrolitos como los alcanos, los ésteres, los alcoholes, el agua, etc.

Dicha ecuación tiene dos partes, una combinatorial (comb) que intenta describir la contribución entrópica y otra residual (res) que describe la contribución energética. De esta forma, para la función de Gibbs se plantea:

$$
G^{E}=G_{c o m b}^{E}+G_{r e s}^{E}
$$

El término combinatorial es función de la composición y tiene en cuenta la estructura molecular de los componentes pero prescinde de la energía de interacción entre las moléculas. El término residual considera la energía de interacción a través de los parámetros energéticos $\Delta u_{i j}$ y por ello debe ser función de la temperatura.

Para una mezcla multicomponente los términos anteriores se definen como:

$$
\left(\frac{G^{E}}{R T}\right)_{c o m b}=\sum_{i} x_{i} \ln \left(\frac{\varphi_{i}}{x_{i}}\right)+\frac{z}{2} \sum_{i} x_{i} q_{i} \ln \left(\frac{\theta_{i}}{\varphi_{i}}\right)
$$




$$
\left(\frac{G^{E}}{R T}\right)_{\text {res }}=-\sum_{i} x_{i} q_{i} \ln \sum_{j}\left(\theta_{j} \tau_{j i}\right)
$$

en donde el índice de coordinación, $z$ es igual a 10 y las expresiones para el parámetro de energía, $\tau_{j i}$, la fracción de volumen, $\varphi_{i}$, y la fracción de área, $\theta_{i}$ vienen dadas por:

$$
\begin{gathered}
\theta_{i}=\frac{q_{i} x_{i}}{\sum_{j} q_{j} x_{j}} \\
\varphi_{i}=\frac{s_{i} x_{i}}{\sum_{j} s_{j} x_{j}} \\
\tau_{j i}=\exp \left(-\frac{u_{j i}-u_{i i}}{R T}\right)=\exp \left(\frac{\Delta u_{i j}}{R T}\right)
\end{gathered}
$$

donde $\Delta u_{i j}$ son los parámetros energéticos ajustables, y $\mathrm{s}_{i} \mathrm{y} q_{i}$, son respectivamente los parámetros estructurales de volumen y área moleculares de Van der Waals. En una mezcla líquida binaria, la ecuación de correlación UNIQUAC para el cálculo del coeficiente de actividad del componente $i$ en la mezcla viene dada por la expresión:

$$
\ln \gamma_{i}=\left(\ln \gamma_{i}\right)_{\text {comb }}+\left(\ln \gamma_{i}\right)_{\text {res }}
$$

donde la parte combinatorial de la ecuación de correlación es debida a las diferencias en el tamaño y la forma de las moléculas en la mezcla líquida, y se expresa como:

$$
\left(\ln \gamma_{i}\right)_{\text {comb }}=\ln \left(\frac{\varphi_{i}}{x_{i}}\right)+\frac{z}{2} q_{i} \ln \left(\frac{\theta_{i}}{\varphi_{i}}\right)+l_{i}-\frac{\varphi_{i}}{x_{i}} \sum_{j} x_{j} l_{j}
$$

$\mathrm{y}$, la parte correspondiente al término residual es debida a las interacciones del resto de las moléculas presentes en la mezcla con la molécula $i$; y podemos definirla de la forma:

$$
\left(\ln \gamma_{i}\right)_{r e s}=q_{i}\left[1-\ln \left(\sum_{j} \theta_{j} \tau_{j i}\right)-\sum_{j} \frac{\theta_{j} \tau_{j i}}{\sum_{k} \theta_{k} \tau_{k j}}\right]
$$

donde el término $l_{i}$, se define como una función de la superficie externa de la molécula y los segmentos de enlace de la molécula: 


$$
l_{i}=\frac{z}{2}\left(r_{i}-q_{i}\right)-\left(r_{i}-1\right)
$$

\subsubsection{UNIFAC}

El método UNIFAC (Funtional-group Activity Coefficients), desarrollado por Fredenslund et al. $(1975,1977)$ combina el método de contribución de grupos con el método UNIQUAC de Abrams y Prausnitz (1975), considerando, al igual que éste, que el logaritmo del coeficiente de actividad de un compuesto puro en la mezcla viene dado como la suma de una parte combinatorial y de otra residual. En este método, la parte combinatorial del coeficiente de actividad de UNIQUAC, se utiliza directamente. Únicamente se encuentran en esta ecuación las propiedades del compuesto puro. Los parámetros $r_{i}$ y $q_{i}$ se determinan como la suma de los parámetros del volumen y la superficie del grupo, $R_{k}$ y $Q_{k}$, mediante las expresiones siguientes:

$$
r_{i}=\sum_{k} N_{k i} R_{i} \quad q_{i}=\sum_{k} N_{k i} Q_{k}
$$

donde $N_{k i}$, es el número de grupos de tipo $k$ en la molécula $i$ y los parámetros de grupo $R_{k} \mathrm{y}$ $Q_{k}$, se obtienen a partir de los volúmenes y las superficies de Van der Waals, $V_{W k}$ y $A_{W k}$, dados por Bondi (1968):

$$
R_{k}=V_{w k} 15.17 \quad Q_{i}=A_{k i} 2.5 \times 10^{9}
$$

debiendo expresar $V_{w k}$, en $\mathrm{cm}^{3} \mathrm{~mol}^{-1} \mathrm{y} A_{w k}$, en $\mathrm{cm}^{2} \mathrm{~mol}^{-1}$.

Los factores de normalización que aparecen en los denominadores de la expresión fueron introducidos por Abrams y Prausnitz.

La parte residual del coeficiente de actividad de la ecuación UNIQUAC se modifica para adaptarla a la solución de grupos funcionales, sustituyéndola por:

$$
\left(\ln \gamma_{i}\right)_{r e s}=\sum_{k} N_{k i}\left(\ln \Gamma_{k}-\ln \Gamma_{k i}\right)
$$


extendiéndose la sumatoria a todos los grupos presentes en la molécula, siendo $\Gamma_{k}$, el coeficiente de actividad residual del grupo $k \mathrm{y}, \Gamma_{k i}$, el coeficiente de actividad residual del grupo $k$ para una mezcla de referencia que solamente contenga las moléculas del tipo $i$.

El coeficiente de actividad residual de grupo se obtiene mediante una expresión:

$$
\ln \Gamma_{k}=Q_{k}\left[1-\ln \left(\sum_{m} \Theta_{m} \Psi_{m k}\right)-\sum_{m} \frac{\Theta_{m} \Psi_{k m}}{\sum_{n} \Theta_{n} \Psi_{n m}}\right]
$$

ecuación también válida para $\ln \Gamma_{k i}$. En esta ecuación, $\Theta_{m}$, es la fracción de superficie del grupo $k$ y la sumatoria se extienden a los diferentes grupos.

Esta fracción de superficie de grupo se obtiene de forma similar a la fracción de superficie de la molécula, $\theta_{i}$, es decir:

$$
\Theta_{m}=\frac{Q_{m} X_{m}}{\sum_{n} Q_{n} X_{n}}
$$

donde $X_{m}$, es la fracción molar del grupo $m$ en la mezcla, que viene dada por:

$$
X_{m}=\frac{\sum_{i} N_{m i} x_{i}}{\sum_{i} \sum_{n} N_{n i} x_{i}}
$$

extendiéndose el índice $i$ a todos los componentes de la mezcla y el índice $n$ a todos los grupos presentes en cada molécula de tipo $i$, de manera que, el numerador de la ecuación es el número total de grupos de tipo $m$ presentes en todas las moléculas de la mezcla y el denominador es el número total de todos los grupos de todos los tipos presentes en todas las moléculas. El parámetro de interacción, $\Psi_{m n}$, adopta la forma:

$$
\Psi_{m n}=\exp \left(-\frac{U_{m n}-U_{n n}}{R T}\right)=\exp \left(-\frac{\alpha_{m n}}{T}\right)
$$

donde $U_{\text {man }}$, es la energía de interacción entre los grupos $m$ y $n$ y $\alpha_{m n}$, son los parámetros de interacción entre esos mismos grupos y que deben ser evaluados a partir de los datos 
experimentales. Nótese que estos parámetros tienen unidades de Kelvin y que $\alpha_{m n} \neq \alpha_{n m}, \mathrm{y}$ $\alpha_{n n}=0$; es decir, para describir la interacción entre dos grupos distintos, son necesarios dos parámetros, siendo nulos los parámetros de interacción entre grupos iguales. En el método UNIFAC original, estos parámetros de interacción entre grupos $\alpha_{m n}$ se consideran independientes de la temperatura.

En definitiva, el coeficiente de actividad del componente i de una mezcla viene dado de la misma forma que en la ecuación UNIQUAC, con la misma contribución combinatorial, aunque expresando los parámetros estructurales de los compuestos puros pero, con la parte residual sustituida por la ecuación correspondiente.

\subsection{Ecuación de Antoine Extendida}

Para poder utilizar la Ec. 2.18 y obtener los valores de equilibrio de fase es necesario realizar el cálculo de la presión de saturación, y una forma de obtenerla es con la ecuación de Antoine extendida que viene reportada en Aspen Plus de donde se sacaron los parámetros necesarios para cada componente. Dicha ecuación es de la siguiente forma:

$$
\ln P^{s a t}=A+\frac{B}{T+C}+D T+E \ln T+F T^{\wedge} G
$$

donde $T$ es en Kelvin y $\mathrm{P}$ en Bar. 


\section{Capítulo 3}

\section{Diseño Conceptual}

En este capítulo se formula el modelo de destilación reactiva por lotes que sirve para la construcción de los mapas de curvas residuales reactivos (MCR-R). Se realiza la representación del sistema reactivo en términos de elemento. Se lleva a cabo la construcción y análisis de los MCR-R. También, se bosqueja la estructura del posible proceso integrado.

\subsection{Qué es el Diseño Conceptual}

La principal labor en diseño conceptual es la generación y comparación de procesos alternativos, del cual un subconjunto prometedor es seleccionado para estudios más detallados (Doherty and Malone, 2001). En este caso el diseño conceptual de una columna de destilación reactiva (CDR) está basado en un análisis termodinámico en términos de la factibilidad reacción-separación, para posteriormente poder realizar la simulación rigurosa del proceso de destilación reactiva (DR) para la producción del biodiesel.

Hace aproximadamente 80 años que se utilizó por primera vez la técnica de destilación reactiva en procesos de esterificación utilizando catálisis homogénea (Keyes, 1932), mientras que su aplicación a procesos de catálisis heterogénea es más reciente (Smith y Huddleston, 1982).

La principal ventaja que produce el uso de la DR consiste en una significativa reducción en la inversión del capital. Además, algunas de sus ventajas están determinadas por la reacción química involucrada. Teóricamente, las interacciones químicas podrían darse en cualquiera de las dos fases, sin embargo, la naturaleza continua del proceso limita fuertemente las posibilidades de la fase vapor como fase reaccionante. El contacto entre los componentes de la mezcla puede ser superior en la fase condensada; por ello, la tecnología de DR es apropiada para sistemas reactivos que pueden alcanzar conversiones aceptables en su fase líquida. 
El tiempo de residencia en la fase líquida de cada etapa en una CDR, es restringido por la velocidad de los flujos internos y por la cantidad de líquido presente en cada etapa. Por tanto, el uso de DR es recomendable cuando (Sánchez-Daza, 2003):

a) La conversión del sistema reactivo es limitado por el equilibrio químico, es decir, la reacción alcanza rápidamente su equilibrio ó

b) Las velocidades de reacción son razonablemente altas bajo condiciones de presión y temperatura en que la destilación es posible.

Algunas reacciones químicas poseen o requieren un significativo calor de reacción, dependiendo si son exotérmicas o endotérmicas. En un proceso de DR el calor de reacción no afecta la temperatura y, por lo tanto, tampoco afecta el equilibrio de la reacción. El calor de reacción provoca transferencia de masa adicional (evaporación o condensación) entre las fases vapor y líquida, y este proceso de transferencia de masa ocurre debido solamente al efecto de la destilación. La temperatura del sistema corresponde al punto de burbuja reactivo para la composición respectiva y será uniforme y constante en una etapa de equilibrio. En el caso de una reacción exotérmica, el calor de reacción se utiliza directamente para la destilación (Granados, 2008).

Sin embargo, la destilación reactiva no presenta ventajas en todos los casos, por lo que es necesario aplicar un método sistemático para predecir cuando este podría o no ser utilizado. Se necesita una investigación concerniente al fenómeno de combinar reacción química con destilación.

El proceso de destilación más sencillo es la destilación simple, o evaporación abierta de una mezcla, donde el líquido se hierve y el vapor que está en contacto con el líquido es removido tan pronto como éste se forma. De esta manera, la composición del líquido podría cambiar continuamente con el tiempo, y entonces el vapor es siempre más rico en el componente más volátil que en el líquido del cual proviene. La trayectoria que describe el cambio en la composición del líquido se denomina curva residual de destilación simple o simplemente curva residual. La colección de todas las curvas residuales de una mezcla se llama mapa de curvas residuales. Estos mapas de curvas residuales contienen exactamente 
la misma información como el correspondiente diagrama de fases para la mezcla, pero representan de una forma más útil de entender y diseñar el sistema de destilación.

Los mapas de curvas residuales reactivos son utilizados por numerosos autores en el diseño, síntesis y análisis de sistemas de destilación no reactiva, ya que se consideran una herramienta importante en el estado inicial del diseño del proceso, porque permite identificar rápidamente las secuencias factibles del proceso. Sin embargo, también se han utilizado como una herramienta de entendimiento en la destilación con reacciones químicas en equilibrio (Barbosa y Doherty, 1988) o aplicando ecuaciones de velocidad para cinéticas ficticias (Solokhin y col., 1990 a, b) o bien mediante expresiones cinéticas experimentales para reacciones catalíticas homogéneas (Venimadhavan y col., 1994) y heterogéneas (Thiel y col., 1997). No obstante, existen varias dificultades numéricas al querer modelar o diseñar un sistema de DR, las cuales tienen su origen principalmente por la naturaleza multicomponente del sistema reactivo, en particular, el uso de variables de composición en unidades molares que no son adecuadas para modelar los sistemas reactivos, debido a que estas variables no tienen la misma dimensión que el número de grados de libertad dados por la regla de fase de Gibbs para sistemas reactivos (Carrera-Rodríguez et al., 2011a; Ung and Doherty, 1995). Por esta razón se ha reportado en la literatura aproximaciones de transformación de la variable composición con la premisa de que los modelos usados para caracterizar estos sistemas de DR sean expresiones matemáticas de la misma forma que los reportados en los sistemas de destilación simple (Wasylkiewicz and Ung, 2000; Seider and Widagdo, 1996)

Barbosa y Doherty (1988) usan variable de composición transformada, para la representación y análisis de los resultados, las ventajas que trae consigo la reducción del espacio de composición, su método usa curvas residuales que están basadas en balances de materia en forma de ecuaciones diferenciales para calcular el número de etapas en la columna encontrando también la etapa de alimentación. Si bien estas composiciones transformadas suman la unidad, como las fracciones molares usuales, su definición involucra valores negativos, en algunos casos, lo cual dificulta la interpretación física de los resultados. Por otro lado, existen métodos gráficos como el de McCabe-Thiele y PonchonSavarit los cuales asumen condiciones de equilibrio para el diseño de destilación reactiva 
(Sánchez-Daza, 2003). También, existen aproximaciones de optimización que han sido aplicadas al diseño optimo de columnas de DR, incluyendo estrategias como programación disyuntiva y optimización estocástica (Jackson y Grossmann, 2001; Cardoso et al., 2000).

Recientemente Carrera-Rodríguez et al. (2011b) reporta un método corto para el diseño de procesos para mezclas reactivas multi-componente. Este método está basado en líneas de destilación en vez de líneas de curvas residuales para el modelado de las etapas de las columnas usando también variable de composición transformada, con este método se logra conocer el número de etapas teóricas, la relación de operación de reflujo y la localización del plato de alimentación, así como los flujos superior y inferior de la columna.

Opuesto a lo anterior, los procedimientos y estrategias para diseño de CDR, que se presentan en este trabajo, se basan en el concepto de elemento (Pérez-Cisneros et al., 1997), así como, la aplicación sistemática de balances de elemento (en lugar de balances molares). Consecuentemente, como variable de composición usamos fracciones de elemento, que siempre suman la unidad y nunca presentan valores negativos.

De esta manera los diagramas de fases reactivos permiten visualizar de manera más sencilla el efecto que imprimen los parámetros más importantes para la simulación y el diseño del proceso de producción. Sin embargo, el empleo de la tecnología de destilación reactiva no siempre reporta ventajas, por lo que es muy importante desarrollar una profunda investigación de los fenómenos involucrados por la combinación de las reacciones químicas que se llevan a cabo simultáneamente con un proceso de destilación. Es por ello que la aplicación del concepto de destilación reactiva en la obtención de biodiesel requiere un análisis cuidadoso del sistema reactivo en términos de al menos tres tópicos: i) el comportamiento termodinámico de la mezcla reactiva; ii) las rutas de reacción y expresiones cinéticas; iii) los fenómenos de transporte de calor y masa.

El análisis termodinámico juega un papel importante en la aplicación tecnológica de la destilación reactiva. Debido a que las propiedades termodinámicas de los compuestos reaccionantes y la apropiada determinación del comportamiento de las fases son necesarias para determinar la factibilidad de la separación. La visualización del comportamiento a través de diagrama de fases o mapa de curvas residuales reactivos (MCR-R) es requerido 
para obtener la tendencia de los procesos de reacción y separación simultáneamente. La correcta expresión cinética es muy importante porque una cinética inapropiada podría conducir a un diseño de proceso no factible. El análisis de los fenómenos de transporte es el más complejo. Los coeficientes de transporte son necesarios para el cálculo de la velocidad de transporte de masa y calor, y su determinación experimental es aun más difícil de obtener. Además, en la destilación reactiva la distribución donde existe un sistema multicomponente concentrado, la aproximación de la ley de Fick no es necesariamente correcta. No obstante, importantes avances sobre esta área han sido reportados por (Krishna and Taylor, 2000).

El diseño conceptual de las columnas de destilación reactiva consta de dos etapas principales:

1) Construcción del mapa de curvas residuales reactivas (MCR-R), para cada reacción. Donde se podrá obtener:

a. El factor de reacción-separación que nos de la máxima conversión.

b. Los diagramas de temperatura contra composición

c. Temperatura a la cual se alcanza la máxima conversión.

2) Evaluación de las propiedades

a. Temperatura de ebullición de los componentes puros

b. Reactividad

c. Formación de fases (diagramas binarios)

En consecuencia, en el presente trabajo se plantea el desarrollo de un diseño conceptual de un proceso de DR para la producción de biodiesel, fundamentado en la estimación apropiada de las propiedades de los componentes puros, en la evaluación del equilibrio líquido-vapor y la cinética de las reacciones catalíticas heterogéneas en fase líquida para la obtención de metil ésteres que conforman al biodiesel, considerando dos reacciones: la esterificación de los ácidos grasos y la transesterificación de los triglicéridos. 


\subsection{Formulación del Modelo: Destilación Reactiva por Lotes}

Para la construcción de los MCR-R para el diseño conceptual de la columna es necesario contar con un modelo que prediga su comportamiento el cual se obtiene a partir del estudio del comportamiento de un destilador Bach reactivo.

De forma general el proceso de destilación reactiva por lotes, es un destilador que opera a presión $P$ constante, y contiene una cantidad suficiente de un catalizador específico para cada reacción en estudio. Posteriormente se llena con una mezcla modelo líquida de $H_{0}$ moles, formada por $N$ componentes, reactivos y productos cuya composición se representa mediante fracciones mol $x_{i}$ como lo muestra el esquema básico de la Figura 3.1. Al mismo tiempo que el destilador se calienta hasta ebullición mediante el suministro de una cantidad $\boldsymbol{Q}$ de calor, en la misma fase líquida se verifica la reacción o reacciones correspondientes.

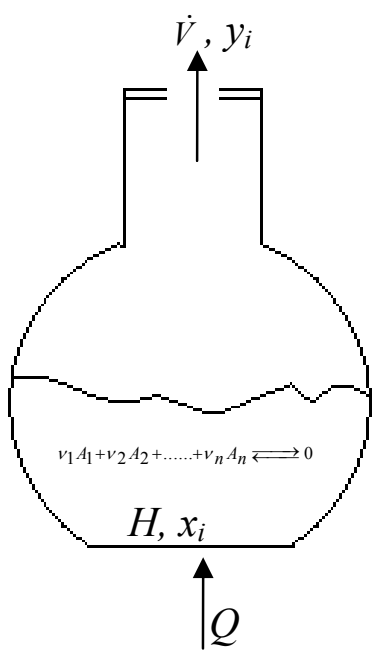

Figura 3.1. Esquema básico de un proceso de destilación reactiva por lotes

Entonces la reacción química se lleva a cabo de manera simultánea con un proceso de destilación provocado por un proceso de calentamiento, el cual conduce la transferencia de masa de la fase líquida a la fase vapor y consecuentemente a la variación de la cantidad de líquido retenido en el destilador $H(t)$ por la separación de un flujo molar de vapor $\dot{V}(t)$ cuya composición se representa mediante fracciones mol $y_{i}$. 
Suponiendo que la fase líquida se encuentra siempre en estado de ebullición, la temperatura en el destilador corresponde con la temperatura de burbuja del líquido con composición $x_{i}$ a la presión de operación $P$ dada, $T=T(X, P)$, consecuentemente, las composiciones de vapor $y_{i}$ y líquido $x_{i}$ permanecen en equilibrio de fases.

El desarrollo de un modelo por destilación reactiva simple es similar al tratamiento de destilación simple sin reacción. Sin embargo, el número de moles en el líquido puede cambiar debido a la vaporización y por la reacción que se está llevando a cabo.

De realizar un balance global de materia para las reacciones química que ocurren en la fase líquida del destilador ilustrado en la Figura 3.1 resulta la siguiente ecuación diferencial:

$$
\frac{d H(t)}{d t}=-\dot{V}(t)+\sum_{j=1}^{R} \frac{H(t)}{H_{0}} M_{c a t}^{0} \nu_{T, j} r_{j} ; \quad 0 \leq t<t_{\max } ;
$$

Donde $M_{\text {cat }}^{0}$ es la masa de catalizador que se encuentra en el destilador y permanece siempre en contacto con la fase reactiva, $v_{T, j}$ es la suma algebraica de todos los coeficientes estequiométricos correspondientes a los $N$ compuestos que intervienen en la reacción $j$, cuya velocidad se determina mediante la expresión cinética $r_{j}$ y $t_{\max }$ define el momento en que el destilador evapora completamente la mezcla líquida.

Asimismo, los balances individuales (o balances por componente) se representan a través del siguiente sistema de ecuaciones diferenciales:

$$
\frac{d\left(H(t) x_{i}\right)}{d t}=-\dot{V}(t) y_{i}+\sum_{j=1}^{R} \frac{H(t)}{H_{0}} M_{c a t}^{0} v_{i, j} r_{j}
$$

donde $i=1,2, \ldots, N$ y $v_{i, j}$, es el coeficiente estequiométrico del compuesto $i$ en la reacción $j$.

Desarrollando el lado derecho de la ecuación 3.2 tenemos:

$$
x_{i} \frac{d H(t)}{d t}+H(t) \frac{d x_{i}}{d t}=-\dot{V}(t) y_{i}+\sum_{j=1}^{R} \frac{H(t)}{H_{0}} M_{c a t}^{0} v_{i, j} r_{j}
$$

La combinación de las ecuaciones obtenidas a partir de los balances de materia individual (Ec.3.3) y global (Ec.3.1) conduce al siguiente sistema de ecuaciones diferenciales ordinarias: 


$$
\frac{d x_{i}}{d t}=\underbrace{\frac{\dot{V}(t)}{H(t)}\left(x_{i}-y_{i}\right)}_{\text {Destilación }}+\underbrace{\sum_{j=1}^{R} \frac{\left(v_{i, j}-x_{i} v_{T, j}\right)}{H_{0}} M_{c a t}^{0} r_{j}}_{\text {Reacción }}
$$

Este sistema de ecuaciones diferenciales consta de dos términos, uno que corresponde con el proceso de destilación convencional y otro que representa el efecto de las reacciones químicas que se llevan a cabo de manera simultánea. Para resolver este sistema de ecuaciones es necesario expresarlo en términos de variables experimentalmente medibles; por ejemplo, ante la imposibilidad física de medir directa y puntualmente la proporción entre el líquido retenido en el destilador y el flujo de vapor que abandona la fase líquida $H(t) / \dot{V}(t)$, el cual se puede traducir como el tiempo de residencia de las moléculas en la fase líquida, se introduce la variable adimensional de tiempo deformado $\xi$ (Melles, 1996) que implica la transformación de la escala finita de tiempo a una escala infinita y que se define de acuerdo con la siguiente expresión:

$$
\xi=\left(\frac{\dot{V}_{0}}{H_{0}}\right) t
$$

adicionalmente, el tiempo de residencia $H(t) / V(t)$ se puede controlar experimentalmente mediante una estrategia apropiada de calentamiento, por ejemplo, mediante un adecuado suministro de calor al destilador es físicamente posible hacer que la velocidad de retiro del vapor sea proporcional a la cantidad de líquido que permanece en el destilador; es decir, que la fracción $\dot{V}(t) / \dot{V}_{0}$ sea igual a $H(t) / H_{0}$, lo que se puede expresar en la forma siguiente:

$$
\frac{H(t)}{\dot{V}(t)}=\frac{H_{0}}{\dot{V}_{0}}=\text { constante }
$$

La introducción de estas expresiones para el tiempo deformado nos permite proponer la siguiente funcionalidad en el tiempo de la fracción molar de cada componente en la fase líquida:

$$
x_{i}=x_{i}[\xi(t)]
$$

Entonces, su derivada con respecto al tiempo $t$ se obtiene mediante la regla de la cadena: 


$$
\frac{d x_{i}}{d t}=\frac{d x_{i}}{d \xi} \cdot \frac{d \xi}{d t} \quad O \quad \text { bien } \quad \frac{d x_{i}}{d \xi}=\frac{d x_{i}}{d t} \cdot\left(\frac{H_{0}}{\dot{V}_{0}}\right)
$$

La sustitución de la expresión obtenida para la nueva variable de tiempo deformado así como la correspondiente a la política de suministro de calor en la ecuación 3.4, permite obtener el siguiente sistema de ecuaciones diferenciales:

$$
\frac{d x_{i}}{d \xi}=x_{i}-y_{i}+\frac{M_{c a t}^{0}}{\dot{V}_{0}} \sum_{j=1}^{R}\left(v_{i, j}-x_{i} v_{T, j}\right) r_{j}
$$

Si introducimos otro parámetro adimensional, llamado factor de reacción-separación $(\alpha)$ el cual puede interpretarse como la proporción entre la rapidez de reacción característica $\left(r_{0}\right)$; en donde la cantidad $r_{0}$ es un valor de referencia calculado para la velocidad de reacción; y una rapidez característica con que las moléculas que se separan del catalizador y abandonan la fase líquida $\left(\dot{V}_{0} / M_{c a t}^{0}\right)$. También se puede decir que este parámetro indica la relación de la cantidad de catalizador cargado en el recipiente de destilación (por ejemplo el área total mojada reaccionante) multiplicado por la velocidad de reacción de referencia sobre el flujo de vaporización. Puede notarse que este parámetro tiene similitud al número de Damkohler, en la forma en que este describe la conversión de un compuesto especifico sobre el transporte convectivo. Sin embargo, en este caso, es preferible usar el parámetro de reacción-separación porque claramente indica que una reacción simultánea y un fenómeno de separación están ocurriendo. Además de que puede cuantificar indirectamente el tiempo de residencia. De esta forma el parámetro de reacción-separación queda expresado como:

$$
\alpha=\frac{r_{0}}{\left(\frac{\dot{V}_{0}}{M_{c a t}^{0}}\right)}=\frac{r_{0} M_{c a t}^{0}}{\dot{V}_{0}}
$$

De esta manera obtenemos un sistema de ecuaciones que representa el comportamiento de la fase líquida del sistema reactivo y cuya solución nos permitirá obtener la composición de la mezcla reactiva en equilibrio de fases como una función del parámetro de reacción separación alfa $(\alpha)$ y por lo tanto podremos obtener los MCR-R.

$$
\frac{d x_{i}}{d \xi}=x_{i}-y_{i}+\alpha \sum_{j=1}^{R}\left(v_{i, j}-x_{i} v_{T, j}\right) \frac{r_{j}}{r_{0}}
$$




\subsection{Representación del Sistema en Términos de Elementos}

La definición de los sistemas reactivos en términos de elementos permite la visualización del diagrama de fases para múltiples sistemas reactivos multi-componentes en figuras de dos o tres dimensiones (en términos de elementos) sin menoscabar la interpretación física del problema. Con base a esta metodología, es posible también estudiar sistemas con más de una reacción y estequiometrias no isomolares (Sánchez-Daza, 2003).

La principal ventaja de la representación de la composición en elemento es que se reduce el dominio del espacio composición y simplifica los cálculos de equilibrio de fase con reacción química (en equilibrio o cinéticamente controlada) (Sánchez-Daza, 2003). También, se simplifica la visualización grafica del comportamiento de la fase reactiva a través del diagrama de fase reactivo o el mapa de curvas residuales reactivo, construido en términos de composición de elemento.

Un punto importante en la computación del equilibrio físico-químico es la correcta caracterización del sistema reactivo. Esta caracterización puede ser hecha a través del uso de la regla de fases aplicado a un sistema reactivo.

La regla de las fases de Gibbs para sistemas reactivos (Denbigh, 1966) nos indica que los grados de libertad en tal sistema (F), dependen del número de fases (NF), y del número mínimo de sustancias que deben estar presentes (M), para obtener un sistema con un número de especies (NC):

$$
\begin{gathered}
F=2-\mathrm{NF}+\mathrm{M} \\
\mathrm{M}=\mathrm{NC}-\mathrm{NR}-\mathrm{S}
\end{gathered}
$$

$\mathrm{M}$ es el número de elementos independientes que constituyen el sistema reactivo, y estos pueden ser átomos, moléculas o grupos de átomos y no necesariamente de la tabla periódica (Pérez-Cisneros et al., 1997). Es importante notar que estos elementos permanecen 
invariables durante el proceso de transformación química, o sea que, la cantidad de ellos es la misma al inicio y al final de la reacción, independientemente, de que sea equimolar o no.

Dado que los procesos de destilación reactiva que estudiamos aquí, sólo coexisten líquido y vapor $(\mathrm{NF}=2)$, resulta que los grados de libertad $(\mathrm{F})$ los determina el número de elementos que conforman un sistema reactivo dado por la Ec. 3.13.

La selección de elementos en sistemas reactivos se ha realizado tradicionalmente a través de los elementos químicos "naturales" que se encuentran presentes en la mezcla, sin embargo es posible elegir libremente cualquier fragmento de reactivo que permanezca invariante a lo largo de la reacción. Con la matriz obtenida de los elementos químicos naturales de los compuestos presentes en la reacción, se puede sacar el rango de dicha matriz lo cual nos proporciona información acerca del número de elementos independientes M y consecuentemente puede darnos el número de reacciones químicas independientes NR si existieran un mayor número de ellas, pero lo más importante es que nos proporciona el número mínimo de descomposiciones moleculares en átomos, fragmentos o radicales que representan una reacción química (Pérez-Cisneros, 1997).

\subsubsection{Reacción de Esterificación}

La reacción considerada es la siguiente $(\mathrm{NR}=1)$ :

$$
\begin{array}{lll}
\mathrm{C}_{17} \mathrm{H}_{33} \mathrm{COOH}+ & \mathrm{CH}_{3} \mathrm{OH} \rightleftarrows \mathrm{C}_{19} \mathrm{H}_{36} \mathrm{O}_{2}+ & \mathrm{H}_{2} \mathrm{O} \\
\text { Acido Oleico } & \text { Metanol } & \text { Metil Oleato }
\end{array}
$$

La matriz de elementos naturales para este caso se presenta en la Tabla 3.1, sin embargo, es posible elegir libremente cualquier fragmento de reactivo que permanezca invariante a lo largo de la reacción. 
Tabla 3.1.-Matriz de elementos naturales para la esterificación del ácido oleico

\begin{tabular}{lllll}
\cline { 1 - 1 } \multicolumn{1}{ll}{ Componente } & $\mathrm{C}_{17} \mathrm{H}_{33} \mathrm{COOH}$ & $\mathrm{CH}_{3} \mathrm{OH}$ & $\mathrm{C}_{19} \mathrm{H}_{36} \mathrm{O}_{2}$ & $\mathrm{H}_{2} \mathrm{O}$ \\
\cline { 1 - 1 } Elemento & & & & \\
$\mathrm{C}$ & 18 & 1 & 19 & 0 \\
$\mathrm{H}$ & 34 & 4 & 36 & 2 \\
$\mathrm{O}$ & 2 & 1 & 2 & 1 \\
\hline
\end{tabular}

El rango de la matriz es igual a 3 , y no se tiene ninguna restricción adicional $(\mathrm{S}=0)$. Por lo que observando la estructura de las moléculas presentes, encontramos que ellas comparten los siguientes grupos o segmentos de moléculas, los cuales pueden ser definidos como los elementos constituyentes de este sistema reactivo:

$$
A=\mathrm{C}_{18} \mathrm{H}_{32} \mathrm{O} ; \quad \mathrm{B}=\mathrm{H}_{2} \mathrm{O} ; \quad \mathrm{C}=\mathrm{CH}_{3} \mathrm{OH} ;
$$

Como resultado tenemos que la reacción química 3.14, puede representarse, en términos de elementos como:

$$
A B+C \rightleftarrows A C+\quad B
$$

Las columnas de la Tabla 3.2 expresan la conformación de cada molécula, en términos de los elementos A, B, y C, y sus filas nos indican la aportación de cada molécula, al total de cada elemento existente en la mezcla.

\begin{tabular}{|c|c|c|c|c|}
\hline Componente & $\mathrm{C}_{17} \mathrm{H}_{31} \mathrm{COOH}$ & $\mathrm{CH}_{3} \mathrm{OH}$ & $\mathrm{C}_{19} \mathrm{H}_{34} \mathrm{O}_{2}$ & $\mathrm{H}_{2} \mathrm{O}$ \\
\hline \multicolumn{5}{|l|}{ Elemento } \\
\hline A & 1 & 0 & 1 & 0 \\
\hline B & 1 & 0 & 0 & 1 \\
\hline $\mathrm{C}$ & 0 & 1 & 1 & 0 \\
\hline
\end{tabular}

Tabla 3.2. Matriz elemental de la esterificación.

\subsubsection{Reacciones de Transesterificación}

Las reacciones consideradas son las siguientes $(\mathrm{NR}=1)$ : 


$$
\begin{array}{lllll}
\mathrm{C}_{57} \mathrm{H}_{104} \mathrm{O}_{6} & + & \mathrm{CH}_{3} \mathrm{OH} \rightleftarrows \mathrm{C}_{39} \mathrm{H}_{72} \mathrm{O}_{5} & + & \mathrm{C}_{19} \mathrm{H}_{36} \mathrm{O}_{2} \\
\text { Trioleina } & & \text { Metanol Dioleina } & & \text { Metil Oleato } \\
\mathrm{C}_{39} \mathrm{H}_{72} \mathrm{O}_{5}+ & \mathrm{CH}_{3} \mathrm{OH} \rightleftarrows \mathrm{C}_{21} \mathrm{H}_{40} \mathrm{O}_{4}+ & \mathrm{C}_{19} \mathrm{H}_{36} \mathrm{O}_{2} \\
\text { Dioleina } & & \text { Metanol Monooleina } & & \text { Metil Oleato } \\
\mathrm{C}_{21} \mathrm{H}_{40} \mathrm{O}_{4}+ & \mathrm{CH}_{3} \mathrm{OH} \rightleftarrows \mathrm{C}_{3} \mathrm{H}_{8} \mathrm{O}_{3}+ & \mathrm{C}_{19} \mathrm{H}_{36} \mathrm{O}_{2} \\
\text { Monooleina } & & \text { Metanol Glicerol } & & \text { Metil Oleato }
\end{array}
$$

\begin{tabular}{|c|c|c|c|c|c|c|}
\hline Componente & $\mathrm{C}_{57} \mathrm{H}_{104} \mathrm{O}_{6}$ & $\mathrm{CH}_{3} \mathrm{OH}$ & $\mathrm{C}_{19} \mathrm{H}_{36} \mathrm{O}_{2}$ & $\mathrm{C}_{39} \mathrm{H}_{72} \mathrm{O}_{5}$ & $\mathrm{C}_{21} \mathrm{H}_{40} \mathrm{O}_{4}$ & $\mathrm{C}_{3} \mathrm{H}_{8} \mathrm{O}_{3}$ \\
\hline \multicolumn{7}{|l|}{ Elemento } \\
\hline $\mathrm{C}$ & 57 & 3 & 57 & 39 & 21 & 3 \\
\hline $\mathrm{H}$ & 104 & 12 & 108 & 72 & 40 & 8 \\
\hline $\mathrm{O}$ & 6 & 3 & 6 & 5 & 4 & 3 \\
\hline
\end{tabular}

La matriz de elementos naturales para este caso se presenta como:

Tabla 3.3. Matriz de elementos naturales para la Transesterificación.

Para este caso el rango de la matriz también es igual a 3 y no se tiene ninguna restricción adicional $(\mathrm{S}=0)$. Por lo que observando la estructura de las moléculas presentes, encontramos que ellas comparten los siguientes grupos o segmentos de moléculas, los cuales pueden ser definidos como los elementos constituyentes de este sistema reactivo:

$$
A=\mathrm{C}_{18} \mathrm{H}_{32} \mathrm{O} ; \quad \mathrm{B}=\mathrm{C}_{3} \mathrm{H}_{8} \mathrm{O}_{3} ; \quad \mathrm{C}=\mathrm{CH}_{3} \mathrm{OH}
$$

Como resultado tenemos que las reacciones químicas 3.17, 3.18 y 3.19, pueden representarse, en términos de elementos como:

$$
\begin{aligned}
& A_{3} B+C \rightleftarrows A_{2} B+A_{2} \\
& A_{2} B+A B+A C \\
& A B+C \quad C \rightleftarrows B C
\end{aligned}
$$

Las columnas de la Tabla 3.4 expresan la conformación de cada molécula, en términos de los elementos A, B, y C, y sus filas nos indican la aportación de cada molécula, al total de cada elemento existente en la mezcla. 
Tabla 3.4. La matriz elemental del sistema reactivo de la transesterificación es la siguiente:

\begin{tabular}{|c|c|c|c|c|c|c|}
\hline Componente & $\mathrm{C}_{57} \mathrm{H}_{104} \mathrm{O}_{6}$ & $\mathrm{CH}_{3} \mathrm{OH}$ & $\mathrm{C}_{19} \mathrm{H}_{36} \mathrm{O}_{2}$ & $\mathrm{C}_{39} \mathrm{H}_{72} \mathrm{O}_{5}$ & $\mathrm{C}_{21} \mathrm{H}_{40} \mathrm{O}_{4}$ & $\mathrm{C}_{3} \mathrm{H}_{8} \mathrm{O}_{3}$ \\
\hline \multicolumn{7}{|l|}{ Elemento } \\
\hline A & 3 & 0 & 1 & 2 & 1 & 0 \\
\hline B & 1 & 0 & 0 & 1 & 1 & 1 \\
\hline $\mathrm{C}$ & 0 & 1 & 1 & 0 & 0 & 0 \\
\hline
\end{tabular}

\subsection{Visualización del Sistema Reactivo en Diagramas de Fase Elementales}

Con el objetivo de cuantificar los elementos mediante intervalos numéricamente definidos, se introduce el concepto de fracción elemento, cuya determinación requiere del cálculo de la cantidad $E_{j}$ en que se encuentra presente el elemento $j$. Pérez-Cisneros (1997) establece que la cantidad $E_{j}$ se puede calcular de acuerdo con la distribución observada en las matrices elementales, a través de las fracciones mol $x_{i}$ y los coeficientes estequiométricos $v_{i}$ de los compuestos involucrados. Mientras que la cantidad total de elemento $E_{T}$ es la suma total de $E_{j}$ para todos los $\mathrm{M}$ elementos presentes.

$$
\begin{gathered}
E_{j}=L \sum_{i=1}^{N} A_{j, i} x_{i} \\
E_{T}=L \sum_{k=1}^{M} \sum_{i=1}^{N} A_{k, i} x_{i}=\sum_{j=1}^{N} E_{j}
\end{gathered}
$$

$L$ es la cantidad del liquido y $A_{j, i}$ es el número de elementos químicos naturales $j$ presentes en el compuesto $i$. De esta manera, las fracciones individuales de los elementos que reducen el espacio composición del sistema reactivo se puede calcular de acuerdo con la siguiente expresión:

$$
W_{j}=\frac{E_{j}}{E_{T}}=\frac{L \sum_{i=1}^{N} A_{j, i} x_{i}}{L \sum_{k=1}^{M} \sum_{i=1}^{N} A_{k, i} x_{i}}=\frac{\sum_{i=1}^{N} A_{j, i} x_{i}}{\sum_{k=1}^{M} \sum_{i=1}^{N} A_{k, i} x_{i}}
$$

De forma que: 


$$
\sum_{K=1}^{M} W_{k}=1
$$

\subsubsection{Reacción de Esterificación}

Las cantidades $E_{j}$ y $E_{T}$ se determinan a través del empleo de las ecuaciones 3.24 y 3.25 en la forma siguiente:

$$
\begin{gathered}
E_{A}=L\left(x_{1}+x_{3}\right) \\
E_{B}=L\left(x_{1}+x_{4}\right) \\
E_{C}=L\left(x_{2}+x_{3}\right) \\
E_{T}=E_{A}+E_{B}+E_{C}=L\left(x_{1}+x_{3}+x_{1}+x_{4}+x_{2}+x_{3}\right)=L\left(2 x_{1}+x_{2}+2 x_{3}+x_{4}\right)
\end{gathered}
$$

Así las fracciones de elemento quedan como:

$$
\begin{aligned}
& \text { a) } W_{A}=\frac{x_{1}+x_{3}}{2 x_{1}+x_{2}+2 x_{3}+x_{4}} \\
& \text { b) } W_{B}=\frac{x_{1}+x_{4}}{2 x_{1}+x_{2}+2 x_{3}+x_{4}} \\
& \text { c) } W_{C}=\frac{x_{2}+x_{3}}{2 x_{1}+x_{2}+2 x_{3}+x_{4}}
\end{aligned}
$$

Como ya se había mencionado anteriormente la aplicación del concepto de elemento al sistema reactivo trae consigo la posibilidad de presentar mezclas reactivas multicomponentes en diagramas de fases reactivos más sencillos, lo que permite visualizar en forma precisa el comportamiento de todos los componentes (reactivos y productos) involucrados en el proceso de separación reactiva a través de un espacio de composición reducido a un espacio tridimensional, cuya geometría se puede determinar bajo la consideración de que cada uno de los elementos estará representado a través de su fracción que posee intervalos perfectamente definidos

$$
0 \leq W_{i} \leq 1
$$


por lo que es posible establecer que el espacio de composición del sistema corresponde a un diagrama triangular (Figura 3.2).

El espacio de composición de la Figura 3.2 puede describirse en los siguientes términos:

1) Los vértices del triangulo, denotados por los puntos $\mathrm{A}, \mathrm{B}$ y $\mathrm{C}$ representan los elementos puros

$$
W_{j}=1
$$

Por ejemplo si:

$$
W_{A}=1 \text { entonces } \quad W_{B}=W_{C}=0
$$

2) Los puntos que se encuentran a lo largo de la arista del triangulo y que forman las líneas que unen dos vértices (líneas A-B, A-C y B-C) representan las mezclas de los elementos; por ejemplo, las aristas A-B representan mezclas de los elementos A y B exclusivamente, por lo que la fracción de cualquier elemento que no sea A o B es $W_{C}=0$

3) Finalmente, todo punto interno del espacio composición de la figura será una mezcla de los 3 elementos, en donde las fracciones de los elementos estará en el intervalo $(0,1)$ :

$$
W_{A}=W_{B}=W_{C} \neq 0
$$

Para determinar los valores de las fracciones de elemento que representan al componente i puro se tiene lo siguiente:

Cuando $x_{1}=1$ (Ácido Oleico) y $x_{2}=x_{3}=x_{4}=0$, entonces:

$$
W_{A}=0.5 ; \quad W_{B}=0.5 ; \quad W_{C}=0
$$

Cuando $x_{2}=1$ (Metanol) y $x_{1}=x_{3}=x_{4}=0$, entonces:

$$
W_{A}=0 ; \quad W_{B}=0 ; \quad W_{C}=1
$$

Cuando $x_{3}=1$ (Metil Oleato) y $x_{1}=x_{2}=x_{4}=0$, entonces:

$$
W_{A}=0.5 ; \quad W_{B}=0 ; \quad W_{C}=0.5
$$

Cuando $x_{4}=1$ (Agua) y $x_{1}=x_{2}=x_{3}=0$, entonces: 


$$
W_{A}=0 ; \quad W_{B}=1 ; \quad W_{C}=0
$$

Los valores calculados se presentan en la Tabla 3.5 y constituyen las coordenadas que se requieren para ubicar a las especies puras en el espacio de composiciones elementales. Donde se puede apreciar que con el uso del concepto de elemento es posible representar a más de 3 componentes en un diagrama ternario como se muestra en la Figura 3.2, donde también se delimita la zona reactiva.

Tabla 3.5. Coordenadas en el espacio vectorial de los compuestos puros presentes en la esterificación.

\begin{tabular}{llll}
\hline Componente Puro & Formula & Representación & Coordenadas $\left(\mathrm{W}_{\mathrm{A}}, \mathrm{W}_{\mathrm{B}}, \mathrm{W}_{\mathrm{C}}\right)$ \\
\hline Ácido Oleico & $\mathrm{C}_{17} \mathrm{H}_{33} \mathrm{COOH}$ & $\mathrm{AB}$ & $(0.5,0.5,0)$ \\
Metanol & $\mathrm{CH}_{3} \mathrm{OH}$ & $\mathrm{C}$ & $(0,0,1)$ \\
Metil Oleato & $\mathrm{C}_{19} \mathrm{H}_{34} \mathrm{O}_{2}$ & AC & $(0.5,0,0.5)$ \\
Agua & $\mathrm{H}_{2} \mathrm{O}$ & B & $(0,1,0)$ \\
\hline
\end{tabular}

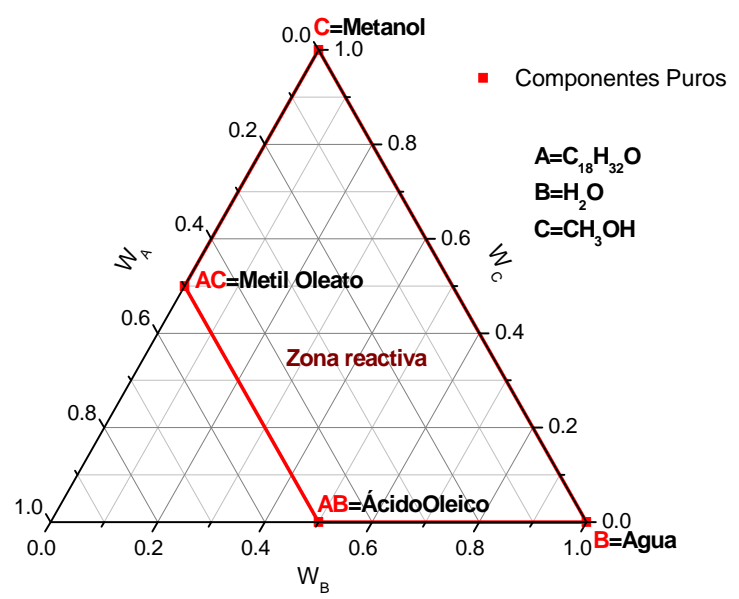

Figura 3.2. Localización de componentes puros en el espacio de composición para la esterificación.

\subsubsection{Reacciones de Transesterificación}

De forma similar al caso anterior se calcula $E_{j}$ para las reacciones presentes en la transesterificación 


$$
\begin{aligned}
E_{A} & =L\left(3 x_{1}+x_{3}+2 x_{4}+x_{5}\right) \\
E_{B} & =L\left(x_{1}+x_{4}+x_{5}+x_{6}\right) \\
E_{C} & =L\left(x_{2}+x_{3}\right) \\
E_{T}=E_{A}+E_{B}+E_{C} & =L\left(4 x_{1}+x_{2}+2 x_{3}+3 x_{4}+2 x_{5}+x_{6}\right)
\end{aligned}
$$

Así que las fracciones de elemento quedan:

$$
\begin{aligned}
& \text { a) } W_{A}=\frac{3 x_{1}+x_{3}+2 x_{4}+x_{5}}{4 x_{1}+x_{2}+2 x_{3}+3 x_{4}+2 x_{5}+x_{6}} \\
& \text { b) } W_{B}=\frac{x_{1}+x_{4}+x_{5}+x_{6}}{4 x_{1}+x_{2}+2 x_{3}+3 x_{4}+2 x_{5}+x_{6}} \\
& \text { c) } W_{C}=\frac{x_{2}+x_{3}}{4 x_{1}+x_{2}+2 x_{3}+3 x_{4}+2 x_{5}+x_{6}}
\end{aligned}
$$

Para determinar los valores de las fracciones de elemento que representan al componente i puro.

Cuando $x_{1}=1$ (Trioleína) y $x_{2}=x_{3}=x_{4}=x_{5}=x_{6}=0$, entonces:

$$
W_{A}=0.75 ; \quad W_{B}=0.25 ; \quad W_{C}=0
$$

Cuando $x_{2}=1$ (Metanol) y $x_{1}=x_{3}=x_{4}=x_{5}=x_{6}=0$, entonces:

$$
W_{A}=0 ; \quad W_{B}=0 ; \quad W_{C}=1
$$

Cuando $x_{3}=1$ (Metil Oleato) y $x_{1}=x_{2}=x_{4}=x_{5}=x_{6}=0$, entonces:

$$
W_{A}=0.5 ; \quad W_{B}=0 ; \quad W_{C}=0.5
$$

Cuando $x_{4}=1$ (Dioleína) y $x_{1}=x_{2}=x_{3}=x_{5}=x_{6}=0$, entonces:

$$
W_{A}=2 / 3 ; \quad W_{B}=1 / 3 ; \quad W_{C}=0
$$

Cuando $x_{5}=1$ (Monoleína) y $x_{1}=x_{2}=x_{3}=x_{4}=x_{6}=0$, entonces:

$$
W_{A}=0.5 ; \quad W_{B}=0.5 ; \quad W_{C}=0
$$

Cuando $x_{6}=1$ (Glicerol) y $x_{1}=x_{2}=x_{3}=x_{4}=x_{5}=0$, entonces:

$$
W_{A}=0 ; \quad W_{B}=1 ; \quad W_{C}=0
$$


Los valores calculados se presentan en la Tabla 3.6, estos constituyen las coordenadas que se requieren para ubicar a las especies puras en el espacio de composiciones elementales. Donde se puede apreciar que con el uso del concepto de elemento es posible representar a más de 3 componentes en un diagrama ternario como se muestra en la Figura 3.3, donde también delimita la zona reactiva.

Tabla 3.6. Coordenadas en el espacio vectorial de composición de los componentes puros presentes en las reacciones de transesterificación

\begin{tabular}{llll}
\hline Componente Puro & Formula & Representación & Coordenadas $\left(\mathrm{W}_{\mathrm{A}}, \mathrm{W}_{\mathrm{B}}, \mathrm{W}_{\mathrm{C}}\right)$ \\
\hline Triglicérido & $\mathrm{C}_{17} \mathrm{H}_{33} \mathrm{COOH}$ & $\mathrm{A}_{3} \mathrm{~B}$ & $(0.75,0.25,0)$ \\
Metanol & $\mathrm{CH}_{3} \mathrm{OH}$ & $\mathrm{C}$ & $(0,0,1)$ \\
Metil Oleato & $\mathrm{C}_{19} \mathrm{H}_{34} \mathrm{O}_{2}$ & AC & $(0.5,0,0.5)$ \\
Diglicérido & $\mathrm{C}_{39} \mathrm{H}_{72} \mathrm{O}_{5}$ & $\mathrm{~A}_{2} \mathrm{~B}$ & $(2 / 3,1 / 3,0)$ \\
Monoglicérido & $\mathrm{C}_{21} \mathrm{H}_{40} \mathrm{O}_{4}$ & AB & $(0.5,0.5,0)$ \\
Glicerol & $\mathrm{C}_{3} \mathrm{H}_{8} \mathrm{O}_{3}$ & B & $(0,1,0)$ \\
\hline
\end{tabular}

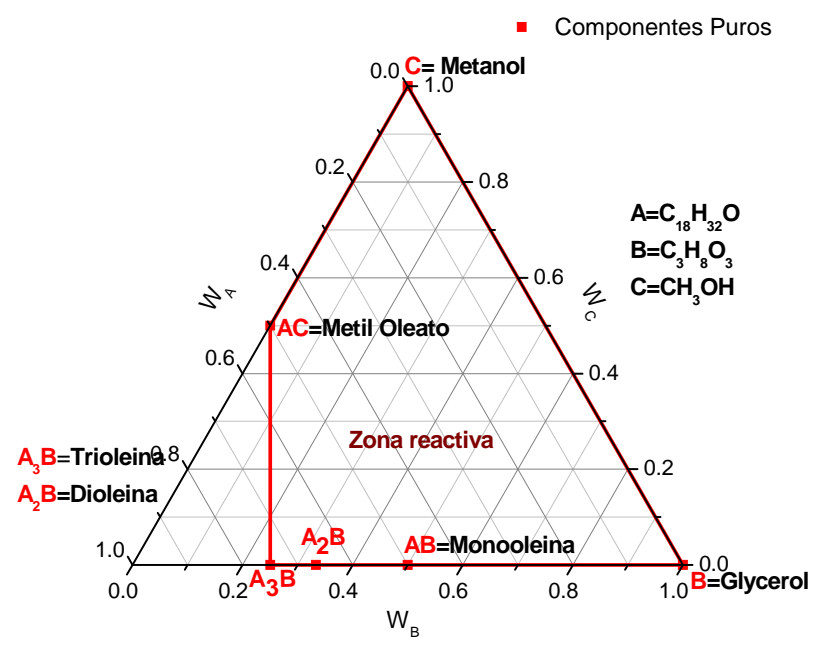

Figura 3.3. Localización de componentes puros en el espacio de composición para la reacciones de transesterificación

\subsection{Construcción de los Mapas de Curvas Residuales Reactivos}

Las curvas residuales que se obtienen a partir de procesos simples de destilación reactiva por lotes a evaporación abierta, constituyen una herramienta muy poderosa para representar el comportamiento de fases en un sistema reactivo ya que son capaces, entre otras cosas, de 
indicar las fronteras de destilación para procesos de destilación continua a reflujo infinito; proporcionan además el vínculo que existe entre el comportamiento termodinámico intrínseco de la mezcla y sus límites característicos de separación tanto en columnas de destilación continua como por lotes.

Específicamente los mapas de curvas residuales reactivos son herramientas altamente útiles para visualizar e ilustrar el diseño conceptual de los procesos de destilación reactiva (Thiel, 1997). A través de los MCR-R es posible: i) visualizar la influencia de la reacción química sobre el comportamiento de la fase, ii) observar hasta donde están las condiciones térmicas del equilibrio químico de la mezcla reaccionante y iii) se puede identificar la presencia de azeotropos reactivos y no reactivos (Ung, 1995).

En esta sección se presenta el algoritmo empleado para el cálculo de curvas residuales reactivas para la esterificación y la transesterificación, tratados de manera individual, a partir de la solución de las ecuaciones diferenciales que se obtiene con el modelo de destilación por lotes (Ec. 3.10 y 3.11), discutido en la primera sección de este capítulo, y cuya solución permitirá, a su vez, determinar las fracciones elemento con las que serán construidas las curvas residuales reactivas en un espacio bidimensional como se ilustra en la Figuras 3.2 y 3.3.

En un proceso de destilación reactiva se asume que el sistema se encuentra en equilibrio de fases, por lo que para evaluar la composición en fase líquida es necesario resolver en primera instancia el problema del equilibrio líquido-vapor del sistema reactivo multicomponente partiendo de la siguiente ecuación:

$$
y_{i} P=\gamma_{i} x_{i} P_{i}^{\circ} \text { sat }
$$

Lo cual implica que la temperatura del sistema multicomponente corresponda a la temperatura de ebullición $T_{b}$, la cual depende del vector composición $X$; por lo tanto los coeficientes de actividad son función de $T_{b}$ y $X$, los valores de estos coeficientes de actividad se obtuvieron usando el método de UNIFAC explicado en el capitulo anterior. Entonces, las fracciones mol del vapor en equilibrio se evalúan a partir de la siguiente relación en el punto de ebullición 


$$
y_{i}=\frac{\gamma_{i}\left(X, T_{b}\right) P_{i}^{\circ}{ }^{s a t}\left(T_{b}\right)}{P} x_{i}
$$

Consecuentemente, la ecuación apropiada para determinar la temperatura de ebullición $T_{b}$ es una combinación de la relación de equilibrio anterior y la suma de las fracciones molares en la fase vapor:

$$
\sum_{i=1}^{N} y_{i}=1
$$

Que se expresa de la forma

$$
\frac{\gamma_{i}\left(X, T_{b}\right) P_{i}^{\circ}{ }^{s a t}\left(T_{b}\right)}{P} x_{i}-1=0
$$

Dado que la ecuación no puede resolverse explícitamente para $T_{b}$, es necesario emplear un método iterativo apropiado, en este trabajo se empleo el método de Newton-Raphson.

Por otra parte la rapidez $r_{j}$ de la reacción $j$ que se verifica en la fase líquida del destilador y cuyo modelo cinético se presento en el capitulo anterior para cada reacción, depende de los coeficientes de actividad, de la temperatura y composición del sistema reactivo, $T_{b}, X$, respectivamente, de manera tal que la rapidez con que ocurre la reacción j se puede representar en la forma:

$$
r_{j}=r_{j}\left(X, T_{b}\right) ; j=1,2, \ldots, R
$$

Tomando en consideración que la temperatura de ebullición $T_{b}$ depende implícitamente de la presión de operación y del vector composición en fase líquida $X$, para la determinación del vector en fase vapor $Y$ y la velocidad de las reacciones químicas que se verifican en el destilador, reescribimos el sistema de ecuaciones 3.11 como el modelo que describe el proceso de destilación reactiva por lotes para la esterificación y la transesterificación:

$$
\begin{aligned}
& \frac{d x_{i}}{d \xi}=x_{i}-y_{i}\left(X, T_{b}\right)+\alpha \sum_{j=1}^{R}\left(v_{i, j}-x_{i} v_{T, j}\right) \frac{r_{j}\left(X, T_{b}\right)}{r_{0}} \\
& i=1,2, \ldots ., N-1 ; \quad j=1,2, \ldots ., R
\end{aligned}
$$

Este modelo considera la solución de $N-1$ ecuaciones diferenciales debido a que es posible emplear la condición de suma de fracciones molares para determinar la fracción del $N$ ésimo componente en la fase líquida $x_{N}$ 


$$
\sum_{i=1}^{N} x_{i}=1
$$

El primer término de la Ec. 3.37 describe el proceso de transferencia de masa a través de la interface líquido-vapor, mientras que el segundo término caracteriza la conversión de los reactivos en la fase líquida debida a las reacciones químicas que se verifican en el sistema. Este segundo término muestra que el efecto de reacción depende del vector composición en fase líquida $X$, su temperatura de ebullición $T_{b}$ a la presión de operación $P \mathrm{y}$, adicionalmente, del factor de reacción separación $\alpha$. De esta manera, si el efecto de reacción es igual a cero es posible interpretar que no hay reacción química (proceso de destilación pura) o que la reacción ha llegado al equilibrio químico.

Por tanto, la solución de las ecuaciones 3.37, requiere valores iniciales para las fracciones molares $\left(X_{k}\right)$ en la fase líquida de los componentes del sistema reactivo (en donde $k$ se refiere únicamente al número de iteración) y la presión de operación $P$.

1. Con los valores de $X_{k}$ y $P$ se determinan la temperatura de ebullición $T_{b, k}$ y $N$ fracciones molares del vapor en el equilibrio (vector $Y_{k}$ ) a través del cálculo del punto de burbuja (Ec. 3.35)

2. Los valores de $X_{k}$ permiten a su vez calcular las fracciones de los elementos $W_{i, k}$ en fase líquida (Ec. 3.26).

3. Con los valores obtenidos de $T_{b, k} \mathrm{y}$ el vector $X_{k}$ dado, se calculan posteriormente las $r_{j, k}$ velocidades de reacción (ecuaciones $2.1 ; 2.2-2.5$ ) de las $R$ reacciones químicas independientes que se verifican en el proceso y cuyos modelos cinéticos dependen del tipo de reacción que se esté estudiando.

4. Una vez que se dispone de la información requerida, $X_{k}, Y_{k}\left(X_{k}, T_{b, k}\right)$ y $r_{j, k}\left(X_{k}, T_{b, k}\right)$, el sistema de ecuaciones diferenciales 3.37 genera un nuevo valor del vector $X_{k+1}$, con el que se vuelven a ejecutar todos los cálculos anteriores.

5. Este proceso de repite hasta que esencialmente $X_{k+1}=X_{k}$

Una vez descrito el algoritmo de cálculo se presentaran los MCR-R obtenidos para cada reacción, donde se eligió una mezcla modelo para cada tipo de reacción que represente la parte del proceso de producción de biodiesel correspondiente. De ahí que la simulación del proceso reactivo se llevo a cabo modificando el parámetro de reacción- separación $\alpha$, desde 
valores mínimos que permiten observar la contribución del efecto de la reacción química, comparada con el proceso no reactivo, hasta valores límite por encima de los cuales la solución del sistema de ecuaciones diferenciales empieza a producir valores negativos para las fracciones molares de los reactivos. Todos los cálculos fueron a presión de 1 Bar.

\subsubsection{Mapas de Curvas Residuales para la Reacción de Esterificación}

Como se expuso en el capitulo dos, para el estudio de la esterificación de los ácidos grasos libres se eligió al ácido oleico como compuesto representativo. En la Tabla 3.7 se presentan los valores de concentración inicial para dos mezclas iniciales diferentes con sus respectivas fracciones elemento iniciales. La primera mezcla (IE) consiste en que inicialmente sólo están presentes los reactivos en presencia de catalizador (esto para poder observar claramente el comportamiento sin reacción), y la segunda (IIE) existen ambos reactivos y productos, estos últimos en baja concentración. Dependiendo de la composición de la mezcla inicial, se tiene los valores finales alcanzados.

Tabla 3.7. Concentraciones iniciales de los compuestos en fracción mol y fracción elemento para la esterificación.

\begin{tabular}{lllll}
\hline Fracción Mol & $x_{A O, 0}$ & $x_{M e O H, 0}$ & $x_{M O, 0}$ & $x_{W, 0}$ \\
\hline Mezcla $I E$ & 0.1 & 0.9 & 0.0 & 0.0 \\
Mezcla $I I E$ & 0.006 & 0.99 & 0.002 & 0.002 \\
Fracción Elemento & $W_{A, 0}$ & $W_{B, 0}$ & $W_{C, 0}$ & \\
Mezcla $I E$ & 0.09091 & 0.09091 & 0.81818 & \\
Mezcla $I I E$ & 0.00794 & 0.00794 & 0.98412 & \\
\hline
\end{tabular}

Los MCR-Rs para las dos mezclas iniciales expuestas en la tabla anterior se presentan en la Figura 3.4 a y b. Para valores de alfa igual a cero (línea punteada de la Figura 3.4a) se puede interpretar que no hay reacción y sólo se lleva a cabo la separación simple de los reactivos y la trayectoria es hacia nodo del componente puro más pesado, en este caso del ácido oleico. Para valores de $\alpha$ cercanos a cero las curvas residuales reactivas son similares a las curvas residuales no reactivas $\alpha=0$, despegándose ligeramente de la línea punteada, 
debido a que la reacción es todavía pequeña (primera línea continua que se despega de la línea punteada de las Figuras 3.4a).

Podemos observar que en las Figuras 3.4 a y b que en el inicio de la reacción las trayectorias de las curvas residuales son similares y conforme se aumenta el valor del factor de reacción separación las trayectorias de las curvas son diferentes, debido a que alfa puede interpretarse como la cantidad de catalizador utilizado, puede decirse que a valores de alfa pequeños el sistema se comporta como un sistema no reactivo y para valores grandes de alfa el sistema se comporta como un sistema con reacción instantánea.

Por ejemplo en la Figura $3.4 \mathrm{~b}$, cuando $\alpha=0.0001$ la curva es casi recta, ya que la reacción está limitada por una baja cantidad de catalizador, y cuando $\alpha=30$ la curva residual reactiva se mueven hacia el nodo limite de composición del metil oleato puro. Podemos concluir que si tenemos una $\alpha=2500$ para la mezcla IE y una $\alpha=30$ para la mezcla IIE, significa que se tienen grandes cantidades de catalizador conjuntamente con bajos flujos de vaporización para las mezclas ó mayores tiempos de residencia.

Cabe resaltar que el valor de $\alpha=2500$ es necesario ya que las concentraciones iniciales de los productos son cero, es decir, si iniciamos el proceso de reacción separación con sólo reactivos la cantidad de catalizador requerido es mucho mayor ya que el metanol tiende a vaporizarse de manera instantánea mientras que en el caso de $\alpha=30$ tenemos una mezcla inicial que contiene agua que permite que el metanol se mantenga mayor tiempo en la fase líquida. 


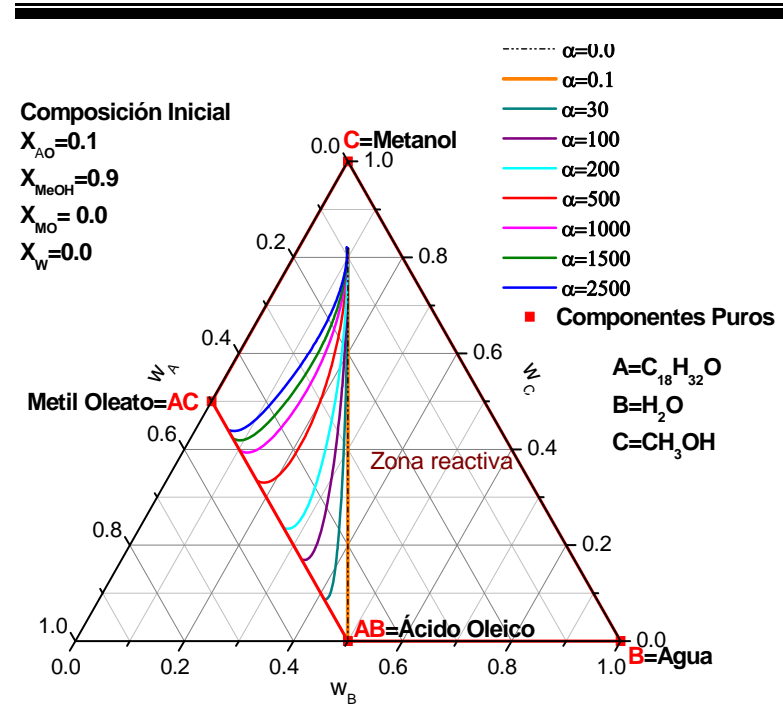

a)

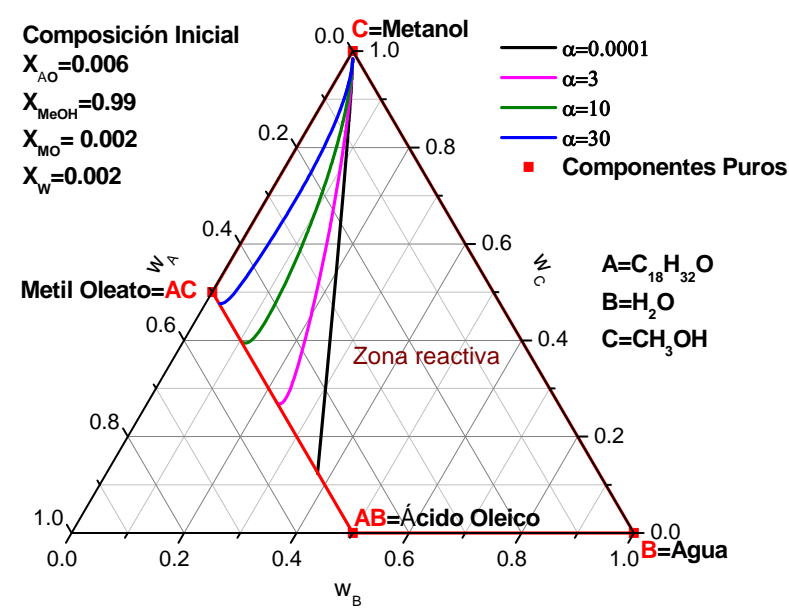

b)

Figura 3.4. MCR-R de la esterificación de ácido oleico con metanol en términos de fracción elemento. a) Mezcla inicial IE; b) Mezcla inicial IIE. Cinética reportada por Tesser et al., 2010.

Las Figuras 3.5 a y b presentan la variación de las fracción mol en la fase líquida con respecto a la temperatura de burbuja correspondiente, cabe notar que en dichas figuras, para temperaturas cercanas a los $400 \mathrm{~K}$ la concentración del metanol alcanza su nivel mínimo y la composición del metil oleato (biodiesel) alcanza su valor máximo a dicha temperatura. También es importante resaltar que la reacción ocurre rápidamente, es decir existe una producción inmediata del metil oleato en el rango de temperaturas de 340-370K. 


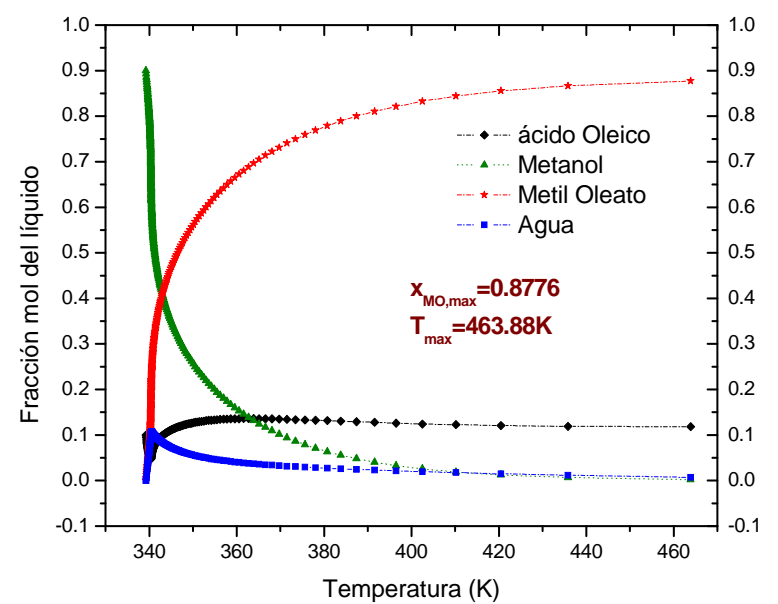

a)

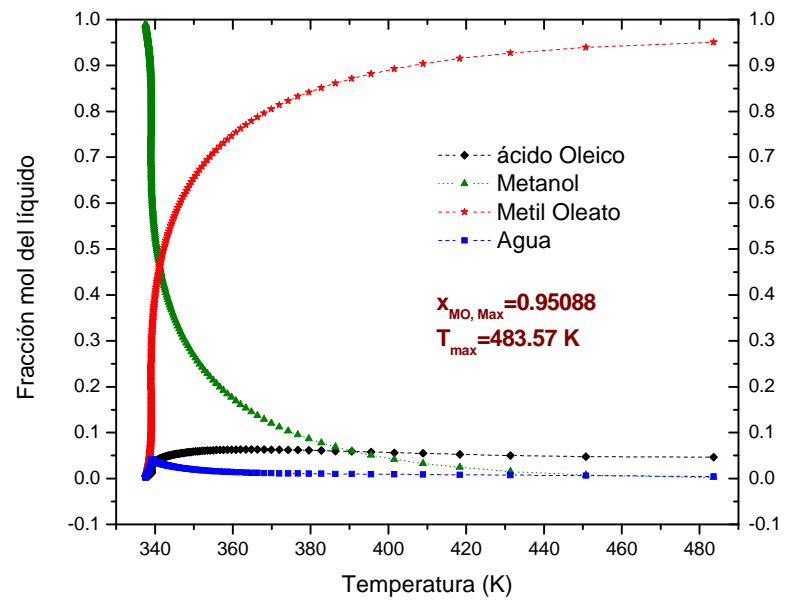

b)

Figura 3.5. Variación de la composición con respecto a la temperatura. a) Mezcla IE, b) Mezcla IIE. Cinética reportada por Tesser et al., 2010.

La Figura 3.6 muestra el comportamiento de velocidad de reacción con respecto a la temperatura, puede notarse que existe un cambio de velocidad de reacción abrupto en el rango de temperatura de 340-345 $\mathrm{K}$ donde la conversión a metil oleato es mayor (ver Figura 3.5), a partir de ahí la velocidad de reacción decrece y posteriormente se incrementa hasta alcanzar los valores máximos dependiendo de la cantidad de catalizador utilizado en la olla de destilación. Si consideramos $\alpha=30$ para las dos mezclas observamos que la velocidad de reacción avanza hacia una sola dirección para la mezcla IE, indicando que la velocidad hacia delante domina en el valor de la velocidad neta de reacción, llegando a un máximo y posteriormente comienza a cambiar de dirección. Para la mezcla IIE observamos una conversión instantánea relevante y posteriormente comienza a incrementarse hasta alcanzar un máximo a una temperatura de $430 \mathrm{~K}$. Considerando la mezcla IE con una $\alpha=2500$ notamos que la velocidad de reacción máxima se alcanza a una temperatura de 440K. Desafortunadamente no se encontró algún trabajo experimental para este sistema con el cual comparar los resultados obtenidos. 


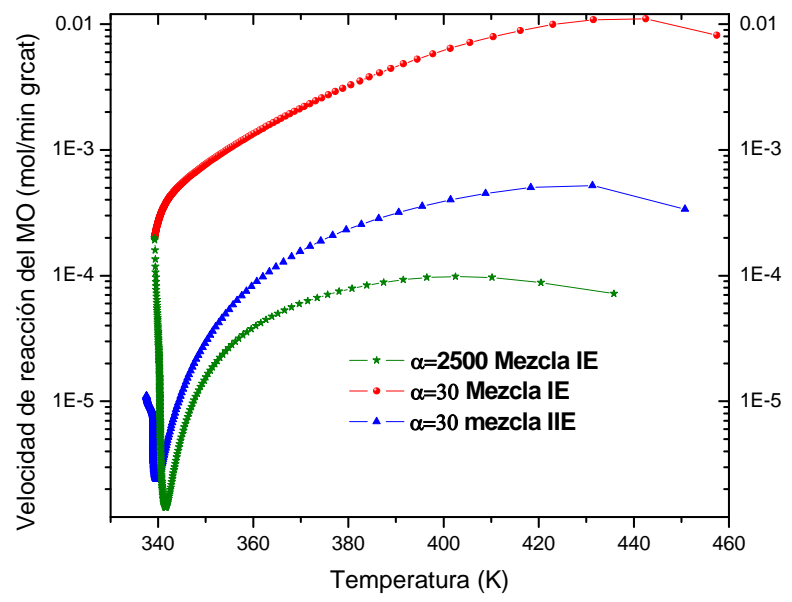

Figura 3.6. Comportamiento de la velocidad de reacción con respecto a la temperatura para las dos mezclas expuestas.

De esta manera con el análisis de los mapas de curvas residuales y apoyadas con el estudio de los diagramas de composición con la temperatura y velocidad de reacción con la temperatura permiten determinar la factibilidad del proceso y establecer de manera preliminar las condiciones de operación apropiadas para una mayor conversión.

\subsubsection{Mapas de Curvas Residuales para las Reacciones de Transesterificación}

Para el caso de la Transesterificación de los triglicéridos se eligió a la trioleína como compuesto representativo. En la Tabla 3.8 se presentan los valores de concentración inicial para dos mezclas modelo iniciales diferentes con sus respectivas fracciones elemento iniciales. Se pretendió que la primera mezcla IT inicialmente consistiera únicamente de reactivos; sin embargo, se encontraron problemas en la solución del equilibrio de fases, por lo tanto, fue necesario que los productos estuvieran presentes aunque sea en muy bajas concentraciones, para no obtener una solución trivial. La segunda mezcla (IIT) tiene tanto reactivos como productos, estos últimos en baja concentración con respecto a los reactivos. Dependiendo de la composición de la mezcla inicial, se tiene los valores finales alcanzados. 
Tabla 3.8. Concentraciones iniciales de los compuestos en fracción mol y fracción elemento para la transesterificación.

\begin{tabular}{lllllll}
\hline Fracción Mol & $x_{T O, 0}$ & $x_{M e O H, 0}$ & $x_{M O, 0}$ & $x_{D O, 0}$ & $x_{M O O, 0}$ & $x_{G l y, 0}$ \\
\hline Mezcla IT & 0.0996 & 0.9 & 0.0001 & 0.0001 & 0.0001 & 0.0001 \\
Mezcla IIT & 0.04 & 0.95 & 0.004 & 0.002 & 0.002 & 0.002 \\
Fracción Elemento & $W_{A, 0}$ & $W_{B, 0}$ & $W_{C, 0}$ & & & \\
Mezcla IT & 0.2303 & 0.07689 & 0.69281 & & & \\
Mezcla IIT & 0.11504 & 0.04071 & 0.84425 & & & \\
\hline
\end{tabular}

Los MCR-Rs para las dos mezclas iniciales expuestas en la tabla anterior se presentan en la Figura 3.7 a y b. Siguiendo la idea sobre la interpretación que se le puede dar al parámetro de reacción-separación que se explicó en el caso de la reacción de esterificación, tenemos que para valores de alfa igual cero (línea punteada de la Figura 3.7a) se puede interpretar que no hay reacción y sólo se lleva a cabo la separación simple de los reactivos, además la trayectoria de la curva es hacia el nodo del componente puro más pesado, en este caso la trioleína, siendo esté y los demás glicéridos los que quedarían como residuo en la olla después de que todo el metanol se ha evaporado. Entonces para valores de $\alpha$ muy cercanos a cero las trayectorias de las curvas residuales reactivas son similares a las curvas residuales no reactivas $\alpha=0$ (primera línea continua que se despega de la línea punteada de las Figuras 3.7a). Podemos observar que en las Figuras 3.7 a y b que en el inicio de la reacción las trayectorias de las curvas residuales son similares y conforme se aumenta el valor del factor de reacción separación las trayectorias de las curvas son diferentes, debido a que alfa puede interpretarse como la cantidad de catalizador utilizado, puede decirse que a valores de alfa pequeños el sistema se comporta como un sistema no reactivo y para valores grandes de alfa el sistema se comporta como un sistema con reacción instantánea.

Por ejemplo en la Figura 3.7b, cuando $\alpha=0.000001$ la curva es casi recta, ya que la reacción está limitada por una baja cantidad de catalizador y cuando $\alpha=0.01$ la curva residual reactiva se mueve hacia el nodo limite de composición del metil oleato puro. Podemos concluir que si tenemos $\alpha=0.1$ para la mezcla IT y una $\alpha=0.01$ para la mezcla IIT, significa que se tienen grandes cantidades de catalizador conjuntamente con bajos flujos de vaporización para las mezclas o mayores tiempos de residencia. 


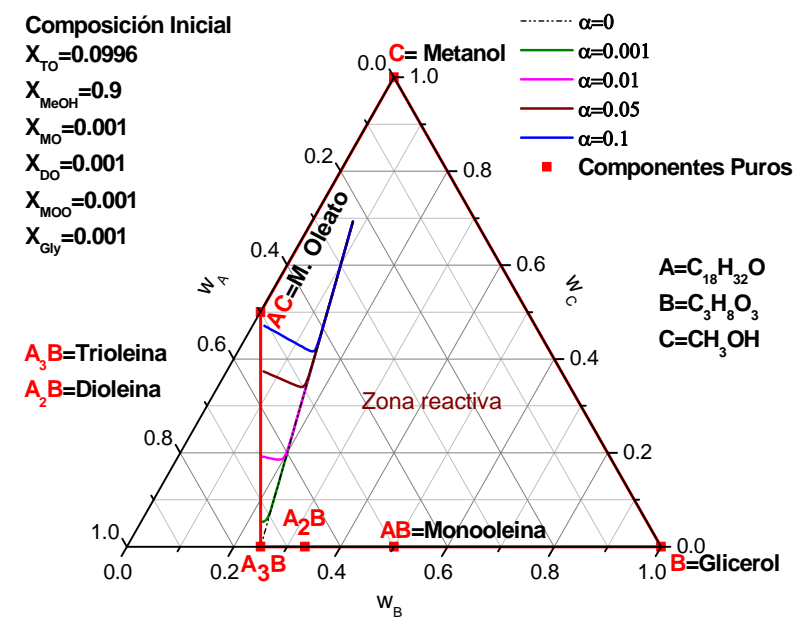

a)

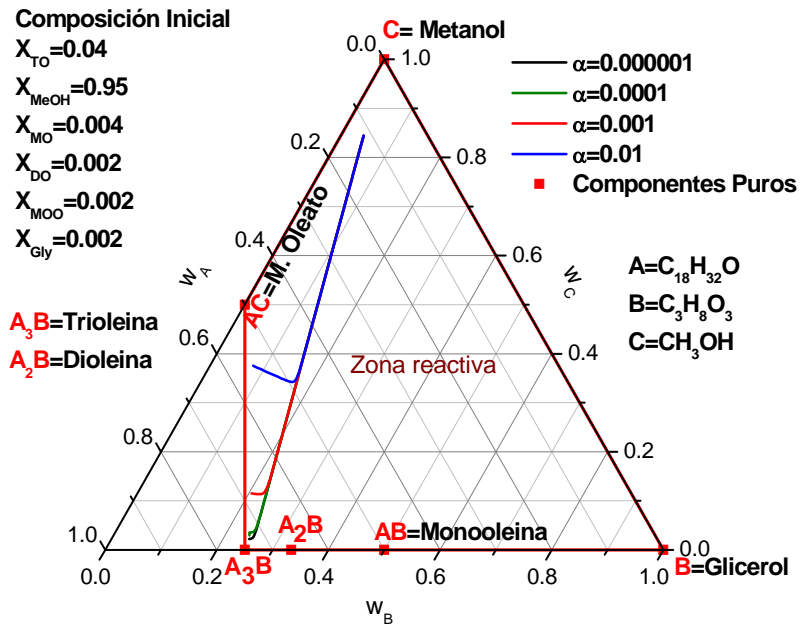

b)

Figura 3.7. MCR-R de la transesterificación de la trioleína con metanol en términos de fracción de elemento. a) Mezcla IT, b) Mezcla IIT. Cinética reportada por Dossin et al., 2006

Cabe resaltar que el valor de $\alpha=0.1$ es necesario ya que las concentraciones iniciales de los productos son casi cero, es decir, si iniciamos el proceso de reacción separación con sólo reactivos la cantidad de catalizador requerido es mucho mayor ya que el metanol tiende a vaporizarse de manera instantánea mientras que en el caso de $\alpha=0.01$ tenemos una mezcla inicial que contiene glicerol que permite que el metanol se mantenga mayor tiempo en la fase líquida.

Las Figuras 3.8 a y b presentan la variación de las fracción mol en la fase líquida con respecto a la temperatura de burbuja correspondiente, cabe notar que en dichas figuras, para temperaturas cercanas a los $460 \mathrm{~K}$ la concentración de metanol alcanza su nivel mínimo y la composición del metil oleato (biodiesel) alcanza su valor máximo a dicha temperatura. También es importante resaltar que la reacción ocurre rápidamente, es decir existe una producción inmediata del metil oleato en el rango de temperaturas de $340-380 \mathrm{~K}$. A temperaturas mayores a $480 \mathrm{~K}$ se tiene un comportamiento irregular, esto puede ser debido a la formación de otras fases o que el glicerol comienza a evaporarse y por tanto su concentración en la mezcla líquida disminuye mientras que el metil oleato se concentra. 


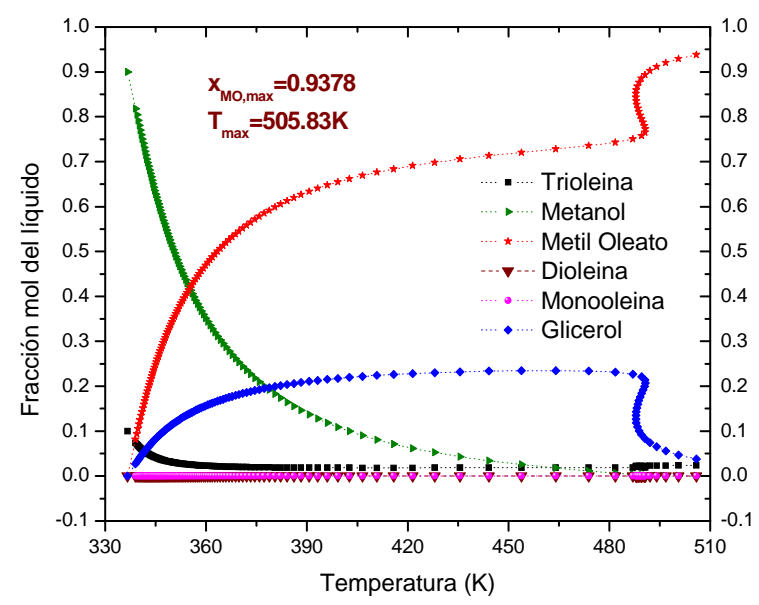

a)

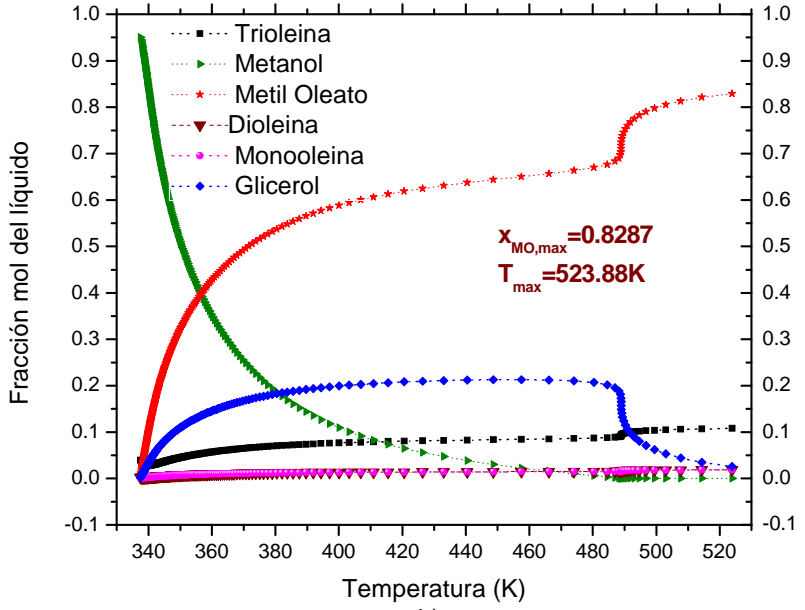

Figura 3.8. Variación de la composición con respecto a la temperatura. a) Mezcla IT, b) Mezcla IIT. Cinética reportada por Dossin et al., 2006.

La Figura 3.9 muestra el comportamiento de velocidad de reacción con respecto a la temperatura, puede notarse que existe un cambio de velocidad de reacción abrupto en el rango de temperatura de 340-350 $\mathrm{K}$ donde la conversión a metil oleato es mayor (ver Figura 3.9), a partir de ahí la velocidad de reacción decrece suavemente hasta $480 \mathrm{~K}$ dependiendo de la cantidad de catalizador utilizado en la olla de destilación. Si consideramos $\alpha=0.01$ para las dos mezclas observamos que la velocidad de reacción avanza hacia la misma dirección hasta $480 \mathrm{~K}$, después de esta temperatura, cada mezcla presenta un comportamiento diferente, la mezcla IT alcanza su valor mínimo a una temperatura de $550 \mathrm{~K}$, mientras que la mezcla IIT alcanza su valor mínimo a una temperatura de $490 \mathrm{~K}$. Tampoco para estos sistemas se encontró algún trabajo experimental con el cual comparar los resultados obtenidos. 


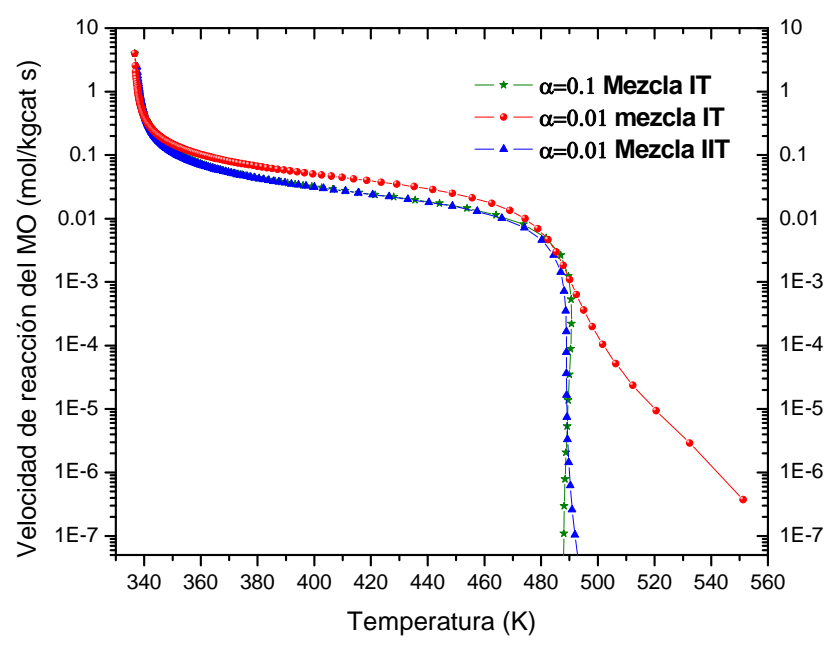

Figura 3.9. Comportamiento de la velocidad de reacción con respecto a la $T$ para las dos mezclas expuestas.

Comparando la velocidad de reacción para las dos reacciones presentadas tenemos la Figura 3.10, ahí observamos que la reacción de esterificación es instantánea y más rápida en comparación con la reacción de transesterificación, como lo reporta Suwannakarn et al., 2009 and López et al., 2008.

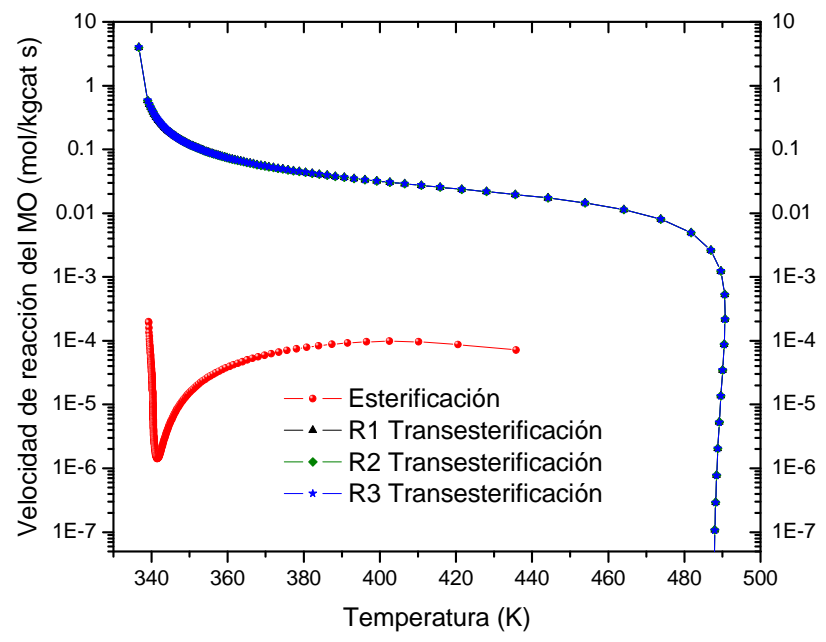

Figura 3.10. Velocidad de reacción para la esterificación y la transesterificación.

Para complementar el análisis se muestran los diagramas binarios para los componentes presentes en la transesterificación, los cuales se obtuvieron usando el método de UNIFAC explicado en el capitulo anterior. En dichos diagramas se visualiza claramente la no 
idealidad de las mezclas. Se realizaron los diagramas para cada sistema, observando que la mayor complejidad existe cuando están en combinación con el glicerol, así que decidimos presentar los diagramas del glicerol con cada compuesto presente en el proceso.

Los diagramas binarios no reactivos fueron obtenidos con Aspen Plus y solo el diagrama binario Trioleína-Glicerol fue obtenido usando UNIFAC en un programa desarrollado en MatLab, ya que las propiedades de la trioleína no se encuentran completamente reportadas en Aspen Plus y por lo tanto el diagrama binario no pudo ser obtenido ahí, ni encontramos algún trabajo experimental con que comparar para este sistema.

Si observamos la Figura 3.11, vemos que el comportamiento de las mezclas es altamente no ideal, principalmente para la mezcla trioleína-glicerol y metil oleato-glicerol. Este comportamiento no ideal puede ser el responsable del comportamiento irregular que presenta el diagrama de T-X de la Figura 3.9 de la transesterificación.

De esta manera con el análisis de los mapas de curvas residuales apoyado con el estudio de los diagramas de composición y temperatura, velocidad de reacción con la temperatura y los diagramas binarios permiten determinar la factibilidad del proceso y establecer de manera preliminar las condiciones de operación apropiadas para una mayor conversión. 


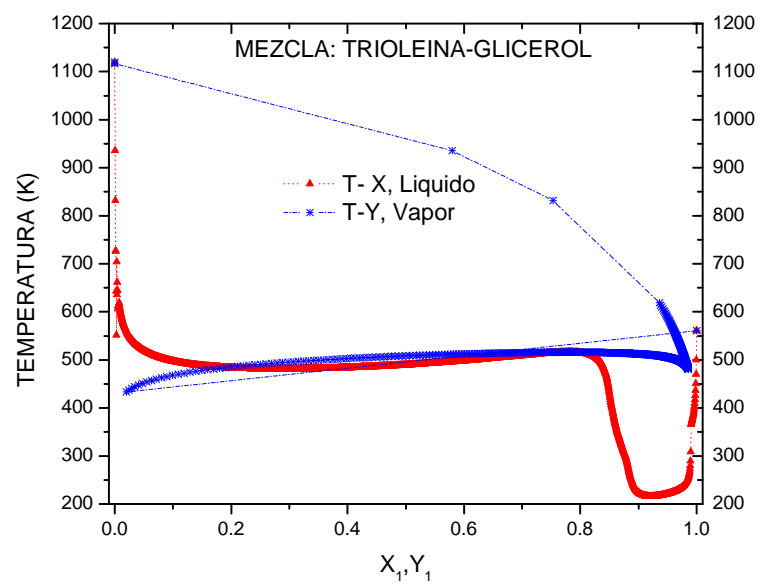

a)

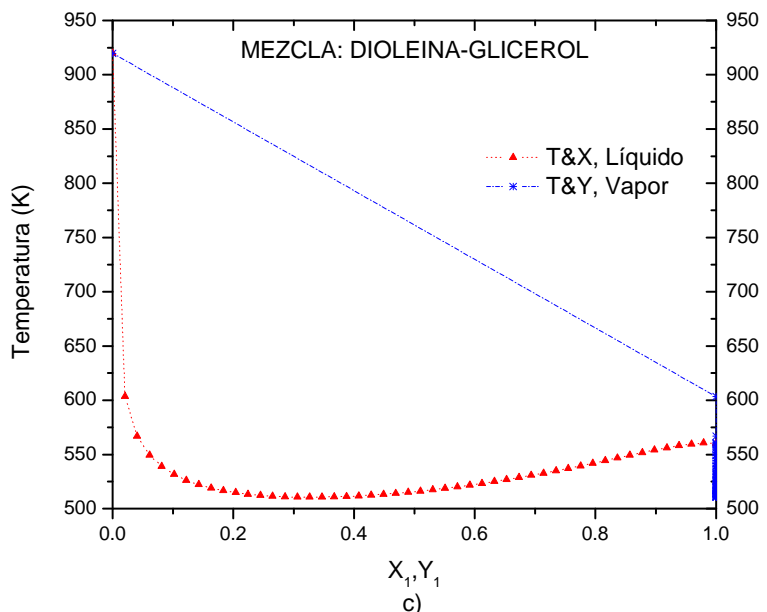

c)

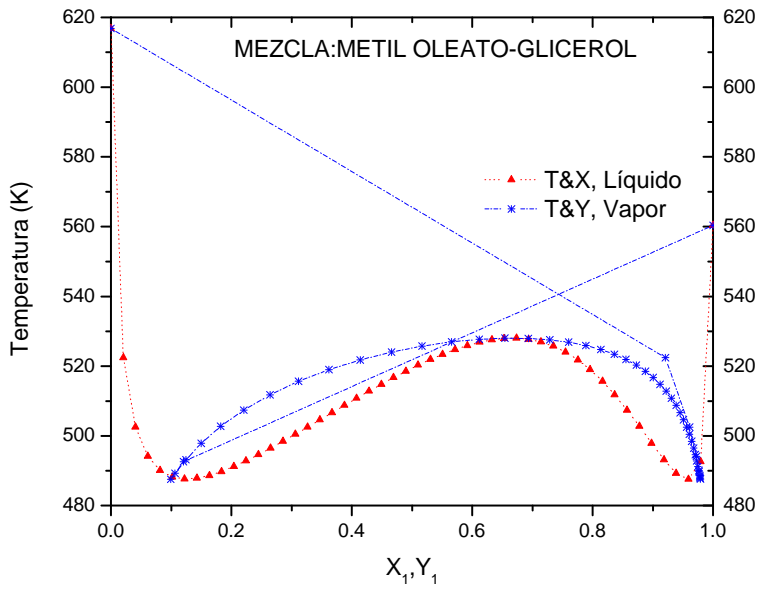

b)

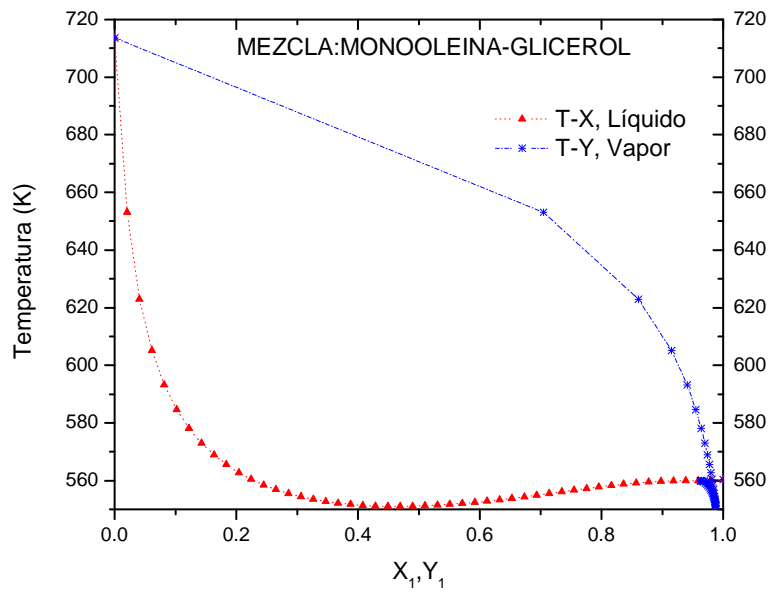

d)

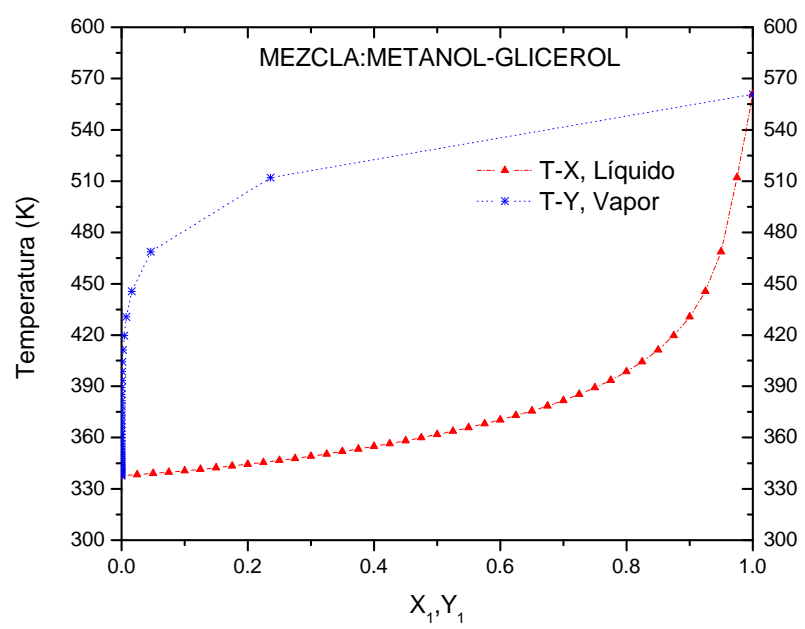

e)

Figura 3.11. Diagramas $T-X, Y$ binarios. a) Sistema: trioleína-glicerol, b) Sistema: metil oleatoglicerol, c) Sistema: dioleína-glicerol, d) Sistema: monoleína-glicerol, e) Sistema: metanolglicerol. 


\subsection{Diseño Conceptual del Proceso Integrado}

Con el estudio hasta ahora realizado, sabemos que es posible la aplicación de DR en la producción de biodiesel y se puede obtener el siguiente diseño conceptual de destilación reactiva que vislumbrar el proceso global de producción de biodiesel, el cual se presenta en la Figura 3.12, en dicho diagrama viene la distribución de los componentes con su respectiva distribución de temperaturas.

Inicialmente se tiene una mezcla modelo de ácido oleico + trioleína, que simulan algún aceite, dicha mezcla entra por la sección superior (por ser más densa) de una columna de DR cargada con un catalizador (Cat 1=Amberlyst 15 del cual su modelo cinético fue expuesto y explicado en el capítulo 2) que acelere la reacción de esterificación, a dicha CDR también entra una corriente de metanol en la sección inferior por ser el más volátil. El metanol que no reacciona y el agua producida se obtienen en la zona de rectificación por ser los componentes más ligeros, por otro lado, el ácido oleico que no reaccionó, la trioleína y el metil oleato se obtendrán por la zona de agotamiento por ser estos más densos. Esta última mezcla pasará a un separador, del cual por un lado tendremos al biodiesel 1 proveniente de la reacción de esterificación y por otro, la trioleína y el ácido oleico que no haya reaccionado, aunque el objetivo será que reaccione todo el ácido oleico y sólo quede la trioleína. Entonces esta corriente pasará a una segunda CDR la cual está cargada con un segundo catalizador heterogéneo como el Óxido de Magnesio ( $\mathrm{MgO}$ ), el cual el modelo cinético se presentó en el capítulo 2, que acelere la reacción de transesterificación, en la parte inferior tiene su respectiva corriente de metanol que reacciona con los triglicéridos, así, se puede decir que el metanol y tal vez el glicerol saldrán por la zona de rectificación, mientras que el biodiesel 2 obtenido de la reacción de transesterificación, la trioleína que no reaccionó y los intermediarios que no hayan reaccionado salgan por la zona de agotamiento, dicha corriente deberá separarse en un equipo de separación. 


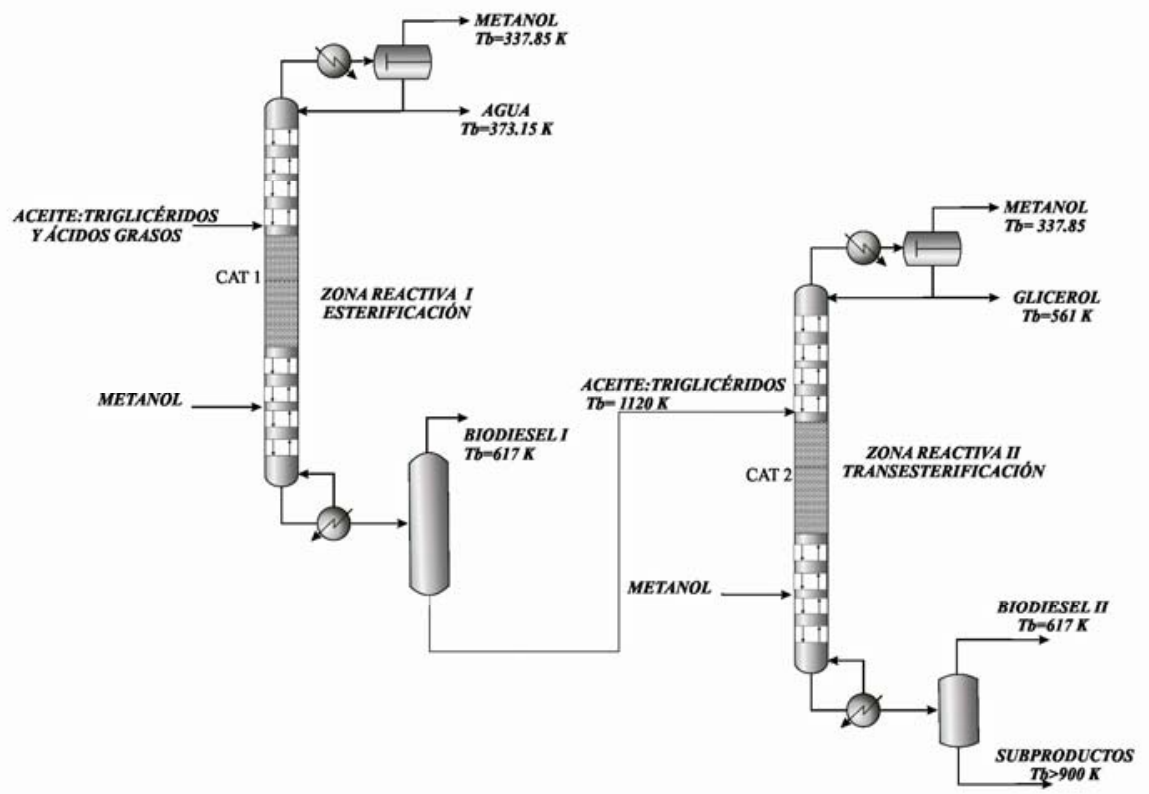

Figura 3.12. Diagrama del diseño conceptual de DR para la producción de biodiesel. 


\section{Capítulo 4}

\section{Simulación Intensiva}

En este capítulo se presentan las simulaciones intensivas para los dos sistemas de estudio, en el cual se probaron diferentes configuraciones de las columnas, eligiendo la más adecuadas para llevar a cabo cada paso del proceso de producción del biodiesel. También se analizó la influencia de los parámetros en la conversión del compuesto de interés.

\subsection{Destilación Reactiva}

En una planta química convencional existen secciones de reacción y secciones de separación, estas contienen sus propios equipos, y en muchos casos las secciones se unen para reciclar materia y energía. En destilación reactiva (DR) la separación y la reacción ocurren en el mismo equipo. Esto puede ocasionar reducciones significativas en número de equipos y energía, siempre y cuando se tengan sistemas reactivos que alcancen conversiones aceptables en la fase líquida. Una ventaja inherente importante de la DR es la característica de producción y remoción simultanea de los productos. Para reacciones químicas reversibles, la remoción de los productos permite que la dirección de la reacción que predomine sea hacia adelante e incremente la producción de los mismos. Por lo que las volatilidades relativas de los reactivos y los productos debieran ser de forma tal que los productos puedan ser rápida y fácilmente removidos de la región en la columna donde la reacción está ocurriendo y que los reactivos no sean perdidos en esta región.

Una importante limitación de la DR es la necesidad de empatar la temperatura favorable para la reacción y la temperatura favorable para la separación. Porque ambas operaciones ocurren en un mismo recipiente, operando a una sola presión, por lo que las temperaturas en la CDR son un ajuste entre el equilibrio liquido-vapor y la composición de los platos. Si 
estas temperaturas son bajas producen velocidades especificas de reacción bajas para la reacción cinética involucrada, y pueden requerir grandes cantidades de catalizador. Si estas temperaturas son muy altas corresponden a constantes de equilibrio muy pequeñas (como puede ocurrir con reacciones reversibles exotérmicas), esto dificultaría alcanzar la conversión deseada, y también podría promover reacciones indeseables (Luyben y Yu, 2008).

Como en destilación sin reacción, una CDR puede ser empacada y/o de platos. Esta CDR generalmente comprende secciones reactivas y no reactivas, por ello se denomina hibrida. En la fase líquida, sobre los platos o el empaque de una sección reactiva ocurre, simultáneamente, la destilación y la o las reacciones. Para efectos de diseño, los platos dentro de esta sección se denominan etapas reactivas. En las secciones no reactivas, solamente sucede la destilación, y los platos dentro de ella, se denominan etapas no reactivas.

Como se mencionó en el capítulo anterior la tecnología de DR es apropiada para sistemas reactivos que pueden alcanzar conversiones aceptables en su fase líquida. Es por ello, que en base al sistema reactivo se clasifican dos tipos principales de columnas de destilación reactiva:

a) CDR cinéticamente controladas: donde se descarta la ocurrencia del equilibrio químico incluyendo una expresión cinética apropiada, pero se mantiene vigente el criterio de que el equilibrio físico se logra completamente, o las desviaciones de él se miden por medio un factor de eficiencia.

b) CDR sujeta al equilibrio físico-químico. Se supone idealmente que el sistema, independientemente del tiempo, alcanza plenamente el equilibrio físico-químico.

En el presente trabajo se considero la CDR cinéticamente controlada, en la cual la generación de productos en cada etapa reactiva depende no sólo de las condiciones de temperatura, presión y composición, como en el caso de las CDR sujetas al equilibrio físico-químico, sino además, de la configuración del medio en el que la reacción se desarrolla. Si la reacción es homogénea, la cantidad del líquido presente en cada etapa reactiva será determinante, si es heterogénea, la generación dependerá de la cantidad de 
catalizador sólido (además de sus características) presente en la columna. Como consecuencia, el diseño de CDR controlada cinéticamente involucra un parámetro adicional el cual se denomina "Holdup" o retención. En reacciones homogéneas en fase líquida, la retención se establece en moles de líquido, para heterogéneas se fija en kg de catalizador. La retención simplemente aparece multiplicando a la expresión cinética correspondiente, es decir, la generación del producto deseado es directamente proporcional al valor de la retención de forma tal que, si este tiende a cero la reacción desaparece y la etapa realizaría un trabajo de destilación normal; en cambio, si este tiende a infinito, en la etapa podría ocurrir el equilibrio químico (Sánchez-Daza, 2003). De ahí la importancia de conocer el valor óptimo de este parámetro y otros parámetros.

Con el análisis y obtención del diseño conceptual presentado en el capitulo anterior, sabemos que puede ser factible el proceso de producción de biodiesel con la DR. El siguiente paso es comprobar la factibilidad en una CDR completa y realizar simulación intensiva para cada parte del proceso (para llevar a cabo la reacción de esterificación y transesterificación respectivamente) y así conocer los parámetros de operación de las CDRs que permitan obtener la mejor conversión a biodiesel.

De manera muy general la configuración de una CDR ideal se muestra en la Figura 4.1, donde el reactivo más ligero se alimenta en la sección inferior (zona de agotamiento) de la columna pero no muy al fondo. El reactivo más pesado se alimenta en la sección superior (zona de rectificación) de la columna pero no muy arriba, y en la parte central de la columna se localiza la sección reactiva (donde se está llevando a cabo una reacción) que contiene un número de platos reactivos que a su vez contienen catalizador.

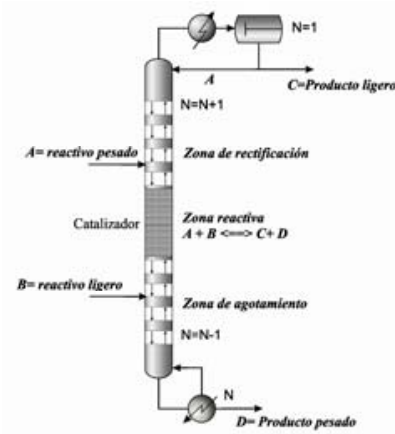

Figura 4.1. Columna de destilación reactiva ideal. 
Se puede observar que el componente B fluye hacia arriba de la columna y reacciona con A que desciende, el producto $\mathrm{C}$ es rápidamente removido en la fase vapor de la zona de reacción y fluye hacia arriba de la columna. Por otro lado, el producto más pesado D es rápidamente removido en la fase líquida de la zona de reacción y fluye hacia abajo de la columna.

La zona de rectificación de la columna donde la alimentación fresca de A es introducida separa al producto ligero $\mathrm{C}$ de todos los componentes más pesados, y así el destilado es obtenido, siendo generalmente el producto $\mathrm{C}$ puro. La zona de agotamiento donde la alimentación fresca de $\mathrm{B}$ es introducida, separa al producto pesado $\mathrm{D}$ de todos los componentes más ligeros, así en el fondo es obtenido principalmente D puro. La velocidad del reflujo y el calor suministrado al rehervidor pueden ser manipulados para mantener la pureza de estos productos.

Los platos son numerados de arriba hacia abajo, contando al condensador como el número uno y al rehervidor como el plato $\mathrm{N}$.

La destilación reactiva es diferente de la destilación convencional en que existen ambas especificaciones: la de composición de los productos y la conversión de la reacción. Para lo cual muchos grados de libertad tendrán que ser ajustados para alcanzar estas especificaciones. Existen muchos grados de libertad en el diseño de columnas de destilación reactiva, estos grados de libertad incluyen a la presión, la retención del plato reactivo, el número de platos reactivos, localización de las corrientes de alimentación de los reactantes, el número platos de agotamiento, el número de platos de rectificación, la relación de reflujo y la energía de entrada al rehervidor, entre otros.

La cantidad de catalizador es un parámetro muy importante en DR porque la velocidad de reacción depende directamente del mismo. Esto significa que la retención debe ser conocida antes de poder diseñar la columna y antes de conocer el diámetro de la columna, que sería trabajo de diseño de detalle. Como resultado, el procedimiento de diseño para la DR es iterativo. Con la retención del plato conocido, la columna es diseñada para guardar la conversión y la pureza deseada de los productos. El diámetro de la columna es calculado 
para correlacionar la carga máxima de vapor. He aquí la influencia de este en la conversión de ácido oleico.

Todas las simulaciones se llevaron a cabo en Aspen Plus, a presión de 1 bar. El modelo de columna de destilación reactiva que se uso es RadFrac que tiene como finalidad desarrollar evaluaciones rigurosas y cálculos de diseño para columnas de destilación reactiva.

Primeramente se fijaron todos los grados de libertad, tomando como guía los valores de las variables obtenidas del proceso reportado por Kiss (2010), para posteriormente comenzar a variar una por una y ver su influencia en el proceso de DR, eligiendo la que nos acerque más a la conversión esperada. En la tabla siguiente se presentan los valores iniciales de los parámetros de operación para ambas columnas en la que se lleva a cabo la esterificación y la transesterificación respectivamente.

Tabla 4.1. Especificaciones iniciales de los parámetros de operación de la CDR para las dos reacciones de estudio.

\begin{tabular}{lll}
\hline Variable & Esterificación & Transesterificación \\
\hline Número de etapas de totales & 15 & 20 \\
Etapas de rectificación & 2 & 3 \\
Etapas reactivas & $11(\mathrm{de} 3$ a 13) & $14(\mathrm{de} 4$ a 17) \\
Etapas de agotamiento & 2 & 3 \\
Relación de reflujo & $1(\mathrm{~mol})$ & $0.5(\mathrm{~mol})$ \\
Relación del rehervidor & $1(\mathrm{~mol})$ & $1(\mathrm{~mol})$ \\
Etapa de alimentación del ácido oleico & 2 & 3 \\
Etapa de alimentación del metanol & 14 & 18 \\
Alimentación del ácido oleico & $100 \mathrm{kmol} / \mathrm{h}\left(\right.$ calentado a $\left.350^{\circ} \mathrm{C}\right)$ & $100 \mathrm{kmol} / \mathrm{h}\left(\mathrm{calentado} \mathrm{a} 600^{\circ} \mathrm{C}\right)$ \\
Alimentación del metanol & $100 \mathrm{kmol} / \mathrm{h}\left(\right.$ calentado a $\left.55^{\circ} \mathrm{C}\right)$ & $650 \mathrm{kmol} / \mathrm{h}\left(\mathrm{calentado} \mathrm{a} 51^{\circ} \mathrm{C}\right)$ \\
Cantidad de catalizador por etapa & $4(\mathrm{~kg} \mathrm{cat})$ & $10000(\mathrm{~L} \mathrm{cat})$ \\
\hline
\end{tabular}

Para todas las simulaciones se consideró que el reactivo más denso se alimente sobre el plato y el reactivo más ligero se alimente entre platos, esto debido a que el componente más denso tiene un punto de ebullición mayor y requiere calentarse para alcanzar el equilibrio físico, mientras que el más ligero lo alcanza fácilmente y lo que necesitamos es que permanezca en fase líquida para la reacción. 
Ahora pasaremos a ver la influencia de cada parámetro de operación. Primero presentaremos las simulaciones para una columna donde se lleva a cabo la esterificación y luego para una donde se lleva a cabo la transesterificación.

\subsection{Determinación de las Condiciones de Operación de la Columna para la Reacción de Esterificación}

La expresión cinética para la reacción de esterificación que se utilizó en todas las simulaciones fue reportada por Tesser (2010) y expuesta en el segundo capítulo. Para este sistema las primeras simulaciones se hicieron usando el método de UNIFAC y posteriormente se cambio a UNIQUAC, esto para ver la influencia del modelo termodinámico en la conversión, además que se quiso homogenizar el uso del modelo tanto para la esterificación como para la transesterificación y es que la transesterificación presento problemas con UNIFAC por falta de propiedades de algunos compuestos involucrados en la transesterificación.

Para llevar a cabo dichas simulaciones se hicieron pruebas con diferentes configuraciones de columna de DR las cuales se presentan en la Figura 4.2. Estas son clasificadas de acuerdo al equipo que poseen en la parte superior de la columna donde se lleva a cabo la separación de la corriente de destilado. De ante mano sabemos que en esta corriente saldrán los compuestos más ligeros como lo son metanol y agua, siendo principal interés lograr que el agua sea retirada de manera eficiente de la columna, debido a que la permanencia de este compuesto dentro de la columna puede ser nocivo para el proceso, además que afecta la conversión a los productos deseados, primero porque un exceso de agua dentro de la columna influye de manera adversa en la actividad del catalizador, además que promueve el desarrollo de la reacción hacia atrás, por lo que es importante obtener el agua pura en la corriente de destilado. De ahí la importancia de estudiar dichas configuraciones. 
a) Columna de destilación reactiva con condensador total (CDR-CT)

b) Columna de destilación reactiva con condensador parcial (CDR-CP)

c) Columna de destilación reactiva sin condensador (CDR-SC)

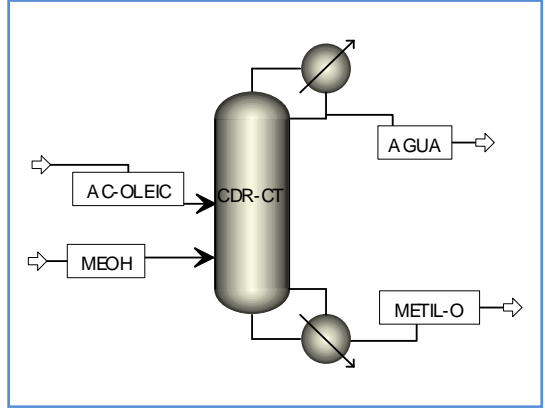

a)

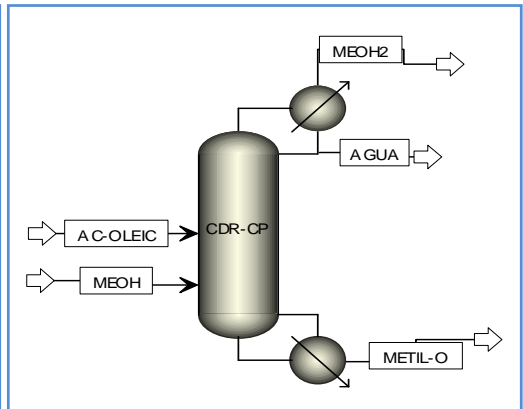

b)

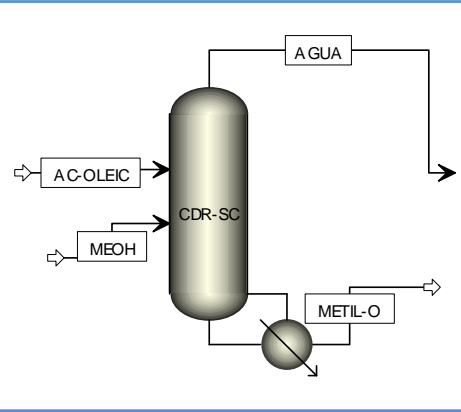

c)

Figura 4.2. Configuración de las diferentes CDR usadas para la producción de biodiesel vía esterificación del ácido oleico. a) CDR-CT, b) CDR-CP y c) CDR-SC

Las decisiones se tomaron de manera secuencial: primero, se analizó en un rango dado de valores de cada parámetro la influencia en la conversión del ácido oleico, de forma tal que se fueron acotando los limites superior e inferior hasta obtener un valor que nos acercara a cumplir con nuestro objetivo "alcanzar una conversión del ácido oleico del 99.9\% mol” en todas las columnas. Una vez encontrados los valores de los parámetros óptimos, los cuales son clasificados como óptimos locales para la columna con condensador total, se tomaron como base para determinar los valores de dichos parámetros de las otras dos configuraciones.

Como ya se mencionó líneas arriba uno de los principales parámetros a analizar es el holdup o cantidad de catalizador ya que la velocidad de reacción depende directamente de este. Así que haciendo un análisis de la influencia que tiene dicho parámetro sobre la conversión del ácido oleico, se obtuvieron los resultados presentados en la Figura 4.3a. De los diferentes valores dados se eligió $1000 \mathrm{~kg}$ de catalizador ya que este reporta una conversión del ácido oleico de $88.78 \%$, aunque la conversión aun no es lo suficientemente alta. Para más detalles de las simulaciones se recomienda ver las tablas de reconocimiento de corrida en el Apéndice A para esta columna. 
Con el holdup elegido, pasamos a realizar un análisis de sensibilidad, siendo que esta es una fuerte herramienta para evaluar el rango óptimo de los parámetros de operación como son: la relación de reflujo y del rehervidor, razón de los reactivos, temperatura de alimentación, número de etapas totales y reactivas entre otros que se muestran líneas abajo.

En la Figura 4.3b podemos observar la influencia de la relación de reflujo y del rehervidor. Para obtener estos datos, primero se varió la relación de reflujo eligiendo el valor que nos daba una mayor conversión y ya con este se varió la relación del rehervidor. El valor que más se acerca a nuestras expectativas de relación de reflujo es de 1 que fue propuesto en un inicio, ya que con valores por arriba o debajo de este la conversión tiende a disminuir, esto porque al mover este parámetro estamos concentrado la corriente de rectificación, con agua y metanol, y porque al recircular el agua a la columna puede influir de manera adversa afectando la actividad del catalizador. Por otro lado, se presenta el comportamiento de la relación del rehervidor en la conversión del ácido oleico, en esta vemos que tiene una mayor influencia sobre la conversión ya que al incrementar su valor, lo que estamos haciendo es dar una mayor energía lo que su vez genera la concentración del ácido oleico, logrando que sea este el que retorne a la columna para que siga reaccionando, esto es posible debido a que tiene menor punto de ebullición en comparación con el biodiesel.

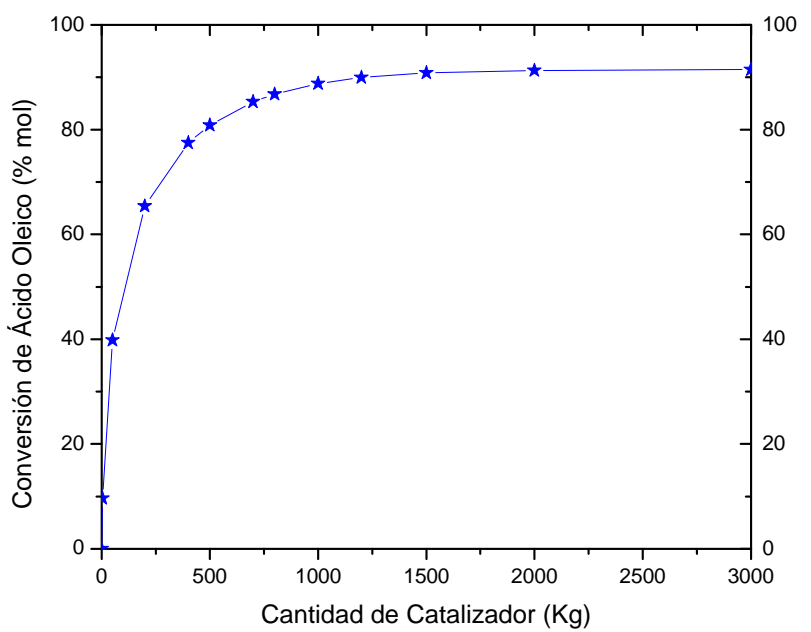

a)

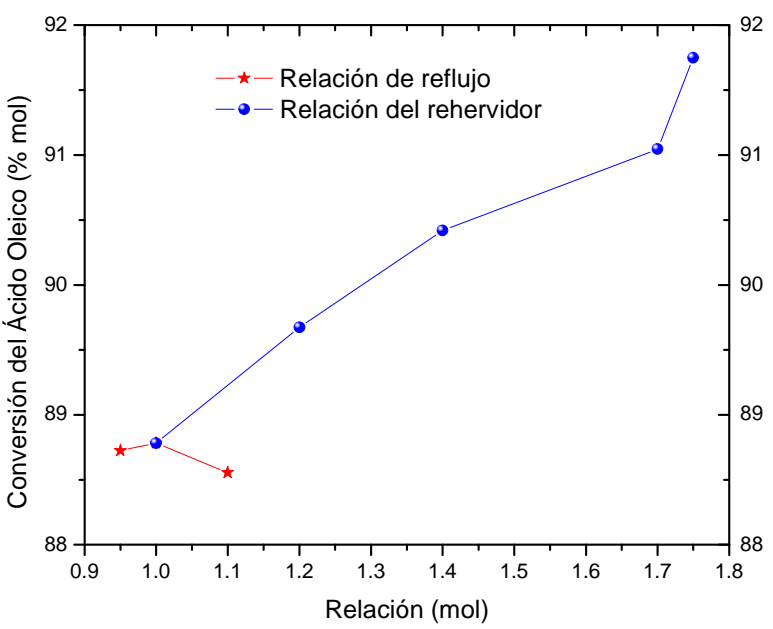

b)

Figura 4.3. Influencia de los parámetros de operación en la conversión del ácido oleico. a) Cantidad de catalizador, b) Relación de reflujo y del rehervidor con $1000 \mathrm{~kg}$ de catalizador. 
Entonces, se eligió la relación del rehervidor de 1.75 que nos da una conversión del $91.75 \%$, ya que a valores mayores a 1.8 la simulación presenta errores probablemente por problemas en el equilibrio de fases.

Otra variable que se analizó fue la razón de alimentación ácido oleico/metanol, obteniendo que la razón 1:1 fue la más óptima ya que con valores menores o mayores se obtiene una disminución de la conversión del ácido oleico. Además se hicieron otras pruebas con una mayor cantidad de catalizador $(1500 \mathrm{~kg})$, obteniendo que con una razón de 0.5:1 se podía conseguir una conversión del 97.27 \% más cercana al objetivo buscado, y es debido que al incrementar la cantidad de catalizador se aumenta área de contacto y como consecuencia se alcanza una mayor conversión, sin embargo, esto a su vez requiere una mayor cantidad de metanol para mojar toda el área, y cabe mencionar que esto trae consigo un menor flujo de metil oleato a la salida (ver el Apéndice A, Tabla A4).

En la Figura 4.4a podemos observar la influencia de la temperatura a la cual se alimentan los reactivos sobre la conversión de ácido oleico. Aquí observamos que si el metanol entra a una temperatura muy cercana a su temperatura de ebullición $\left(\mathrm{Tb}=64^{\circ} \mathrm{C}\right)$ la conversión del ácido oleico disminuye y esto es debido a que la reacción se lleva a cabo en fase líquida, entonces, mientras más tiempo se mantenga en contacto el ácido con el metanol mayor conversión se puede esperar. Por ende, si el metanol se introduce a mayor temperatura provocaremos su evaporación y disminución de la concentración de este en la fase líquida. Por lo tanto, la temperatura de alimentación del metanol debe hacerse entre 55 y $60{ }^{\circ} \mathrm{C}$, se utilizo $55^{\circ} \mathrm{C}$ para asegurar la presencia de este en la fase líquida. Cosa similar pasa con la temperatura de alimentación del ácido oleico, de ahí que se encontró que la temperatura óptima a la que debe alimentarse es $326^{\circ} \mathrm{C}$, que es menor a su temperatura de ebullición $\left(\mathrm{Tb}=359.85^{\circ} \mathrm{C}\right)$. Con esto hasta el momento hemos conseguido una conversión del 93.55\%. 


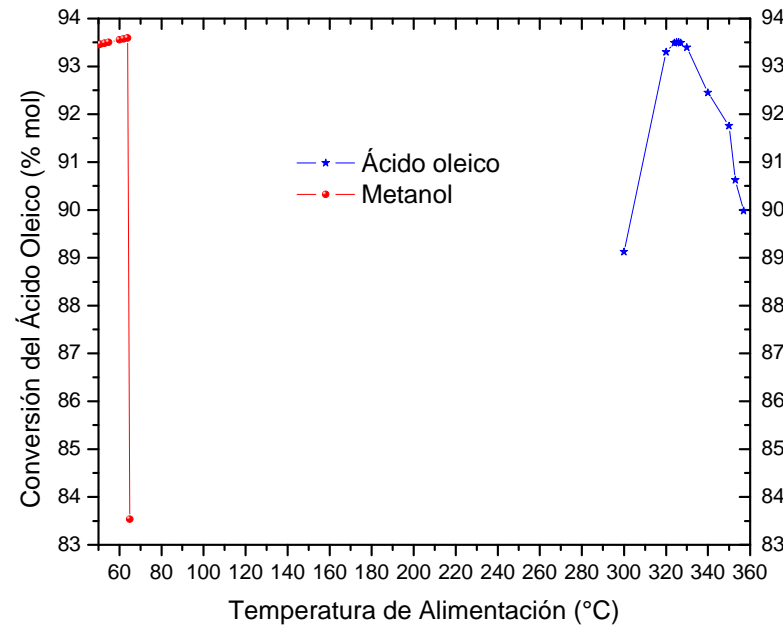

a)

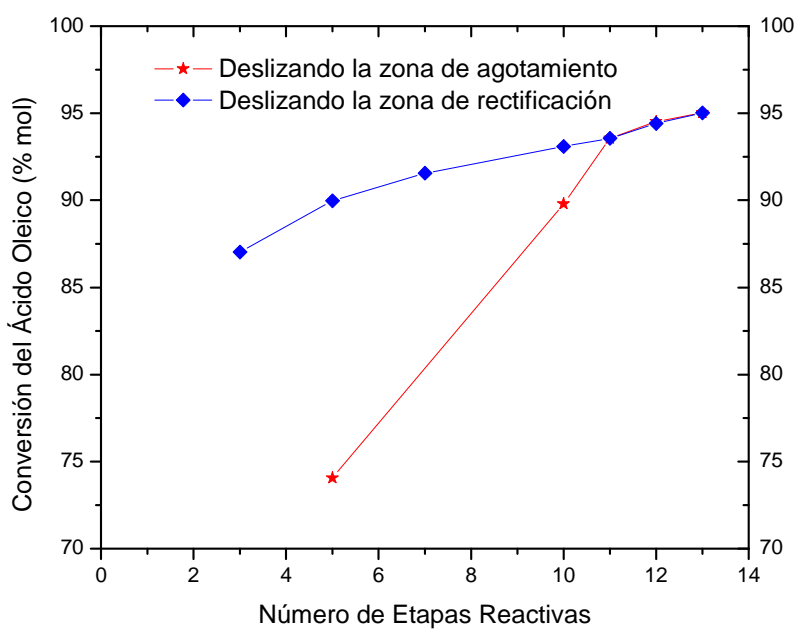

b)

Figura 4.4. a) Influencia de la temperatura de alimentación de los reactivos sobre la conversión del ácido oleico. b) Influencia de la variación del número de etapas sobre la conversión del ácido.

Con los parámetros de operación fijados hasta el momento, toca el turno de observar la variación del número de etapas reactivas (Figura 4.4b). En cada prueba se buscó respetar que la alimentación de los reactivos sea una etapa antes o una después de la zona reactiva dependiendo cuál sea el caso. Considerando así dos casos, uno donde el número de etapas reactivas iba de menor a mayor desplazando las etapas de rectificación y otro donde el número de etapas reactivas se incrementaban desplazando las etapas de agotamiento. Siendo así, que cuando se analizó el primer caso se fijaron 2 etapas de agotamiento y cuando se analizó el segundo caso se fijaron 2 etapas de rectificación. Con esto, a su vez podemos analizar la influencia del aumento de número de etapas de rectificación y agotamiento sobre la conversión del ácido oleico. Observando la Figura 4.4b encontramos, que conforme aumenta el número de etapas reactivas se incrementa la conversión del ácido oleico en ambos casos. Sin embargo, se tiene una fuerte variación en la conversión al incrementar el número de etapas de agotamiento, ya que vaporizó al metanol antes de llegar a la zona de reacción. Mientras que si incrementamos el número de etapas de rectificación la variación en la conversión es menor, además sabemos que la zona de agotamiento es la de mayor temperatura en la columna. En general la mejor conversión se obtuvo considerando 13 etapas reactivas con una de rectificación y una de agotamiento, alcanzando una conversión del 95.02\%. 
Otro parámetro que se observó fue la etapa de alimentación de los reactivos. Con esto encontramos que si la alimentación del ácido oleico era muy arriba de las etapas reactivas la simulación nos arrojaba soluciones triviales, esto debido a que existe un conflicto termodinámico entre los componentes presentes, principalmente entre el agua y el aceite, ya que estamos forzando el equilibrio liquido-vapor entre dos componentes cuando son inmiscibles. Es por ello, que la alimentación se debe introducir una etapa antes o en la primera etapa reactiva. Para el caso del metanol, tampoco nos conviene alimentarla etapas después de la zona reactiva, porque nuevamente estaremos provocamos su evaporación antes de llegar a esta zona.

Hasta ahora se han estudiado los principales parámetros y observado su influencia, pero aun no hemos alcanzado nuestro objetivo que es encontrar las condiciones de operación de la columna a la cual se obtenga una conversión del $99.9 \%$, pues hasta el momento sólo hemos alcanzado una conversión del $95.02 \%$. Por lo tanto, proseguimos a incrementar el número de etapas totales y por ende aumentar el número de etapas reactivas, hasta lograr el objetivo.

Se realizaron varias simulaciones incrementando el número de etapas totales utilizando dos modelos termodinámicos: UNIFAC y UNIQUAC, que se presentan en la Figura 4.5. En dicha figura vemos que con el método UNIFAC conseguimos mejores conversiones y se necesita un mayor número de etapas de rectificación, aunque, no existe mucha variación entre usar 32 o 34 etapas. Para el caso de las simulaciones usando UNIQUAC existe una diferencia un poco más marcada entre usar 32 y 34 etapas, sin embargo, seguimos sin alcanzar la conversión deseada. Ambos métodos fueron explicados en el primer capítulo, donde, nos percatamos que en forma general son métodos similares, sin embargo, la principal diferencia radica en la forma de considerar las energías de interacción, donde el método de UNIQUAC considera la interacción molecular mientras que UNIFAC considera la interacción entre grupos funcionales, lo que permite tener cálculos más aproximados y una mejor conversión en este caso, sin embargo, para llevar a cabo las simulaciones se requieren otras propiedades, las cuales no es fácil obtenerlas para todos nuestros compuestos, principalmente para el sistema de transesterificación donde fue necesario usar UNIQUAC. 


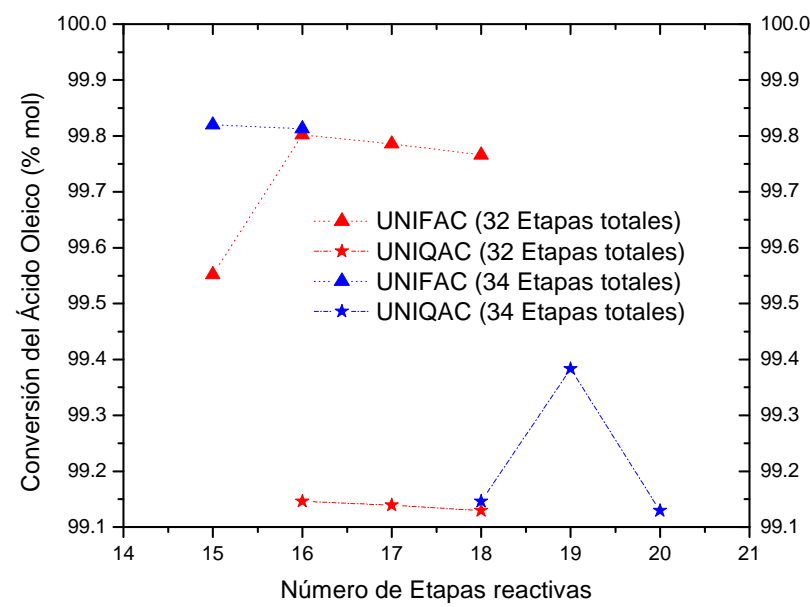

Figura 4.5. Influencia del número de etapas totales y reactivas, con diferentes modelos termodinámicos.

Entonces usando el método de UNIQUAC y una columna de 34 etapas totales, proseguimos a mover nuevamente algunos parámetros que resultaron más influyentes en la conversión, como son: número de etapas reactivas, la relación de rehervidor y temperatura de alimentación de ácido oleico hasta alcanzar la conversión deseada. En la Tabla 4.2 se presentan los resultados de las simulaciones que al ir moviendo cada parámetro nos dieron mayor conversión del ácido oleico, sin embargo, la forma en que se fue variando cada parámetro se presenta con más detalle en el Apéndice A.

El procedimiento descrito anteriormente para encontrar las condiciones óptimas de operación de CDR-CT, fue seguido de forma similar para los otros dos tipos de columnas: la CDR-CP y la CDR-SC. Se partió utilizando la misma configuración de 15 etapas totales (11 reactivas, 2 de rectificación y 2 de agotamiento) presentado en la Tabla 4.1. Sólo que para estas se tomaron como valores iniciales los parámetros encontrados para CDR-CT como son: relación del rehervidor $(\mathrm{RB}=1)$, relación de reflujo $(\mathrm{RF}=1)$, la cantidad de catalizador $\left(1000 \mathrm{~kg}\right.$ de catalizador), la temperatura de alimentación de los reactivos $\left(326^{\circ} \mathrm{C}\right.$ para ácido oleico y $55^{\circ} \mathrm{C}$ para el metanol). Y ya con estos se comenzó a variar parámetro por parámetro de forma tal que se alcanzara la conversión deseada.

Todas las tablas de las simulaciones presentan una columna que dice corrida. La interpretación es la siguiente: letra $\mathrm{S}$ significa que se trata de una simulación realizada, el 
número que le sigue adjunto indica el número de parámetro que se está modificando que viene de acuerdo a el orden en que se fue modificando cada parámetros (en los apéndices viene el nombre del parámetro que se está modificando y cada tabla esta numerada en orden), el segundo número indica el número de modificaciones que se le han hecho a un mismo parámetro. La fila sombreada es la simulación elegida como la que nos acerca más a nuestro objetivo, o en el caso de las tablas de resultados condensados es la simulación final elegida como la más conveniente una vez que el objetivo de un $99.9 \%$ de conversión ha sido alcanzado. 
Tabla 4.2. Resultados condensados de las simulaciones para CDR-CT. Siendo optima una relación de reflujo de 1 y $1000 \mathrm{~kg}$ de catalizador y una razón de alimentación $\mathrm{AO} / \mathrm{MeOH}(\mathrm{kmol} / \mathrm{h})$ de 1:1.

\begin{tabular}{|c|c|c|c|c|c|c|c|c|c|c|c|c|c|c|c|c|c|}
\hline \multirow{4}{*}{$\begin{array}{c}\text { Corri } \\
\mathrm{da}\end{array}$} & \multicolumn{10}{|c|}{ Entrada de simulación } & \multicolumn{7}{|c|}{ Salida de resultados } \\
\hline & \multicolumn{5}{|c|}{ Número de Etapas } & \multirow{3}{*}{$\begin{array}{l}\text { Ali } \\
\text { m. } \\
\text { de } \\
\text { AO }\end{array}$} & \multicolumn{2}{|c|}{$\begin{array}{c}\text { Temperatura de } \\
\text { alim. }\left({ }^{\circ} \mathrm{C}\right)\end{array}$} & \multirow{3}{*}{$\begin{array}{l}\text { Reh } \\
\text { ervi } \\
\text { dor }\end{array}$} & \multirow{3}{*}{$\begin{array}{c}\text { Modelo } \\
\text { Termodiná } \\
\text { mico }\end{array}$} & \multirow[t]{3}{*}{$\begin{array}{l}\text { Conversió } \\
\text { n del AO }\end{array}$} & \multicolumn{2}{|c|}{$\begin{array}{c}\text { Flujo de MO } \\
(\mathrm{kmol} / \mathrm{h})\end{array}$} & \multirow{3}{*}{$\begin{array}{l}\text { Tempera } \\
\left({ }^{\circ} \mathrm{C}\right) \\
\text { Domo }\end{array}$} & tura & \multicolumn{2}{|c|}{$\begin{array}{c}\text { Flujo de AO } \\
(\mathrm{kmol} / \mathrm{h})\end{array}$} \\
\hline & \multicolumn{2}{|c|}{ Rxn } & \multirow{2}{*}{$\begin{array}{l}\text { Rect } \\
\text { ifica } \\
\text { ción }\end{array}$} & \multirow{2}{*}{$\begin{array}{l}\text { Ago } \\
\text { tami } \\
\text { ento }\end{array}$} & \multirow{2}{*}{$\begin{array}{l}\text { To } \\
\text { tal }\end{array}$} & & \multirow[t]{2}{*}{$\mathrm{AO}$} & \multirow{2}{*}{$\begin{array}{c}\mathrm{MeO} \\
\mathrm{H}\end{array}$} & & & & \multirow[t]{2}{*}{ Domo } & \multirow[t]{2}{*}{ Total } & & \multirow[t]{2}{*}{ Fondo } & \multirow[t]{2}{*}{ Domo } & \multirow[t]{2}{*}{ Fondo } \\
\hline & $\begin{array}{c}\text { Tota } \\
1\end{array}$ & Rango & & & & & & & & & & & & & & & \\
\hline S1-9 & 11 & $3-13$ & 2 & 2 & 15 & 2 & 350 & 55 & 1 & UNIFAC & 0.88782 & 0.222 & 88.792 & 87.5 & 343.4 & 8.796 & 2.422 \\
\hline S2-2 & 11 & $3-13$ & 2 & 2 & 15 & 2 & 350 & 55 & 1 & UNIFAC & 0.88782 & 0.222 & 88.782 & 87.5 & 343.4 & 8.796 & 2.422 \\
\hline S3-5 & 11 & $3-13$ & 2 & 2 & 15 & 2 & 350 & 55 & 1.75 & UNIFAC & 0.9175 & 0.199 & 91.75 & 88.4 & 343.7 & 8.885 & 0.029 \\
\hline $\mathrm{S} 4-2$ & 11 & $3-13$ & 2 & 2 & 15 & 2 & 350 & 55 & 1.75 & UNIFAC & 0.9175 & 0.199 & 91.75 & 88.4 & 343.7 & 8.885 & 0.029 \\
\hline S5-5 & 11 & $3-13$ & 2 & 2 & 15 & 2 & 326 & 55 & 1.75 & UNIFAC & 0.93503 & 0.049 & 93.503 & 91.8 & 343.8 & 5.354 & 1.143 \\
\hline S5-16 & 11 & $3-13$ & 2 & 2 & 15 & 2 & 326 & 60 & 1.75 & UNIFAC & 0.93553 & 0.048 & 93.553 & 91.8 & 343.8 & 5.355 & 1.092 \\
\hline S6-8 & 13 & $2-14$ & 1 & 1 & 15 & 2 & 326 & 60 & 1.75 & UNIFAC & 0.9502 & 0.366 & 95.02 & 92.7 & 343.7 & 4.904 & 0.76 \\
\hline S7-1 & 16 & $3-18$ & 2 & 2 & 20 & 1 & 326 & 60 & 1.75 & UNIFAC & 0.94341 & 0.044 & 94341 & 92.3 & 343.7 & 5.372 & 0.287 \\
\hline S8-5 & 13 & $11-23$ & 10 & 2 & 25 & 10 & 326 & 60 & 1.75 & UNIFAC & 0.9939 & 1.438 & 99.39 & 94.5 & 343.8 & 0.61 & Trace \\
\hline S9-5 & 17 & $12-28$ & 11 & 2 & 30 & 12 & 326 & 55 & 1.75 & UNIFAC & 0.99738 & 1.732 & 99.738 & 93.7 & 343.8 & 0.262 & trace \\
\hline S9-9 & 16 & $15-30$ & 14 & 2 & 32 & 15 & 326 & 55 & 1.75 & UNIFAC & 0.99802 & 1.732 & 99.802 & 93.7 & 343.8 & 0.198 & trace \\
\hline S9-12 & 15 & $17-32$ & 16 & 2 & 34 & 17 & 326 & 55 & 1.75 & UNIFAC & 0.9982 & 1.832 & 99.82 & 93.7 & 343.8 & 0.18 & trace \\
\hline S10-1 & 16 & $15-30$ & 14 & 2 & 32 & 14 & 326 & 55 & 1.75 & UNIQUAC & 0.99146 & 0.478 & 99.146 & 98.9 & 343.7 & 0.854 & trace \\
\hline $\begin{array}{l}\text { S10- } \\
11\end{array}$ & 19 & $14-32$ & 13 & 2 & 34 & 14 & 322 & 55 & 1.7 & UNIQUAC & 0.99929 & 0.047 & 99.929 & 99.8 & 343.7 & 0.071 & trace \\
\hline
\end{tabular}


En la Figura 4.6 se presenta la influencia que tiene la relación de reflujo y del rehervidor en la conversión del ácido oleico en cada tipo de columna. Para cada caso, primero se varió la relación de reflujo, posteriormente fijando el valor de este que nos dio mayor conversión se varió la relación del rehervidor. En este caso el valor óptimo de relación de reflujo que encontramos fue de 0.4 para la CDR-CP y de 0.3 para la CDR-SC ya que estamos concentrado la corriente de rectificación, con agua y metanol, y esta no influye tanto en la conversión del ácido. La relación del rehervidor fue de 1.7 para la CDR-CP y de 1.6 para la CDR-SC, para este último al dar mayores valores de 1.6 la simulación no converge.

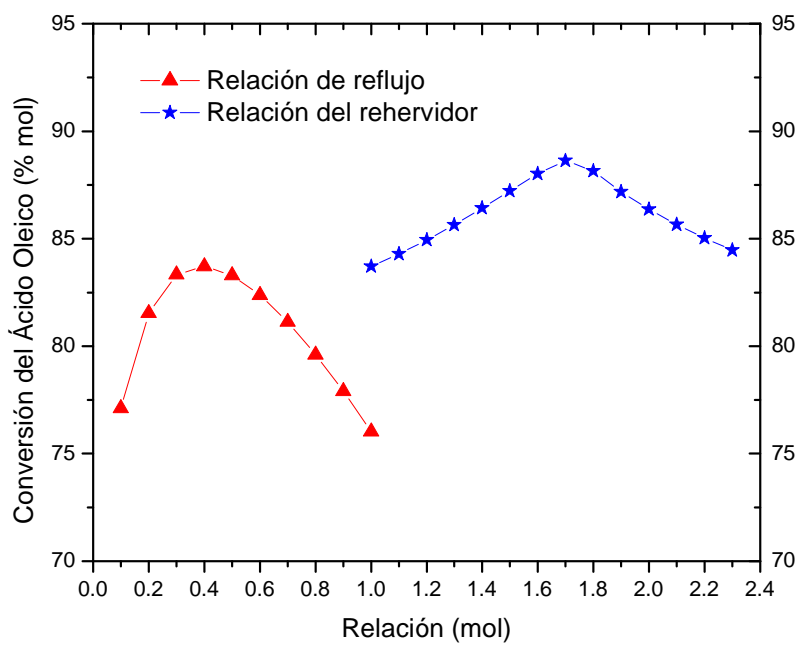

a)

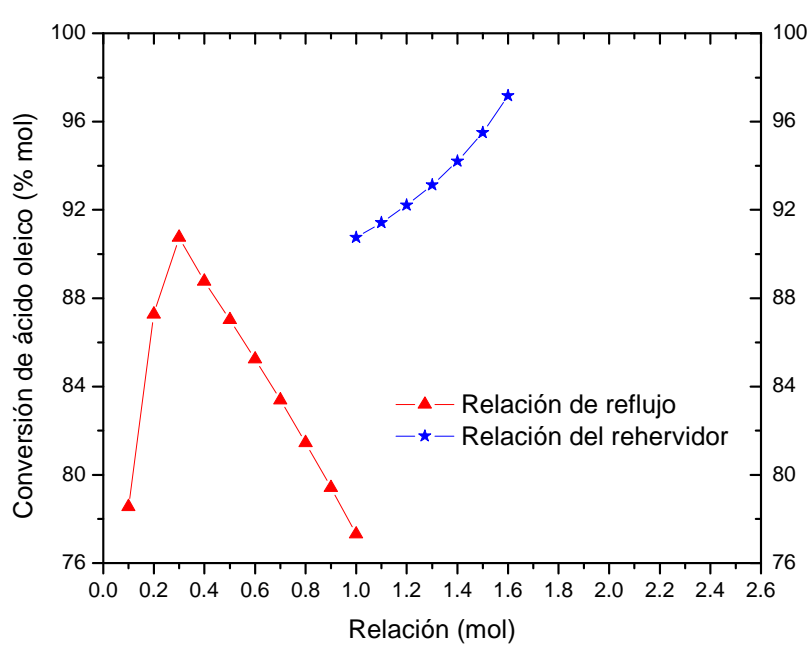

b)

Figura 4.6. Influencia de la relación del rehervidor y reflujo sobre la conversión de ácido oleico. a) CDR-CP, b) CDR-SC.

En general se puede decir que a valores bajos de la relación de reflujo la influencia es considerable en ambos casos ya que presenta un incremento en la conversión del 10\% aproximadamente. Además, podemos observar que en la CDR-SC la influencia de estos parámetros es más pronunciada, incrementando la relación del rehervidor se logró alcanzar el 97.2\% en la conversión, mientras, que para la CDR-CP se logra una conversión del 88.63 \%. En ambos casos nos conviene utilizar relaciones de reflujo pequeñas alrededor de 0.3 a 0.5 . Con los resultados obtenidos se procedió a buscar la mejor combinación de estos parámetros. Se incremento el número de etapas totales y reactivas y cuando fue necesario la temperatura de alimentación de los reactivos. Todos estos cambios se presentan en las Tablas 4.3 y 4.4. 
Tabla 4.3. Resultados condensados de las simulaciones para CDR-CP. Utilizando una temperatura de alimentación del $\mathrm{AO}$ de $326^{\circ} \mathrm{C}, 1000 \mathrm{~kg}$ de catalizador, 2 etapas de agotamiento, UNIQUAC para predecir el equilibrio de fases y una razón de alimentación de AO/MeOH de 1:1 (kmol/h)

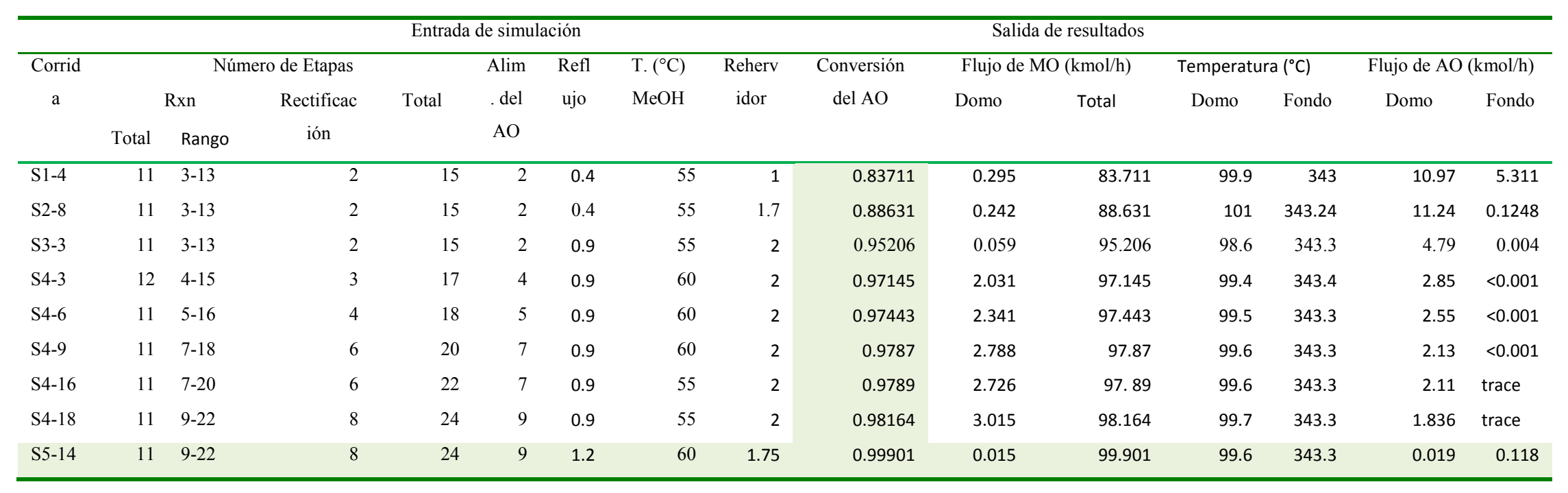

Tabla 4.4. Resultados condensados de las simulaciones para CDR-SC. Utilizando una temperatura de alimentación del AO a 326 y de MeOH a $55^{\circ} \mathrm{C}, 1000 \mathrm{~kg}$ de catalizador, 2 etapas de agotamiento, UNIQUAC para predecir el equilibrio de fases y una razón de alimentación de AO/MeOH de $1: 1(\mathrm{kmol} / \mathrm{h})$.

\begin{tabular}{|c|c|c|c|c|c|c|c|c|c|c|c|c|c|c|}
\hline \multicolumn{8}{|c|}{ Entrada de simulación } & \multicolumn{7}{|c|}{ Salida de resultados } \\
\hline \multirow[t]{3}{*}{ Corrida } & \multicolumn{3}{|c|}{ Número de Etapas } & \multirow{3}{*}{ Total } & \multirow[t]{3}{*}{ Alim. } & \multirow[t]{3}{*}{ Reflujo } & \multirow{3}{*}{$\begin{array}{l}\text { Reher } \\
\text { vidor }\end{array}$} & \multirow{3}{*}{$\begin{array}{c}\text { Conversión del } \\
\text { AO }\end{array}$} & \multicolumn{2}{|c|}{ Flujo de MO (kmol/h) } & \multicolumn{2}{|c|}{ Temperatura $\left({ }^{\circ} \mathrm{C}\right)$} & \multicolumn{2}{|c|}{ Flujo de $\mathrm{AO}(\mathrm{kmol} / \mathrm{h})$} \\
\hline & & $x n$ & Rectifica & & & & & & Domo & Total & Domo & Fondo & Domo & Fondo \\
\hline & Total & Rango & ción & & & & & & & & & & & \\
\hline S1-3 & 11 & $3-13$ & 2 & 15 & 2 & 0.3 & 1 & 0.90744 & 0.001 & 90.744 & 147.29 & 343.7 & 0.014 & 9.241 \\
\hline S2-7 & 11 & $3-13$ & 2 & 15 & 2 & 1 & 1.6 & 0.9717 & 0.001 & 97.17 & 154.59 & 343.62 & 0.03 & 2.81 \\
\hline S3-2 & 11 & $4-14$ & 3 & 16 & 3 & 1 & 1.9 & 0.99498 & trace & 99.498 & 100 & 343.4 & $<0.001$ & 0.502 \\
\hline S3-8 & 11 & $5-15$ & 4 & 17 & 4 & 0.8 & 2 & 0.99545 & $<0.001$ & 99.545 & 104.9 & 343.4 & $<0.001$ & 0.455 \\
\hline S3-13 & 14 & $3-16$ & 2 & 18 & 3 & 0.5 & 2 & 0.99885 & 0.001 & 99.885 & 126.2 & 343.4 & 0.002 & 0.115 \\
\hline S3-16 & 15 & $3-17$ & 2 & 19 & 3 & 0.5 & 2 & 0.99926 & $<0.001$ & 99.926 & 126 & 343.4 & 0.002 & 0.072 \\
\hline
\end{tabular}


De forma más clara, en la Tabla 4.5 se presentan los parámetros de operación finales que se encontraron para cada configuración de las columnas propuestas.

Tabla 4.5. Especificaciones de diseño finales para los casos base presentados en la Figura 4.2.

\begin{tabular}{|c|c|c|c|}
\hline Variable & CDR-CT & CDR-CP & CDR-SC \\
\hline Presión de la columna & $1 \mathrm{bar}$ & $1 \mathrm{bar}$ & 1 bar \\
\hline Número de etapas de totales & 34 & 24 & 19 \\
\hline Etapas de rectificación & 13 & 8 & 2 \\
\hline Etapas reactivas & 19 (de 14 a 32$)$ & 14 (de 9 a 22$)$ & 15 (de 3 a 17$)$ \\
\hline Etapas de agotamiento & 2 & 2 & 2 \\
\hline Relación de reflujo & $1(\mathrm{~mol})$ & 1 & 0.5 (mol) \\
\hline Relación del rehervidor & $1(\mathrm{~mol})$ & $1.75(\mathrm{~mol})$ & $2(\mathrm{~mol})$ \\
\hline Etapa de alimentación del ácido oleico & 14 & 9 & 3 \\
\hline Etapa de alimentación del metanol & 33 & 23 & 18 \\
\hline Alimentación del ácido oleico & $\begin{array}{l}100 \mathrm{kmol} / \mathrm{h} \text { (calentado a } \\
322^{\circ} \mathrm{C} \text { ) }\end{array}$ & $\begin{array}{l}100 \mathrm{kmol} / \mathrm{h} \text { (calentado } \\
\left.\text { a } 326^{\circ} \mathrm{C}\right)\end{array}$ & $\begin{array}{l}100 \mathrm{kmol} / \mathrm{h} \text { (calentado } \\
\left.\text { a } 326^{\circ} \mathrm{C}\right)\end{array}$ \\
\hline Alimentación del metanol & $\begin{array}{l}100 \mathrm{kmol} / \mathrm{h} \text { (calentado a } \\
55^{\circ} \mathrm{C} \text { ) }\end{array}$ & $\begin{array}{l}100 \mathrm{kmol} / \mathrm{h} \text { (calentado } \\
\text { a } 60^{\circ} \mathrm{C} \text { ) }\end{array}$ & $\begin{array}{l}100 \mathrm{kmol} / \mathrm{h} \text { (calentado } \\
\left.\text { a } 55^{\circ} \mathrm{C}\right)\end{array}$ \\
\hline Cantidad de catalizador por etapa & 1000 (kg cat) & 1000 (kg cat) & 1000 (kg cat) \\
\hline Conversión del ácido oleico & 99.929 & 99.901 & 99.926 \\
\hline Flujo molar de $\mathrm{MO}$ en el fondo & $99.881 \mathrm{kmol} / \mathrm{h}$ & $99.848 \mathrm{kmol} / \mathrm{h}$ & $99.926 \mathrm{kmol} / \mathrm{h}$ \\
\hline Flujo másico de $\mathrm{MO}$ en el fondo & $29614.4813 \mathrm{~kg} / \mathrm{h}$ & $29637.7884 \mathrm{~kg} / \mathrm{h}$ & $29647.8853 \mathrm{~kg} / \mathrm{h}$ \\
\hline Carga térmica del condensador & $-2415.7929 \mathrm{~kW}$ & $-2079.0956 \mathrm{~kW}$ & $-1836.2888 \mathrm{~kW}$ \\
\hline Carga térmica del rehervidor & $4568.6906 \mathrm{~kW}$ & $4655.9723 \mathrm{~kW}$ & $5047.284 \mathrm{~kW}$ \\
\hline Temperatura del condensador & $99.844^{\circ} \mathrm{C}$ & $99.6098^{\circ} \mathrm{C}$ & $125.980^{\circ} \mathrm{C}$ \\
\hline Temperatura del rehervidor & $343.733^{\circ} \mathrm{C}$ & $343.31{ }^{\circ} \mathrm{C}$ & $343.37^{\circ} \mathrm{C}$ \\
\hline Carga térmica total absoluta & $6984.4835 \mathrm{~kW}$ & $6735.0679 \mathrm{~kW}$ & $6883.5728 \mathrm{~kW}$ \\
\hline Poder calorífico total del biodiesel & $308484.18 \mathrm{~kW}$ & $308726.962 \mathrm{~kW}$ & $308832.138 \mathrm{~kW}$ \\
\hline
\end{tabular}

Considerando que el poder calórico del biodiesel es de $37.5 \mathrm{MJ} / \mathrm{kg}$ (Billen et al., 2004), se calculó el poder calorífico total disponible del biodiesel producido. Cabe notar que el poder calorífico disponible que da el biodiesel que se obtiene en cada columna es mucho mayor que la el poder calorífico requerido por el condensador y el rehervidor en cada columna, lo que valida la sustentabilidad del proceso. No obstante cabe decir que se requiere un estudio energético y de análisis de costos de operación a detalle para asegurar con más certeza la sustentabilidad del proceso. 
En la Figura 4.7 se presentan los perfiles de composición en la fase líquida a lo largo de cada columna, donde la parte sombreada corresponde a la zona reactiva. La CDR-CT (Figura 4.7a) presenta una meseta a partir de la etapa 7 a 16, donde la composición del ácido oleico se mantiene casi constante y cercano a 1 en la fase líquida, posteriormente hay un decremento de la concentración del mismo de la etapa 18 a 28 después de que empieza la zona reactiva. Como consecuencia del decremento del ácido oleico existe un incremento exponencial en la fracción mol del metil oleato hasta la etapa 29, después de esta se concentra el metil oleato hasta salir casi puro, mientras que la concentración del metanol y el agua se mantiene casi invariable a lo largo de la columna en la fase líquida y con valores cercanos a cero, sin embargo, la concentración del agua aumenta de forma instantánea del plato 3 al 1 lo que permite que salga casi pura.

La CDR-CP (Figura 4.7b) presenta la mayor concentración de ácido oleico solo en la etapa de alimentación (etapa 9) de ahí hacia la derecha y hacia la izquierda la concentración disminuye. De manera similar a la columna anterior, aunque el consumo principal de este se da en la parte superior de la zona reactiva, son necesarias etapas adicionales para promover la conversión completa, no obstante, el número de etapas reactivas son menores a las que necesita la columna anterior. A la vez que disminuye la concentración del ácido oleico, aumenta la concentración del metil oleato. La concentración del metanol y el agua también se mantiene casi invariable en la fase líquida con valores cercanos a cero, y la concentración del agua aumenta de forma instantánea del plato 3 al 1 lo que permite que salga el agua casi pura de forma parecida a la CDR-CT.

En la CDR-SC (Figura 4.7c) existe cambio en la concentración del ácido oleico a lo largo de toda la columna ya que está ocupada en su mayoría por la zona reactiva, al menos en 15 etapas existe reacción y solo cuatro de separación incluyendo el rehervidor y el condensador. Así, el ácido oleico y el metanol se consumen en la zona reactiva al tiempo que también logran separase los productos que se están formando como son el agua y el metil oleato en la zona respectiva. Vemos que las secciones no reactivas debajo de la zona reactiva no influyen de manera benéfica y las de arriba de la zona reactiva tienen un mayor efecto ya que logran retirar el agua de la columna. De forma similar a las columnas anteriores la concentración del 
metanol y el agua se mantienen casi invariables en la fase líquida y con valores cercanos a cero, pero la concentración del agua se incrementa hasta 0.53 de la etapa 2 a la 1 .

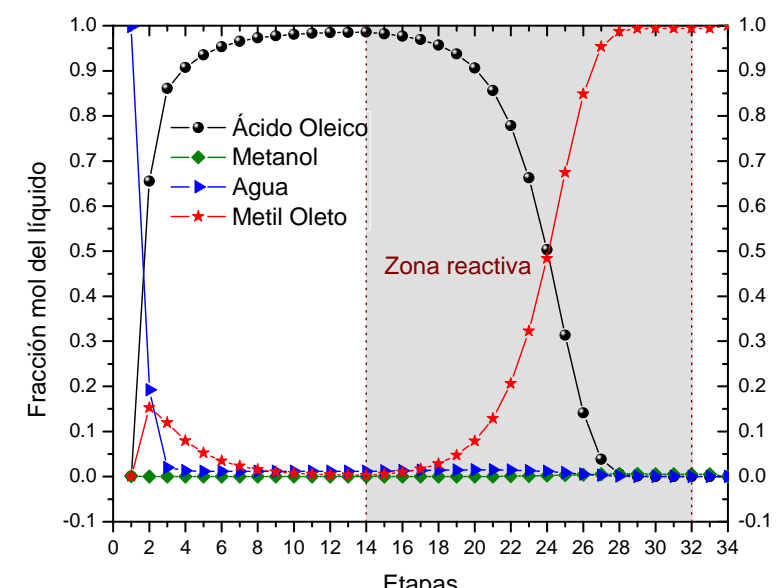

a)
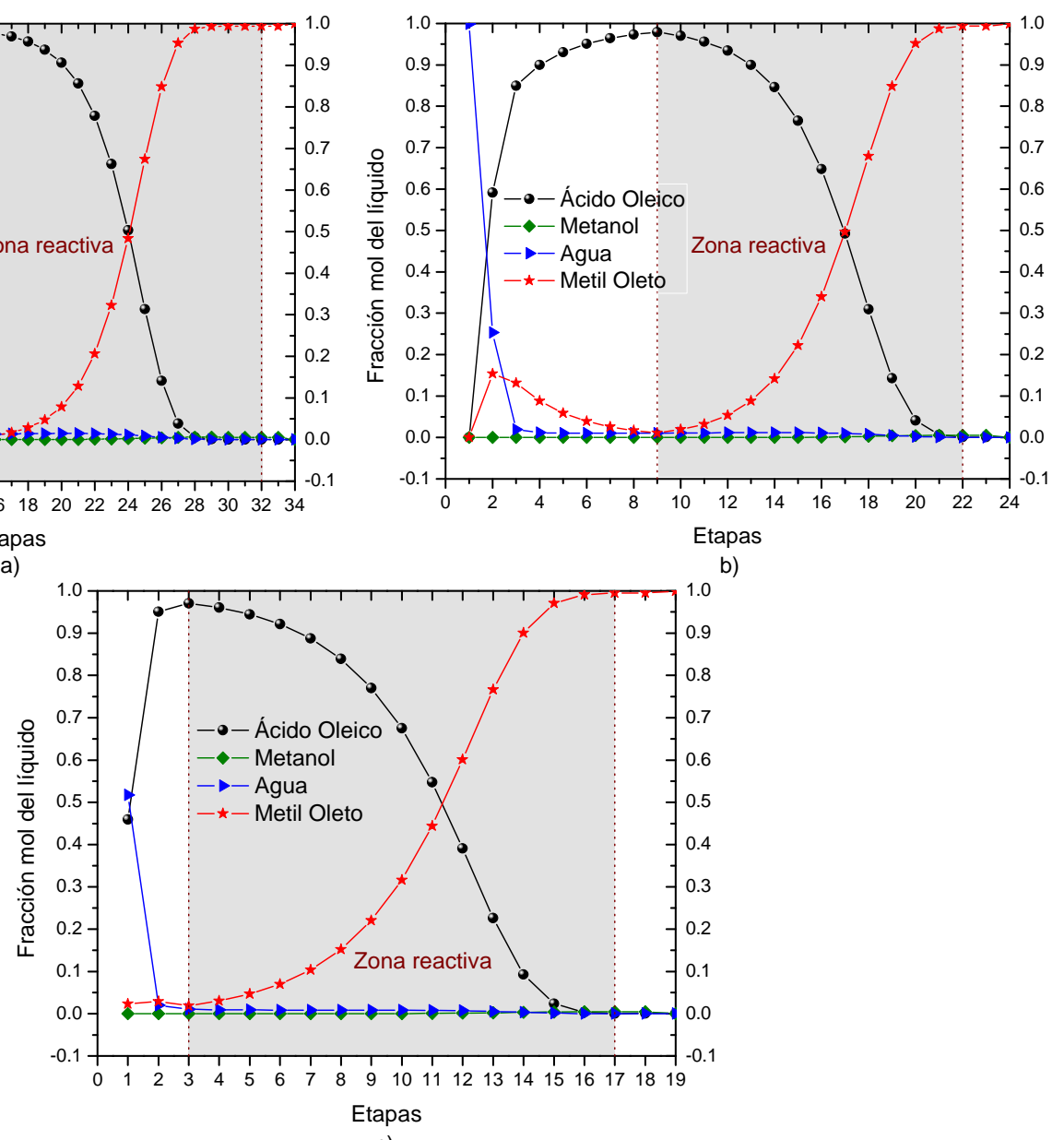

c)

Figura 4.7. Perfiles de composición en la fase líquida para cada columna. a) CDR-CT, b) CDRCP y c) CDR-SC.

En la Figura 4.8 se presentan los perfiles de composición en la fase vapor para cada tipo de columna, igualmente la zona sombreada corresponde a la zona reactiva. En la Figura 4.8a observamos una meseta de la etapa 6 a 14, donde, la concentración del ácido oleico se mantiene constante en 0.3 aproximadamente, después de ahí, entra a la zona reactiva y decrece su concentración en fase vapor, hasta la etapa 28 que se hace constante con valores cercanos a cero, mientras el metil oleato incrementa su composición en esta misma zona hasta la etapa 28, haciéndose constante hasta la etapa 33, después de está crece su concentración hasta 1 en el rehervidor. La concentración del metanol es mayor en la etapa de 
alimentación y decrece conforme va subiendo en la columna hasta acercarse a cero, por el contrario el agua va aumentando su concentración conforme sube en la columna hasta salir pura en el condensador.

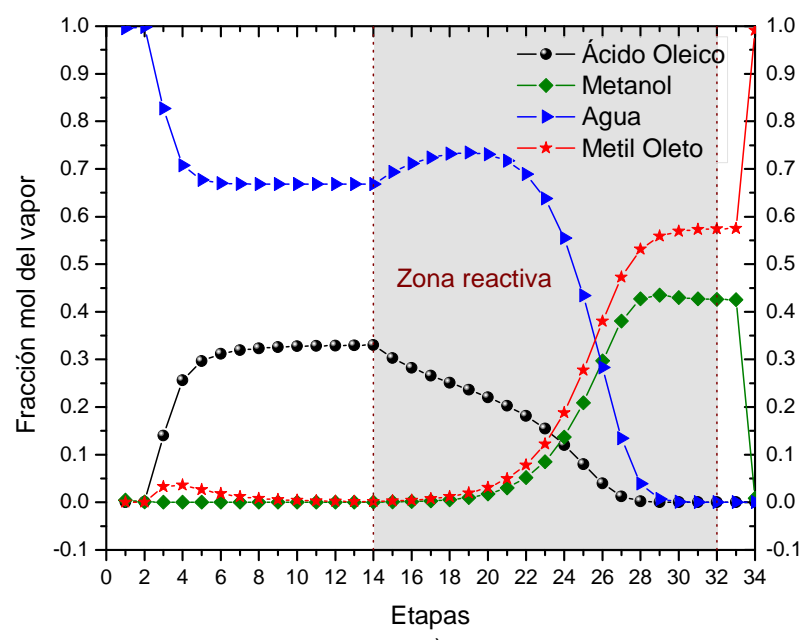

a)

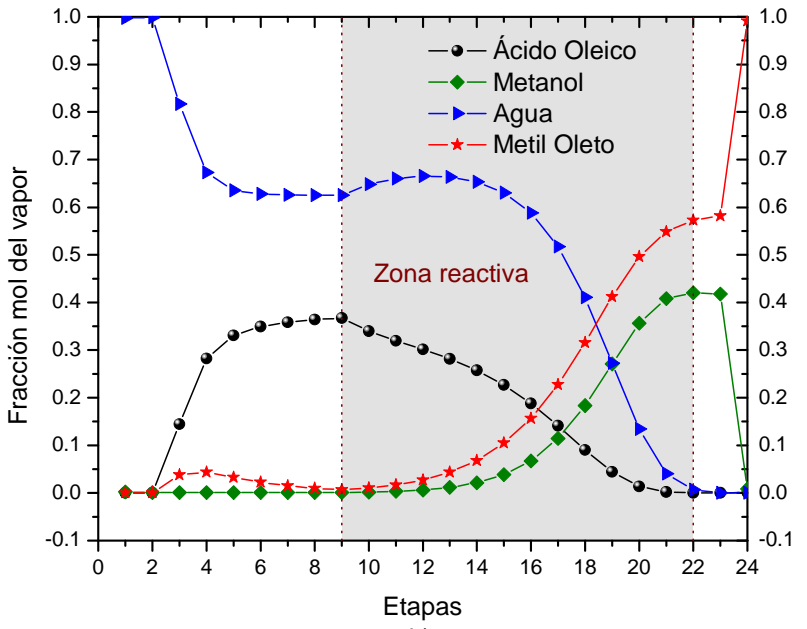

b)

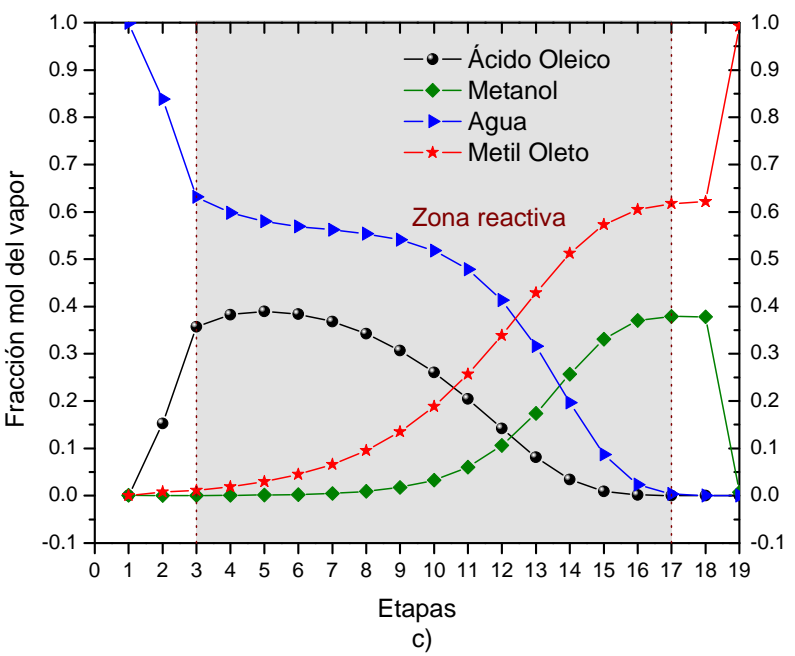

Figura 4.8. Perfiles de composición en la fase vapor para cada columna. a) CDR-CT, b) CDRCP y c) CDR-SC.

En la Figura 4.8b existe una concentración del ácido oleico y del agua en la zona de rectificación, del primero porque ahí está su alimentación y la segunda porque va saliendo de la zona de producción, así, en cuanto el ácido llega a la zona reactiva reacciona y por tanto desaparece al salir de la zona reactiva, a su vez el metanol decrece su concentración conforme se desplaza hacia arriba de la columna, hasta que su concentración es casi nula 
saliendo de la zona reactiva, mientras que el metil oleato se concentra en la zona reactiva y se concentra hasta salir puro del rehervidor.

En la CDR-SC la tendencia es más uniforme, los productos se forman y se van separando al mismo tiempo a lo largo de toda la columna, hasta obtener los productos puros en el destilado y en el fondo.

En la Figura 4.9 se presentan los perfiles de temperatura para cada columna, también la zona sombreada corresponde a la zona reactiva. De forma general la menor temperatura se localiza en las 3 primeras etapas para todos los casos.

De la etapa 4 en adelante la temperatura se mantiene constante ya que la velocidad de reacción es despreciable en esta zona para el caso de la CDR-CT y CDR-CP, estas últimas, operan a un rango de temperatura similar de 100 a $350^{\circ} \mathrm{C}$, los extremos son las temperaturas de ebullición de los componentes puros aproximadamente y la mayor variación de la temperatura se da en la zona reactiva en un rango de temperatura de $300-325^{\circ} \mathrm{C}$ aproximadamente para estos dos casos.

Para el caso de CDR-SC el rango de operación de la columna es de 125 a $350^{\circ} \mathrm{C}$, esto debido a que como el equipo no tiene condensador el agua sale principalmente en fase vapor como se muestra en la Figura 4.11c. 


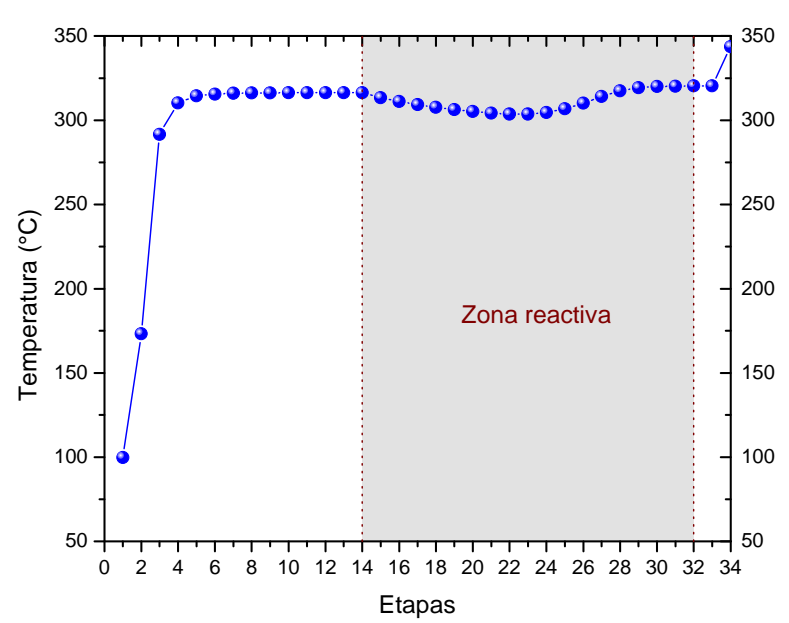

Etapas

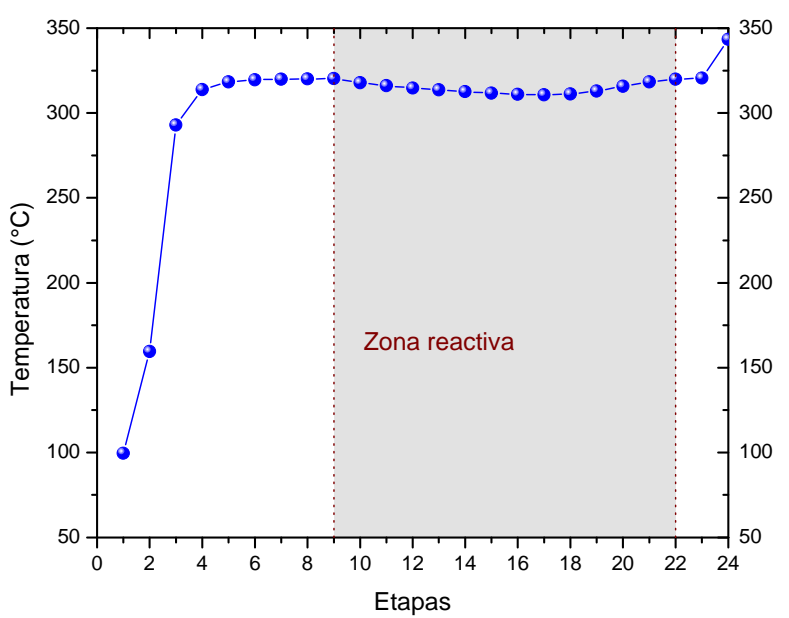

b)

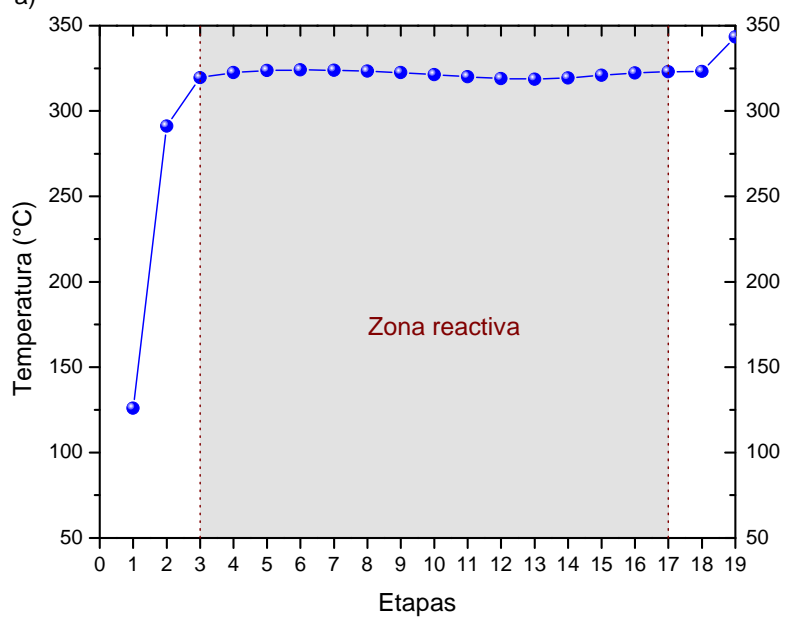

c)

Figura 4.9. Perfiles de temperatura para cada tipo de columna. a) CDR-CT, b) CDR-CP, c) CDR-SC

En la Figura 4.10 se presentan los perfiles de velocidad de reacción que se desarrollan dentro de cada columna. En todos los casos, la velocidad empieza a incrementarse en las primeras etapas reactivas que es cuando la concentración de ácido es mayor, llega a un máximo aproximado de $24(\mathrm{kmol} / \mathrm{h})$ y luego disminuye. La mayor velocidad se alcanza en las últimas etapas reactivas. La CDR-CT lo alcanza en la etapa 26, la CDR-CP en la etapa 19 y la CDRSC en la etapa 14. 


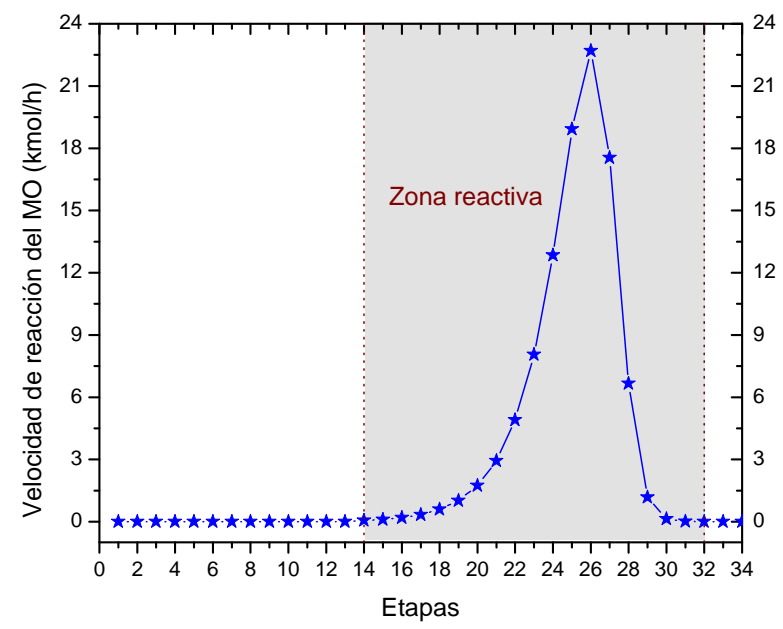

a)

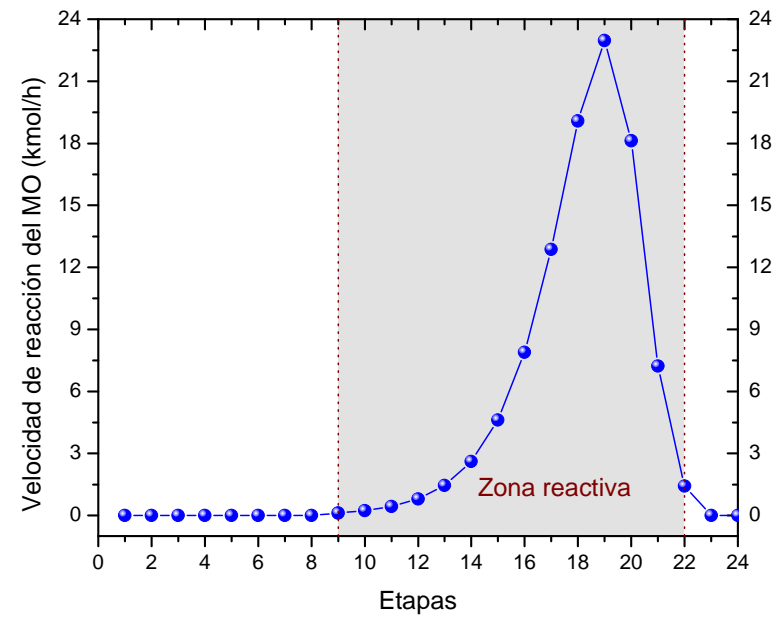

b)

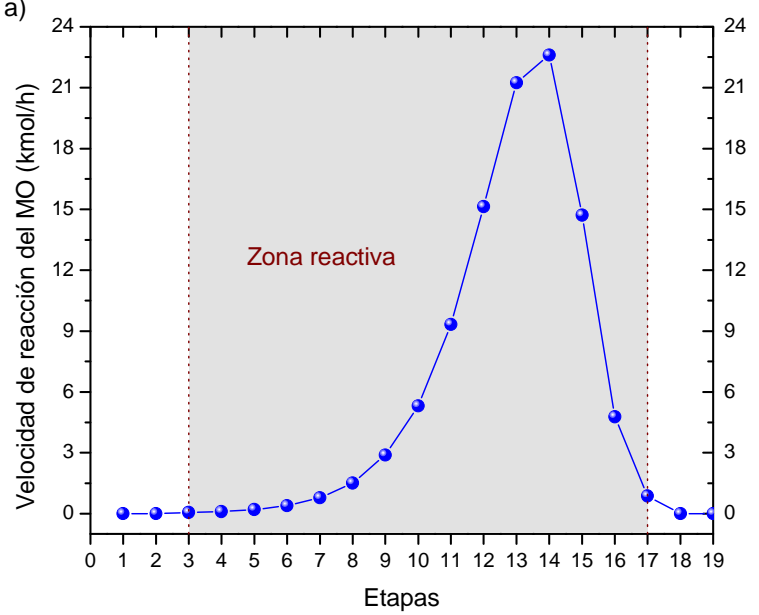

c)

Figura 4.10. Perfil de velocidad de reacción para cada columna. a) CDR-CT, b) CDR-CP, c) CDR-SC

En la Figura 11 se muestra el comportamiento del flujo molar de la fase líquida y vapor para cada columna. El comportamiento es similar para todos los casos en la zona reactiva, conforme se incrementan las etapas reactivas los flujos se incrementan en ambas fases a un máximo y después disminuyen en el rehervidor. En la zona de rectificación el flujo de ambas fases varía de forma diferente. En las CDR-CT y CDR-SC el flujo del vapor es constante en las etapas inmediatas a la parte superior de la zona reactiva, disminuyendo ligeramente hasta la etapa 3 donde se presenta un incremento hacia la etapa 2 y después un descenso al llegar al condensador. En cambio el flujo líquido disminuye etapas arriba de la zona de reacción, siendo más marcado en la etapa más inmediata a esta, y posteriormente aumenta cuando llega al condensador. En la CDR-SC los dos flujos se comportan similarmente a lo largo de toda la columna. 


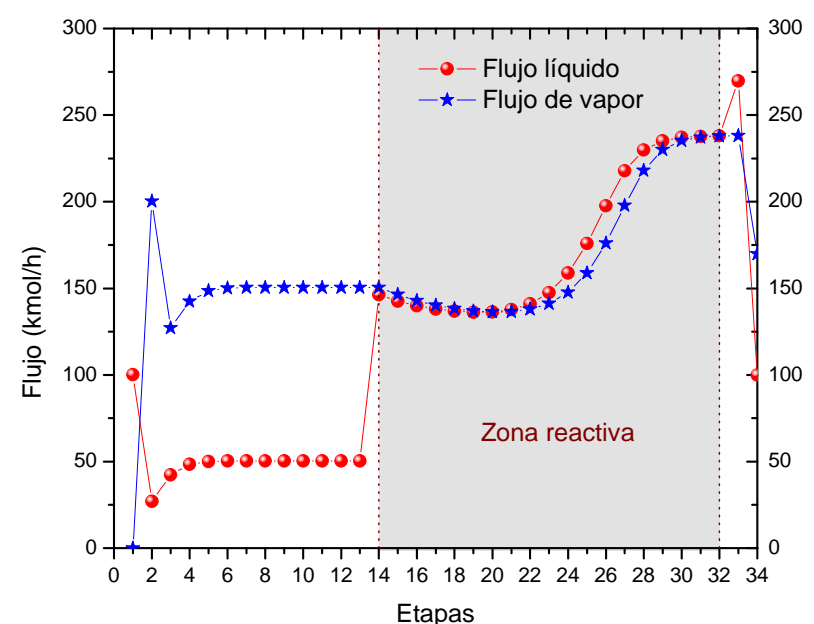

a)

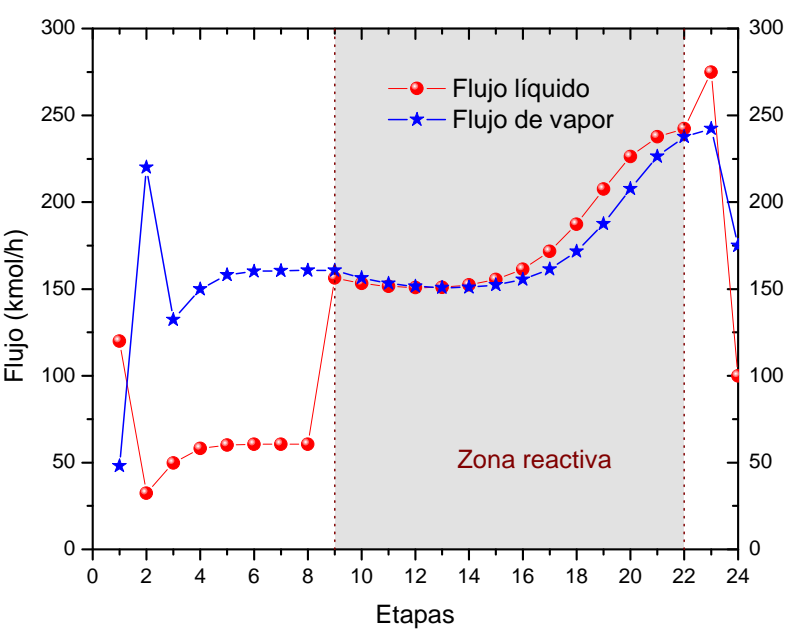

b)

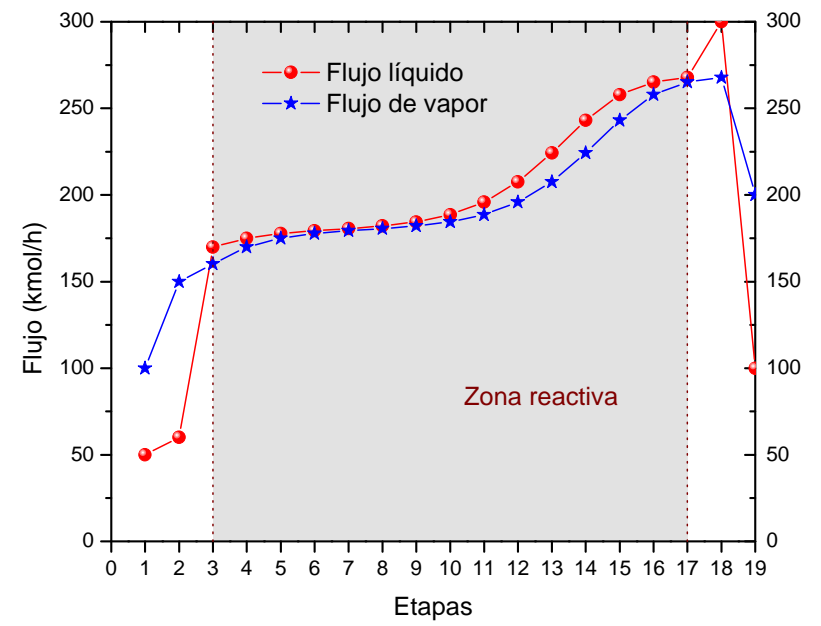

c)

Figura 4.11. Perfiles de los flujos molares para la fase líquida y vapor. a) CDR-CT, b) CDR-CP y c) CDR-SC.

Por último, en la Figura 4.12 se presenta el mapa de curvas residuales reactivo de cada columna en términos de elemento. Aquí podemos observar que para la CDR-CT y la CDRCP las curvas residuales reactivas abarcan la concentración desde el metil oleato puro $(\mathrm{WA}=0.5)$ que se obtiene en el fondo de la columna hasta el agua que sale pura en el destilado $(\mathrm{WB}=1)$. A simple vista vemos que el caso de la CDR-SC, obtenemos metil oleato puro en el fondo de la columna, pero aquí pareciera que no obtenemos el agua pura sino que lleva residuos de ácido oleico y trazas de metil oleato, debido tal vez a que la alimentación del primero está muy cercana a la primera etapa lo que provoca que el agua arrastre esta junto con ella. Pero como el ácido es más denso que el agua se logra recircular, y es posible obtener finalmente al agua pura en la corriente de salida del destilado. 


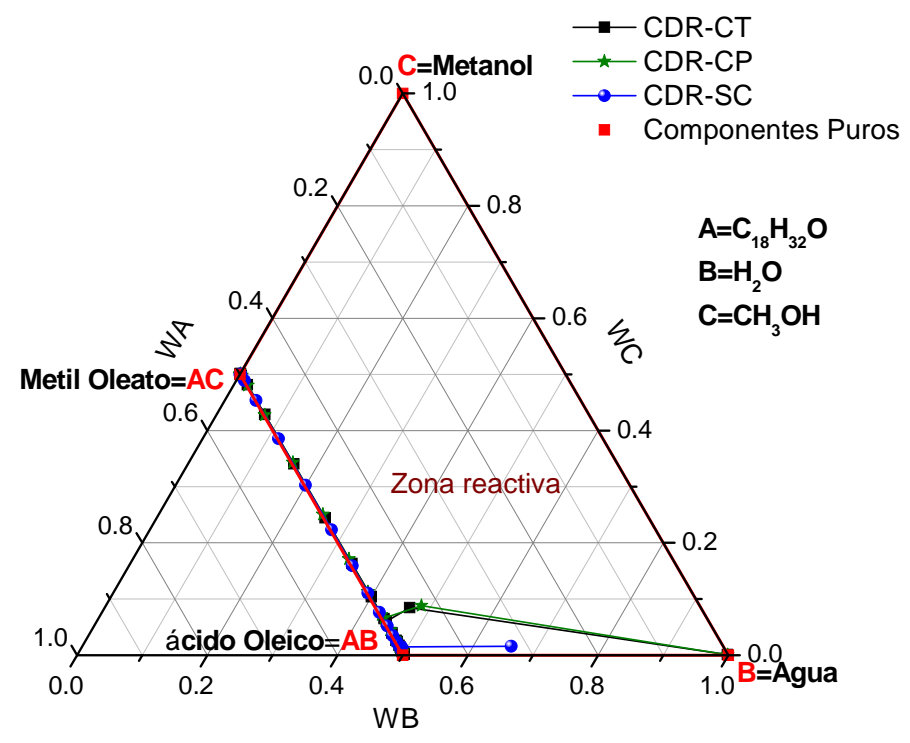

Figura 4.12. Mapas de curvas residuales reactivos para cada columna estudiada.

A manera de conclusión, la selección del diseño se basó en alcanzar una conversión del 99.9\% del ácido oleico y una pureza del 99.9\% de Metil Oleato en el fondo de la columna, y como un extra también en base a los valores de los parámetros finales se eligió la configuración más conveniente.

Como ya se menciono párrafos arriba en forma general la diferencia en la configuración de las columnas radica en el equipo de separación localizado en la parte superior de cada columna. Sabemos que la relación estequiometria de la reacción de esterificación es uno a uno, que finalmente la razón de alimentación optima que se encontró para cada columna es también de 1:1 AO/MeOH y que además se logra una conversión molar del 99.9\% en cada caso, esto produce que tanto el metanol como el ácido oleico se están consumiendo casi al $100 \%$, y en su lugar agua y metil oleato se están formando. Entonces, en la parte superior de la columna se obtiene solo agua (por ser el componente más volátil) y en el fondo de la columna se obtiene solo metil oleato o biodiesel lo que puede evita requerir un equipo de separación en la corriente de salida del destilado. Por ello, la configuración de la CDR-SC, es más viable para llevar a cabo esta reacción, pues obtenemos la conversión de ácido oleico esperada, usando un menor número de etapas totales, con una relación de reflujo menor aunque, la relación del rehervidor necesario es mayor en comparación con las otras dos columnas. Aun así, finalmente la cantidad total de carga térmica que se necesita para esta columna es menor que la que necesita la CDR-CT y ligeramente mayor a la que necesita la 
CDR-CP, además que hemos podido ver que los perfiles que se desarrollan dentro de esta columna son más estables, es por todo ello que será esta la que se use en el proceso integrado para la producción global del biodiesel.

\subsection{Determinación de las Condiciones de Operación de la Columna para las Reacciones de Transesterificación}

Para este sistema se encontraron diversas dificultades en la simulación intensiva, entre ellas está el modelo cinético a utilizar y el modelo termodinámico para el equilibrio de fases. Se sabe que la reacción de transesterificación catalizada alcalinamente es el método de producción de biodiesel más común, debido a la rápida velocidad de reacción y a que es menos corrosivo con el equipo industrial. De ahí que la cinética de reacción de transesterificación usando catalizador homogéneo este mejor estudiado en comparación con la catalizada heterogéneamente.

Existen algunos estudios disponibles para cinéticas de transesterificación usando catalizadores heterogéneos. Sabemos que la reacción de transesterificación es una reacción reversible y requiere un exceso de alcohol para desplazar la reacción hacia delante. Además, la velocidad de reacción heterogénea es más compleja ya que considera la difusión interna, difusión externa, adsorción, desorción, la reacción de superficie y la no idealidad de las mezclas, también depende de la concentración de los sitios del catalizador sobre la superficie entre otras cosas (Endalew et al., 2011). Es por ello que se probaron varios modelos, como el reportado por Dossin et al. (2006) el cual usa Oxido de Magnesio como catalizador (MgO), obteniendo un modelo de cinética intrínseca, Huang et al (2009) que utiliza Metóxido de Magnesio $\left(\mathrm{Mg}\left(\mathrm{OCH}_{3}\right)_{2}\right)$ el cual reporta un modelo cinético de velocidad de reacción aparente, y por último se utilizó el modelo cinético homogéneo reportado por Narváez et al. (2007), el cual utiliza hidróxido de sodio $(\mathrm{NaOH})$ como catalizador.

Debido a las dificultades computacionales que presentaban los modelos cinéticos de Dossin et al. (2006) y Huang et al (2009) se decidió adoptar el modelo homogéneo de Narváez et al. 
(2007) el cual se introduce directamente en Aspen, sólo que a ciertas condiciones reportaba problemas de convergencia debido a las condiciones de alimentación de los reactivos, de ahí que se decidió usar como valores iniciales el perfil de temperaturas para cada etapa obtenido en la simulación usando el modelo de Huang aunque arrojaba conversiones muy bajas $(0.1 \%)$ aproximadamente, y fue en ese momento que la simulación corrió para toda la gama de concentraciones y condiciones posibles para obtener la conversión deseada. Por ello, decimos que aunque existen diversos modelos cinéticos, las pruebas experimentales con estos aun son escasas y no del todo confiables, como se mencionó anteriormente los modelos cinéticos aun siguen siendo escasos para el estudio de la transesterificación heterogénea, por tanto existe mucho trabajo por hacer en el área de materiales catalíticos para la transesterificación.

Al usar la expresión cinética reportada por Narváez et al. (2007) nos ayuda a obtener un diseño básico de la columna de destilación reactiva, no obstante, se espera que en un futuro no muy lejano se desarrollen catalizadores heterogéneos que tengan la misma actividad catalítica que este catalizador y puedan usarse para el diseño real de la columna.

Para este sistema el procedimiento seguido es similar al descrito para la reacción de esterificación. Las decisiones se tomaron de manera secuencial: primero, se analizó en un rango dado de valores de cada parámetro la influencia en la conversión de la Trioleína, de forma tal que se fueron acotando los limites superior e inferior hasta obtener un valor que nos acercara a cumplir con nuestro objetivo "alcanzar una conversión de la trioleína del 99.9\% mol" en todas las columnas. Una vez encontrados los valores de los parámetros óptimos, los cuales son clasificados como óptimos locales para la columna con condensador total, se tomaron como base para determinar los valores de dichos parámetros de las otras dos configuraciones. Encontrando que la mejor configuración de la columna es la CDR-CT mostrada en la Figura 4.13, ya que las otras daban bajos rendimiento y se necesitaban condiciones superiores para alcanzar el objetivo. Como se comentó en el estudio realizado para la esterificación, la principal diferencia entre las configuraciones de las columnas era el tipo de condensador, en este sistema el único componente que llega al condensador es el metanol, que es mucho más volátil que los demás componentes que están presentes, en este caso nos conviene el condensador total porque así el metanol se retorna a la columna en fase 
líquida y como las reacciones se llevan a cabo sólo en esta fase, esto beneficia la conversión de los triglicéridos. De esta manera, se presentan las simulaciones hechas sólo para esta configuración de la columna.

Aquí también, se realizó un análisis de sensibilidad, siendo que esta es una fuerte herramienta para evaluar el rango óptimo de los parámetros de operación como son: la relación de reflujo y del rehervidor, razón de los reactivos, temperatura de alimentación, número de etapas totales y reactivas entre otros que se muestran líneas abajo.

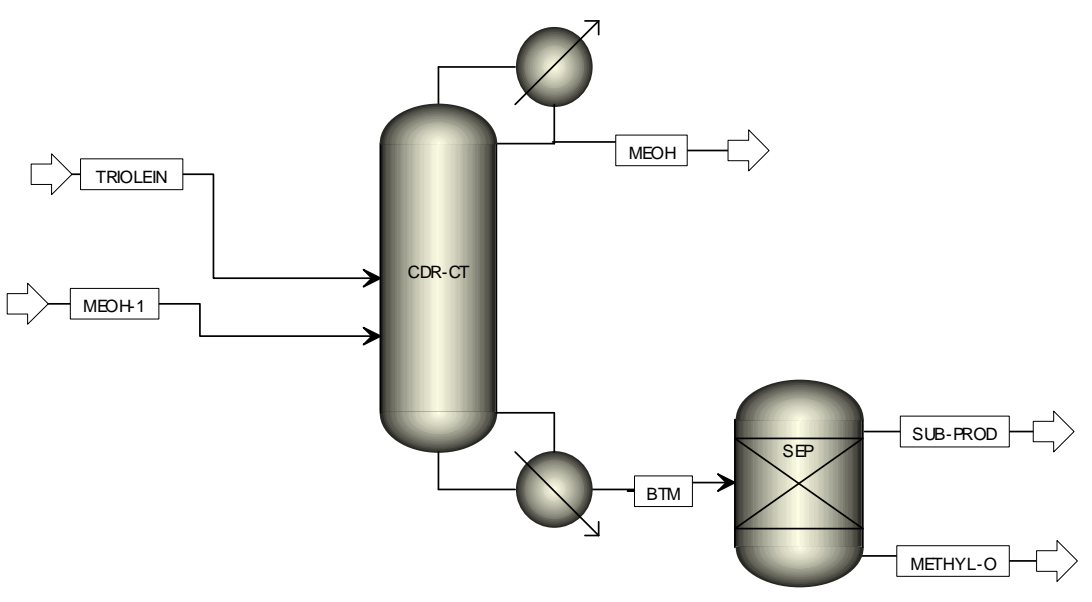

Figura 4.13. Diagrama de la primera columna utilizada para la transesterificación (CDR-CT1).

En la Figura 4.14a se presenta la influencia de la relación de reflujo y la relación del rehervidor donde vemos que el reflujo en este caso influye de forma más marcada que en el sistema de esterificación. Esta reacción también es reversible y se sabe que se necesitan 3 moles de metanol por cada mol de trioleína, además, es necesario introducir un exceso de metanol para desplazar la reacción hacia delante y producir los productos deseados. Ahora, la marcada diferencia de temperaturas de ebullición que existe entre los triglicéridos con respecto al metanol, permite que el metanol llegue a la parte superior de la columna y que entre al condensador, entonces, al aumentar el reflujo lo que se está recirculando es el metanol en fase líquida reaccionando así con los triglicéridos y por ende formándose el metil oleato. No obstante, la relación del rehervidor sigue siendo importante porque permite la recirculación de los triglicéridos y principalmente de la trioleína que aun no ha reaccionado, lo que ayuda a alcanzar la alta conversión deseada. Por lo tanto, se eligió una relación de reflujo de 1.7 y una relación del rehervidor de 1.8. 
Los detalles de todas las simulaciones y variación de los parámetros para este sistema se presentan en los Apéndices D y E.

Una vez fijos estos dos parámetros se pasó a variar la temperatura de alimentación de los reactivos, en la Figura 4.14b se presentan los resultados obtenidos. Primero se varió la T de alimentación del metanol encontrando que el valor más conveniente es a $55^{\circ} \mathrm{C}$ ya que a $60^{\circ} \mathrm{C}$ se acerca más a su punto de ebullición lo que generaría que se evapore antes de entrar en la zona reactiva. Mientras que la temperatura óptima de alimentación para la trioleína es de $830^{\circ} \mathrm{C}$ para no acercarse mucho a su temperatura de ebullición que es de $846.85^{\circ} \mathrm{C}$ y evitar su evaporación. Con esto, hasta el momento se ha logrado alcanzar una conversión de trioleína de $89.968 \%$ mol.

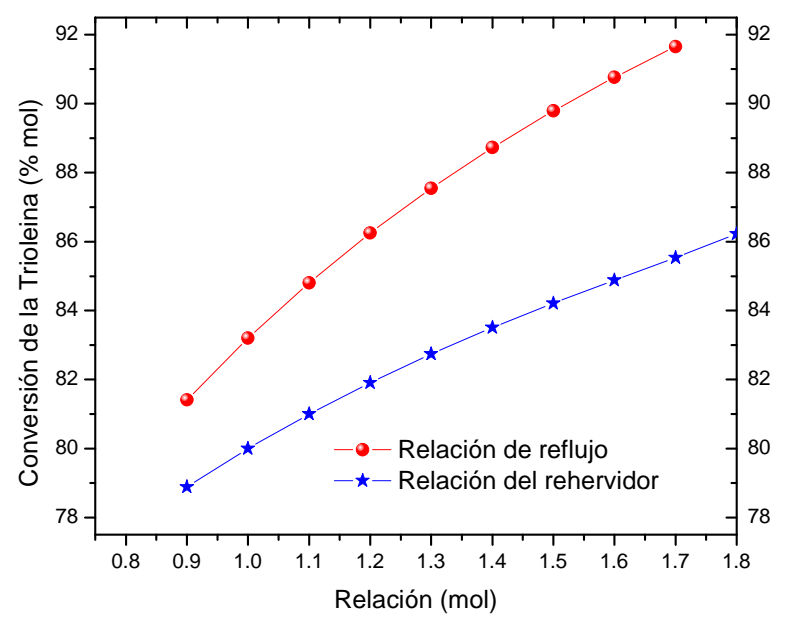

a)

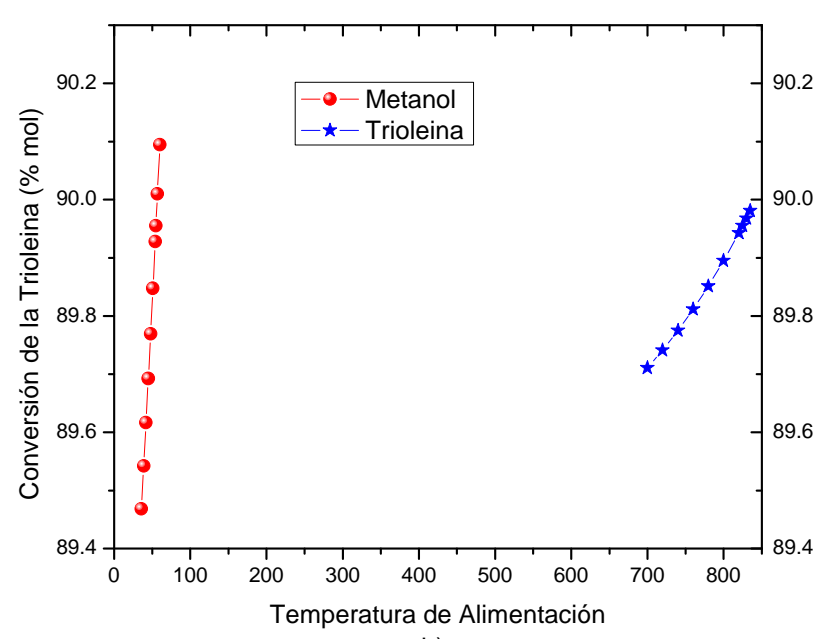

b)

Figura 4.14. Influencia de la razón y la temperatura de alimentación de los reactivos en la conversión de la trioleína. a) Relación de reflujo y del rehervidor, b) Temperatura de alimentación del metanol y la trioleína.

En la Figura 4.15a, se muestra el comportamiento de la conversión de la trioleína al variar la cantidad de catalizador. Donde se observa un incremento importante hasta los 1000L porque después de este valor, el cambio en la conversión molar es sólo del $0.05 \%$ aproximadamente.

Posteriormente se muestra en la Figura $4.15 \mathrm{~b}$ el efecto de la alimentación de metanol. Se encontró un incremento considerable en la conversión al aumentar el flujo, lo que era de esperarse porque así ayuda a que se desplacen hacia adelante las reacciones que están ocurriendo. Se conoce que tan sólo, usando el proceso convencional para la producción de 
biodiesel usando catalizador homogéneo, se necesita una razón triglicérido/metanol de 6:1 según lo reportado por Narváez et. al. (2007) y Noureddini and Zhu, (1997) y usando catalizador heterogéneo de 9 y 10 según Huang et al. (2009) y Dossin et. al., (2006), por lo que es normal que se requiera un exceso de metanol, además de que no se debe olvidar que la reacción y la separación se están llevando a cabo al mismo tiempo. En este caso se eligió usar un flujo del metanol de 1500L con el cual se logra alcanzar una conversión de la trioleína del 98.596\%mol.

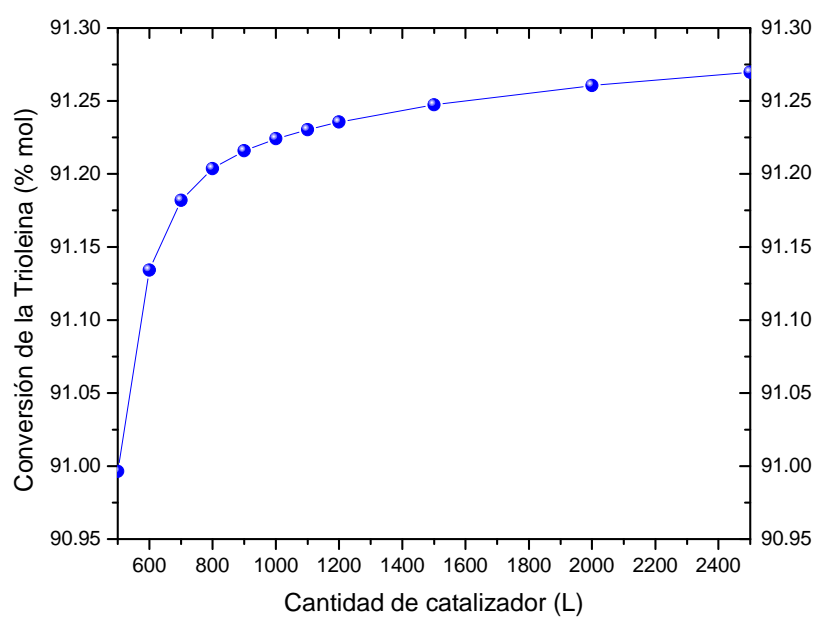

a)

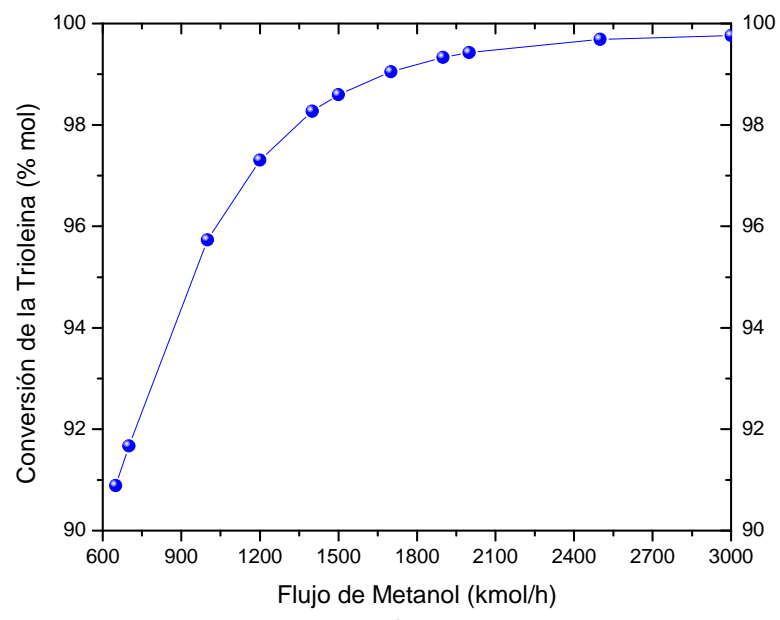

b)

Figura 4.15. a) Influencia de la cantidad de catalizador y b) Influencia del flujo molar de metanol.

Con una columna de destilación reactiva con condensador total y una sola corriente de metanol (CDR-CT1), se modificó nuevamente la relación de reflujo y del rehervidor, además, del número de etapas totales y reactivas hasta encontrar la conversión deseada. En la Tabla 4.6 se presentan los resultados condensados de cada simulación al variar cada parámetro, sin embargo, para más detalles de las simulaciones ver el Apéndice D.

También aquí las tablas de las simulaciones presentan una columna que dice corrida. La interpretación es la siguiente: letra S significa que se trata de una simulación realizada, el número que le sigue adjunto indica el número de parámetro que se está modificando que viene de acuerdo a el orden en que se fue modificando cada parámetros (en los apéndices viene el nombre del parámetro que se está modificando y cada tabla esta numerada en orden), el segundo número indica el número de modificaciones que se le han hecho a un 
mismo parámetro. La fila sombreada es la simulación elegida como la que nos acerca más a nuestro objetivo, o en el caso de las tablas de resultados condensados es la simulación final elegida como la más conveniente una vez que el objetivo de un $99.9 \%$ de conversión ha sido alcanzado. 
Tabla 4.6 Resultados condensados de las simulaciones para CDR-CT1. Siendo optimo 3 etapas de agotamiento.

\begin{tabular}{|c|c|c|c|c|c|c|c|c|c|c|c|c|c|c|c|c|c|c|c|c|c|c|c|c|c|}
\hline \multicolumn{14}{|c|}{ Entrada de simulación } & \multicolumn{12}{|c|}{ Salida de resultados } \\
\hline \multirow{4}{*}{$\begin{array}{l}\text { Co } \\
\text { rri } \\
\text { da }\end{array}$} & \multirow{4}{*}{$\begin{array}{c}\text { Razón } \\
\text { TO/Me } \\
\mathrm{OH} \\
(\mathrm{kmol} / \\
\text { h) }\end{array}$} & \multicolumn{4}{|c|}{ Número de Etapas } & \multicolumn{2}{|c|}{$\begin{array}{l}\text { Alimen } \\
\text { tación }\end{array}$} & \multirow{4}{*}{$\begin{array}{l}\text { Re } \\
\text { flu } \\
\text { jo }\end{array}$} & \multicolumn{2}{|c|}{$\begin{array}{l}\text { T. de alim. } \\
\qquad\left({ }^{\circ} \mathrm{C}\right)\end{array}$} & \multirow{4}{*}{$\begin{array}{l}\text { Re } \\
\text { her } \\
\text { vid } \\
\text { or }\end{array}$} & \multirow{4}{*}{$\begin{array}{l}\text { Catal } \\
\text { izado } \\
\text { r (L) }\end{array}$} & \multirow{4}{*}{$\begin{array}{c}\text { Conver } \\
\text { sión } \\
\text { del AO }\end{array}$} & \multicolumn{2}{|c|}{$\begin{array}{c}\text { Flujo de MO } \\
(\mathrm{kmol} / \mathrm{h})\end{array}$} & \multicolumn{2}{|c|}{$\begin{array}{l}\text { Temperatura } \\
\left({ }^{\circ} \mathrm{C}\right)\end{array}$} & \multicolumn{2}{|c|}{$\begin{array}{c}\text { Flujo de TO } \\
(\mathrm{kmol} / \mathrm{h})\end{array}$} & \multicolumn{2}{|c|}{$\begin{array}{l}\text { Flujo DO } \\
(\mathrm{kmol} / \mathrm{h})\end{array}$} & \multicolumn{2}{|c|}{$\begin{array}{c}\text { Flujo MOO } \\
(\mathrm{kmol} / \mathrm{h})\end{array}$} & \multicolumn{2}{|c|}{$\begin{array}{l}\text { Flujo Glicerol } \\
(\mathrm{kmol} / \mathrm{h})\end{array}$} \\
\hline & & & $2 x n$ & Recti & To & $\mathrm{T}$ & M & & $\mathrm{AO}$ & M & & & & Dom & Total & Domo & Fond & Do & Fondo & Fo & Do & Fond & Dom & Fo & Domo \\
\hline & & To & Rang & ficac & tal & $\mathrm{O}$ & $\mathrm{eO}$ & & & $\mathrm{eO}$ & & & & o & & & o & mo & & nd & mo & o & o & ndo & \\
\hline & & tal & o & ión & & & $\mathrm{H}$ & & & $\mathrm{H}$ & & & & & & & & & & o & & & & & \\
\hline S1- & $1: 6.5$ & 14 & $4-17$ & 3 & 20 & 3 & 18 & 1.7 & 821 & 51 & 1 & 1000 & 91.652 & $4.8 \mathrm{E}-$ & 231. & 64.45 & 326. & 8.3 & $2.8 \mathrm{E}-14$ & 9.3 & 0 & 25.1 & $1.0 \mathrm{E}$ & 57. & $8.9 \mathrm{E}-$ \\
\hline 9 & & & & & & & & & & & & 0 & & 16 & 19 & & 70 & 5 & & & & 3 & -23 & 21 & 11 \\
\hline S2- & $1: 6.5$ & 14 & $4-17$ & 3 & 20 & 3 & 18 & 1.3 & 821 & 51 & 1.8 & 1000 & 86.224 & 3.7E- & 201. & 64.45 & 180. & 13. & $1.2 \mathrm{E}-13$ & 11. & 0 & 29.7 & $1.5 \mathrm{E}$ & 42. & 2.7E- \\
\hline 10 & & & & & & & & & & & & 0 & & 15 & 90 & & 99 & 77 & & 04 & & 77 & -22 & 95 & 10 \\
\hline S3- & $1: 6.5$ & 14 & $4-17$ & 3 & 20 & 3 & 18 & 1.7 & 821 & 55 & 1.8 & 1000 & 89.955 & $8.0 \mathrm{E}-$ & 221. & 64.45 & 170. & 10. & $3.9 \mathrm{E}-14$ & 10. & 0 & 26.8 & $2.1 \mathrm{E}$ & 52. & $1.1 \mathrm{E}-$ \\
\hline 8 & & & & & & & & & & & & 0 & & 16 & 62 & & 44 & 04 & & 69 & & 65 & -23 & 40 & 10 \\
\hline S4- & 1:6.5 & 14 & $4-17$ & 3 & 20 & 3 & 18 & 1.7 & 830 & 55 & 1.8 & 1000 & 89.968 & 7.9E- & 221. & 64.45 & 170. & 10. & $3.9 \mathrm{E}-14$ & 10. & 0 & 26.8 & $2.1 \mathrm{E}$ & 52. & $1.1 \mathrm{E}-$ \\
\hline 8 & & & & & & & & & & & & 0 & & 16 & 69 & & 38 & 03 & & 68 & & 53 & -23 & 44 & 10 \\
\hline S5- & 1:6.5 & 14 & $4-17$ & 3 & 20 & 3 & 18 & 1.7 & 830 & 55 & 1.8 & 1000 & 91.224 & 1.7E- & 228. & 64.45 & 339. & 8.7 & $2.2 \mathrm{E}-14$ & 9.6 & 0 & 25.6 & $5.6 \mathrm{E}$ & 55. & $2.4 \mathrm{E}-$ \\
\hline 6 & & & & & & & & & & & & & & 17 & 72 & & 78 & 76 & & 45 & & 65 & -25 & 91 & 12 \\
\hline S6- & 1:6.5 & 14 & $4-17$ & 3 & 20 & 2 & 18 & 1.7 & 830 & 55 & 1.8 & 1000 & 90.077 & $1.4 \mathrm{E}-$ & 222. & 64.45 & 165. & 9.9 & $3.3 \mathrm{E}-03$ & 10. & 0 & 27.1 & $1.8 \mathrm{E}$ & 52. & $5.8 \mathrm{E}-$ \\
\hline 1 & & & & & & & & & & & & & & 14 & 20 & & 28 & 19 & & 46 & & 06 & -21 & 51 & 12 \\
\hline S6- & 1:6.5 & 16 & $2-17$ & 1 & 20 & 2 & 18 & 1.7 & 830 & 55 & 1.8 & 1000 & 90.241 & 0.00 & 223. & 64.45 & 164. & 9.7 & $4.8 \mathrm{E}-03$ & 10. & $1 \mathrm{E}-$ & 26.9 & $7.2 \mathrm{E}$ & 52. & $3.8 \mathrm{E}-$ \\
\hline 10 & & & & & & & & & & & & & & 03 & 13 & & 72 & 54 & & 33 & 20 & 29 & -07 & 98 & 04 \\
\hline S7- & 1:15 & 16 & $2-17$ & 1 & 20 & 2 & 18 & 1.7 & 830 & 55 & 1.8 & 1000 & 98.596 & $4.5 \mathrm{E}-$ & 278. & 64.45 & 96.0 & 1.4 & 2.7E-04 & 2.4 & 9E- & 12.1 & $6.7 \mathrm{E}$ & 84. & $2.0 \mathrm{E}-$ \\
\hline 6 & & & & & & & & & & & & & & 05 & 87 & & 2 & 04 & & 04 & 23 & 13 & -08 & 08 & 04 \\
\hline S8- & 1:15 & 16 & $2-17$ & 1 & 20 & 2 & 18 & 1.7 & 830 & 55 & 4 & 1000 & 99.561 & $1.9 \mathrm{E}-$ & 289. & 64.45 & 123. & 0.4 & $5.1 \mathrm{E}-05$ & 0.9 & $1 \mathrm{E}-$ & 7.12 & $2.4 \mathrm{E}$ & 91. & $1.6 \mathrm{E}-$ \\
\hline 5 & & & & & & & & & & & & & & 05 & 65 & & 53 & 39 & & 53 & 23 & 6 & -08 & 48 & 04 \\
\hline S8- & 1:15 & 16 & $2-17$ & 1 & 20 & 2 & 18 & 3 & 830 & 55 & 4 & 1000 & 99.778 & $4.2 \mathrm{E}-$ & 294. & 64.45 & 104. & 0.2 & $3.5 \mathrm{E}-06$ & 0.3 & $6 \mathrm{E}-$ & 4.05 & $4.1 \mathrm{E}$ & 95. & 7.1E- \\
\hline 11 & & & & & & & & & & & & & & 06 & 58 & & 49 & 22 & & 53 & 25 & 1 & -09 & 37 & 05 \\
\hline S9- & 1:15 & 21 & $2-22$ & 1 & 25 & 2 & 23 & 3 & 830 & 55 & 4 & 1000 & 99.937 & $1.9 \mathrm{E}-$ & 297. & 64.45 & 329. & 0.0 & $6.3 \mathrm{E}-07$ & 0.1 & 0 & 2.38 & $1.7 \mathrm{E}$ & 97. & $5.8 \mathrm{E}-$ \\
\hline 5 & & & & & & & & & & & & & & 06 & 16 & & 61 & 6 & & 38 & & & -09 & 42 & 05 \\
\hline
\end{tabular}


Como sabemos en este sistema se están formando subproductos (dioleína y monoleína) provenientes de las reacciones consecutivas las cuales en algunas zonas su concentración se incrementa, como lo muestra la Figura 4.16. En este caso se muestra el perfil de concentración en la fase líquida de la simulación obtenida antes de cambiar el flujo de metanol que entra a la columna. De la etapa 1 a 4 la concentración de la monoleína y principalmente de la dioleína se incrementan debido a que comienzan a formarse, manteniéndose casi constante el resto de la zona reactiva. Es por ello que se decidió probar una segunda propuesta de configuración de columna de destilación reactiva (Figura 4.17) con un condensador total y dos corrientes de alimentación de metanol (CDR-CT2), esto con la intención de que se promueva convertir la monoleína y la dioleína conforme se van formando a lo largo de la zona reactiva.

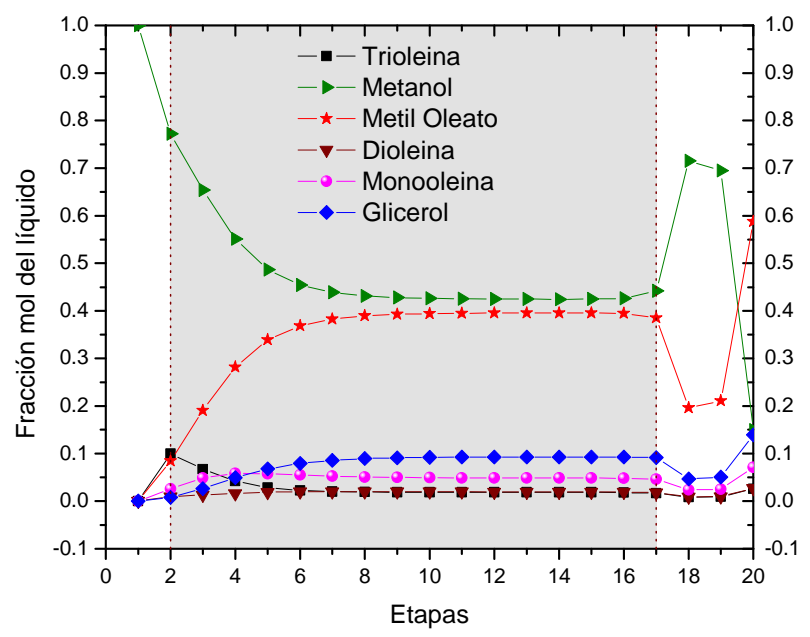

Figura 4.16. Perfiles de concentración en la fase líquida usando un flujo de metanol de 650 $\mathrm{kmol} / \mathrm{h}$.

Primero se varió el flujo de metanol de la corriente inferior localizada siempre en la etapa 23 (llamada corriente 2), moviendo la posición de otra corriente superior (conocida como corriente 1) con un flujo de $500 \mathrm{kmol} / \mathrm{h}$. Después, se fijo un flujo de metanol de $500 \mathrm{kmol} / \mathrm{h}$ en la corriente 2 y se varió el flujo y la posición de la corriente 1, hasta encontrar la conversión deseada. Se determinó, que usando un mayor flujo en la corriente 1 tiene mayor efecto sobre la conversión que usar un mayor flujo en la corriente 2, esto puede ser debido a que la mayor velocidad de reacción se lleva a cabo en las primeras etapas reactivas. 


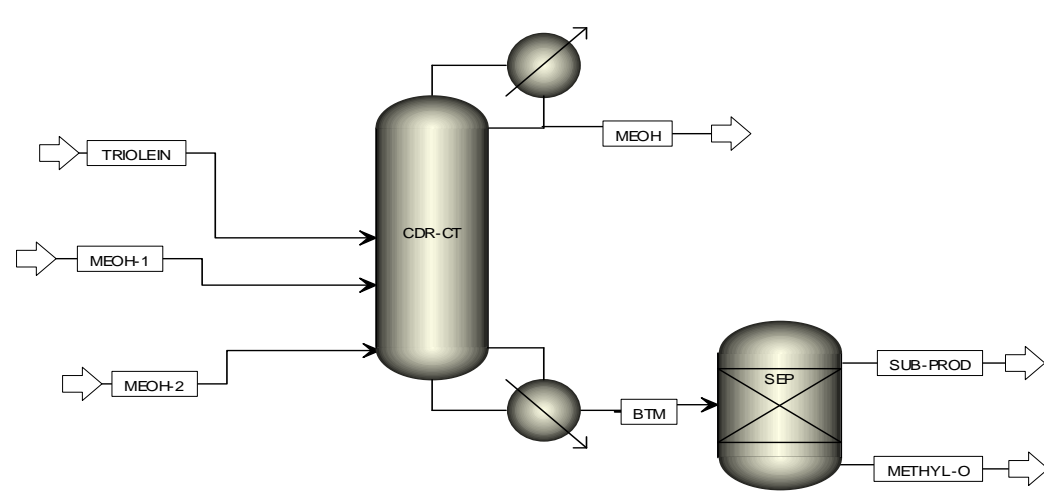

Figura 4.17. Diagrama de la segunda columna utilizada para la transesterificación (CDRCT2)

En la Tabla 4.7 se presentan los resultados de las simulaciones para la CDR-CT2 que al mover cada parámetro nos dieron mayor conversión de la trioleína, sin embargo, la forma en que se fue variando cada parámetro se presenta con más detalle en el Apéndice E. 
Tabla 4.7. Resultados condensados de las simulaciones para CDR-CT2. Manteniendo 25 etapas totales, 3 de agotamiento, 1 de rectificación, 21 etapas reactivas (2-22), 1000L de catalizador, una relación del rehervidor de 4 y la alimentación de la $\mathrm{TO}$ en la etapa 2 a $830^{\circ} \mathrm{C}$ y la $\mathrm{MeoH}$ a $55^{\circ} \mathrm{C}$.

\begin{tabular}{|c|c|c|c|c|c|c|c|c|c|c|c|c|c|c|c|c|c|c|}
\hline \multicolumn{9}{|c|}{ Entrada de simulación } & \multicolumn{10}{|c|}{ Salida de resultados } \\
\hline \multirow[t]{2}{*}{$\begin{array}{c}\text { Corrid } \\
\text { a }\end{array}$} & \multicolumn{2}{|c|}{ Flujo kmol/h } & \multicolumn{2}{|c|}{$\begin{array}{c}\text { Etapa } \\
\text { Alimentación } \\
\mathrm{MeOH}\end{array}$} & \multirow[t]{2}{*}{$\begin{array}{l}\text { Refl } \\
\text { ujo }\end{array}$} & \multirow[t]{2}{*}{$\begin{array}{l}\text { Conver } \\
\text { sión } \\
\text { del AO }\end{array}$} & \multicolumn{2}{|c|}{$\begin{array}{l}\text { Flujo de MO } \\
(\mathrm{kmol} / \mathrm{h})\end{array}$} & \multicolumn{2}{|c|}{ Temperatura $\left({ }^{\circ} \mathrm{C}\right)$} & \multicolumn{2}{|c|}{$\begin{array}{c}\text { Flujo de TO } \\
(\mathrm{kmol} / \mathrm{h})\end{array}$} & \multicolumn{2}{|c|}{$\begin{array}{l}\text { Flujo DO } \\
(\mathrm{kmol} / \mathrm{h})\end{array}$} & \multicolumn{2}{|c|}{$\begin{array}{c}\text { Flujo MOO } \\
(\mathrm{kmol} / \mathrm{h})\end{array}$} & \multicolumn{2}{|c|}{ Flujo Glic kmol/h } \\
\hline & $\begin{array}{l}\text { Corrien } \\
\text { te } 1\end{array}$ & $\begin{array}{l}\text { Corrien } \\
\text { te } 2\end{array}$ & $\begin{array}{l}\text { Corrien } \\
\text { te } 1\end{array}$ & $\begin{array}{l}\text { Corrien } \\
\text { te } 2\end{array}$ & & & Domo & Total & Domo & Fondo & Domo & Fondo & Fondo & Domo & $\begin{array}{c}\text { Fond } \\
\text { o }\end{array}$ & Domo & Fondo & Domo \\
\hline $1-3$ & 500 & 700 & 6 & 23 & 3 & 99.791 & $6.5 \mathrm{E}-06$ & 294.84 & 64.45 & 121.89 & 0.209 & $9.6 \mathrm{E}-06$ & 0.328 & $2 \mathrm{E}-24$ & 3.87 & $7.1 \mathrm{E}-09$ & 95.59 & $7.9 \mathrm{E}-05$ \\
\hline $1-7$ & 500 & 700 & 10 & 23 & 3 & 99.803 & $6.5 \mathrm{E}-06$ & 294.90 & 64.45 & 121.90 & 0.197 & $9.6 \mathrm{E}-06$ & 0.325 & $2 \mathrm{E}-24$ & 3.86 & 7.1E-09 & 95.62 & $7.9 \mathrm{E}-05$ \\
\hline $1-11$ & 500 & 800 & 13 & 23 & 3 & 99.803 & $5.6 \mathrm{E}-06$ & 295.13 & 64.45 & 114.48 & 0.196 & $6.7 \mathrm{E}-06$ & 0.296 & $1 \mathrm{E}-24$ & 3.68 & $5.9 \mathrm{E}-09$ & 95.82 & 7.6E-05 \\
\hline $2-2$ & 600 & 500 & 6 & 23 & 3 & 99.794 & $7.8 \mathrm{E}-06$ & 294.77 & 64.45 & 132.83 & 0.206 & $1.4 \mathrm{E}-05$ & 0.337 & $3 E-24$ & 3.94 & $8.8 \mathrm{E}-09$ & 95.52 & $8.3 \mathrm{E}-05$ \\
\hline 2-5 & 600 & 500 & 11 & 23 & 3 & 99.915 & $7.8 \mathrm{E}-06$ & 295.56 & 64.45 & 133.13 & 0.085 & $1.4 \mathrm{E}-05$ & 0.2903 & $2.6 \mathrm{E}-24$ & 3.60 & $8.8 \mathrm{E}-09$ & 96.02 & $8.3 \mathrm{E}-05$ \\
\hline 2-14 & 1000 & 500 & 12 & 23 & 3 & 99.951 & $4.1 \mathrm{E}-06$ & 297.28 & 64.45 & 104.80 & 0.049 & 3.5E-06 & 0.130 & $6 \mathrm{E}-25$ & 2.30 & $4.1 \mathrm{E}-09$ & 97.51 & $7.1 \mathrm{E}-05$ \\
\hline 2-19 & 1000 & 500 & 13 & 23 & 3 & 99.951 & 4.1E-06 & 297.28 & 64.45 & 104.80 & 0.049 & $3.5 \mathrm{E}-06$ & 0.130 & $6 \mathrm{E}-25$ & 2.31 & 4.1E-09 & 97.51 & 7.1E-05 \\
\hline $2-22$ & 1000 & 500 & 14 & 23 & 3 & 99.952 & $4.1 \mathrm{E}-06$ & 297.28 & 64.45 & 104.80 & 0.048 & 3.5E-06 & 0.131 & $6 \mathrm{E}-25$ & 2.31 & $4.1 \mathrm{E}-09$ & 97.50 & 7.1E-05 \\
\hline $3-1$ & 600 & 500 & 11 & 23 & 3.5 & 99.929 & $5.3 \mathrm{E}-06$ & 296.06 & 64.45 & 124.24 & 0.071 & 7.3E-06 & 0.241 & $1.3 \mathrm{E}-24$ & 3.2 & 5.7E-09 & 96.44 & 6.7E-05 \\
\hline
\end{tabular}


En la Tabla 4.8 se muestran las especificaciones finales de los parámetros de operación de las dos configuraciones de columna propuestas para la transesterificación.

Tabla 4.8. Especificaciones de diseño de los casos base utilizados para la transesterificación.

\begin{tabular}{|c|c|c|}
\hline Variable & CDR-CT1 & CDR-CT2 \\
\hline Presión de la columna & $1 \mathrm{bar}$ & 1 bar \\
\hline Número de etapas de totales & 25 & 25 \\
\hline Etapas de rectificación & 1 & 1 \\
\hline Etapas reactivas & $21($ de 2 a 22$)$ & 21 (de 2 a 22$)$ \\
\hline Etapas de agotamiento & 3 & 3 \\
\hline Relación de reflujo & $3(\mathrm{~mol})$ & 3.5 \\
\hline Relación del rehervidor & $4(\mathrm{~mol})$ & $4(\mathrm{~mol})$ \\
\hline Etapa de alimentación de trioleína & 2 & 2 \\
\hline Etapa de alimentación del metanol 1 & 23 & 11 \\
\hline Etapa de alimentación del metanol 2 & -- & 23 \\
\hline Alimentación de trioleína & $100 \mathrm{kmol} / \mathrm{h}$ (calentado a $830^{\circ} \mathrm{C}$ ) & $100 \mathrm{kmol} / \mathrm{h}$ (calentado a $\left.830^{\circ} \mathrm{C}\right)$ \\
\hline Alimentación del metanol 1 & $1500 \mathrm{kmol} / \mathrm{h}$ (calentado a $55^{\circ} \mathrm{C}$ ) & $600 \mathrm{kmol} / \mathrm{h}$ (calentado a $\left.55^{\circ} \mathrm{C}\right)$ \\
\hline Alimentación del metanol 2 & -- & $500 \mathrm{kmol} / \mathrm{h}$ (calentado a $55^{\circ} \mathrm{C}$ ) \\
\hline Retención de líquido por etapa & $1000(\mathrm{~L})$ & $1000(\mathrm{~L})$ \\
\hline Conversión de trioleína & 99.937 & 99.929 \\
\hline Flujo molar de MO en el fondo & $297.16 \mathrm{kmol} / \mathrm{h}$ & $296.06 \mathrm{kmol} / \mathrm{h}$ \\
\hline Flujo másico de $\mathrm{MO}$ en el fondo & $88105.5105 \mathrm{~kg} / \mathrm{h}$ & $87774.2925 \mathrm{~kg} / \mathrm{h}$ \\
\hline Carga térmica del condensador & $-47203.71 \mathrm{~kW}$ & $-28006.707 \mathrm{~kW}$ \\
\hline Carga térmica del rehervidor & $60640.2696 \mathrm{~kW}$ & $26853.0692 \mathrm{~kW}$ \\
\hline Temperatura del condensador & $64.45^{\circ} \mathrm{C}$ & $64.45^{\circ} \mathrm{C}$ \\
\hline Temperatura del rehervidor & $329.6122^{\circ} \mathrm{C}$ & $124.23^{\circ} \mathrm{C}$ \\
\hline Carga térmica total absoluta & $107843.97 \mathrm{~kW}$ & $54859.7762 \mathrm{~kW}$ \\
\hline Poder calórico total del biodiesel & $917765.734 \mathrm{~kW}$ & $914315.547 \mathrm{~kW}$ \\
\hline
\end{tabular}

De manera similar que en la esterificación, considerando que el poder calórico del biodiesel es de $37.5 \mathrm{MJ} / \mathrm{kg}$ (Billen et al., 2004), se calculó el poder calorífico total disponible del biodiesel producido. También, para este caso el poder calorífico disponible que da el biodiesel que se obtiene en cada columna es mucho mayor que la el poder calorífico requerido por el condensador y el rehervidor en cada columna, lo que valida la sustentabilidad del proceso. No obstante cabe decir que se requiere un estudio energético y de análisis de costos de operación a detalle para asegurar con más certeza la sustentabilidad del proceso. 
Al analizar la tabla anterior puede notarse la disminución en la energía requerida para llevar a cabo la reacción de transesterificación usando 2 corrientes de alimentación de metanol, ya que con una corriente necesitamos casi el doble de energía y la cantidad de metanol requerido es de $400 \mathrm{kmol} / \mathrm{h}$ más que cuando se usan 2 corrientes. Se probó usar 3 corrientes de alimentación de metanol pero no se encontró mayor beneficio.

En la Figura 4.18 se presentan los perfiles de composición en la fase líquida. Las concentraciones de los triglicéridos se mantienen muy bajas, debido al exceso de metanol que se encuentra a lo largo de toda la columna. La mayor concentración de la trioleína es donde se alimenta, posteriormente hay un decremento de esta, aunque aparentemente su consumo se da principalmente en las primeras etapas reactivas, son necesarias etapas adicionales para promover la conversión completa. En ambas figuras la fracción mol de la dioleína y la monoleína son cercanas a cero.

En la Figura 4.18a se muestra que la concentración del metil oleato y el glicerol tienen un mayor incremento de la etapa 2 a la 10, posteriormente el cambio es menos marcado en el resto de la zona reactiva, pero saliendo de esta zona se incrementa hasta llegar al rehervidor. El mayor cambio de la concentración del metanol se da de la etapa 24 a la 22 y sigue incrementando conforme sube la columna hasta salir puro en el condensador.

En la Figura 4.18b observamos dos zonas bien diferenciadas: la primera es de la etapa 2 a 13 y la segunda es de 14-24. En la primera zona se da el mayor cambio en la concentración de todos los componentes presentes, la aparición de los productos de las reacciones y el consumo de los productos de las mismas, en la etapa 14 las concentraciones del metil oleato y glicerol disminuyen y la del metanol aumenta, manteniéndose casi constante en la zona 2. Aquí la concentración del biodiesel en el fondo de la columna es menor porque la cantidad de metanol que tenemos en el fondo es mayor. 


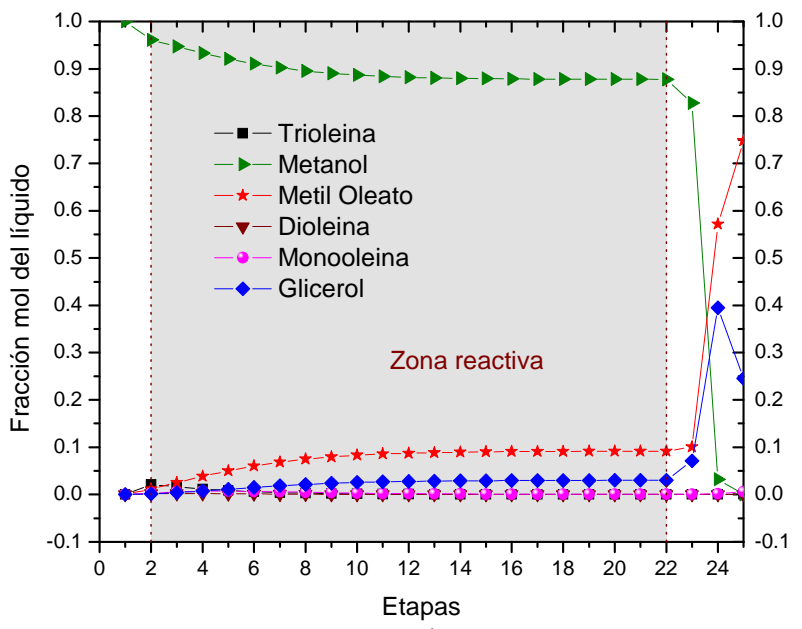

a)

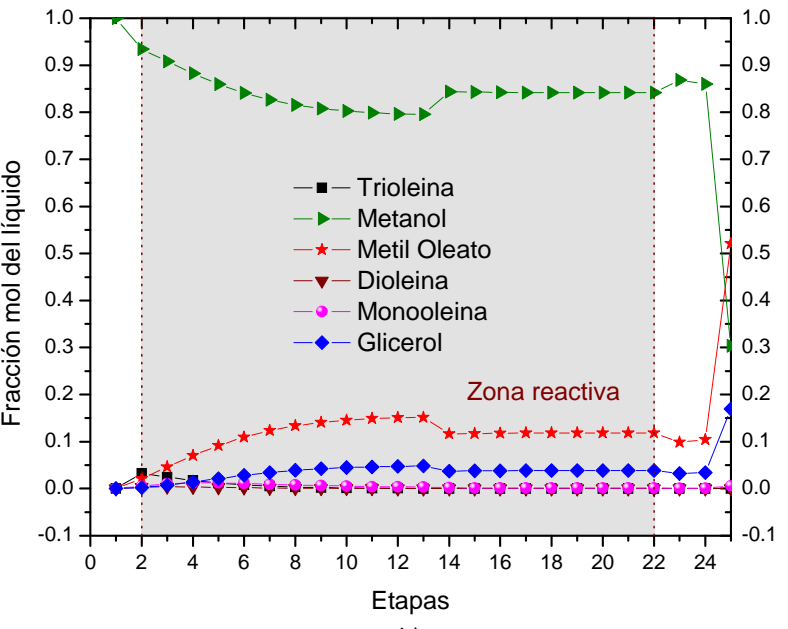

b)

Figura 4.18. Perfiles de composición en la fase líquida para cada columna. a) CDR-CT1, b) CDR-CT2.

En la Figura 4.19 se muestran los perfiles de composición en la fase vapor. En general la gran diferencia en temperaturas de ebullición entre los glicéridos y el metanol son los causantes de que este último se encuentre en mayor composición en la fase vapor.

En la Figura 4.19a se observa que la fracción mol del metanol es casi uno en las etapas 1-23 luego de estas etapas decrece hasta casi cero en el fondo de la columna, como consecuencia de la disminución hay un incremento en la fracción mol del glicerol y el metil oleato. Mientras que en la Figura 4.19b tenemos que la fase vapor es casi puro metanol en toda la columna y la fracción mol del resto de los componentes son casi cero.

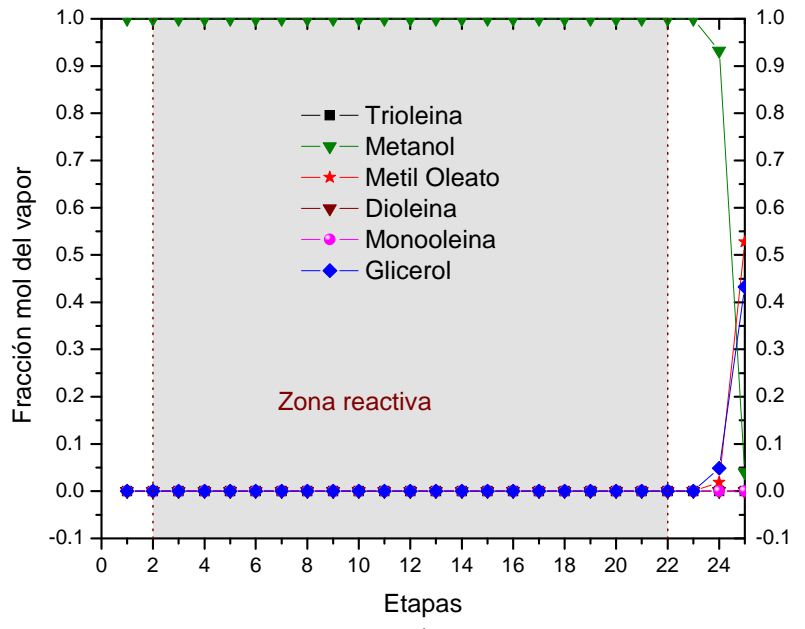

a)

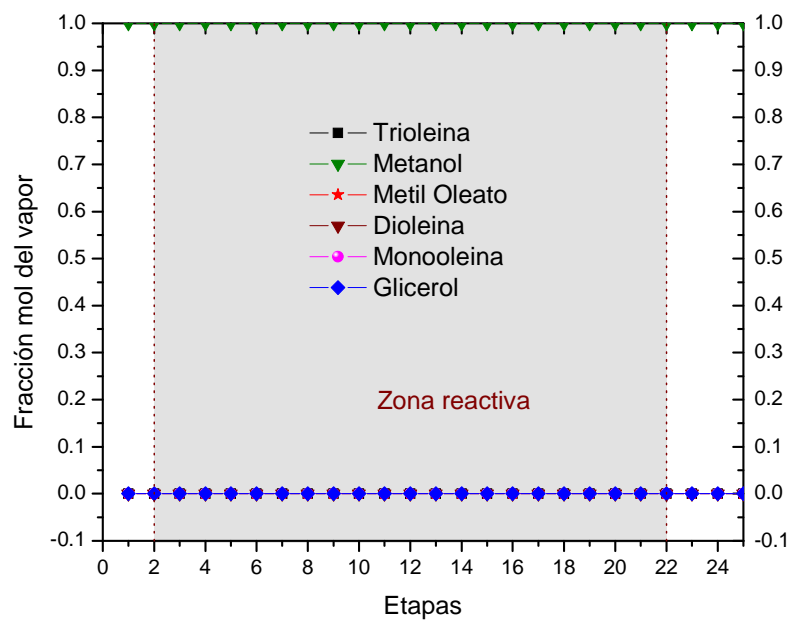

b)

Figura 4.19. Perfiles de composición en la fase vapor para cada columna. a) CDR-CT1, b) CDR-CT2. 
La Figura 4.20 presenta los perfiles de temperatura de las dos columnas. En la Figura 4.20a la temperatura es de $64.45^{\circ} \mathrm{C}$ en el condensador y en toda la zona reactiva se mantiene casi constante alrededor de $70^{\circ} \mathrm{C}$, en las últimas 3 etapas de la columna se incrementa considerablemente hasta $330^{\circ} \mathrm{C}$ aproximadamente. Mientras que en la Figura 4.20b la temperatura es más variable, en el condensador también es de $64.45^{\circ} \mathrm{C}$, pero en la zona reactiva tiene dos zonas marcadas: de la etapa 2 a 13 la temperatura tiende a incrementarse hasta $76^{\circ} \mathrm{C}$ aproximadamente, luego disminuye de la etapa 13 a la 14 esto es debido a que en la etapa 11 se está alimentando metanol en fase líquida, después, de la etapa 14 a la 22 se mantiene casi constante, luego disminuye $y$ se incrementa hasta $124^{\circ} \mathrm{C}$ aproximadamente. La diferencia en la temperatura del fondo de las columnas se debe a que la composición de las mezclas es diferente y por tanto la temperatura de mezcla lo es también. En la CDR-CT1 existe en su mayoría biodiesel y glicerol, mientras que en la CDR-CT2 existe también una cantidad considerable de metanol en el fondo de esta columna.

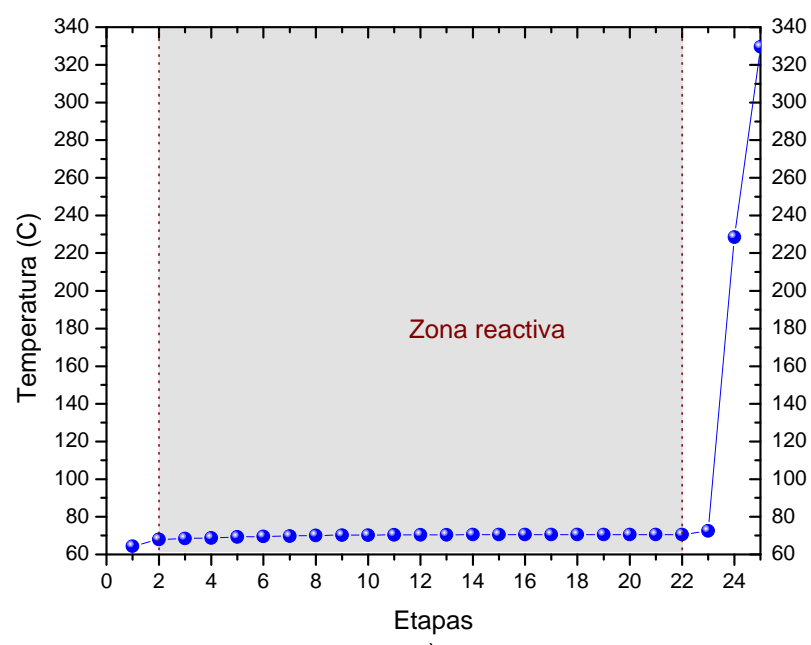

a)

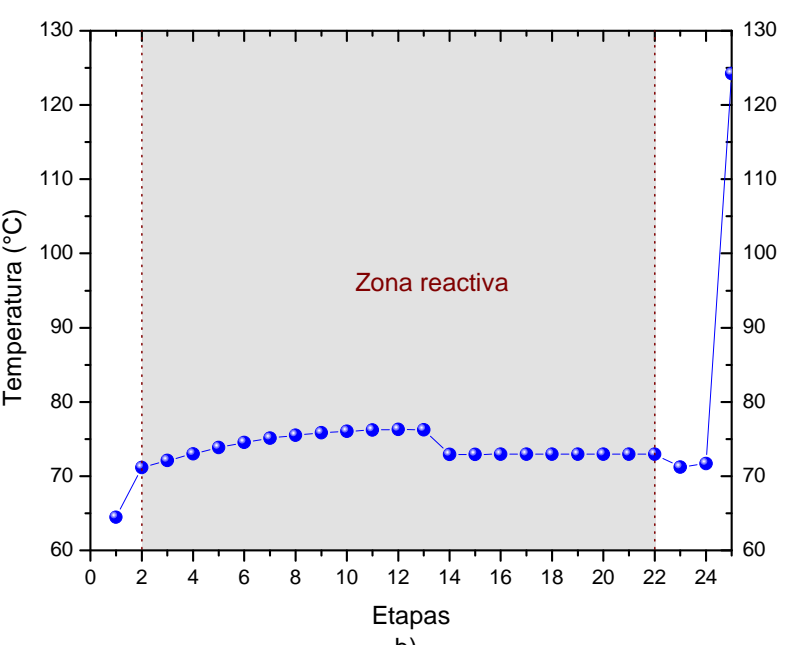

b)

Figura 4.20. Perfiles de temperatura en las diferentes columnas. a) CDR-CT1, b) CDR-CT2.

En la Figura 4.21 se muestra el perfil de velocidad de aparición de los productos y desaparición de los reactivos. Aquí vemos que el cambio más relevante de velocidad se da en las primeras etapas reactivas cerca de donde se alimenta la trioleína. El comportamiento de los perfiles de velocidad en las figuras a y b son similares, la máxima velocidad de formación del metil oleato se da en la etapa 3, la del glicerol es en la etapa 5 y la de la 
dioleína y monoleína se da en la etapa 2 en ambas columnas. Sin embargo, en términos generales la CDR-CT2 alcanza mayores velocidades de reacción, por ejemplo la velocidad máxima de formación del biodiesel es de $47 \mathrm{kmol} / \mathrm{h}$ en la CDR-CT1 y $52 \mathrm{kmol} / \mathrm{h}$ en la CDR-CT2. También, al observar la velocidad de reacción de la dioleína y la monoleína tenemos que la velocidad de formación máxima de la dioleína es superior en la CDR-CT1 $(8 \mathrm{kmol} / \mathrm{h})$ que en la CDR-CT2 (de $7 \mathrm{kmol} / \mathrm{h})$, mientras que para la monoleína es inversa, en la CDR-CT2 se alcanza una mayor velocidad de formación (12 kmol/h) que en la CDRCT1 (de $10 \mathrm{kmol} / \mathrm{h}$ ). Esto puede ser debido a que en la CDR-CT2 la desaparición de la dioleína es promovida por el metanol que entra en la parte intermedia de la columna al tiempo que este se va formando, mientras que en la CDR-CT1 la dioleína se forma más Zona reactivarápidamente que la velocidad en que desaparece.

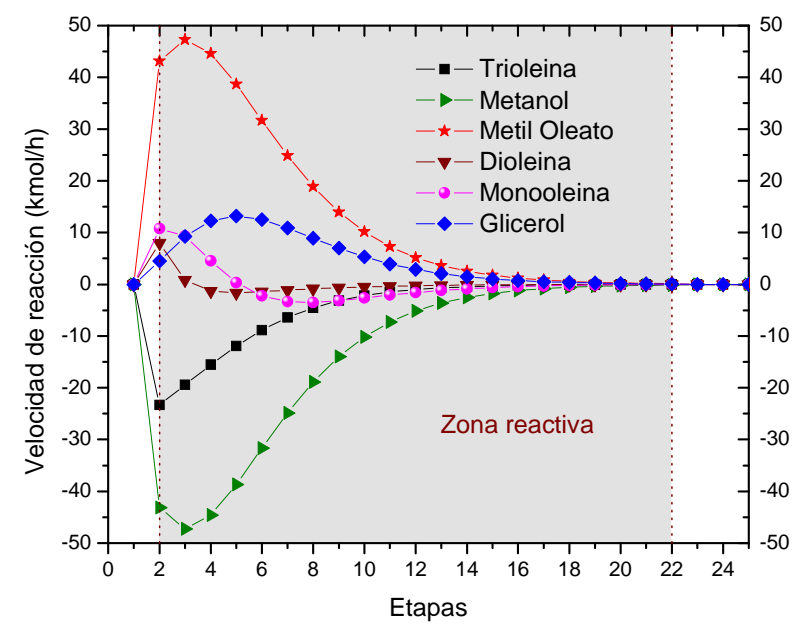

a)

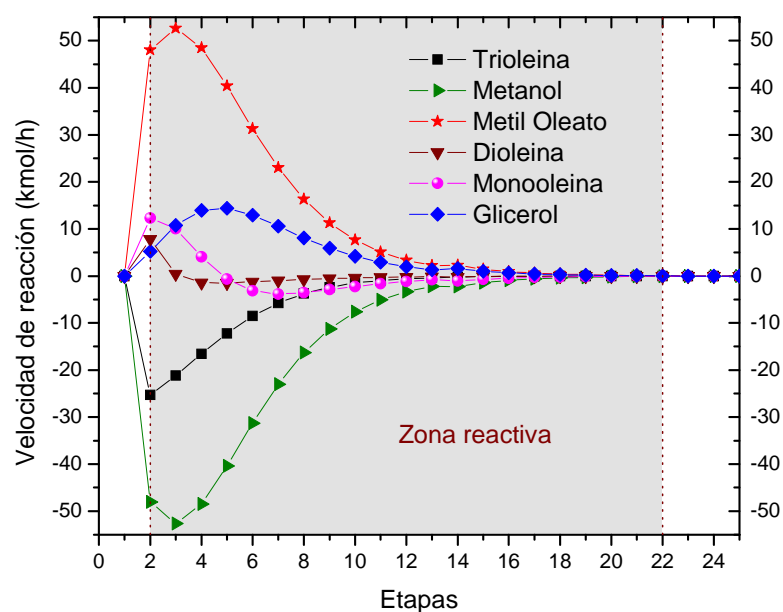

b)

Figura 4.217. Perfil de velocidad de reacción en cada columna. a) CDR-CT1, b) CDR-CT2.

En la Figura 4.22 se presentan los flujos molares del líquido y el vapor dentro de las columnas. Sabemos que a la CDR-CT1 se está alimentando un flujo mayor de metanol (15000 kmol/h) y debido al punto de ebullición de éste, en su mayoría se le encuentra en fase vapor, a su vez, esto genera la diferencia de flujos (1000 kmol/h aproximadamente) casi constante a lo largo de casi toda la columna. En la Figura 4.22b tenemos menos cantidad de flujo, ya que en total sólo se está alimentando $1100 \mathrm{kmol} / \mathrm{h}$ de metanol y la misma cantidad de trioleína que en la otra columna, y debido a que este flujo esta divido en dos corrientes, permite que los flujos de vapor y líquido sean similares en las etapas del 
fondo de la columna que es donde se localizan dichas corrientes, mientras que en la etapas superiores el flujo de vapor es mayor que la del liquido y esto porque en esa zona se está alimentando la trioleína y se están formando monoleína y dioleína que tienen puntos de ebullición mayores, y que por lo tanto elevan la temperatura global de esa zona, lo que provoca la vaporización principalmente del metanol.

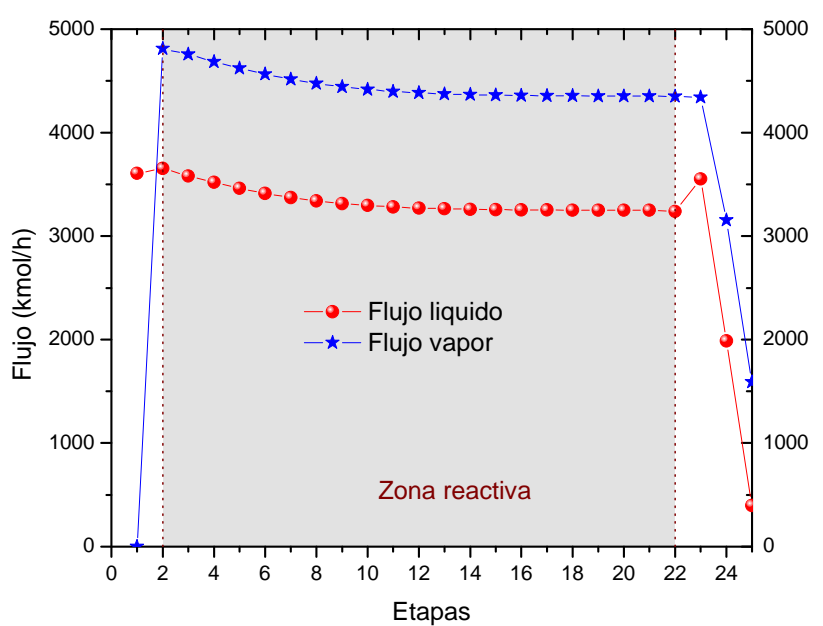

a)

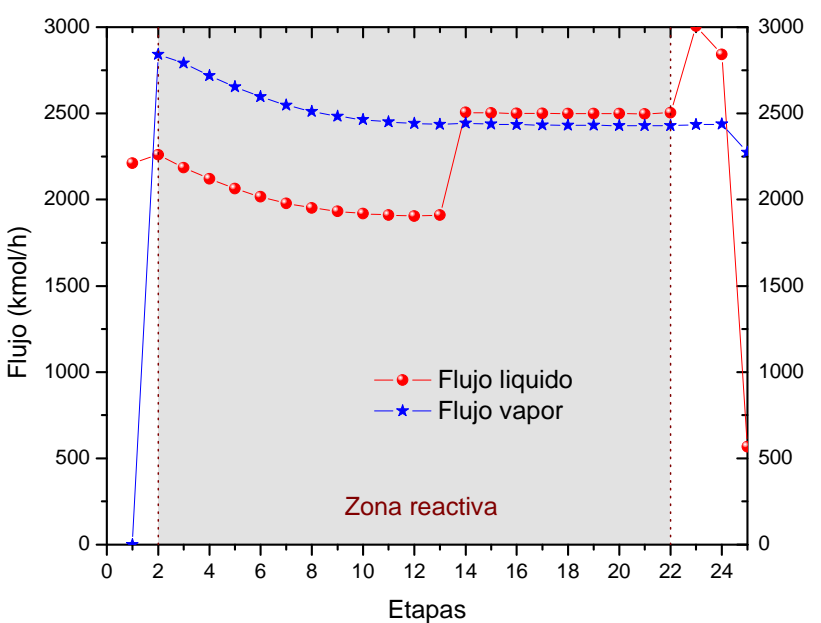

b)

Figura 4.2218. Perfiles de flujo de líquido y vapor en cada columna. a) CDR-CT1, b) CDRCT2.

En la Figura 4.23 se presenta el mapa de curvas residuales en términos de elemento de las columnas estudiadas para la reacción de transesterificación. Aquí vemos que en ningún caso obtenemos al biodiesel puro, esto debido a que tenemos exceso de metanol, sin embargo, para el caso de la CDR-CT1 se aprecia como la curva residual se dirige hacia el nodo de composición del metil oleato puro. En ambos casos se logra obtener en el destilado solo metanol $(\mathrm{WC}=1)$. 


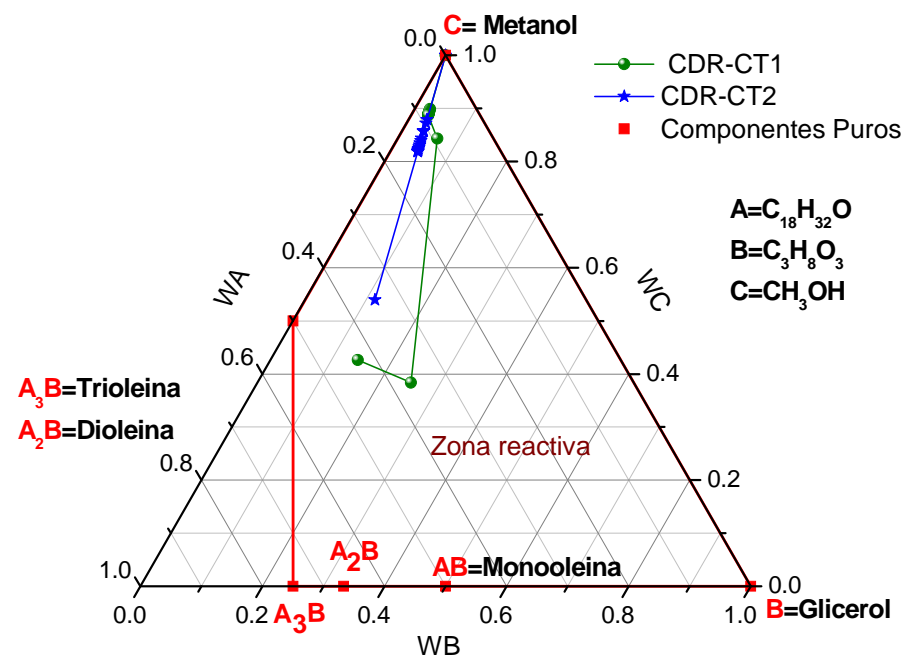

Figura 4.23. Mapa de Curvas residuales reactivos en términos de elemento de las diferentes columnas estudiadas para este sistema.

De forma similar que el sistema anterior, la selección del diseño se basó en alcanzar una conversión del 99.9\% de la trioleína y una pureza del 99.9\% de Metil Oleato en el fondo de la columna, y como un extra también en base a los valores de los parámetros finales se eligió la configuración más conveniente.

Con todo lo anterior queda claro que la columna que más nos conviene es la CDR-CT2 ya que se necesita menor energía para su operación y menor cantidad de metanol para lograr la conversión esperada del $99.928 \%$ de trioleína. 


\section{Capítulo 5}

\section{Proceso de Reacción-Separación Integrado}

Una vez obtenida la configuración de la columna que es adecuada para cada sistema reactivo, el siguiente paso es acoplar las dos operaciones para poder tratar aceites que contengan cantidades considerables de ácidos grasos libres (por ejemplo cualquier aceite que contengan $4.5 \%$ peso de ácidos grasos libres) los cuales son difíciles de tratar con el proceso convencional de producción de biodiesel.

\subsection{Proceso integrado}

El alto costo de producción del biodiesel ha sido y es el mayor obstáculo para su comercialización, su producción no podría ser posible si no fuera porque está exento de impuesto y subsidiado por el gobierno, ya que su costo de producción es mayor que la del diesel fósil. Se reporta que este alto costo se debe principalmente al costo generado en el tratamiento para obtener aceites vírgenes o lo suficientemente puros, con un contenido menor a $2.5 \%$ peso de ácidos grasos libres (Leung et al., 2010) para poderlos convertir a biodiesel usando los procesos convencionales. Se menciona que tan sólo, el costo para la refinación de los aceites abarca cerca del 80\% del costo total de producción del biodiesel (Lam et al., 2009). Es por ello que la materia prima para obtener el biodiesel se ha vuelto una variable crucial a tratar para lograr obtener biodiesel de menor costo. Entre las alternativas a este problema está generar tecnologías que puedan tratar materias primas como lo son los aceites quemados o sin refinar que contienen entre 0.5 y $15 \%$ peso de ácidos grasos libres (Lam et al., 2010).

Por lo anterior, el objetivo de este capítulo es la integración de las columnas antes estudiadas y encontrar los parámetros óptimos para su operación, de forma que podamos 
tratar aceites refinados y aceites con altas impurezas (como los aceites quemados). Para ello necesitamos dos columnas: la columna de destilación reactiva sin condensador (CDR-SC) para llevar a cabo la reacción de esterificación y una columna de destilación reactiva con condensador total con dos corrientes de metanol (CDR-CT2) para llevar a cabo la reacción de transesterificación.

El proceso considera que en la primera columna por la parte superior entra trioleína y ácido oleico $(\mathrm{AO}+\mathrm{TO})$ en cierta proporción de forma tal que se incorpore a la simulación un rango de composición de dicha corriente representando diferentes tipos de aceites. En la parte inferior de la columna se tiene la alimentación de metanol (MeOH-1). En esta columna se buscó que todo el ácido oleico reaccione, formándose así el primer biodiesel y el agua correspondiente que se forma se separa completamente, un flash. La corriente del fondo lleva biodiesel, trioleína y un poco de metanol, ya que este ultimo entra en exceso a la columna para poder alcanzar una conversión del ácido del 99.9\% de la cantidad que se alimente, ya que debido a la presencia de trioleína las condiciones de operación de la columna se modifican un poco, entre ellas la razón de alimentación de $\mathrm{AO} / \mathrm{MeOH}$ ya no puede ser 1:1. Se intento poner un separador para esta corriente para separar el primer biodiesel, pero no se encontró una buena separación pues es un poco difícil separar esta mezcla, entonces se probó introducir esta corriente directamente en la CDR-CT, lo cual no presento alteración del proceso, al contrario el metanol que aún no había reaccionado podría ayudar en la reacción que se lleva a cabo en esta columna. Por tanto, a la CDR-CT entran trioleína, metil oleato y metanol que no ha reaccionado en la CDR-SC, además, a esta misma se alimentan dos corrientes de metanol, en esta columna se busca que toda la trioleína se transforme a biodiesel. A la salida de la CDR-CT tenemos el biodiesel, glicerol, dioleína y monoleína que queda en el fondo. Para separar dicha corriente se propuso un separador para obtener el biodiesel puro.

Entonces el diagrama final del proceso integrado se presenta a continuación: 


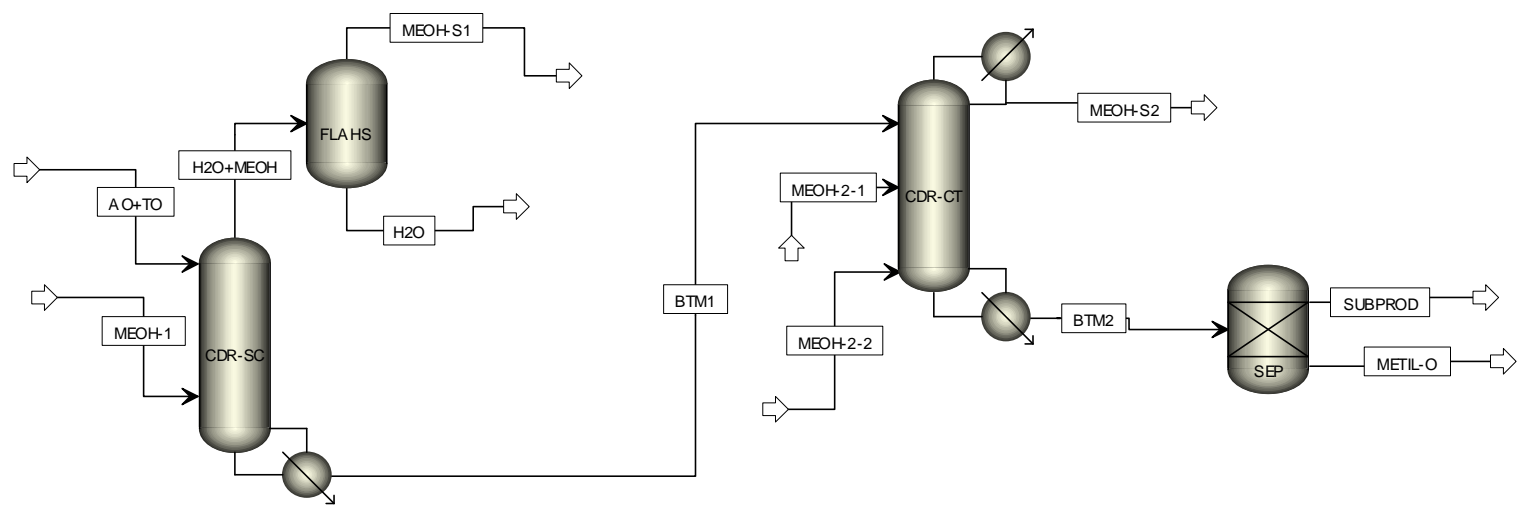

Figura 5.1. Diagrama global del proceso de producción de biodiesel.

Primero que nada se arranco la simulación con las condiciones finales de operación de las columnas obtenidas a las secciones anteriores proponiendo una razón de alimentación de trioleína/ácido oleico de 10:90. Posteriormente, comenzó a variarse esta razón como se muestra en la Tabla 5.1 y cuando era necesario se modificaban algunos parámetros. La Tabla 5.2 presenta los resultados que se obtienen en la CDR-CT donde se lleva a cabo la transesterificación ya que al modificar los valores de la columna de esterificación se tenía que modifica las condiciones de operación de la columna de transesterificación para que esta siguiera funcionando correctamente. Sólo se puede simular hasta una razón de alimentación de 87:13, aunque a esta razón la simulación presenta ya muchas dificultades, esto puede ser debido a que existen dificultades con el equilibrio termodinámico. Es por ello que decidimos simular un posible aceite que contenga un $4.5 \%$ peso de ácidos grasos libres (86:14 TO/AO), como ejemplo el aceite de oliva ya que este contiene la Trioleina en mayor proporción y por consecuencia el ácido oleico. Ya con esta razón (86:14 TO/AO), se busco lograr un mejor funcionamiento de la CDR-CT donde se está llevando a cabo las reacciones de transesterificación de la trioleína, esto se presenta en la Tabla 5.3. 
Capítulo 5: Proceso de Reacción-Separación Integrado

Tabla 5.1. Resultados condensados de las simulaciones para CDR-SC donde se lleva a cabo la esterificación. Manteniendo 19 etapas totales, 2 de agotamiento, 2 de rectificación, 15 etapas reactivas (3-17) y la alimentación de la $\mathrm{TO}$ en la etapa 3 a $326^{\circ} \mathrm{C}$ y la $\mathrm{MeoH}$ a $55^{\circ} \mathrm{C}$.

\begin{tabular}{|c|c|c|c|c|c|c|c|c|c|c|c|c|c|c|c|c|c|c|c|c|}
\hline \multirow{3}{*}{$\begin{array}{l}\text { Corr } \\
\text { ida }\end{array}$} & \multicolumn{9}{|c|}{ Entrada de simulación } & \multicolumn{11}{|c|}{ Salida de resultados } \\
\hline & \multicolumn{2}{|c|}{ Fracción masa } & \multirow{2}{*}{$\begin{array}{c}\text { Razón } \\
\text { TO/AO } \\
\text { (kmol/ } \\
\text { h) }\end{array}$} & \multirow{2}{*}{$\begin{array}{l}\text { Re } \\
\text { he } \\
\text { rvi } \\
\text { do } \\
r\end{array}$} & \multirow{2}{*}{$\begin{array}{c}\text { Re } \\
\text { fluj } \\
\circ\end{array}$} & \multirow{2}{*}{$\begin{array}{c}\text { Flujo } \\
\text { de } \\
\mathrm{MeO} \\
\mathrm{H} \\
(\mathrm{kmo} \\
1 / \mathrm{h})\end{array}$} & \multirow{2}{*}{$\begin{array}{l}\text { Cata } \\
\text { lizad } \\
\text { or } \\
(\mathrm{Kg})\end{array}$} & \multicolumn{2}{|c|}{$\begin{array}{c}\text { Flujo de MO } \\
(\mathrm{kmol} / \mathrm{h})\end{array}$} & \multicolumn{2}{|c|}{$\begin{array}{l}\text { Temperatura } \\
\text { CDR-SC }\left({ }^{\circ} \mathrm{C}\right)\end{array}$} & \multicolumn{2}{|c|}{$\begin{array}{c}\text { Flujo de AO } \\
(\mathrm{kmol} / \mathrm{h})\end{array}$} & \multicolumn{2}{|c|}{$\begin{array}{c}\text { Flujo de TO } \\
(\mathrm{kmol} / \mathrm{h})\end{array}$} & \multirow{2}{*}{$\begin{array}{c}\text { Conver } \\
\text { sión } \\
\text { del AO }\end{array}$} & \multicolumn{2}{|c|}{$\begin{array}{c}\text { Temperatura CD } \\
\left({ }^{\circ} \mathrm{C}\right)\end{array}$} & \multicolumn{2}{|c|}{$\begin{array}{l}\text { Flujo de Agua } \\
(\mathrm{kmol} / \mathrm{h})\end{array}$} \\
\hline & TO & $\mathrm{AO}$ & & & & & & Fondo & Domo & Domo & Fondo & Domo & Fondo & $\begin{array}{c}\text { Dom } \\
\text { o }\end{array}$ & Fondo & & Domo & Fondo & Domo & $\begin{array}{c}\text { Fond } \\
\mathrm{o}\end{array}$ \\
\hline S1-1 & 0.258 & 0.742 & $10: 90$ & 2 & 0.5 & 90 & 1000 & & & & & & & & & & & & & \\
\hline S1-2 & 0.258 & 0.742 & $10: 90$ & 2 & 0.7 & 90 & 1000 & 89.950 & 0.0003 & 117.75 & 349.16 & 0.049 & 0.0006 & 10.0 & $1.7 \mathrm{E}-06$ & 89.950 & 99.64 & 66.86 & 89.94 & 66.8 \\
\hline S1-3 & 0.439 & 0.561 & $20: 80$ & 2 & 0.7 & 80 & 1000 & 79.938 & 0.0031 & 136.78 & 355.98 & 0.055 & 0.0038 & 19.9 & $1.6 \mathrm{E}-05$ & 79.941 & 99.65 & 66.22 & 79.93 & 66.2 \\
\hline S1-4 & 0.573 & 0.427 & $30: 70$ & 1.8 & 0.7 & 70 & 1000 & 69.933 & 0.0093 & 150.45 & 364.06 & 0.047 & 0.0099 & 29.9 & $4.8 \mathrm{E}-05$ & 69.943 & 99.65 & 66.06 & 69.94 & 66.0 \\
\hline S1-5 & 0.676 & 0.324 & $40: 60$ & 0.8 & 0.1 & 70 & 1000 & 55.414 & $2.9 \mathrm{E}-08$ & 100.02 & 197.55 & 4.586 & $6.6 \mathrm{E}-06$ & 39.9 & 4.1E-05 & 55.414 & 99.64 & 76.26 & 54.95 & 76.2 \\
\hline S1-6 & 0.758 & 0.242 & $50: 50$ & 0.8 & 0.1 & 130 & 1000 & 50.000 & $3.1 \mathrm{E}-08$ & 94.13 & 137.70 & 0.00 & $3.5 \mathrm{E}-09$ & 50.0 & $1.9 \mathrm{E}-06$ & 50.000 & 99.64 & 64.21 & 49.99 & 64.2 \\
\hline S1-7 & 0.825 & 0.175 & $60: 40$ & 0.8 & 0.1 & 70 & 1000 & 40.000 & 7.3E-08 & 99.58 & 173.95 & 0.0003 & $6.5 \mathrm{E}-08$ & 59.9 & $7.4 \mathrm{E}-05$ & 40.000 & 99.64 & 64.30 & 39.99 & 64.3 \\
\hline S1-8 & 0.88 & 0.12 & $30: 70$ & 0.8 & 0.1 & 70 & 1000 & 30.000 & 2.4E-08 & 98.68 & 165.72 & 0.0001 & $6.3 \mathrm{E}-09$ & 69.9 & $1.6 \mathrm{E}-05$ & 30.000 & 99.64 & 64.23 & 30.00 & 64.2 \\
\hline S1-9 & 0.926 & 0.074 & $20: 80$ & 0.8 & 0.1 & 70 & 1000 & 20.000 & $8.3 \mathrm{E}-09$ & 98.63 & 158.64 & 0.0002 & $1.6 \mathrm{E}-09$ & 79.9 & $7.8 \mathrm{E}-06$ & 20.000 & 99.648 & 64.23 & 19.99 & 64.2 \\
\hline $\begin{array}{l}\text { S1- } \\
10\end{array}$ & 0.947 & 0.053 & $15: 85$ & 0.8 & 0.1 & 70 & 1000 & 15.000 & 4.5E-09 & 99.26 & 155.56 & 0.0004 & $1.2 \mathrm{E}-09$ & 84.9 & $8.6 \mathrm{E}-06$ & 20.000 & 99.64 & 64.25 & 14.99 & 64.2 \\
\hline $\begin{array}{l}\text { S1- } \\
11\end{array}$ & 0.947 & 0.053 & $15: 85$ & 0.8 & 0.1 & 70 & 900 & 15.000 & 4.3E-09 & 99.26 & 155.56 & 0.0005 & $1.3 \mathrm{E}-09$ & 84.9 & $8.9 \mathrm{E}-06$ & 15.000 & 99.64 & 64.25 & 14.98 & 64.2 \\
\hline $\begin{array}{l}\text { S1- } \\
12\end{array}$ & 0.947 & 0.053 & $15: 85$ & 0.8 & 0.1 & 70 & 800 & 14.999 & 4.1E-09 & 99.26 & 155.56 & 0.0006 & $1.3 \mathrm{E}-09$ & 84.9 & $9.2 \mathrm{E}-06$ & 14.999 & 99.64 & 64.25 & 14.98 & 64.2 \\
\hline $\begin{array}{l}\text { S1- } \\
13\end{array}$ & 0.951 & 0.049 & $14: 86$ & 0.8 & 0.1 & 70 & 800 & 13.999 & $3.1 \mathrm{E}-09$ & 99.48 & 154.98 & 0.0008 & $1.4 \mathrm{E}-09$ & 85.9 & $1.0 \mathrm{E}-05$ & 13.999 & 99.64 & 64.28 & 13.97 & 64.2 \\
\hline $\begin{array}{l}\text { S1- } \\
14\end{array}$ & 0.955 & 0.045 & $13: 87$ & 0.8 & 0.1 & 70 & 900 & 12.999 & 1.7E-09 & 99.76 & 154.41 & 0.0010 & $1.5 \mathrm{E}-09$ & 86.9 & $1.2 \mathrm{E}-05$ & 12.999 & 99.64 & 64.41 & 12.96 & 64.4 \\
\hline
\end{tabular}


Tabla 5.2. Resultados condensados de las simulaciones para CDR-CT donde se lleva a cabo la transesterificación, conforme varia los parámetros de la columna de esterificación. Manteniendo 25 etapas totales, 3 de agotamiento, 1 de rectificación, 21 etapas reactivas (2-22), 1000L de catalizador, una relación del rehervidor de 4 y la alimentación de la $\mathrm{TO}$ en la etapa 2 a $830^{\circ} \mathrm{C} \mathrm{y} \mathrm{la} \mathrm{MeoH}$ a $55^{\circ} \mathrm{C}$, un flujo de $500 \mathrm{kmol} / \mathrm{h}$ de la corriente de metanol en la etapa 23.

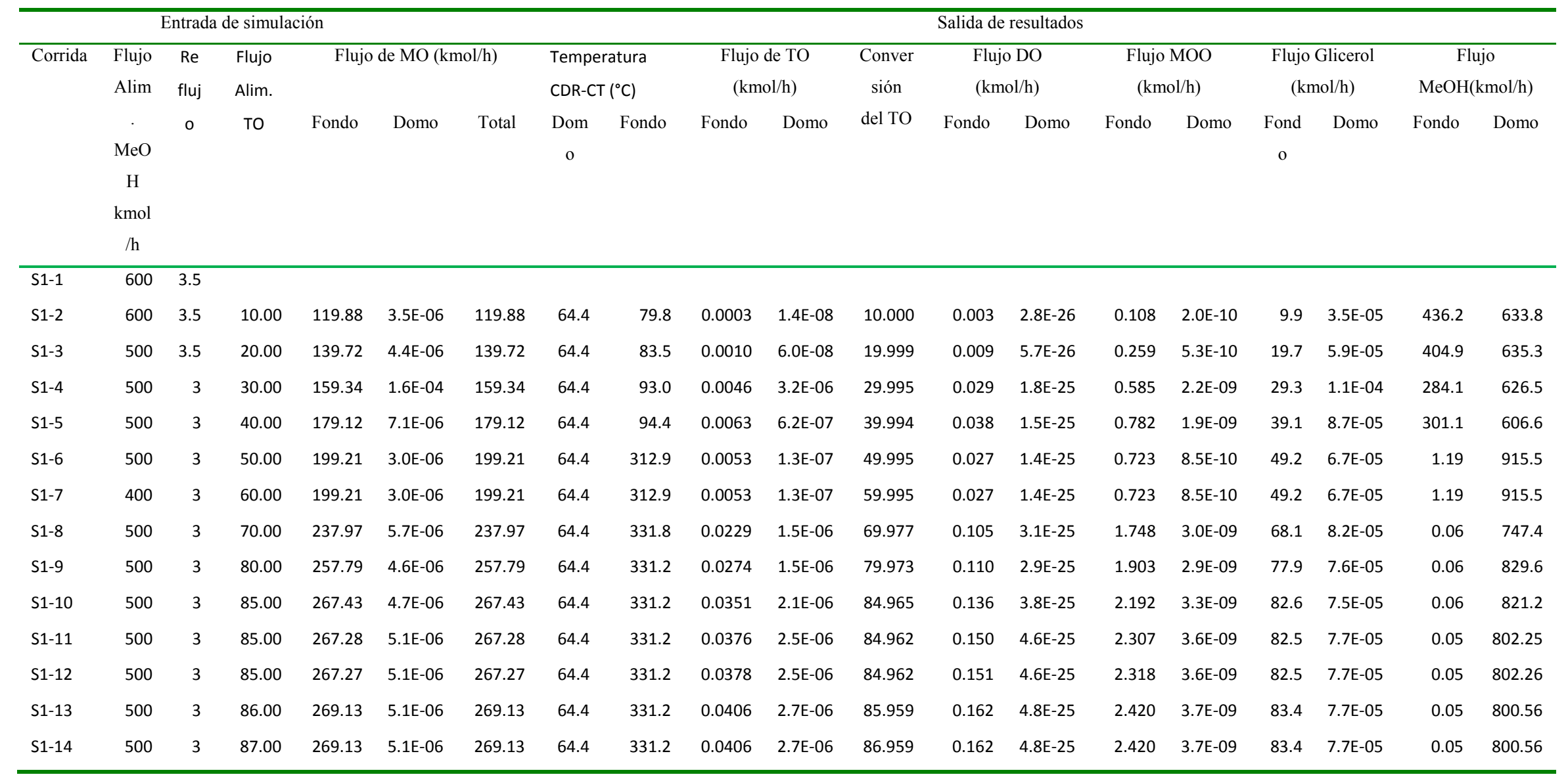


Tabla 5.3. Resultados condensados de las simulaciones para CDR-CT donde se lleva a cabo la transesterificación. Manteniendo los parámetros de CDR-SC constantes, 25 etapas totales, 3 de agotamiento, 1 de rectificación, 21 etapas reactivas (2-22), 1000L de catalizador, una relación del rehervidor de 4 y la alimentación de la $\mathrm{TO}$ en la etapa 2 a $830^{\circ} \mathrm{C}$ y la $\mathrm{MeoH}$ a $55^{\circ} \mathrm{C}$, un flujo de $500 \mathrm{kmol} / \mathrm{h}$ de la corriente de metanol en la etapa 23.

\begin{tabular}{|c|c|c|c|c|c|c|c|c|c|c|c|c|c|c|c|c|c|c|c|c|}
\hline \multicolumn{6}{|c|}{ Entrada de simulación } & \multicolumn{15}{|c|}{ Salida de resultados } \\
\hline \multirow[t]{2}{*}{$\begin{array}{l}\text { Corr } \\
\text { ida }\end{array}$} & \multirow{2}{*}{$\begin{array}{l}\text { Flujo } \\
\text { Alim. } \\
\mathrm{MeOH} \\
\mathrm{kmol} / \mathrm{h}\end{array}$} & \multirow{2}{*}{$\begin{array}{l}\text { Re } \\
\text { he } \\
\text { rvi }\end{array}$} & \multirow{2}{*}{$\begin{array}{c}\text { Re } \\
\text { fluj } \\
\text { o }\end{array}$} & \multirow{2}{*}{$\begin{array}{l}\text { Flujo } \\
\text { Alim. } \\
\text { TO }\end{array}$} & \multicolumn{3}{|c|}{ Flujo de $\mathrm{MO}(\mathrm{kmol} / \mathrm{h})$} & \multicolumn{2}{|c|}{$\begin{array}{l}\text { Temperatura } \\
\text { CDR-CT }\left({ }^{\circ} \mathrm{C}\right)\end{array}$} & \multicolumn{2}{|c|}{$\begin{array}{c}\text { Flujo de TO } \\
(\mathrm{kmol} / \mathrm{h})\end{array}$} & \multirow{2}{*}{$\begin{array}{c}\text { Conver } \\
\text { sión } \\
\text { del TO }\end{array}$} & \multicolumn{2}{|c|}{$\begin{array}{l}\text { Flujo DO } \\
(\mathrm{kmol} / \mathrm{h})\end{array}$} & \multicolumn{2}{|c|}{$\begin{array}{c}\text { Flujo MOO } \\
(\mathrm{kmol} / \mathrm{h})\end{array}$} & \multicolumn{2}{|c|}{$\begin{array}{l}\text { Flujo Glicerol } \\
(\mathrm{kmol} / \mathrm{h})\end{array}$} & \multicolumn{2}{|c|}{$\begin{array}{c}\text { Flujo } \\
\mathrm{MeOH}(\mathrm{kmol} / \mathrm{h})\end{array}$} \\
\hline & & & & & Fondo & Domo & Total & $\begin{array}{l}\text { Dom } \\
\text { o }\end{array}$ & $\begin{array}{l}\text { Fond } \\
\text { o }\end{array}$ & Fondo & Domo & & Fondo & Domo & Fondo & Domo & $\begin{array}{c}\text { Fond } \\
\text { o }\end{array}$ & Domo & Fondo & Domo \\
\hline \multirow[t]{2}{*}{ S2-1 } & 400 & 3.5 & 3 & 86.00 & 268.38 & $7.1 \mathrm{E}-06$ & 268.38 & 64.4 & 331. & 0.060 & $5.4 \mathrm{E}-06$ & 85.940 & 0.24 & $1.0 \mathrm{E}-24$ & 2.97 & $5.5 \mathrm{E}-09$ & 82.7 & $8.4 \mathrm{E}-05$ & 0.06 & 701.31 \\
\hline & & & & & & & & & 2 & & & & & & & & 4 & & & \\
\hline \multirow[t]{2}{*}{ S2-2 } & 500 & 3.5 & 3 & 86.00 & 269.22 & $5.1 \mathrm{E}-06$ & 269.22 & 64.4 & 330. & 0.039 & 2.7E-06 & 85.961 & 0.15 & $4.8 \mathrm{E}-25$ & 2.36 & $3.8 \mathrm{E}-09$ & 83.4 & 7.7E-05 & 0.08 & 800.44 \\
\hline & & & & & & & & & 7 & & & & & & & & 5 & & & \\
\hline \multirow[t]{2}{*}{ S2-3 } & 400 & 3 & 3 & 86.00 & 268.49 & 7.1E-06 & 268.49 & 64.4 & 330. & 0.058 & $5.4 \mathrm{E}-06$ & 85.942 & 0.22 & $1.0 \mathrm{E}-24$ & 2.89 & $5.5 \mathrm{E}-09$ & 82.8 & $8.4 \mathrm{E}-05$ & 0.10 & 701.15 \\
\hline & & & & & & & & & 6 & & & & & & & & 3 & & & \\
\hline \multirow[t]{2}{*}{ S2-4 } & 500 & 3 & 3 & 86.00 & 269.27 & $5.1 \mathrm{E}-06$ & 269.27 & 64.4 & 329. & 0.038 & 2.7E-06 & 85.962 & 0.15 & $4.9 \mathrm{E}-25$ & 2.32 & $3.8 \mathrm{E}-09$ & 83.5 & 7.7E-05 & 0.15 & 800.32 \\
\hline & & & & & & & & & 8 & & & & & & & & 0 & & & \\
\hline \multirow[t]{2}{*}{ S2-5 } & 400 & 2.5 & 3 & 86.00 & 268.56 & $7.1 \mathrm{E}-06$ & 268.56 & 64.4 & 329. & 0.056 & $5.4 \mathrm{E}-06$ & 85.944 & 0.21 & $1.0 \mathrm{E}-24$ & 2.84 & $5.5 \mathrm{E}-09$ & 82.8 & $8.4 \mathrm{E}-05$ & 0.21 & 700.97 \\
\hline & & & & & & & & & 2 & & & & & & & & 9 & & & \\
\hline \multirow[t]{2}{*}{ S2-6 } & 500 & 2.5 & 3 & 86.00 & 269.31 & $5.1 \mathrm{E}-06$ & 269.31 & 64.4 & 326. & 0.038 & 2.7E-06 & 85.962 & 0.14 & $4.9 \mathrm{E}-25$ & 2.29 & $3.8 \mathrm{E}-09$ & 83.5 & 7.7E-05 & 0.38 & 800.06 \\
\hline & & & & & & & & & 9 & & & & & & & & 3 & & & \\
\hline \multirow[t]{2}{*}{ S2-7 } & 400 & 2.5 & 2.5 & 86.00 & 267.57 & $1.3 \mathrm{E}-05$ & 267.57 & 64.4 & 288. & 0.092 & 1.7E-05 & 85.908 & 0.31 & $3.7 \mathrm{E}-24$ & 3.52 & $1.2 \mathrm{E}-08$ & 82.0 & $1.1 \mathrm{E}-04$ & 3.85 & 698.32 \\
\hline & & & & & & & & & 5 & & & & & & & & 7 & & & \\
\hline \multirow[t]{2}{*}{ S2-8 } & 500 & 2.5 & 2.5 & 86.00 & 268.61 & $9.6 \mathrm{E}-06$ & 268.61 & 64.4 & 300. & 0.055 & $8.6 \mathrm{E}-06$ & 85.945 & 0.21 & $1.7 \mathrm{E}-24$ & 2.81 & $7.8 \mathrm{E}-09$ & 82.9 & $1.0 \mathrm{E}-04$ & 2.68 & 798.45 \\
\hline & & & & & & & & & 0 & & & & & & & & 3 & & & \\
\hline \multirow[t]{2}{*}{ S2-9 } & 400 & 2.5 & 3.5 & 86.00 & 269.22 & 4.2E-06 & 269.22 & 64.4 & 327. & 0.040 & $2.1 \mathrm{E}-06$ & 85.960 & 0.15 & 3.7E-25 & 2.35 & $3.0 \mathrm{E}-09$ & 83.4 & $6.5 \mathrm{E}-05$ & 0.34 & 700.18 \\
\hline & & & & & & & & & 3 & & & & & & & & 6 & & & \\
\hline
\end{tabular}


Las especificaciones finales de las columnas para llevar a cabo el proceso integrado para la producción completa del biodiesel se presenta en la Tabla 5.4.

Tabla 5.4. Especificaciones finales de los casos base usados en el proceso global de producción de biodiesel.

\begin{tabular}{|c|c|c|}
\hline Variable & CDR-SC & CDR-CT2 \\
\hline Presión de la columna & $1 \mathrm{bar}$ & 1 bar \\
\hline Número de etapas de totales & 19 & 25 \\
\hline Etapas de rectificación & 2 & 1 \\
\hline Etapas reactivas & 15 (de 3 a 17$)$ & 21 (de 2 a 22$)$ \\
\hline Etapas de agotamiento & 2 & 3 \\
\hline Relación de reflujo & $0.1(\mathrm{~mol})$ & 2.5 \\
\hline Relación del rehervidor & $0.8(\mathrm{~mol})$ & $3(\mathrm{~mol})$ \\
\hline Etapa de alimentación & $3(\mathrm{AO})$ & $2(\mathrm{TO})$ \\
\hline Etapa de alimentación del metanol 1 & 18 & 11 \\
\hline Etapa de alimentación del metanol 2 & --- & 23 \\
\hline Flujo de alimentación & $\begin{array}{l}14 / 86(\mathrm{AO} / \mathrm{TO}) \mathrm{kmol} / \mathrm{h} \text { (calentado a } \\
\left.326^{\circ} \mathrm{C}\right)\end{array}$ & $85.99 \mathrm{kmol} / \mathrm{h}$ \\
\hline Alimentación del metanol 1 & $70 \mathrm{kmol} / \mathrm{h}$ (calentado a $\left.55^{\circ} \mathrm{C}\right)$ & $\begin{array}{l}400 \mathrm{kmol} / \mathrm{h} \text { (calentado a } \\
55^{\circ} \mathrm{C} \text { ) }\end{array}$ \\
\hline Alimentación del metanol 2 & --- & $\begin{array}{l}500 \mathrm{kmol} / \mathrm{h} \text { (calentado a } \\
55^{\circ} \mathrm{C} \text { ) }\end{array}$ \\
\hline Cantidad de catalizador por etapa & $800(\mathrm{~kg})$ & $1000(\mathrm{~L})$ \\
\hline Conversión & $9.99(\mathrm{AO})$ & 99.943 (TO) \\
\hline Flujo molar de $\mathrm{MO}$ en el fondo & $13.999 \mathrm{kmol} / \mathrm{h}$ & $268.597 \mathrm{kmol} / \mathrm{h}$ \\
\hline Flujo másico de $\mathrm{MO}$ en el fondo & $4150.685 \mathrm{~kg} / \mathrm{h}$ & $75486.661 \mathrm{~kg} / \mathrm{h}$ \\
\hline Carga térmica del condensador & $-132.35 \mathrm{~kW}$ & $-27521.403 \mathrm{~kW}$ \\
\hline Carga térmica del rehervidor & $117.0387 \mathrm{~kW}$ & $36953.4047 \mathrm{~kW}$ \\
\hline Temperatura del condensador & $99.48^{\circ} \mathrm{C}$ & $64.45^{\circ} \mathrm{C}$ \\
\hline Temperatura del rehervidor & $154.97{ }^{\circ} \mathrm{C}$ & $229.84^{\circ} \mathrm{C}$ \\
\hline Carga térmica total absoluta & $249.388 \mathrm{~kW}$ & $64474.807 \mathrm{~kW}$ \\
\hline Poder calórico total del biodiesel & $43236.3114 \mathrm{~kW}$ & $786319.388 \mathrm{~kW}$ \\
\hline
\end{tabular}

Finalmente para el proceso integrado se calculó el poder calorífico total disponible del biodiesel producido en cada columna, considerando que el poder calórico del biodiesel es de $37.5 \mathrm{MJ} / \mathrm{kg}$ (Billen et al., 2004). Obteniendo que el poder calorífico disponible que da el biodiesel que se obtiene en cada columna es mucho mayor que la el poder calorífico requerido por el condensador y el rehervidor en cada columna, lo que valida la 
sustentabilidad del proceso integrado para la producción de biodiesel. Recalcando que se requiere un estudio energético y de análisis de costos de operación a detalle para asegurar con más certeza la sustentabilidad del proceso.

A continuación se presentan los perfiles que se desarrollan dentro de estas columnas.

En la Figura 5.2 se presentan los perfiles de concentración en la fase líquida para las dos columnas que se están utilizando. En la Figura 5.2a vemos los perfiles de concentración en la CDR-SC donde se está llevando a cabo la reacción de esterificación, estos perfiles difieren a los obtenidos cuando sólo se alimenta ácido oleico, ya que se está alimentando mayoritariamente trioleína junto con el ácido oleico, además de que la presencia de la primera se mantiene principalmente en fase líquida (por ser muy densa) y no reacciona dentro de esta columna. Se logró obtener muy buena conversión del ácido oleico, el mayor consumo de este y el metanol se da entre la etapa de alimentación y la etapa 8 aproximadamente y ya no a lo largo de toda la zona reactiva como antes era. Como consecuencia la concentración del metil oleato y del agua también incrementan. El agua sale completamente arriba de la columna, pero gran parte del metanol que no reacciona se va al fondo de la columna, ya que está entrando en exceso. Aun con esto, es conveniente porque puede reaccionar con la trioleína en la segunda columna.

En la Figura 5.2b se muestra el perfil de composición de la CDR-CT, en esta figura vemos un comportamiento similar al obtenido en la sección anterior con alimentación de trioleína, solo que en este caso el mayor cambio se da entre la etapa 2 y 11 que son menos etapas que cuando solo tenemos alimentación de trioleína que este era de la 2 a la 14, además la concentración de la mezcla del fondo es diferente, pues existe una mayor concentración de metil oleato y una nula concentración de metanol lo que es conveniente porque se está logrando una mejor separación. 

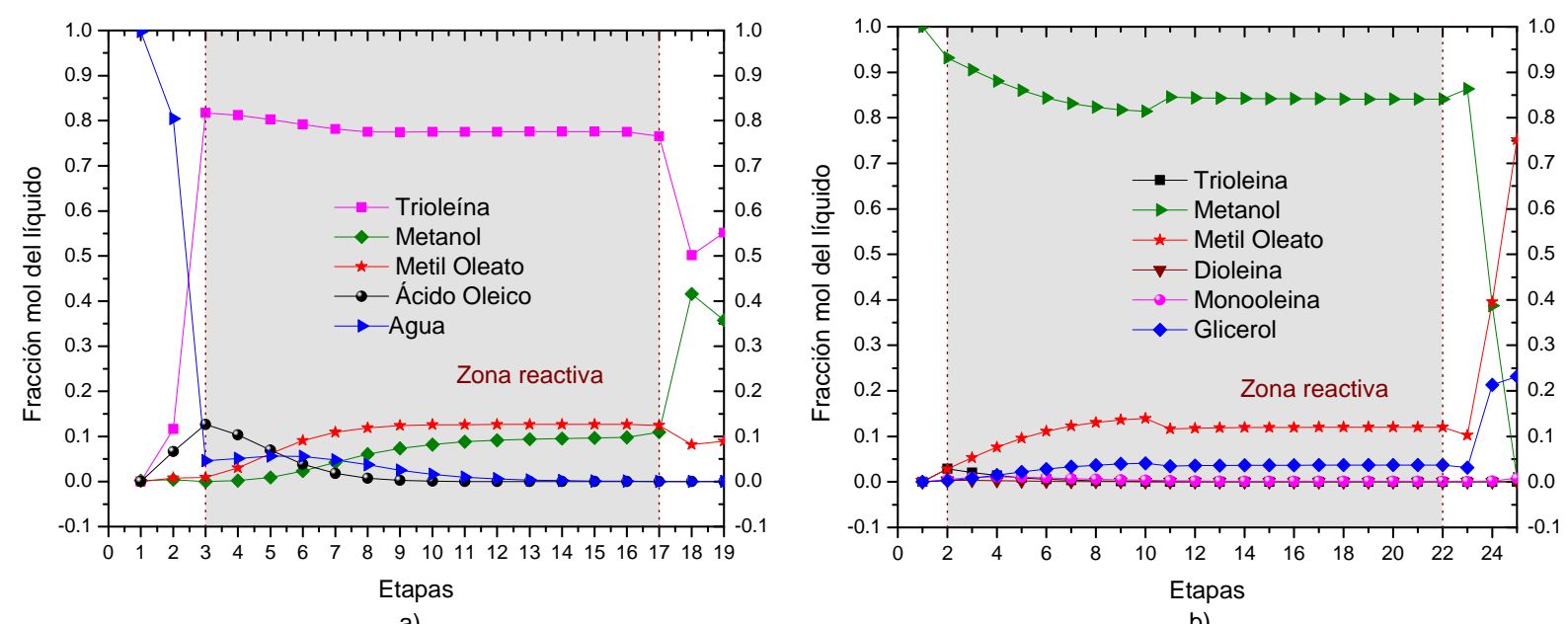

a)

Figura 5.2. Perfiles de concentración en la fase líquida. a) Reacción de esterificación usando CDR-SC, b) Reacción de transesterificación usando CDR-CT.

En la Figura 5.3 se presentan los perfiles de concentración en fase vapor. En la Figura 5.3a existe un cambio bien marcado con respecto a cuando sólo se alimentaba ácido oleico, aquí tenemos que la concentración del agua y del metanol incrementan a lo largo de toda la columna solo que en direcciones opuestas, cada uno al extremo del otro. La concentración de la trioleína se mantiene casi constante durante toda la columna aunque en bajas concentraciones. Ahora analizando la Figura 5.3b tenemos casi el mismo comportamiento que cuando sólo se alimentaba trioleína, la diferencia radica en la composición de la mezcla en el fondo de la columna, pues ahora contiene metanol, glicerol y metil oleato, cuando la otra columna contenía metanol principalmente. 


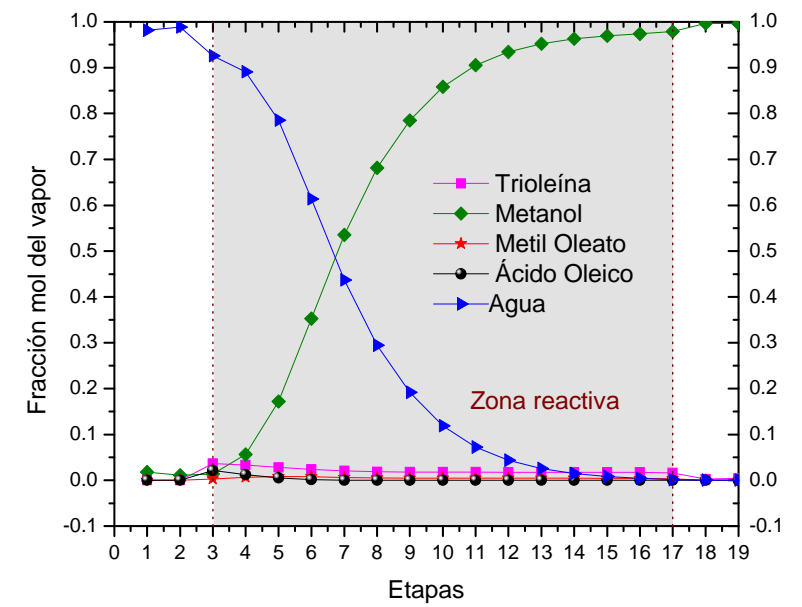

a)

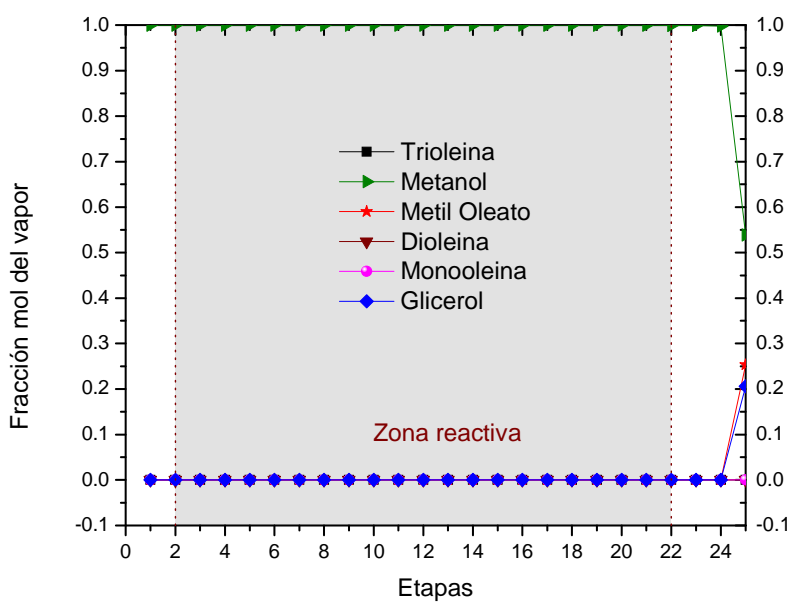

b)

Figura 5.3. Perfiles de la fracción vapor en las columnas. a) Reacción de esterificación CDR-CS, b) Reacción de transesterificación CDR-CT.

En la Figura 5.4 se muestran los perfiles de temperatura en cada columna. En la Figura 5.4a tenemos que la máxima temperatura se encuentra en la etapa de alimentación de la trioleína y el ácido. De esta etapa hasta llegar al fondo hay una disminución pronunciada hasta llegar al hervidor donde aumenta ligeramente. En cambio en el condensador se alcanza una temperatura de $100^{\circ} \mathrm{C}$ que es la correspondiente a la del agua pura. En la Figura 5.4b tenemos que la temperatura es más constante a lo largo de toda la columna incrementando instantáneamente en las últimas 3 etapas del fondo, y la temperatura del hervidores mayor debido a la composición de la mezcla que es diferente a la columna usando solo trioleína desde un inicio. 


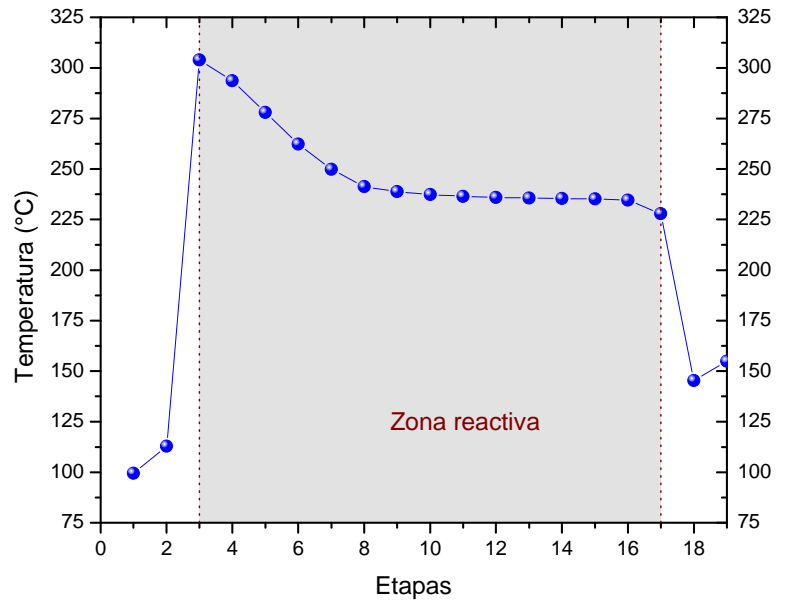

a)

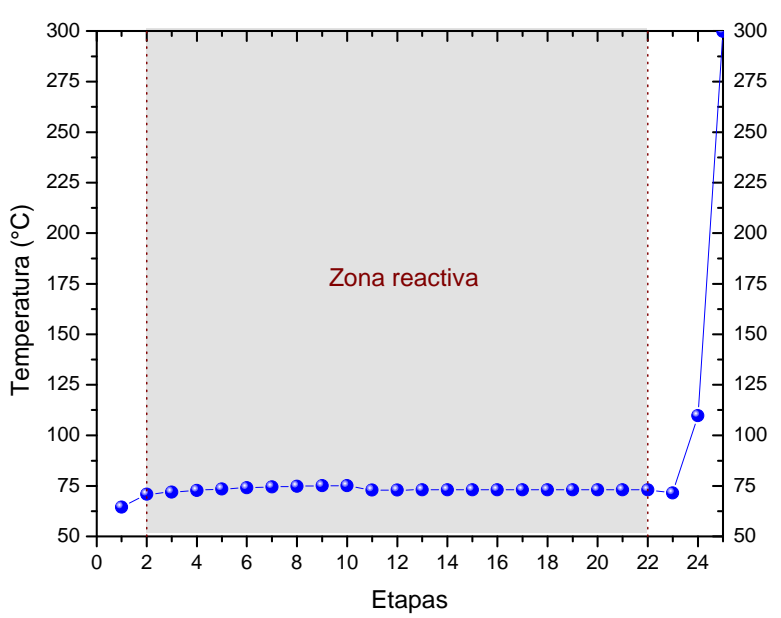

b)

Figura 5.4. Perfiles de temperatura en las columnas. a) Reacción de esterificación, b) Reacción de transesterificación.

En la Figura 5.4 notamos los perfiles de velocidad de las reacciones que se están llevando a cabo en cada columna. En la Figura 5.4a vemos que al contrario que cuando solo entraba ácido oleico que la máxima velocidad de reacción era en las etapas inferiores de la columna ahora tenemos que la mayor velocidad de reacción se localiza en las etapas superiores, etapas cercanas a la de alimentación, alcanzado un máximo de $3.5 \mathrm{kmol} / \mathrm{h}$ en la etapa 5 . Mientras que la Figura 5.4b presenta un comportamiento muy similar al caso estudiado en la sección anterior que usa solo trioleína desde un inicio, sin embargo la velocidad máxima que se alcanza en este caso es de $49.45 \mathrm{kmol} / \mathrm{h}$ que es $3 \mathrm{kmol} / \mathrm{h}$ menos que en el caso anterior mencionado. 


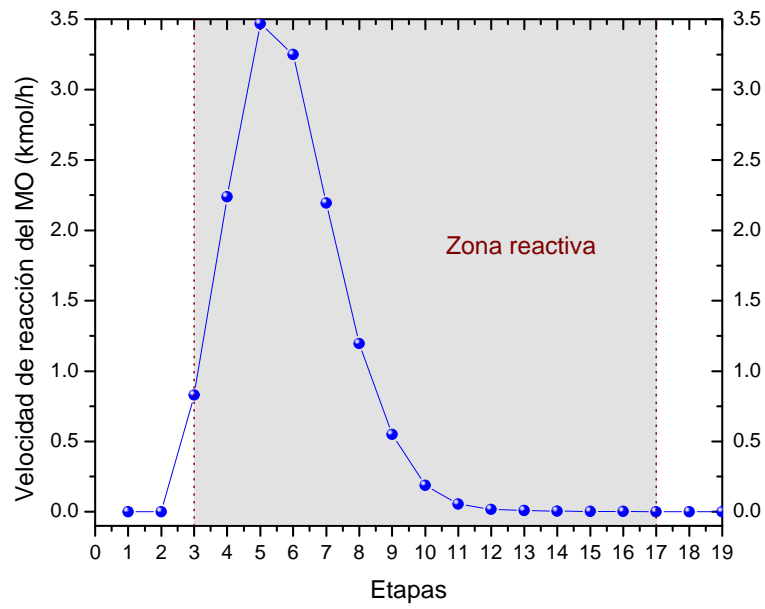

a)

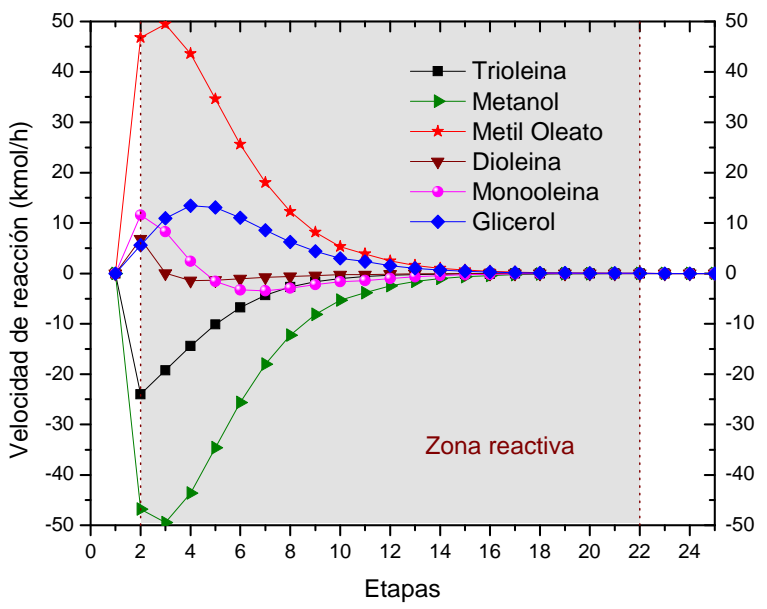

b)

Figura 5.5. Perfiles de velocidad para cada columna. a) Reacción de esterificación CDR-SC. b) Reacción de transesterificación CDR-CT.

Finalmente en la Figura 5.6 se presentan los perfiles de flujo del líquido y el vapor a lo largo de las columnas. Aquí podemos ver claramente que los flujos que se manejan en la CDR-SC para llevar a cabo una reacción de esterificación son menores que los que maneja CDR-CT para la transesterificación. En la Figura 5.6a observamos que el flujo del líquido es mucho mayor que el flujo de vapor y esto es porque el mayor flujo es el de la trioleína que tiene punto de ebullición muy diferente a los demás componentes presentes, además las temperaturas que se alcanzan en toda la columna no dejan que esta cambie de fase fácilmente. Es por ello que el flujo líquido en el fondo de la columna es mucho mayor que el vapor y la cantidad de este en el condensador es muy baja. En la Figura 5.6b tenemos que el flujo del vapor es mayor que la del líquido y existe un incremento del flujo del líquido donde se localiza la corriente intermedia del metanol. 


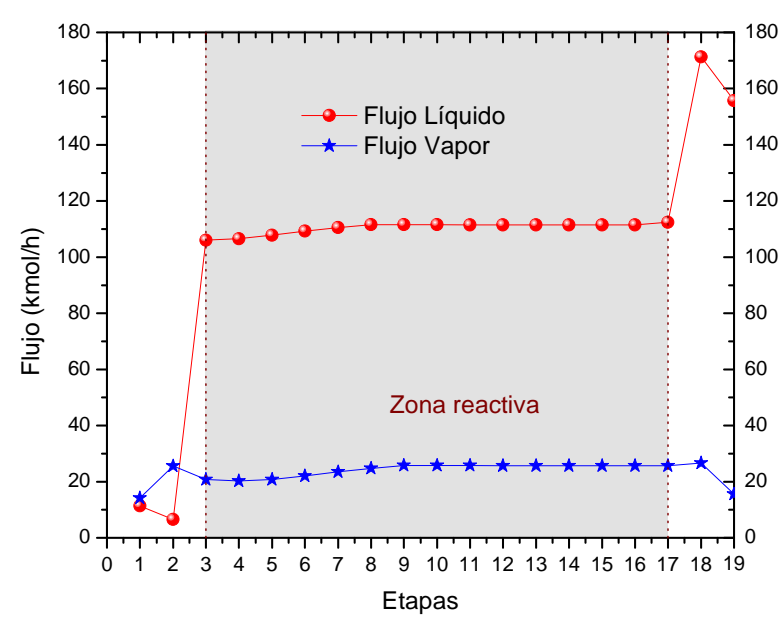

a)

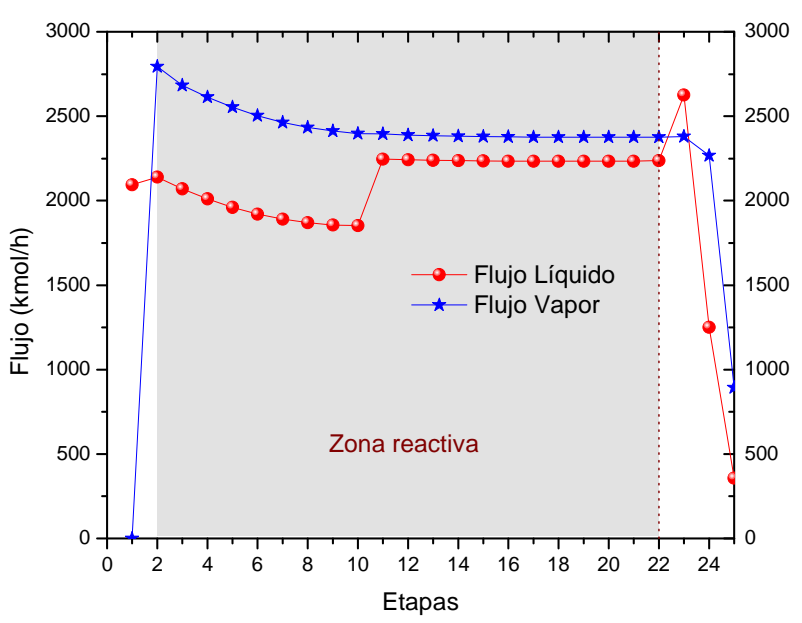

b)

Figura 5.6. Perfiles de flujo líquido y vapor dentro de las columnas. a) Reacción de esterificación CDR-SC y b) Reacción de transesterificación CDR-CT.

Con todo esto vemos que el proceso integrado nos permite producir biodiesel usando materia prima de baja calidad obteniendo una alta conversión. Por lo que este proceso puede ser una buena alternativa para producir biodiesel. 


\section{Capítulo 6}

\section{Conclusiones}

En el presente trabajo se desarrolló una metodología para el diseño y análisis del proceso de producción de biodiesel por destilación reactiva. El desarrollo de un proceso integrado de destilación reactiva para la producción de biodiesel representa una alternativa viable por las ventajas potenciales que ofrece este tipo de tecnología para el ahorro de energía y por la reducción en gastos de inversión y operación del proceso.

El diseño conceptual obtenido a partir del la construcción y análisis de los mapas de curvas residuales demostró que el proceso de destilación reactiva era posible para los dos sistemas de estudio (esterificación y transesterificación), permitiendo así en ese punto bosquejar el posible proceso integrado de obtención de biodiesel. Además, la construcción de los mapas de curvas residuales reactivos permitieron conocer el nivel de conversión de los compuestos a diferentes valores del factor de reacción-separación, o específicamente de la cantidad de catalizador utilizado.

A través de simulaciones intensivas realizadas con tres tipos de configuraciones de las columnas de destilación reactiva probadas para la esterificación: CDR-CT, CDR-CP y CDR-SC se logró una conversión del 99.9\%. No obstante, la CDR-SC representa la opción más viable ya que la carga térmica neta necesaria para su operación es la menor de las tres opciones, además de ser la más estable.

Para la transesterificación se encontró que CDR-CT es la mejor opción para la obtención de biodiesel y se determinó que introducir el metanol en dos corrientes a lo largo de la columna ayuda al proceso disminuyendo la carga térmica neta necesaria a casi la mitad que la que se necesita con una sola corriente.

También se encontró que es preferible acoplar las dos columnas alimentando directamente la corriente del fondo que sale de la columna de esterificación a la columna de 
transesterificación, permitiendo así, estudiar aceites con diferentes cantidades de impurezas obteniendo conversiones hasta del 99.9\%. El diseño final del proceso integrado consiste de una columna de destilación reactiva para la esterificación con 19 etapas totales, de las cuales 15 son reactivas, operando a una relación de reflujo de 0.1 y una relación del rehervidor de 0.8 conectada a una segunda columna de destilación reactiva para la transesterificación que considera 25 etapas totales, de las cuales 21 son reactivas, distribuidas en dos zonas reactivas. La segunda columna opera a una relación de reflujo de 2.5 y una relación del rehervidor de 3. Finalmente, el proceso de separación-reacción integrado demostró su flexibilidad operacional para diferentes cargas y tipos de aceites vegetales.

Es importante mencionar que es necesario mucho más trabajo de investigación en torno a nuevos materiales catalíticos para las reacciones de transesterificación. 


\section{Bibliografía}

Anuario Estadístico 2011 de Pemex

A. Kiss, A., A. C. Dimian, et al. (2007). Biodiesel production by integrated reactiveseparation design. Computer Aided Chemical Engineering. P. Valentin and A. Paul Şerban, Elsevier. Volume 24: 1283-1288.

Abrams, D. S. and J. M. Prausnitz (1975). "Statistical thermodynamics of liquid mixtures: A new expression for the excess Gibbs energy of partly or completely miscible systems." AIChE Journal 21(1): 116-128.

Achten, W. M. J., L. Verchot, et al. (2008). "Jatropha bio-diesel production and use." Biomass and Bioenergy 32(12): 1063-1084.

Anton A, K. (2010). "Separative reactors for integrated production of bioethanol and biodiesel." Computers \&amp; Chemical Engineering 34(5): 812-820.

Billen, J., Roeling, Monik., Nuijsenburg, M., Oomen, A., Reniers, J., Schmeits, J., Wezel, R., "Biodiesel II Or vegetable oil", February 2004

Cardoso, M. F., R. L. Salcedo, et al. (2000). "Optimization of reactive distillation processes with simulated annealing." Chemical Engineering Science 55(21): 5059-5078.

Carrera-Rodríguez, M., J. G. Segovia-Hernández, et al. (2011a). "A Short Method To Calculate Residue Curve Maps in Multireactive and Multicomponent Systems." Industrial \& Engineering Chemistry Research 50(4): 2157-2166.

Carrera-Rodríguez, M., J. G. Segovia-Hernández, et al. (2011b). "Short-Cut Method for the Design of Reactive Distillation Columns." Industrial \& Engineering Chemistry Research 50(18): 10730-10743.

Chang, A. F. and Y. A. Liu (2010). "Integrated Process Modeling and Product Design of Biodiesel Manufacturing." Industrial \& Engineering Chemistry Research 49(3): 1197-1213.

Clements, L. D., "Blending Rules for Formulating Biodiesel Fuel”, University of Nebraska -Lincoln (1996)

Di Serio, M., R. Tesser, et al. (2008). "Heterogeneous catalysts for biodiesel production." Energy \& Fuels 22(1): 207-217.

Doherty, M. F. and M. F. Malone (2001). Conceptual design of distillation systems. New York, McGraw-Hill Companies.

Dossin, T. F., M.-F. Reyniers, et al. (2006). "Simulation of heterogeneously MgO-catalyzed transesterification for fine-chemical and biodiesel industrial production." Applied Catalysis B: Environmental 67(1-2): 136-148.

Endalew, A. K., Y. Kiros, et al. (2011). "Inorganic heterogeneous catalysts for biodiesel production from vegetable oils." Biomass \& Bioenergy 35(9): 3787-3809. 
Fredenslund, A., J. Gmehling, et al. (1977). Vapor-liquid equilibria using UNIFAC : a group contribution method. Amsterdam, New York, New York, Elsevier Science Ltd.

Fredenslund, A., R. L. Jones, et al. (1975). "Group-contribution estimation of activity coefficients in nonideal liquid mixtures." AIChE Journal 21(6): 1086-1099.

Furuta, S., H. Matsuhashi, et al. (2004). "Biodiesel fuel production with solid superacid catalysis in fixed bed reactor under atmospheric pressure." Catalysis Communications 5(12): 721-723.

Furuta, S., H. Matsuhashi, et al. (2006). "Biodiesel fuel production with solid amorphouszirconia catalysis in fixed bed reactor." Biomass \& Bioenergy 30(10): 870-873.

Gaya, J. C. A. and M. K. Patel (2002). Biodiesel from rapeseed oil and used frying oil in European Union Universiteot Utrecht.

Granados-Aguilar, A. S. (2008). Análisis del Comportamiento de un Proceso de Destilación Reactiva para Hidrodesulfuración Profunda del Diesel. Facultad de Quimica México, D. F., Universidad Nacional Autónoma de Mexico Doctorado en Ingeniería Química.

Guggenheim, E. A. (1952). Mixtures : the theory of the equilibrium properties of some simple classes of mixtures, solutions and alloys. Oxford, Clarendon Press.

Huang, K., Q. L. Xu, et al. (2009). "Multi-Step Controlled Kinetics of the Transesterification of Crude Soybean Oil with Methanol by $\mathrm{Mg}(\mathrm{OCH}(3))(2)$." Chemical Engineering \& Technology 32(10): 1595-1604.

Jackson, J. R. and I. E. Grossmann (2001). "A disjunctive programming approach for the optimal design of reactive distillation columns." Computers \&amp; Chemical Engineering 25(11-12): 1661-1673.

Keyes, D. B. (1932). "Esterification Processes and Equipment." Industrial \& Engineering Chemistry 24(10): 1096-1103.

Lam, M. K., M. T. Lee, et al. (2010). "Homogeneous, heterogeneous and enzymatic catalysis for transesterification of high free fatty acid oil (waste cooking oil) to biodiesel: A review." Biotechnology Advances 28(4): 500-518.

Lam, M. K., K. T. Tan, et al. (2009). "Malaysian palm oil: Surviving the food versus fuel dispute for a sustainable future." Renewable \& Sustainable Energy Reviews 13(6-7): 14561464.

Leung, D. Y. C., X. Wu, et al. (2010). "A review on biodiesel production using catalyzed transesterification." Applied Energy 87(4): 1083-1095.

López, D. E., J. G. Goodwin Jr, et al. (2008). "Esterification and transesterification using modified-zirconia catalysts." Applied Catalysis A: General 339(1): 76-83.

Lotero, E., Y. J. Liu, et al. (2005). "Synthesis of biodiesel via acid catalysis." Industrial \& Engineering Chemistry Research 44(14): 5353-5363.

Luyben, W. L. and C.-C. Yu (2008). Reactive Distillation Design and Control. United States of America, John Wiley \& Sons, Inc., Hoboken, New Jersey. 
Machado, G. D., D. A. G. Aranda, et al. (2011). "Computer Simulation of Fatty Acid Esterification in Reactive Distillation Columns." Industrial \& Engineering Chemistry Research 50(17): 10176-10184.

Marchetti, J. M., V. U. Miguel, et al. (2007). "Possible methods for biodiesel production." Renewable and Sustainable Energy Reviews 11(6): 1300-1311.

Narváez, P., S. Rincón, et al. (2007). "Kinetics of Palm Oil Methanolysis." Journal of the American Oil Chemists' Society 84(10): 971-977.

Nigam, P. S. and A. Singh (2011). "Production of liquid biofuels from renewable resources." Progress in Energy and Combustion Science 37(1): 52-68.

Noureddini, H. and D. Zhu (1997). "Kinetics of transesterification of soybean oil." Journal of the American Oil Chemists' Society 74(11): 1457-1463.

Omota, F., A. C. Dimian, et al. (2003). "Fatty acid esterification by reactive distillation. Part 1: equilibrium-based design." Chemical Engineering Science 58(14): 3159-3174.

Omota, F., A. C. Dimian, et al. (2003). "Fatty acid esterification by reactive distillation: Part 2 - kinetics-based design for sulphated zirconia catalysts." Chemical Engineering Science 58(14): 3175-3185.

Payawan, J. L. M., J. A. Damasco, et al. (2010). "Transesterification of Oil Extract from Locally-Cultivated Jatropha curcas using a Heterogeneous Base Catalyst and Determination of its Properties as a Viable Biodiesel." Philippine Journal of Science 139(1): 105-116.

Pérez Cisneros, E. S., R. Gani, et al. (1997). "Reactive separation systems-I. Computation of physical and chemical equilibrium." Chemical Engineering Science 52(4): 527-543.

Pérez-Cisneros, E. S. (1997). Modelling, Design and Analysis of Reactive Separation Processes. Lyngby, Denmark, The Technical University of Denmark. Ph. D. .

Pinnarat, T. and P. E. Savage (2008). "Assessment of noncatalytic biodiesel synthesis using supercritical reaction conditions." Industrial \& Engineering Chemistry Research 47(18): 6801-6808.

Sánchez-Daza, O. (2004). Diseño de Procesos de Destilación Reactiva una Nueva metodología Basada en el Concepto de Elemento. División de Ciencias Básicas e Ingeniería. México, D. F., Universidad Autónoma Metropolitana Unidad Iztapalapa. Doctorado en Ciencias

SENER, "Potenciales y Viabilidad del Uso de Bioetanol y Biodiesel para el Transporte en México", (Noviembre 2006)

Scott, R. L. (1956). "Corresponding States Treatment of Nonelectrolyte Solutions." The Journal of Chemical Physics 25(2): 193-205.

Seider, W. D. and S. Widagdo (1996). "Multiphase equilibria of reactive systems." Fluid Phase Equilibria 123(1-2): 283-303.

Smith, L. A. and M. N. Huddleston (1982). "New MTBE design now commercial. [Methyl tertiary butyl ether]." Journal Name: Hydrocarbon Process.; (United States); Journal Volume: 61:3: Medium: X; Size: Pages: 121-123. 
Solokhin, A. V. and S. A. Blagov (1996). "Reactive-distillation is an advanced technique of reaction process operation." Chemical Engineering Science 51(11): 2559-2564.

Solokhin, A. V., S. A. Blagov, et al. (1990a). "Open evaporation processes accompied by chemical reaction in the liquid phase." Theoretical Fundamentals in Chemical Engineering 24: pp. 103-109.

Solokhin, A. V., S. A. Blagov, et al. (1990b). "Dynamic systems for open evaporation process in presence of A-B chemical reaction." Theoretical Fundamentals in Chemical Engineering 24: pp. 377-382.

Suwannakarn, K., E. Lotero, et al. (2009). "Simultaneous Free Fatty Acid Esterification and Triglyceride Transesterification Using a Solid Acid Catalyst with in Situ Removal of Water and Unreacted Methanol." Industrial \& Engineering Chemistry Research 48(6): 2810-2818.

Suwannakarn, K., E. Lotero, et al. (2009). "Simultaneous Free Fatty Acid Esterification and Triglyceride Transesterification Using a Solid Acid Catalyst with in Situ Removal of Water and Unreacted Methanol." Industrial \& Engineering Chemistry Research 48(6): 2810-2818.

Taylor, R. and R. Krishna (2000). "Modelling reactive distillation." Chemical Engineering Science 55(22): 5183-5229.

Tesser, R., L. Casale, et al. (2010). "Kinetics and modeling of fatty acids esterification on acid exchange resins." Chemical Engineering Journal 157(2-3): 539-550.

Thiel, C., K. Sundmacher, et al. (1997a). "Residue curve maps for heterogeneously catalysed reactive distillation of fuel ethers MTBE and TAME." Chemical Engineering Science 52(6): 993-1005.

Thiel, C., K. Sundmacher, et al. (1997b). "Synthesis of ETBE: Residue curve maps for the heterogeneously catalysed reactive distillation process." Chemical Engineering Journal 66(3): 181-191.

Ung, S. and M. F. Doherty (1995). "Vapor-liquid phase equilibrium in systems with multiple chemical reactions." Chemical Engineering Science 50(1): 23-48.

Venimadhavan, G., G. Buzad, et al. (1994). "Effect of kinetics on residue curve maps for reactive distillation." AIChE Journal 40(11): 1814-1824.

Viveros-García, T., J. A. Ochoa-Tapia, et al. (2005). "Conceptual design of a reactive distillation process for ultra-low sulfur diesel production." Chemical Engineering Journal 106(2): 119-131.

Wasylkiewicz, S. K. and S. Ung (2000). "Global phase stability analysis for heterogeneous reactive mixtures and calculation of reactive liquid-liquid and vapor-liquid-liquid equilibria." Fluid Phase Equilibria 175(1-2): 253-272.

Wilson, G. M. (1964). "Vapor-Liquid Equilibrium. XI. A New Expression for the Excess Free Energy of Mixing." Journal of the American Chemical Society 86(2): 127-130.

Zhang, Y., M. A. Dube, et al. (2003). "Biodiesel production from waste cooking oil: 1. Process design and technological assessment." Bioresource Technology 89(1): 1-16. 


\section{Apéndice A: Columna de Destilación Reactiva con Condensador Total (CDR-CT), para la reacción de esterificación.}

Todas las tablas de las simulaciones presentan una columna que dice corrida. La interpretación es la siguiente: letra S significa que se trata de una simulación realizada, el número que le sigue adjunto indica el número de parámetro que se está modificando que viene de acuerdo a el orden en que se fue modificando cada parámetros (en los apéndices viene el nombre del parámetro que se está modificando y cada tabla esta numerada en orden), el segundo número indica el número de modificaciones que se le han hecho a un mismo parámetro. La fila sombreada es la simulación elegida como la que nos acerca o nos da la conversión objetivo de $99.9 \%$ dependiendo de cuál sea el caso.

Tabla A1. Variación de la cantidad de catalizador. Usando una razón de alimentación de AO/MeOH de 1:1, Alimentando al $\mathrm{AO}$ en la etapa 2 a $350^{\circ} \mathrm{C}$, el $\mathrm{MeOH}$ en la etapa 14 a $55^{\circ} \mathrm{C}, 15$ etapas totales, 2 de agotamiento y 2 de rectificación y 11 reactivas (3-13), la relación de reflujo de 1 y del rehervidor 1 y UNIFAC como método termodinámico.

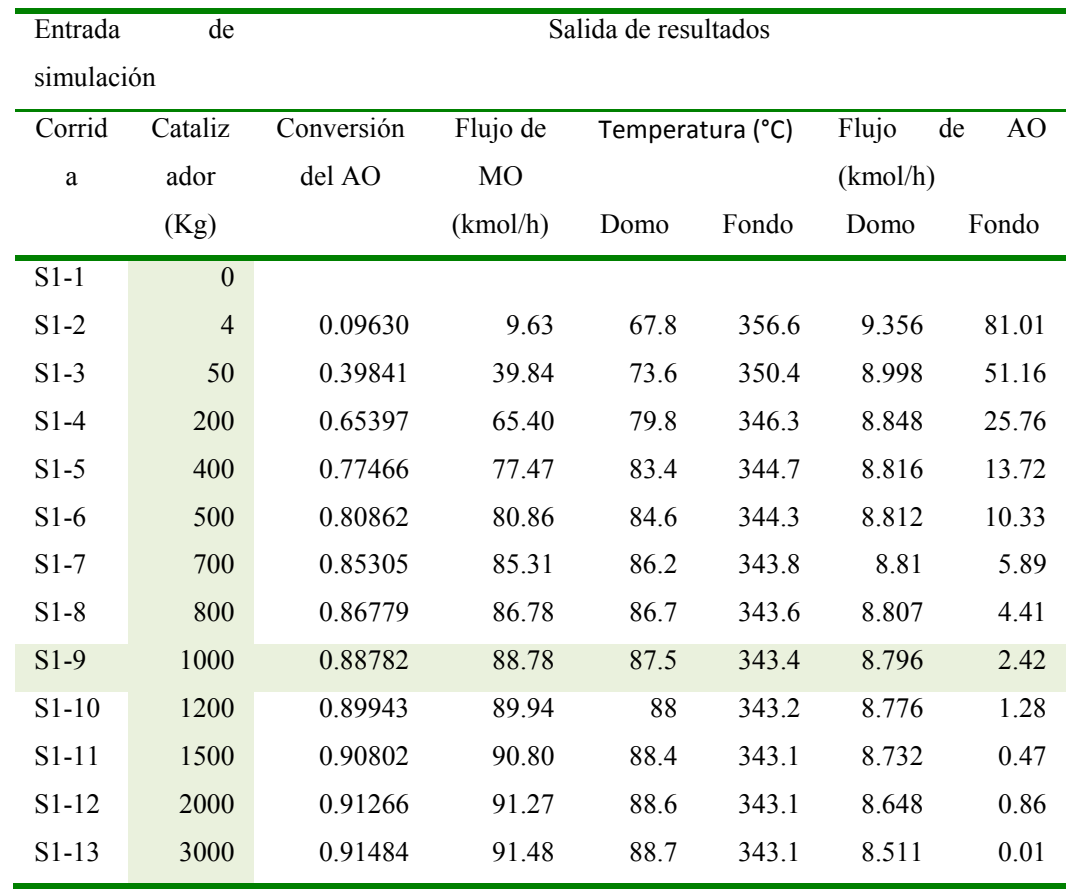


Tabla A2. Variación de la relación de reflujo. Usando una razón de alimentación de $\mathrm{AO} / \mathrm{MeOH}$ de 1:1, Alimentando al $\mathrm{AO}$ en la etapa $2\left(350^{\circ} \mathrm{C}\right)$, el MeOH en la etapa $14\left(55^{\circ} \mathrm{C}\right), 15$ etapas totales, 2 de agotamiento y 2 de rectificación y 11 reactivas (3-13), la relación del rehervidor de 1 y UNIFAC como método termodinámico.

\begin{tabular}{|c|c|c|c|c|c|c|c|c|}
\hline \multicolumn{3}{|c|}{ Entrada de simulación } & \multicolumn{6}{|c|}{ Salida de resultados } \\
\hline \multirow[t]{2}{*}{ Corrida } & \multirow[t]{2}{*}{ Reflujo } & \multirow{2}{*}{$\begin{array}{l}\text { Catalizador } \\
\qquad(\mathrm{Kg})\end{array}$} & \multirow{2}{*}{$\begin{array}{c}\text { Conversión del } \\
\text { AO }\end{array}$} & \multirow{2}{*}{$\begin{array}{l}\text { Flujo de MO } \\
\qquad(\mathrm{kmol} / \mathrm{h})\end{array}$} & \multicolumn{2}{|c|}{ Temperatura $\left({ }^{\circ} \mathrm{C}\right)$} & \multicolumn{2}{|c|}{ Flujo de AO (kmol/h) } \\
\hline & & & & & Domo & Fondo & Domo & Fondo \\
\hline S2-1 & 0.95 & 1000 & 0.88724 & 0.258 & 87.2 & 343.3 & 9.413 & 1.863 \\
\hline $\mathrm{S} 2-2$ & 1 & 1000 & 0.88782 & 0.222 & 87.5 & 343.4 & 8.796 & 2.422 \\
\hline S2-3 & 1.1 & 1000 & 0.88554 & 0.166 & 88.0 & 343.5 & 7.669 & 3.777 \\
\hline $\mathrm{S} 2-4$ & 1 & 1500 & 0.90802 & 90.802 & 88.4 & 343.1 & 8.732 & 0.466 \\
\hline S2-5 & 1.2 & 1500 & 0.9148 & 0.128 & 89.9 & 343.3 & 6.676 & 1.844 \\
\hline S2-6 & 1.3 & 1500 & 0.91175 & 0.095 & 90.2 & 343.4 & 5.805 & 3.02 \\
\hline S2-7 & 1.4 & 1500 & 0.90473 & 0.071 & 90.2 & 343.5 & 5.026 & 4.501 \\
\hline
\end{tabular}

Tabla A3. Variación del rehervidor. Usando una razón de alimentación de AO/MeOH de 1:1, Alimentando al AO en la etapa $2\left(350^{\circ} \mathrm{C}\right)$ y el $\mathrm{MeOH}$ en la etapa $14\left(55^{\circ} \mathrm{C}\right)$, son 15 etapas totales, 2 de agotamiento y 2 de rectificación y 11 reactivas (3-13), y UNIFAC como método termodinámico.

\begin{tabular}{|c|c|c|c|c|c|c|c|c|c|}
\hline \multicolumn{3}{|c|}{ Entrada de simulación } & \multicolumn{7}{|c|}{ Salida de resultados } \\
\hline \multirow[t]{2}{*}{ Corrida } & \multirow[t]{2}{*}{ Reflujo } & \multirow[t]{2}{*}{$\begin{array}{l}\text { Reherv } \\
\text { idor }\end{array}$} & \multirow[t]{2}{*}{$\begin{array}{c}\text { Catalizador } \\
(\mathrm{Kg})\end{array}$} & \multirow[t]{2}{*}{$\begin{array}{c}\text { Conversión } \\
\text { del AO }\end{array}$} & \multirow[t]{2}{*}{$\begin{array}{c}\text { Flujo de MO } \\
(\mathrm{kmol} / \mathrm{h})\end{array}$} & \multicolumn{2}{|c|}{ Temperatura $\left({ }^{\circ} \mathrm{C}\right)$} & \multicolumn{2}{|l|}{$\begin{array}{l}\text { Flujo de } \\
(\mathrm{kmol} / \mathrm{h})\end{array}$} \\
\hline & & & & & & Domo & Fondo & Domo & Fondo \\
\hline S3-1 & 1 & 1 & 1000 & 0.88782 & 0.222 & 87.5 & 343.4 & 8.796 & 2.422 \\
\hline S3-2 & 1 & 1.2 & 1000 & 0.89673 & 0.214 & 87.9 & 343.5 & 8.829 & 1.498 \\
\hline S3-3 & 1 & 1.4 & 1000 & 0.90418 & 0.206 & 88.2 & 343.6 & 8.858 & 0.724 \\
\hline S3-4 & 1 & 1.7 & 1000 & 0.91047 & 0.199 & 88.4 & 343.7 & 8.883 & 0.07 \\
\hline S3-5 & 1 & 1.75 & 1000 & 0.9175 & 0.199 & 88.4 & 343.7 & 8.885 & 0.029 \\
\hline S3-6 & 1 & 1.8 & 1000 & & & & & & \\
\hline S3-7 & 1.2 & 1 & 1500 & 0.9148 & 0.128 & 89.9 & 343.3 & 6.676 & 1.844 \\
\hline S3-8 & 1.2 & 1.5 & 1500 & 0.92942 & 0.116 & 90.6 & 343.6 & 6.723 & 0.335 \\
\hline S3-9 & 1.2 & 1.7 & 1500 & 0.93196 & 0.114 & 90.7 & 343.7 & 6.731 & 0.073 \\
\hline S3-10 & 1.2 & 1.9 & 1500 & 0.93266 & 0.113 & 90.8 & 343.8 & 6.734 & $<0.001$ \\
\hline S3-11 & 1.2 & 2 & 1500 & 0.92649 & 0.635 & 89.7 & 343.8 & 7.351 & trace \\
\hline
\end{tabular}


Tabla A4. Variación de la razón de alimentación $\mathrm{AO} / \mathrm{MeOH}$. Alimentando al $\mathrm{AO}$ en la etapa 2 a $350^{\circ} \mathrm{C}$, el $\mathrm{MeOH}$ en la etapa 14 a $55^{\circ} \mathrm{C}, 15$ etapas totales, 2 de agotamiento y 2 de rectificación y 11 reactivas (3-13) y UNIFAC como método termodinámico.

\begin{tabular}{|c|c|c|c|c|c|c|c|c|c|c|c|}
\hline \multicolumn{5}{|c|}{ Entrada de simulación } & \multicolumn{7}{|c|}{ Salida de resultados } \\
\hline \multirow[t]{2}{*}{ Corrida } & \multirow{2}{*}{$\begin{array}{c}\text { Razón } \\
\mathrm{AO} / \mathrm{MeO} \\
\mathrm{H} \\
(\mathrm{kmol} / \mathrm{h})\end{array}$} & \multirow[t]{2}{*}{$\begin{array}{l}\text { Refl } \\
\text { ujo }\end{array}$} & \multirow[t]{2}{*}{$\begin{array}{l}\text { Reherv } \\
\text { idor }\end{array}$} & \multirow{2}{*}{$\begin{array}{c}\text { Cataliz } \\
\text { ador } \\
(\mathrm{Kg})\end{array}$} & \multirow{2}{*}{$\begin{array}{l}\text { Conversi } \\
\text { ón del } \\
\mathrm{AO}\end{array}$} & \multicolumn{2}{|c|}{$\begin{array}{c}\text { Flujo de MO } \\
(\mathrm{kmol} / \mathrm{h})\end{array}$} & \multicolumn{2}{|c|}{$\begin{array}{l}\text { Temperatura } \\
\left({ }^{\circ} \mathrm{C}\right)\end{array}$} & \multicolumn{2}{|c|}{$\begin{array}{c}\text { Flujo de AO } \\
(\mathrm{kmol} / \mathrm{h})\end{array}$} \\
\hline & & & & & & Domo & Total & $\begin{array}{c}\text { Dom } \\
\text { o }\end{array}$ & Fondo & Domo & Fondo \\
\hline S4-1 & $0.9: 1$ & 1 & 1.75 & 1000 & 0.88014 & 0.229 & 79.213 & 84.5 & 344.1 & 7.234 & 3.553 \\
\hline S4-2 & 01:01 & 1 & 1.75 & 1000 & 0.9175 & 0.199 & 91.75 & 88.4 & 343.7 & 8.885 & 0.029 \\
\hline S4-3 & $1.1: 1$ & 1 & 1.75 & 1000 & 0.8439 & 0.208 & 92.833 & 88.4 & 344.5 & 10.263 & 6.904 \\
\hline S4-4 & 02:01 & 1.2 & 1.9 & 1500 & 0.49993 & 1.197 & 99.998 & 82.4 & 348.8 & 31.867 & 68.157 \\
\hline S4-5 & $1.5: 1$ & 1.2 & 1.9 & 1500 & 0.749935 & 0.405 & 99.987 & 86 & 346.4 & 19.82 & 30.193 \\
\hline S4-6 & 01:01 & 1.2 & 1.9 & 1500 & 0.93266 & 0.113 & 93.266 & 90.8 & 343.8 & 6.734 & $<0.001$ \\
\hline S4-7 & $0.9: 1$ & 1.2 & 1.9 & 1500 & 0.94047 & 0.124 & 84.643 & 87.3 & 343.7 & 5.355 & 0.002 \\
\hline S4-8 & $0.55: 1$ & 1.2 & 1.9 & 1500 & 0.97269 & 0.018 & 53.498 & 75.4 & 343.5 & 1.286 & 0.216 \\
\hline S4-9 & $0.5: 1$ & 1.2 & 1.9 & 1500 & 0.9727 & 0.009 & 48.636 & 73.8 & 343.6 & 0.85 & 0.515 \\
\hline S4-10 & $0.45: 1$ & 1.2 & 1.9 & 1500 & 0.96137 & 0.003 & 43.262 & 72.3 & 343.7 & 0.493 & 1.245 \\
\hline S4-11 & $0.4: 1$ & 1.2 & 1.9 & 1500 & 0.9398 & 0.001 & 36.99 & 70.8 & 344 & 0.235 & 2.755 \\
\hline S4-12 & $0.3: 1$ & 1.2 & 1.9 & 1500 & 0.8176 & trace & 20.88 & 67.8 & 346.6 & 0.18 & 9.102 \\
\hline
\end{tabular}


Tabla A5. Variación de la $\mathrm{T}$ de alimentación $\mathrm{AO}(\mathrm{Tb}=359.85)$ y $\mathrm{MeOH}(\mathrm{Tb}=64.7)$. Alimentando al AO en la etapa 2 y el MeOH en la etapa 14, 15 etapas totales, 2 de agotamiento y 2 de rectificación y 11 reactivas (313) y UNIFAC como método termodinámico.

\begin{tabular}{|c|c|c|c|c|c|c|c|c|c|c|c|c|c|}
\hline \multicolumn{7}{|c|}{ Entrada de simulación } & \multicolumn{7}{|c|}{ Salida de resultados } \\
\hline \multirow[t]{2}{*}{$\begin{array}{c}\text { Corrid } \\
\mathrm{a}\end{array}$} & \multirow{2}{*}{$\begin{array}{c}\text { Razón } \\
\mathrm{AO} / \mathrm{MeO} \\
\mathrm{H} \\
(\mathrm{kmol} / \mathrm{h})\end{array}$} & \multirow{2}{*}{$\begin{array}{c}\text { Ref } \\
\text { luj } \\
\text { o }\end{array}$} & \multicolumn{2}{|c|}{$\begin{array}{l}\text { Temperatura de } \\
\text { alim. }\left({ }^{\circ} \mathrm{C}\right)\end{array}$} & \multirow{2}{*}{$\begin{array}{c}\text { Rehe } \\
\text { rvido } \\
r\end{array}$} & \multirow{2}{*}{$\begin{array}{c}\text { Catal } \\
\text { izado } \\
\mathrm{r} \\
(\mathrm{Kg})\end{array}$} & \multirow{2}{*}{$\begin{array}{c}\text { Conversi } \\
\text { ón del } \\
\text { AO }\end{array}$} & \multicolumn{2}{|c|}{$\begin{array}{c}\text { Flujo de MO } \\
(\mathrm{kmol} / \mathrm{h})\end{array}$} & \multicolumn{2}{|c|}{$\begin{array}{l}\text { Temperatura } \\
\left({ }^{\circ} \mathrm{C}\right)\end{array}$} & \multicolumn{2}{|c|}{$\begin{array}{c}\text { Flujo de AO } \\
(\mathrm{kmol} / \mathrm{h})\end{array}$} \\
\hline & & & $\mathrm{AO}$ & $\mathrm{MeOH}$ & & & & Domo & Total & $\begin{array}{c}\text { Dom } \\
\text { o }\end{array}$ & $\begin{array}{c}\text { Fond } \\
\text { o }\end{array}$ & $\begin{array}{c}\text { Dom } \\
\text { o }\end{array}$ & $\begin{array}{c}\text { Fond } \\
\text { o }\end{array}$ \\
\hline S5-1 & $1: 1$ & 1 & 300 & 55 & 1.75 & 1000 & 0.89125 & 0.01 & 89.125 & 89.9 & 344.5 & 2.478 & 8.40 \\
\hline S5-2 & $1: 1$ & 1 & 320 & 55 & 1.75 & 1000 & 0.93299 & 0.0 .63 & 93.299 & 92.1 & 343.9 & 4.581 & 2.12 \\
\hline S5-3 & $1: 1$ & 1 & 324 & 55 & 1.75 & 1000 & 0.93487 & 0.43 & 93.487 & 91.9 & 343.8 & 5.09 & 1.42 \\
\hline S5-4 & $1: 1$ & 1 & 325 & 55 & 1.75 & 1000 & 0.93502 & 0.63 & 93.502 & 91.9 & 343.8 & 5.221 & 1.28 \\
\hline S5-5 & $1: 1$ & 1 & 326 & 55 & 1.75 & 1000 & 0.93503 & 0.049 & 93.503 & 91.8 & 343.8 & 5.354 & 1.14 \\
\hline S5-6 & $1: 1$ & 1 & 327 & 55 & 1.75 & 1000 & 0.93492 & 0.63 & 93.492 & 91.7 & 343.8 & 5.488 & 1.02 \\
\hline S5-7 & $1: 1$ & 1 & 330 & 55 & 1.75 & 1000 & 0.93392 & 0.0 .63 & 93.392 & 91.4 & 343.8 & 5.898 & 0.71 \\
\hline S5-8 & $1: 1$ & 1 & 340 & 55 & 1.75 & 1000 & 0.92448 & 0.116 & 92.448 & 90 & 343.7 & 7.342 & 0.17 \\
\hline S5-9 & $1: 1$ & 1 & 350 & 55 & 1.75 & 1000 & 0.9175 & 0.199 & 91.75 & 88.4 & 343.7 & 8.885 & 0.03 \\
\hline S5-10 & $1: 1$ & 1 & 353 & 55 & 1.75 & 1000 & 0.90621 & 0.23 & 90.621 & 88 & 343.7 & 9.364 & 0.02 \\
\hline S5-11 & $1: 1$ & 1 & 357 & 55 & 1.75 & 1000 & 0.8998 & 0.276 & 89.98 & 87.3 & 343.7 & 10.01 & 0.01 \\
\hline S5-12 & $1: 1$ & 1 & 359 & 55 & 1.75 & 1000 & & & & & & & \\
\hline S5-13 & $1: 1$ & 1 & 326 & 48 & 1.75 & 1000 & 0.93434 & 0.049 & 93.439 & 91.7 & 343.8 & 5.352 & 1.12 \\
\hline S5-14 & $1: 1$ & 1 & 326 & 50 & 1.75 & 1000 & 0.93453 & 0.049 & 93.453 & 91.7 & 343.8 & 5.353 & 1.19 \\
\hline S5-15 & $1: 1$ & 1 & 326 & 51 & 1.75 & 1000 & 0.93463 & 0.049 & 93.463 & 91.8 & 343.8 & 5.353 & 1.18 \\
\hline S5-16 & $1: 1$ & 1 & 326 & 53 & 1.75 & 1000 & 0.93484 & 0.049 & 93.484 & 91.8 & 343.8 & 5.353 & 1.16 \\
\hline S5-17 & $1: 1$ & 1 & 326 & 55 & 1.75 & 1000 & 0.93503 & 0.049 & 93.503 & 91.8 & 343.8 & 5.354 & 1.14 \\
\hline S5-18 & $1: 1$ & 1 & 326 & 60 & 1.75 & 1000 & 0.93553 & 0.048 & 93.504 & 91.8 & 343.8 & 5.355 & 1.09 \\
\hline S5-19 & $1: 1$ & 1 & 326 & 62 & 1.75 & 1000 & 0.93573 & 0.048 & 93.573 & 91.8 & 343.8 & 5.355 & 1.07 \\
\hline S5-20 & $1: 1$ & 1 & 326 & 64 & 1.75 & 1000 & 0.93592 & 0.048 & 93.592 & 91.8 & 343.8 & 5.356 & 1.05 \\
\hline S5-21 & $1: 1$ & 1 & 326 & 65 & 1.75 & 1000 & 0.83535 & 0.085 & 83.535 & 86.8 & 345.2 & 5.181 & 11.2 \\
\hline S5-22 & $0.5: 1$ & 1.2 & 330 & 55 & 1.9 & 1500 & 0.93822 & 0.002 & 46.911 & 73 & 344 & 0.372 & 2.72 \\
\hline S5-23 & $0.5: 1$ & 1.2 & 350 & 55 & 1.9 & 1500 & 0.9727 & 0.009 & 48.636 & 73.8 & 343.6 & 0.85 & 0.52 \\
\hline S5-24 & $0.5: 1$ & 1.2 & 353 & 55 & 1.9 & 1500 & 0.97356 & 0.011 & 48.677 & 73.9 & 343.5 & 0.948 & 0.37 \\
\hline S5-25 & $0.5: 1$ & 1.2 & 356 & 55 & 1.9 & 1500 & 0.97358 & 0.014 & 48.679 & 74 & 343.5 & 1.054 & 0.27 \\
\hline S5-26 & $0.5: 1$ & 1.2 & 357 & 55 & 1.9 & 1500 & 0.97344 & 0.015 & 48.672 & 74 & 343.5 & 1.09 & 0.24 \\
\hline S5-27 & $0.5: 1$ & 1.2 & 358 & 55 & 1.9 & 1500 & 0.97322 & 0.016 & 48.661 & 74 & 343.5 & 1.128 & 0.21 \\
\hline S5-28 & $0.5: 1$ & 1.2 & 356 & 53 & 1.9 & 1500 & 0.97342 & 0.014 & 48.672 & 74 & 343.5 & 1.054 & 0.28 \\
\hline S5-29 & $0.5: 1$ & 1.2 & 356 & 60 & 1.9 & 1500 & 0.97394 & 0.014 & 48.697 & 74 & 343.5 & 1.054 & 0.25 \\
\hline S5-30 & $0.5: 1$ & 1.2 & 356 & 62 & 1.9 & 1500 & 0.97408 & 0.014 & 48.704 & 74 & 343.5 & 1.054 & 0.24 \\
\hline S5-31 & $0.5: 1$ & 1.2 & 356 & 64 & 1.9 & 1500 & 0.9742 & 0.014 & 48.711 & 74 & 343.5 & 1.054 & 0.24 \\
\hline S5-32 & $0.5: 1$ & 1.2 & 356 & 65 & 1.9 & 1500 & 0.86858 & 0.014 & 43.429 & 72.8 & 345 & 1.054 & 5.52 \\
\hline
\end{tabular}


Tabla A6. Variación de la Número de etapas reactivas, desplazando las etapas de rectificación y desplazando las etapas de agotamiento. Usando UNIFAC como método termodinámico y una razón de alimentación de $\mathrm{AO} / \mathrm{MeOH} 1: 1$ con $1000 \mathrm{~kg}$ de catalizador y $0.5: 1$ con $1500 \mathrm{~kg}$ de catalizador.

\begin{tabular}{|c|c|c|c|c|c|c|c|c|c|c|c|c|c|c|c|}
\hline \multicolumn{9}{|c|}{ Entrada de simulación } & \multicolumn{7}{|c|}{ Salida de resultados } \\
\hline \multirow[t]{3}{*}{ Corrida } & \multicolumn{4}{|c|}{ Número de Etapas } & \multirow[t]{3}{*}{$\begin{array}{l}\text { Refl } \\
\text { ujo }\end{array}$} & \multirow{3}{*}{$\begin{array}{l}\text { Temperatur } \\
\text { a de alim. } \\
\left({ }^{\circ} \mathrm{C}\right) \mathrm{AO}\end{array}$} & \multirow[t]{3}{*}{$\begin{array}{c}\text { Rehervid } \\
\text { or }\end{array}$} & \multirow[t]{3}{*}{$\begin{array}{c}\text { Catalizad } \\
\text { or }(\mathrm{Kg})\end{array}$} & \multirow[t]{3}{*}{$\begin{array}{c}\text { Conversión } \\
\text { del AO }\end{array}$} & \multicolumn{2}{|c|}{ Flujo de $\mathrm{MO}(\mathrm{kmol} / \mathrm{h})$} & \multicolumn{2}{|c|}{ Temperatura $\left({ }^{\circ} \mathrm{C}\right)$} & \multicolumn{2}{|c|}{$\begin{array}{c}\text { Flujo de AO } \\
(\mathrm{kmol} / \mathrm{h})\end{array}$} \\
\hline & & $\mathrm{xn}$ & Rectifi & Agota & & & & & & Domo & Total & Domo & Fondo & Domo & Fondo \\
\hline & Total & Rango & cación & miento & & & & & & & & & & & \\
\hline S6-1 & 1 & 13 & 12 & 2 & 1 & 326 & 1.75 & 1000 & & & & & & & \\
\hline S6-2 & 3 & $11-13$ & 10 & 2 & 1 & 326 & 1.75 & 1000 & 0.87033 & $<0.001$ & 87.033 & 88.4 & 344.5 & 5.47 & 7.501 \\
\hline S6-3 & 5 & $9-13$ & 8 & 2 & 1 & 326 & 1.75 & 1000 & 0.89971 & trace & 89.97 & 89.8 & 344.2 & 5.48 & 4.551 \\
\hline S6-4 & 7 & $7-13$ & 6 & 2 & 1 & 326 & 1.75 & 1000 & 0.9155 & $<0.001$ & 91.55 & 90.6 & 344 & 5.49 & 2.965 \\
\hline S6-5 & 10 & $4-13$ & 3 & 2 & 1 & 326 & 1.75 & 1000 & 0.9308 & 0.006 & 93.08 & 91.5 & 343.8 & 5.46 & 1.463 \\
\hline S6-6 & 11 & $3-13$ & 2 & 2 & 1 & 326 & 1.75 & 1000 & 0.93553 & 0.048 & 93.553 & 91.8 & 343.8 & 5.36 & 1.092 \\
\hline S6-7 & 12 & $2-13$ & 1 & 2 & 1 & 326 & 1.75 & 1000 & 0.94403 & 0.403 & 94.403 & 92.4 & 343.8 & 4.84 & 0.758 \\
\hline S6-8 & 13 & $2-14$ & 1 & 1 & 1 & 326 & 1.75 & 1000 & 0.9502 & 0.366 & 95.02 & 92.7 & 343.7 & 4.90 & 0.76 \\
\hline S6-9 & 1 & 3 & 2 & 12 & 1 & 326 & 1.75 & 1000 & 0.52726 & 1.814 & 52.726 & 76.4 & 349.1 & 6.37 & 40.90 \\
\hline S6-10 & 5 & $3-7$ & 2 & 8 & 1 & 326 & 1.75 & 1000 & 0.74064 & 0.104 & 74.064 & 83.1 & 346.2 & 5.07 & 20.86 \\
\hline S6-11 & 10 & $3-12$ & 2 & 3 & 1 & 326 & 1.75 & 1000 & 0.89791 & 0.065 & 89.791 & 89.8 & 344.2 & 5.28 & 4.929 \\
\hline S6-12 & 11 & $3-13$ & 2 & 2 & 1 & 326 & 1.75 & 1000 & 0.93553 & 0.048 & 93.553 & 91.8 & 343.8 & 5.36 & 1.092 \\
\hline S6-13 & 12 & $3-14$ & 2 & 1 & 1 & 326 & 1.75 & 1000 & 0.9451 & 0.043 & 94.509 & 92.4 & 343.7 & 5.38 & 0.114 \\
\hline S6-14 & 1 & 13 & 12 & 2 & 1.2 & 353 & 1.9 & 1500 & 0.83942 & trace & 41.971 & 72.5 & 345 & 1.06 & 6.967 \\
\hline S6-15 & 5 & $9-13$ & 8 & 2 & 1.2 & 353 & 1.9 & 1500 & 0.95288 & trace & 47.644 & 73.7 & 343.7 & 1.05 & 1.307 \\
\hline S6-16 & 10 & $4-13$ & 3 & 2 & 1.2 & 353 & 1.9 & 1500 & 0.96988 & 0.001 & 48.495 & 73.9 & 343.6 & 1.02 & 0.482 \\
\hline S6-17 & 11 & $3-13$ & 2 & 2 & 1.2 & 353 & 1.9 & 1500 & 0.97402 & 0.011 & 48.701 & 73.9 & 343.5 & 0.95 & 0.351 \\
\hline S6-18 & 12 & $2-13$ & 1 & 2 & 1.2 & 353 & 1.9 & 1500 & 0.98788 & 0.295 & 49.394 & 73.9 & 343.5 & 0.47 & 0.135 \\
\hline S6-19 & 1 & 3 & 2 & 12 & 1.2 & 353 & 1.9 & 1500 & 0.46984 & 0.067 & 23.492 & 68.8 & 350 & 1.09 & 25.44 \\
\hline S6-20 & 5 & $3-7$ & 2 & 8 & 1.2 & 353 & 1.9 & 1500 & & & & & & & \\
\hline S6-21 & 10 & $3-12$ & 2 & 3 & 1.2 & 353 & 1.9 & 1500 & 0.91572 & 0.011 & 45.785 & 73.2 & 344.1 & 0.94 & 3.265 \\
\hline S6-22 & 12 & $3-14$ & 2 & 1 & 1.2 & 353 & 1.9 & 1500 & 0.98076 & 0.011 & 49.038 & 74 & 343.5 & 0.94 & 0.014 \\
\hline
\end{tabular}


Tabla A7. Variación del número de etapas reactivas y no reactivas. Usando una razón de alimentación de $\mathrm{AO} / \mathrm{MeOH}$ de $1: 1$, Alimentando al $\mathrm{AO}$ en la etapa 2 a $326^{\circ} \mathrm{C}$ y el $\mathrm{MeOH}$ en la etapa 19 a $60^{\circ} \mathrm{C}, 20$ etapas totales, una relación de reflujo de $1 \mathrm{y}$ del rehervidor $1.75,1000 \mathrm{~kg}$ de catalizador y UNIFAC como método termodinámico.

\begin{tabular}{|c|c|c|c|c|c|c|c|c|c|c|c|}
\hline \multicolumn{6}{|c|}{ Entrada de simulación } & \multicolumn{6}{|c|}{ Salida de resultados } \\
\hline \multirow{3}{*}{$\begin{array}{l}\text { Corrid } \\
\text { a }\end{array}$} & \multicolumn{4}{|c|}{ Número de Etapas } & \multirow{3}{*}{$\begin{array}{c}\text { Conversión } \\
\text { del AO }\end{array}$} & \multicolumn{2}{|c|}{$\begin{array}{c}\text { Flujo de MO } \\
(\mathrm{kmol} / \mathrm{h})\end{array}$} & \multicolumn{2}{|c|}{ Temperatura $\left({ }^{\circ} \mathrm{C}\right)$} & \multicolumn{2}{|c|}{ Flujo de $\mathrm{AO}(\mathrm{kmol} / \mathrm{h})$} \\
\hline & \multicolumn{2}{|c|}{ Rxn } & \multirow{2}{*}{$\begin{array}{l}\text { Rectific } \\
\text { ación }\end{array}$} & \multirow{2}{*}{$\begin{array}{l}\text { Agota } \\
\text { miento }\end{array}$} & & \multirow[t]{2}{*}{ Domo } & \multirow[t]{2}{*}{ Total } & \multirow[t]{2}{*}{ Domo } & \multirow[t]{2}{*}{ Fondo } & \multirow[t]{2}{*}{ Domo } & \multirow[t]{2}{*}{ Fondo } \\
\hline & Total & Rango & & & & & & & & & \\
\hline S7-1 & 16 & $3-18$ & 2 & 2 & 0.94341 & 0.044 & 94.341 & 92.3 & 343.7 & 5.372 & 0.287 \\
\hline S7-2 & 15 & $4-18$ & 3 & 2 & 0.94132 & 0.005 & 94.132 & 92.1 & 343.7 & 5.467 & 0.401 \\
\hline S7-3 & 14 & $5-18$ & 4 & 2 & 0.93977 & 0.001 & 93.977 & 92 & 343.7 & 5.489 & 0.534 \\
\hline S7-4 & 11 & $8-18$ & 7 & 2 & 0.93337 & trace & 93.337 & 91.6 & 343.8 & 5.495 & 1.168 \\
\hline$S 7-5$ & 11 & $7-17$ & 6 & 3 & & & & & & & \\
\hline S7-6 & 10 & $7-16$ & 10 & 2 & 0.84434 & $<0.001$ & 84.434 & 87.2 & 344.8 & 5.454 & 10.112 \\
\hline
\end{tabular}

Tabla A8. Variación del número de etapas reactivas y no reactivas. Usando una razón de alimentación de $\mathrm{AO} / \mathrm{MeOH}$ de $1: 1$, Alimentando al $\mathrm{AO}$ a $326^{\circ} \mathrm{C}$ y el $\mathrm{MeOH}$ en la etapa 24 a $60^{\circ} \mathrm{C}, 25$ etapas totales, una relación de reflujo de $1 \mathrm{y}$ del rehervidor de $1.75,1000 \mathrm{~kg}$ de catalizador y UNIFAC como método termodinámico.

\begin{tabular}{|c|c|c|c|c|c|c|c|c|c|c|c|c|}
\hline \multicolumn{6}{|c|}{ Entrada de simulación } & \multicolumn{7}{|c|}{ Salida de resultados } \\
\hline \multirow[t]{3}{*}{$\begin{array}{l}\text { Corrid } \\
\text { a }\end{array}$} & \multicolumn{4}{|c|}{ Número de Etapas } & \multirow{3}{*}{$\begin{array}{l}\text { Alim } \\
\text {. del } \\
\text { AO }\end{array}$} & \multirow[t]{3}{*}{$\begin{array}{c}\text { Conversión } \\
\text { del AO }\end{array}$} & \multicolumn{2}{|c|}{$\begin{array}{c}\text { Flujo de MO } \\
(\mathrm{kmol} / \mathrm{h})\end{array}$} & \multicolumn{2}{|c|}{$\begin{array}{l}\text { Temperatura } \\
\left({ }^{\circ} \mathrm{C}\right)\end{array}$} & \multicolumn{2}{|c|}{$\begin{array}{c}\text { Flujo de AO } \\
(\mathrm{kmol} / \mathrm{h})\end{array}$} \\
\hline & \multicolumn{2}{|c|}{ Rxn } & \multirow{2}{*}{$\begin{array}{l}\text { Rectifi } \\
\text { cación }\end{array}$} & \multirow{2}{*}{$\begin{array}{l}\text { Agota } \\
\text { miento }\end{array}$} & & & Domo & Total & Dom & Fondo & Domo & Fondo \\
\hline & Total & Rango & & & & & & & o & & & \\
\hline S8-1 & 16 & $8-23$ & 7 & 2 & 7 & 0.99155 & 1.163 & 99.155 & 94.8 & 343.8 & 0.845 & trace \\
\hline S8-2 & 17 & $7-23$ & 6 & 2 & 6 & 0.9904 & 1.031 & 99.04 & 94.6 & 343.8 & 0.96 & trace \\
\hline S8-3 & 18 & $6-23$ & 5 & 2 & 5 & 0.98903 & 0.876 & 98.903 & 95.1 & 343.8 & 1.097 & trace \\
\hline S8-4 & 14 & $10-23$ & 9 & 2 & 9 & 0.99329 & 0.915 & 99.329 & 94.6 & 343.8 & 0,671 & trace \\
\hline S8-5 & 13 & $11-23$ & 10 & 2 & 10 & 0.9939 & 1.438 & 99.39 & 94.5 & 343.8 & 0.61 & trace \\
\hline S8-6 & 15 & $9-23$ & 8 & 2 & 8 & & & & & & & \\
\hline S8-7 & 15 & $8-22$ & 7 & 3 & 8 & & & & & & & \\
\hline S8-8 & 14 & $10-23$ & 9 & 2 & 8 & 0.98937 & 0.915 & 98.937 & 95.1 & 343.8 & 1,063 & trace \\
\hline S8-9 & 13 & $11-23$ & 10 & 2 & 8 & 0.98645 & 0.592 & 98.052 & 95.6 & 343.8 & 1.355 & trace \\
\hline S8-10 & 12 & $12-23$ & 11 & 2 & 8 & & & & & & & \\
\hline S8-11 & 11 & $13-23$ & 12 & 2 & 8 & 0.98282 & 0.208 & 98.282 & 96.5 & 343.8 & 1.718 & trace \\
\hline S8-12 & 10 & $14-23$ & 13 & 2 & 8 & 0.98193 & 0.118 & 98.193 & 96.7 & 343.8 & 1.807 & $<0.001$ \\
\hline S8-13 & 7 & $17-23$ & 16 & 2 & 8 & 0.97999 & 0.023 & 97.999 & 96.8 & 343.8 & 1.99 & 0.011 \\
\hline
\end{tabular}


Tabla A9. Variación del número de etapas totales, reactivas y no reactivas. Alimentación del $\mathrm{MeOH}$ una etapa después de la última etapa reactiva. Usando una razón de alimentación de $\mathrm{AO} / \mathrm{MeOH}$ de 1:1, Alimentando al $\mathrm{AO}$ a $326^{\circ} \mathrm{C}$, una relación de reflujo de $1 \mathrm{y}$ del rehervidor de $1.75,1000 \mathrm{~kg}$ de catalizador y UNIFAC como método termodinámico.

\begin{tabular}{|c|c|c|c|c|c|c|c|c|c|c|c|c|c|c|}
\hline \multicolumn{9}{|c|}{ Entrada de simulación } & \multicolumn{6}{|c|}{ Salida de resultados } \\
\hline \multirow[t]{2}{*}{$\begin{array}{c}\text { Corrid } \\
\mathrm{a}\end{array}$} & \multirow[b]{2}{*}{$\begin{array}{l}\text { To } \\
\text { tal }\end{array}$} & \multicolumn{3}{|c|}{ Número de Etapas } & \multirow[b]{2}{*}{ Total } & \multirow{2}{*}{$\begin{array}{c}\text { Ali } \\
\text { m. } \\
\text { del } \\
\text { A } \\
\text { O }\end{array}$} & \multirow{2}{*}{$\begin{array}{c}\text { Tempe } \\
\text { ratura } \\
\text { de } \\
\text { alim. } \\
\left({ }^{\circ} \mathrm{C}\right) \\
\mathrm{MeOH}\end{array}$} & \multirow{2}{*}{$\begin{array}{c}\text { Conversi } \\
\text { ón del } \\
\text { AO }\end{array}$} & \multicolumn{2}{|c|}{$\begin{array}{c}\text { Flujo de MO } \\
(\mathrm{Kmol} / \mathrm{h})\end{array}$} & \multicolumn{2}{|c|}{$\begin{array}{l}\text { Temperatura } \\
\left({ }^{\circ} \mathrm{C}\right)\end{array}$} & \multicolumn{2}{|c|}{$\begin{array}{c}\text { Flujo de AO } \\
(\mathrm{Kmol} / \mathrm{h})\end{array}$} \\
\hline & & $\begin{array}{l}\text { Rxn } \\
\text { Rango }\end{array}$ & $\begin{array}{l}\text { Re } \\
\text { cti } \\
\text { fic } \\
\text { aci } \\
\text { ón }\end{array}$ & $\begin{array}{c}\text { Agot } \\
\text { amie } \\
\text { nto }\end{array}$ & & & & & Domo & Total & $\begin{array}{c}\text { Dom } \\
\text { o }\end{array}$ & Fondo & $\begin{array}{c}\text { Dom } \\
\text { o }\end{array}$ & $\begin{array}{c}\text { Fond } \\
\text { o }\end{array}$ \\
\hline S9-1 & 15 & $15-28$ & 14 & 2 & 30 & 14 & 55 & 0.99541 & 1.494 & 99.541 & 93.9 & 343.8 & 0.459 & trace \\
\hline S9-2 & 16 & $13-28$ & 12 & 2 & 30 & 11 & 55 & & & & & & & \\
\hline S9-3 & 17 & $12-28$ & 11 & 2 & 30 & 11 & 55 & 0.99469 & 1.407 & 97.889 & 93.9 & 343.9 & 0.531 & trace \\
\hline S9-4 & 17 & $12-28$ & 11 & 2 & 30 & 12 & 60 & 0.99723 & 1.836 & 99.723 & 94.4 & 343.8 & 0.277 & trace \\
\hline S9-5 & 17 & $12-28$ & 11 & 2 & 30 & 12 & 55 & 0.99738 & 1.732 & 99.738 & 93.7 & 343.8 & 0.262 & trace \\
\hline S9-6 & 18 & $11-28$ & 10 & 2 & 30 & 11 & 55 & & & & & & & \\
\hline S9-7 & 15 & $16-30$ & 15 & 2 & 32 & 16 & 55 & & & & & & & \\
\hline S9-8 & 15 & $16-30$ & 15 & 2 & 32 & 15 & 55 & 0.99552 & 1.507 & 99.552 & 93.9 & 343.8 & 0.1 & trace \\
\hline S9-9 & 16 & $15-30$ & 14 & 2 & 32 & 15 & 55 & 0.99802 & 1.732 & 99.802 & 93.7 & 343.8 & 0.198 & trace \\
\hline S9-10 & 17 & $14-30$ & 13 & 2 & 32 & 14 & 55 & 0.99786 & 1.791 & 99.786 & 93.7 & 343.8 & 0.214 & trace \\
\hline S9-11 & 18 & $13-30$ & 12 & 2 & 32 & 13 & 55 & 0.99766 & 1.766 & 99.766 & 93.7 & 343.8 & 0.234 & trace \\
\hline S9-12 & 15 & $17-32$ & 16 & 2 & 34 & 17 & 55 & 0.9982 & 1.832 & 99.82 & 93.7 & 343.8 & 0.18 & trace \\
\hline S9-13 & 16 & $16-32$ & 15 & 2 & 34 & 16 & 55 & 0.99813 & 1.823 & 99.813 & 93.7 & 343.8 & 0.187 & trace \\
\hline S9-14 & 16 & $16-32$ & 15 & 2 & 34 & 15 & 55 & & & & & & & \\
\hline
\end{tabular}


Tabla A10. Variación del número de etapas totales y reactivas. La alimentación del MeOH una etapa después de la última etapa reactiva. Usando una razón de alimentación de $\mathrm{AO} / \mathrm{MeOH}$ de 1:1, Alimentando al MeOH a $55^{\circ} \mathrm{C}$, una relación de reflujo de 1 y del rehervidor de $1.75,1000 \mathrm{~kg}$ de catalizador y UNIQUAC como método termodinámico.

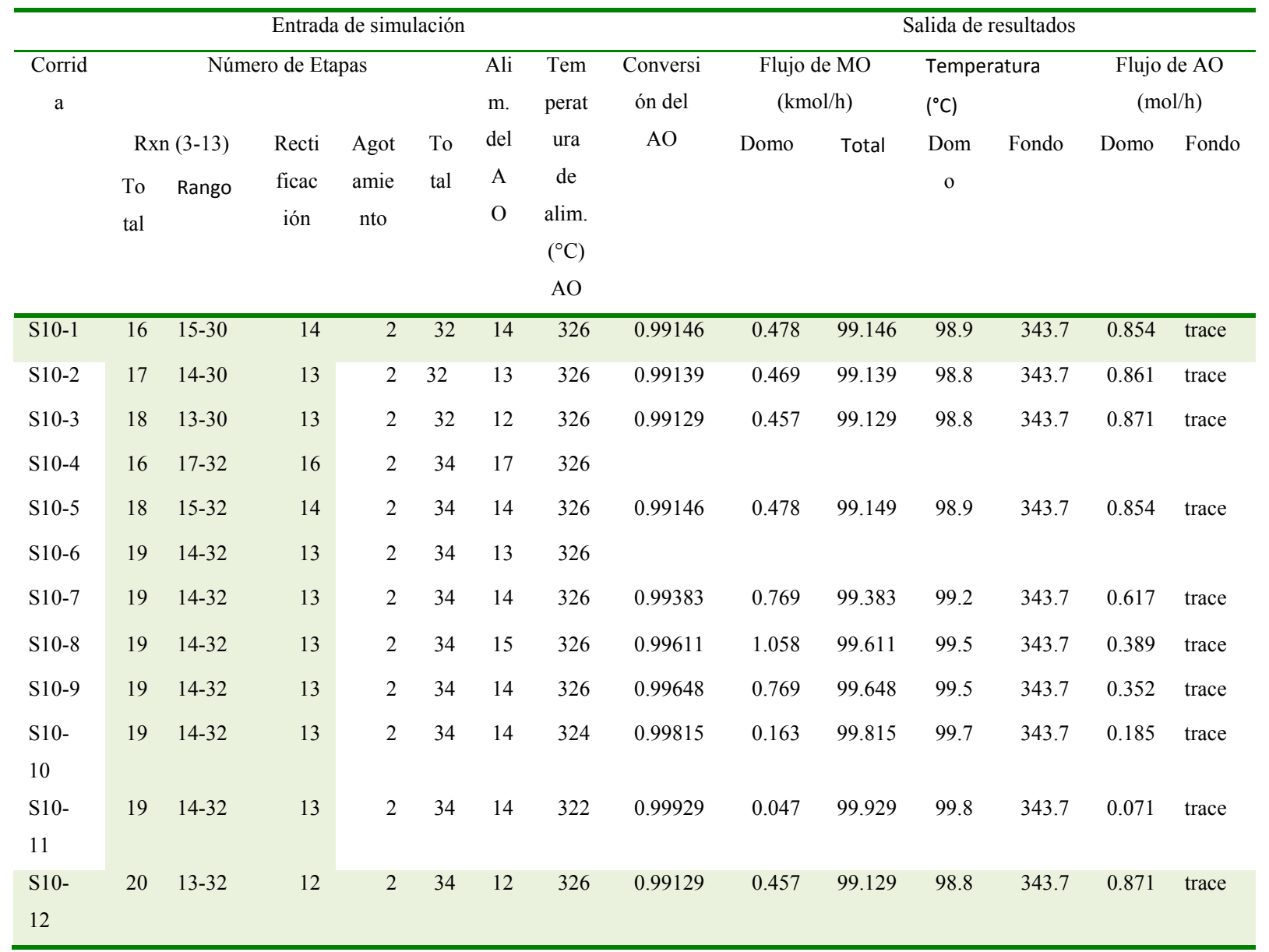




\section{Apéndice B. Columna de Destilación Reactiva con Condensador Parcial. (CDR-CP), para la reacción de esterificación.}

Tabla B1- Variación de reflujo. Usando una razón de alimentación de $\mathrm{AO} / \mathrm{MeOH}$ de 1:1, alimentando al AO en la etapa 2 a $326^{\circ} \mathrm{C}$, el $\mathrm{MeOH}$ en la etapa 14 a $55^{\circ} \mathrm{C}, 15$ etapas totales, 2 de agotamiento, 2 de rectificación y 11 reactivas (3-13), una relación del rehervidor de $1,1000 \mathrm{~kg}$ de catalizador y UNIQUAC como método termodinámico.

\begin{tabular}{|c|c|c|c|c|c|c|c|c|}
\hline \multicolumn{2}{|c|}{ Entrada de simulación } & \multicolumn{7}{|c|}{ Salida de resultados } \\
\hline \multirow[t]{2}{*}{ Corrida } & \multirow[t]{2}{*}{ Reflujo } & \multirow[t]{2}{*}{$\begin{array}{c}\text { Conversión } \\
\text { del AO }\end{array}$} & \multicolumn{2}{|c|}{$\begin{array}{c}\text { Flujo de MO } \\
(\mathrm{kmol} / \mathrm{h})\end{array}$} & \multicolumn{2}{|c|}{ Temperatura $\left({ }^{\circ} \mathrm{C}\right)$} & \multicolumn{2}{|c|}{$\begin{array}{c}\text { Flujo de AO } \\
(\mathrm{kmol} / \mathrm{h})\end{array}$} \\
\hline & & & Domo & Total & Domo & Fondo & Domo & Fondo \\
\hline S1-1 & 0.1 & 0.77104 & 1.305 & 77.104 & 111.1 & 342.1 & 22.787 & 0.10 \\
\hline S1-2 & 0.2 & 0.81534 & 0.752 & 81.534 & 106.2 & 342.3 & 17.454 & 1.01 \\
\hline S1-3 & 0.3 & 0.8334 & 0.458 & 83.34 & 102.6 & 342.6 & 13.715 & 2.94 \\
\hline S1-4 & 0.4 & 0.83711 & 0.295 & 83.711 & 99.9 & 343 & 10.978 & 5.31 \\
\hline S1-5 & 0.5 & 0.8329 & 0.197 & 83.29 & 97.7 & 343.4 & 8.914 & 7.79 \\
\hline S1-6 & 0.6 & 0.82376 & 0.136 & 82.376 & 95.9 & 343.8 & 7.317 & 10.30 \\
\hline S1-7 & 0.7 & 0.81123 & 0.095 & 81.123 & 94.4 & 344.1 & 6.051 & 12.82 \\
\hline S1-8 & 0.8 & 0.7961 & 0.067 & 79.61 & 93.1 & 344.5 & 5.03 & 15.3 \\
\hline S1-9 & 0.9 & 0.7791 & 0.048 & 77.91 & 91.9 & 344.9 & 4.193 & 17.89 \\
\hline S1-10 & 1 & 0.7602 & 0.034 & 76.02 & 90.6 & 345.2 & 3.5 & 20.48 \\
\hline
\end{tabular}

Tabla B2- Variación del rehervidor. Usando una razón de alimentación de $\mathrm{AO} / \mathrm{MeOH}$ de 1:1, alimentando al $\mathrm{AO}$ en la etapa 2 a $326^{\circ} \mathrm{C}$, el $\mathrm{MeOH}$ en la etapa 14 a $55^{\circ} \mathrm{C}, 15$ etapas totales, 2 de agotamiento y 2 de rectificación y 11 reactivas (3-13), la relación de reflujo $0.4,1000 \mathrm{~kg}$ de catalizador y UNIQUAC como método termodinámico.

\begin{tabular}{|c|c|c|c|c|c|c|c|c|}
\hline \multicolumn{2}{|c|}{ Entrada de simulación } & \multicolumn{7}{|c|}{ Salida de resultados } \\
\hline \multirow[t]{2}{*}{ Corrida } & \multirow[t]{2}{*}{ Rehervidor } & \multirow[t]{2}{*}{$\begin{array}{c}\text { Conversión } \\
\text { del AO }\end{array}$} & \multirow{2}{*}{ 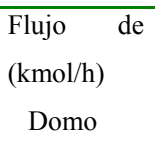 } & \multirow{2}{*}{$\begin{array}{r}\text { MO } \\
\text { Total }\end{array}$} & \multicolumn{2}{|c|}{ Temperatura $\left({ }^{\circ} \mathrm{C}\right)$} & \multicolumn{2}{|c|}{$\begin{array}{c}\text { Flujo de AO } \\
(\mathrm{kmol} / \mathrm{h})\end{array}$} \\
\hline & & & & & Domo & Fondo & Domo & Fondo \\
\hline S2-1 & 1 & 0.83711 & 0.295 & 83.711 & 99.85 & 343 & 10.978 & 5.311 \\
\hline S2-2 & 1.1 & 0.84297 & 0.289 & 84.297 & 100.05 & 343.17 & 11.007 & 4.696 \\
\hline $\mathrm{S} 2-3$ & 1.2 & 0.84946 & 0.283 & 84.946 & 100.27 & 343.27 & 11.040 & 4.014 \\
\hline S2-4 & 1.3 & 0.85647 & 0.276 & 85.647 & 100.51 & 343.32 & 11.077 & 3.277 \\
\hline S2-5 & 1.4 & 0.86421 & 0.267 & 86.421 & 100.77 & 343.32 & 11.118 & 2.461 \\
\hline S2-6 & 1.5 & 0.87225 & 0.258 & 87.225 & 101.04 & 343.3 & 11.163 & 1.612 \\
\hline S2-7 & 1.6 & 0.88018 & 0.249 & 88.018 & 101.31 & 343.26 & 11.208 & 0.775 \\
\hline S2-8 & 1.7 & 0.88631 & 0.242 & 88.631 & 101.52 & 343.24 & 11.245 & 0.125 \\
\hline S2-9 & 1.8 & 0.88154 & 0.501 & 88.154 & 102.2 & 343.26 & 11.846 & 0 \\
\hline S2-10 & 1.9 & 0.8718 & 1.154 & 87.18 & 103.49 & 343.29 & 12.820 & 0 \\
\hline S2-11 & 2 & 0.86363 & 1.906 & 86.363 & 104.83 & 343.3 & 13.637 & 0 \\
\hline S2-12 & 2.1 & 0.85654 & 2.713 & 85.654 & 106.17 & 343.32 & 14.346 & 0 \\
\hline
\end{tabular}


Tabla B3-Mejor combinación de relación del rehervidor y reflujo. Usando una razón de alimentación de $\mathrm{AO} / \mathrm{MeOH}$ de $1: 1$, alimentando al $\mathrm{AO}$ en la etapa 2 a $326^{\circ} \mathrm{C}$, el $\mathrm{MeOH}$ en la etapa 14 a $55^{\circ} \mathrm{C}, 15$ etapas totales, 2 de agotamiento y 2 de rectificación y 11 reactivas (3-13), 1000kg de catalizador y UNIQUAC como método termodinámico.

\begin{tabular}{|c|c|c|c|c|c|c|c|c|c|c|}
\hline \multicolumn{4}{|c|}{ Entrada de simulación } & \multicolumn{7}{|c|}{ Salida de resultados } \\
\hline \multirow[t]{2}{*}{ Corrida } & \multirow{2}{*}{$\begin{array}{c}\text { Alim. } \\
\text { del } \\
\text { AO }\end{array}$} & \multirow[t]{2}{*}{ Reflujo } & \multirow[t]{2}{*}{ Rehervidor } & \multirow[t]{2}{*}{$\begin{array}{c}\text { Conversión } \\
\text { del AO }\end{array}$} & \multicolumn{2}{|c|}{$\begin{array}{c}\text { Flujo de MO } \\
(\mathrm{kmol} / \mathrm{h})\end{array}$} & \multicolumn{2}{|c|}{ Temperatura $\left({ }^{\circ} \mathrm{C}\right)$} & \multicolumn{2}{|c|}{$\begin{array}{c}\text { Flujo de AO } \\
(\mathrm{kmol} / \mathrm{h})\end{array}$} \\
\hline & & & & & Domo & Total & Domo & Fondo & Domo & Fondo \\
\hline S3-1 & 2 & 1 & 2 & 0.95906 & 0.008 & 0.95906 & 98.4 & 343.4 & 3.696 & 0.398 \\
\hline S3-2 & 2 & 0.9 & 1.9 & 0.93504 & 0.018 & 93.504 & 97.8 & 343.6 & 4.378 & 2.118 \\
\hline S3-3 & 2 & 0.9 & 2 & 0.95206 & 0.059 & 95.206 & 98.6 & 343.3 & 4.79 & 0.004 \\
\hline S3-4 & 2 & 0.9 & 2.1 & 0.94348 & 0.299 & 94.348 & 98.9 & 343.4 & 5.651 & 0.001 \\
\hline
\end{tabular}

Tabla B4- Variación del número de etapas totales y no reactivas. Usando una razón de alimentación de $\mathrm{AO} / \mathrm{MeOH}$ de $1: 1$, alimentando al $\mathrm{AO}$ a $326^{\circ} \mathrm{C}$, una relación de reflujo de 0.9 y una relación del rehervidor de $2,1000 \mathrm{~kg}$ de catalizador y UNIQUAC como método termodinámico.

\begin{tabular}{|c|c|c|c|c|c|c|c|c|c|c|c|c|c|c|}
\hline \multicolumn{9}{|c|}{ Entrada de simulación } & \multicolumn{6}{|c|}{ Salida de resultados } \\
\hline \multirow[t]{3}{*}{ Corrida } & \multicolumn{5}{|c|}{ Número de Etapas } & \multirow{3}{*}{$\begin{array}{l}\text { Ali } \\
\text { m. } \\
\text { del } \\
\text { A } \\
\text { O }\end{array}$} & \multirow{3}{*}{$\begin{array}{c}\text { Tempe } \\
\text { ratura } \\
\text { de } \\
\text { alim. } \\
\left({ }^{\circ} \mathrm{C}\right) \\
\mathrm{MeOH}\end{array}$} & \multirow{3}{*}{$\begin{array}{c}\text { Conversi } \\
\text { ón del } \\
\text { AO }\end{array}$} & \multicolumn{2}{|c|}{$\begin{array}{c}\text { Flujo de MO } \\
(\mathrm{kmol} / \mathrm{h})\end{array}$} & \multicolumn{2}{|c|}{$\begin{array}{l}\text { Temperatura } \\
\left({ }^{\circ} \mathrm{C}\right)\end{array}$} & \multicolumn{2}{|c|}{$\begin{array}{c}\text { Flujo de AO } \\
(\mathrm{kmol} / \mathrm{h})\end{array}$} \\
\hline & & $\mathrm{kn}$ & Recti & Agot & To & & & & Domo & Total & Dom & Fondo & Domo & Fondo \\
\hline & $\begin{array}{c}\text { Tota } \\
1\end{array}$ & $\begin{array}{l}\text { Rang } \\
\text { o }\end{array}$ & $\begin{array}{l}\text { ficac } \\
\text { ión }\end{array}$ & $\begin{array}{l}\text { amie } \\
\text { nto }\end{array}$ & tal & & & & & & o & & & \\
\hline S4-1 & 11 & $3-13$ & 2 & 2 & 15 & 2 & 60 & 0.95216 & 0.057 & 95.216 & 98.6 & 343.3 & 4.784 & $<0.001$ \\
\hline S4-2 & 13 & $3-15$ & 2 & 2 & 17 & 2 & 60 & & & & & & & \\
\hline S4-3 & 12 & $4-15$ & 3 & 2 & 17 & 4 & 60 & 0.97145 & 2.031 & 97.145 & 99.4 & 343.4 & 2.855 & $<0.001$ \\
\hline S4-4 & 11 & $5-15$ & 4 & 2 & 17 & 4 & 60 & 0.96575 & 2.031 & 96.576 & 99.1 & 343.3 & 3.425 & 0.001 \\
\hline S4-5 & 12 & $5-16$ & 4 & 2 & 18 & 4 & 60 & 0.96576 & 1.442 & 96.576 & 99.1 & 343.3 & 3.424 & $<0.001$ \\
\hline S4-6 & 12 & $5-16$ & 4 & 2 & 18 & 5 & 60 & 0.97443 & 2.341 & 97.443 & 99.5 & 343.3 & 2.557 & $<0.001$ \\
\hline S4-7 & 13 & $4-16$ & 3 & 2 & 18 & 3 & 60 & 0.965183 & 1.039 & 96.183 & 99 & 343.3 & 3.817 & trace \\
\hline S4-8 & 13 & $4-16$ & 3 & 2 & 18 & 4 & 60 & 0.97146 & 2.03 & 97.146 & 99.4 & 343.3 & 2.854 & $<0.001$ \\
\hline S4-9 & 12 & $7-18$ & 6 & 2 & 20 & 7 & 60 & 0.9787 & 2.788 & 97.87 & 99.6 & 343.3 & 2.13 & $<0.001$ \\
\hline S4-10 & 13 & $6-18$ & 5 & 2 & 20 & 6 & 60 & 0.97678 & 2.585 & 97.678 & 99.6 & 343.3 & 2.322 & $<0.001$ \\
\hline S4-11 & 12 & $7-18$ & 6 & 2 & 20 & 6 & 55 & 0.97 .078 & 1.88 & 97.078 & 99.3 & 343.3 & 2.922 & $<0.001$ \\
\hline S4-12 & 13 & $6-18$ & 5 & 2 & 20 & 5 & 55 & 0.96872 & 1.666 & 96.872 & 99.2 & 343.3 & 3.128 & $<0.001$ \\
\hline S4-13 & 11 & $8-18$ & 7 & 2 & 20 & 7 & 55 & 0.97244 & 2.756 & 97.244 & 99.4 & 343.3 & 2.756 & 0.001 \\
\hline S4-14 & 13 & $8-20$ & 7 & 2 & 22 & 7 & 55 & 0.97245 & 2.053 & 97.245 & 99.4 & 343.3 & 2.755 & $<0.001$ \\
\hline S4-15 & 14 & $7-20$ & 6 & 2 & 22 & 6 & 55 & 0.97078 & 1.879 & 97.078 & 99.3 & 343.3 & 2.922 & trace \\
\hline S4-16 & 14 & $7-20$ & 6 & 2 & 22 & 7 & 55 & 0.9789 & 2.726 & 97.89 & 99.6 & 343.3 & 2.11 & trace \\
\hline S4-17 & 14 & $7-20$ & 6 & 2 & 22 & 7 & 60 & 0.9787 & 2.786 & 97.87 & 99.6 & 343.3 & 2.13 & trace \\
\hline S4-18 & 14 & $9-22$ & 8 & 2 & 24 & 9 & 55 & 0.98164 & 3.015 & 98.164 & 99.7 & 343.3 & 1.836 & trace \\
\hline S4-19 & 15 & $8-22$ & 7 & 2 & 24 & 8 & 55 & 0.98043 & 2.887 & 98.043 & 99.7 & 343.3 & 1.957 & Trace \\
\hline
\end{tabular}


Tabla B5.- Variación de la relación de reflujo y del rehervidor. Usando una razón de alimentación de $\mathrm{AO} / \mathrm{MeOH}$ de 1:1, alimentando al AO en la etapa 9 a $326^{\circ} \mathrm{C}$, el MeOH en la etapa 21, 24 etapas totales, 2 de agotamiento y 8 de rectificación y 14 reactivas $(9-22), 1000 \mathrm{~kg}$ de catalizador y UNIQUAC como método termodinámico.

\begin{tabular}{|c|c|c|c|c|c|c|c|c|c|c|}
\hline \multicolumn{5}{|c|}{ Entrada de simulación } & \multicolumn{6}{|c|}{ Salida de resultados } \\
\hline \multirow[t]{2}{*}{ Corrida } & \multirow[t]{2}{*}{ Reflujo } & \multirow{2}{*}{$\begin{array}{c}\text { T de alim. } \\
\left({ }^{\circ} \mathrm{C}\right) \\
\mathrm{MeOH}\end{array}$} & \multirow[t]{2}{*}{ Rehervidor } & \multirow[t]{2}{*}{$\begin{array}{c}\text { Conversión } \\
\text { del AO }\end{array}$} & \multicolumn{2}{|c|}{$\begin{array}{c}\text { Flujo de MO } \\
(\mathrm{kmol} / \mathrm{h})\end{array}$} & \multicolumn{2}{|c|}{ Temperatura $\left({ }^{\circ} \mathrm{C}\right)$} & \multicolumn{2}{|c|}{$\begin{array}{c}\text { Flujo de AO } \\
(\mathrm{kmol} / \mathrm{h})\end{array}$} \\
\hline & & & & & Domo & Total & Domo & Fondo & Domo & Fondo \\
\hline S5-1 & 0.9 & 55 & 1.97 & 0.98237 & 2.751 & 98.237 & 99.6 & 343.3 & 1.763 & trace \\
\hline S5-2 & 0.91 & 55 & 1.97 & 0.98293 & 2.6821 & 98.293 & 99.6 & 343.3 & 1.707 & trace \\
\hline S5-3 & 0.95 & 55 & 1.97 & 0.98503 & 2.411 & 98.503 & 99.5 & 343.3 & 1.497 & trace \\
\hline S5-4 & 1 & 55 & 1.97 & 0.9874 & 2.086 & 98.74 & 99.4 & 343.3 & 1.26 & $<0.001$ \\
\hline S5-5 & 1 & 55 & 1.9 & 0.98928 & 1.526 & 98.928 & 99.4 & 343.3 & 1.072 & $<0.001$ \\
\hline S5-6 & 1 & 55 & 1.8 & 0.99252 & 1.526 & 99.252 & 99.5 & 343.3 & 0.748 & $<0.001$ \\
\hline S5-7 & 1 & 55 & 1.7 & 0.99644 & 0.197 & 99.644 & 99.7 & 343.3 & 0.348 & 0.008 \\
\hline S5-8 & 1 & 55 & 1.6 & 0.99664 & 0.033 & 99.664 & 99.5 & 343.3 & 0.0 .048 & 0.288 \\
\hline S5-9 & 1 & 55 & 1.65 & 0.99744 & 0.073 & 99.744 & 99.6 & 343.3 & 0.0 .161 & 0.095 \\
\hline S5-10 & 1.1 & 55 & 1.65 & 0.99794 & 0.005 & 99.794 & 99.6 & 343.3 & 0.007 & 0.199 \\
\hline S5-11 & 1.1 & 60 & 1.65 & 0.99803 & 0.007 & 99.803 & 99.6 & 343.3 & 0.009 & 0.188 \\
\hline S5-12 & 1.1 & 60 & 1.7 & 0.99828 & 0.39 & 99.828 & 99.6 & 343.3 & 0.068 & 0.104 \\
\hline S5-13 & 1.2 & 60 & 1.7 & 0.99849 & 0.001 & 99.849 & 99.6 & 343.3 & 0.001 & 0.152 \\
\hline S5-14 & 1.2 & 60 & 1.75 & 0.99901 & 0.015 & 99.901 & 99.6 & 343.3 & 0.019 & 0.118 \\
\hline
\end{tabular}




\section{Apéndice C. Columna de Destilación Reactiva sin Condensador (CDR-SC), para la reacción de esterificación.}

Tabla C1.- Variación de reflujo. Usando una razón de alimentación de $\mathrm{AO} / \mathrm{MeOH}$ de 1:1, alimentando al AO en la etapa 2 a $326^{\circ} \mathrm{C}$, el $\mathrm{MeOH}$ en la etapa 14 a $55^{\circ} \mathrm{C}, 15$ etapas totales, 2 de agotamiento, 2 de rectificación y 11 reactivas (3-13), una relación del rehervidor de $1,1000 \mathrm{~kg}$ de catalizador y UNIQUAC como método termodinámico.

\begin{tabular}{|c|c|c|c|c|c|c|c|c|c|c|}
\hline \multicolumn{4}{|c|}{ Entrada de simulación } & \multicolumn{7}{|c|}{ Salida de resultados } \\
\hline \multirow[t]{2}{*}{ Corrida } & \multirow[t]{2}{*}{ Reflujo } & \multicolumn{2}{|c|}{$\mathrm{T}$ de alim. $\left({ }^{\circ} \mathrm{C}\right)$} & \multirow[t]{2}{*}{$\begin{array}{l}\text { Conversión } \\
\text { del AO }\end{array}$} & \multicolumn{2}{|c|}{ Flujo de $\mathrm{MO}(\mathrm{kmol} / \mathrm{h})$} & \multicolumn{2}{|c|}{ Temperatura $\left({ }^{\circ} \mathrm{C}\right)$} & \multicolumn{2}{|c|}{$\begin{array}{c}\text { Flujo de AO } \\
(\mathrm{kmol} / \mathrm{h})\end{array}$} \\
\hline & & $\mathrm{AO}$ & $\mathrm{MeOH}$ & & Domo & Total & Domo & Fondo & Domo & Fondo \\
\hline S1-1 & 0.1 & 326 & 55 & 0.78551 & 1.673 & 78.551 & 295.68 & 342.13 & 21.412 & 0.037 \\
\hline $\mathrm{S} 1-2$ & 0.2 & 326 & 55 & 0.87272 & 0.862 & 87.272 & 280.03 & 342.38 & 11.975 & 0.754 \\
\hline $\mathrm{S} 1-3$ & 0.3 & 326 & 55 & 0.90744 & 0.001 & 90.744 & 147.29 & 343.7 & 0.014 & 9.241 \\
\hline $\mathrm{S} 1-4$ & 0.4 & 326 & 55 & 0.88765 & $9.5 \mathrm{E}-05$ & 88.765 & 120.57 & 343.95 & 0.001 & 11.234 \\
\hline $\mathrm{S} 1-5$ & 0.5 & 326 & 55 & 0.87015 & $2.3 \mathrm{E}-05$ & 87.015 & 110.4 & 344.18 & 0 & 12.984 \\
\hline S1-6 & 0.6 & 326 & 55 & 0.85233 & $8.1 \mathrm{E}-06$ & 85.233 & 104.67 & 344.42 & 0 & 14.767 \\
\hline S1-7 & 0.7 & 326 & 55 & 0.83386 & $3.4 \mathrm{E}-06$ & 83.386 & 101 & 344.67 & 0 & 16.614 \\
\hline $\mathrm{S} 1-8$ & 0.8 & 326 & 55 & 0.81445 & $1.7 \mathrm{E}-06$ & 81.445 & 98.46 & 344.93 & 0 & 18.555 \\
\hline S1-9 & 0.9 & 326 & 55 & 0.79411 & $9.2 \mathrm{E}-07$ & 79.411 & 96.59 & 345.21 & 0 & 20.589 \\
\hline $\mathrm{S} 1-10$ & 1 & 326 & 55 & 0.77305 & $5.3 \mathrm{E}-07$ & 77.305 & 95.16 & 345.5 & 0 & 22.695 \\
\hline
\end{tabular}

Tabla C2.- Variación del rehervidor. Usando una razón de alimentación de $\mathrm{AO} / \mathrm{MeOH}$ de 1:1, alimentando al $\mathrm{AO}$ en la etapa 2 a $326^{\circ} \mathrm{C}$, el $\mathrm{MeOH}$ en la etapa 14 a $55^{\circ} \mathrm{C}, 15$ etapas totales, 2 de agotamiento y 2 de rectificación y 11 reactivas (3-13), la relación de reflujo 1, 1000kg de catalizador y UNIQUAC como método termodinámico.

\begin{tabular}{|c|c|c|c|c|c|c|c|c|}
\hline \multicolumn{3}{|c|}{ Entrada de simulación } & \multicolumn{6}{|c|}{ Salida de resultados } \\
\hline \multirow[t]{2}{*}{ Corrida } & \multirow[t]{2}{*}{ Rehervidor } & \multirow[t]{2}{*}{ Conversión del AO } & \multicolumn{2}{|c|}{ Flujo de $\mathrm{MO}(\mathrm{kmol} / \mathrm{h})$} & \multicolumn{2}{|c|}{ Temperatura $\left({ }^{\circ} \mathrm{C}\right)$} & \multicolumn{2}{|c|}{ Flujo de $\mathrm{AO}(\mathrm{kmol} / \mathrm{h})$} \\
\hline & & & Domo & Total & Domo & Fondo & Domo & Fondo \\
\hline S2-1 & 1 & 0.90744 & 0.001 & 90.744 & 88.48 & 343.7 & 0.01 & 9.24 \\
\hline S2-2 & 1.1 & 0.91419 & 0.001 & 91.419 & 89.06 & 343.83 & 0.01 & 8.57 \\
\hline S2-3 & 1.2 & 0.92212 & 0.001 & 92.212 & 89.77 & 343.9 & 0.02 & 7.77 \\
\hline S2-4 & 1.3 & 0.93132 & 0.001 & 93.132 & 90.65 & 343.91 & 0.02 & 6.85 \\
\hline S2-5 & 1.4 & 0.9421 & 0.001 & 94.21 & 91.76 & 343.87 & 0.02 & 5.77 \\
\hline S2-6 & 1.5 & 0.95501 & 0.001 & 95.501 & 93.21 & 343.78 & 0.02 & 4.48 \\
\hline S2-7 & 1.6 & 0.9717 & 0.001 & 97.17 & 95.33 & 343.62 & 0.03 & 2.81 \\
\hline S2-8 & 1.7 & 0.98993 & 0.005 & 98.993 & 98.16 & 343.38 & 0.22 & 0.75 \\
\hline
\end{tabular}


Tabla C3.- Variación del número de etapas totales, reactivas y no reactivas. La alimentación del MeOH una etapa después de la última etapa reactiva. Usando una razón de alimentación de $\mathrm{AO} / \mathrm{MeOH}$ de $1: 1$, alimentando al $\mathrm{AO}$ a $326^{\circ} \mathrm{C}$, el $\mathrm{MeOH}$ a $55^{\circ} \mathrm{C}, 1000 \mathrm{~kg}$ de catalizador y UNIQUAC como método termodinámico.

\begin{tabular}{|c|c|c|c|c|c|c|c|c|c|c|c|c|c|c|c|}
\hline \multicolumn{8}{|c|}{ Entrada de simulación } & \multicolumn{8}{|c|}{ Salida de resultados } \\
\hline \multirow[t]{3}{*}{ Corrida } & & & \multicolumn{2}{|c|}{ Número de Etapas } & \multirow{3}{*}{ Total } & \multirow[t]{3}{*}{$\begin{array}{l}\text { Alim. } \\
\text { del AO }\end{array}$} & \multirow[t]{3}{*}{ Reflujo } & \multirow[t]{3}{*}{ Rehervidor } & \multirow[t]{3}{*}{$\begin{array}{c}\text { Conversión } \\
\text { del AO }\end{array}$} & \multicolumn{2}{|c|}{$\begin{array}{c}\text { Flujo de MO } \\
(\mathrm{kmol} / \mathrm{h})\end{array}$} & \multicolumn{2}{|c|}{ Temperatura $\left({ }^{\circ} \mathrm{C}\right)$} & \multicolumn{2}{|c|}{$\begin{array}{c}\text { Flujo de AO } \\
(\mathrm{kmol} / \mathrm{h})\end{array}$} \\
\hline & \multicolumn{2}{|c|}{ Rxn (3-13) } & Rectificación & Agotamiento & & & & & & Domo & Total & Domo & Fondo & Domo & Fondo \\
\hline & Total & Rango & & & & & & & & & & & & & \\
\hline S3.1 & 10 & $5-14$ & 4 & 2 & 16 & 4 & 1 & 1.9 & 0.99233 & $<0.001$ & 99.233 & 100 & 343.4 & $<0.001$ & 0.767 \\
\hline S3-2 & 11 & $4-14$ & 3 & 2 & 16 & 3 & 1 & 1.9 & 0.99498 & trace & 99.498 & 100 & 343.4 & $<0.001$ & 0.502 \\
\hline S3-3 & 12 & $3-14$ & 2 & 2 & 16 & 2 & 1 & 1.9 & 0.9436 & trace & 94.36 & 99.5 & 344.1 & $<0.001$ & 5.64 \\
\hline S3-4 & 11 & $5-15$ & 4 & 2 & 17 & 4 & 1 & 1.9 & 0.99528 & $<0.001$ & 99.528 & 100 & 343.4 & $<0.001$ & 0.472 \\
\hline S3-5 & 11 & $5-15$ & 4 & 2 & 17 & 4 & 1 & 1.8 & 0.99481 & trace & 99.481 & 99.7 & 343.4 & $<0.001$ & 0.519 \\
\hline S3-6 & 11 & $5-15$ & 4 & 2 & 17 & 4 & 1 & 2 & 0.99544 & $<0.001$ & 99.544 & 100.8 & 343.4 & $<0.001$ & 0.456 \\
\hline S3.7 & 11 & $5-15$ & 4 & 2 & 17 & 4 & 0.9 & 2 & 0.99545 & $<0.001$ & 99.545 & 102.3 & 343.4 & $<0.001$ & 0.455 \\
\hline S3-8 & 11 & $5-15$ & 4 & 2 & 17 & 4 & 0.8 & 2 & 0.99545 & $<0.001$ & 99.545 & 104.9 & 343.4 & $<0.001$ & 0.455 \\
\hline S3-10 & 13 & $4-16$ & 3 & 2 & 18 & 3 & 0.8 & 2 & 0.9982 & $<0.001$ & 99.782 & 104.6 & 343.4 & $<0.001$ & 0.18 \\
\hline S3-11 & 13 & $4-16$ & 3 & 2 & 18 & 4 & 0.8 & 2 & 0.99824 & $<0.001$ & 99.824 & 104.8 & 343.4 & $<0.001$ & 0.176 \\
\hline S3-12 & 14 & $3-16$ & 2 & 2 & 18 & 3 & 0.8 & 2 & 0.99882 & $<0.001$ & 99.882 & 104.6 & 343.4 & $<0.001$ & 0.118 \\
\hline S3-13 & 14 & $3-16$ & 2 & 2 & 18 & 3 & 0.5 & 2 & 0.99885 & 0.001 & 99.885 & 126.2 & 343.4 & 0.002 & 0.115 \\
\hline S3-14 & 14 & $4-17$ & 3 & 2 & 19 & 4 & 0.5 & 2 & 0.99889 & 0.001 & 99.889 & 126.4 & 343.4 & 0.002 & 0.109 \\
\hline S3-15 & 15 & $3-17$ & 3 & 2 & 19 & 3 & 0.5 & 2 & 0.99926 & $<0.001$ & 99.926 & 126 & 343.4 & 0.002 & 0.072 \\
\hline
\end{tabular}




\section{Apéndice D. Columna de Destilación Reactiva con Condensador Total y una sola corriente de metanol (CDR-CT1), para la reacción de transesterificación.}

En todas las simulaciones siguientes se usa UNIQUAC como método termodinámico.

Tabla D1. Relación de reflujo. Usando una razón de alimentación de TO/MeOH de 1:6.5, alimentando la TO en la etapa 3 a $821^{\circ} \mathrm{C}$, el $\mathrm{MeOH}$ en la etapa 18 a $51^{\circ} \mathrm{C}, 20$ etapas totales, 3 de agotamiento, 3 de rectificación y 14 reactivas (4-17), una relación del rehervidor de 1, 10000L de catalizador.

\begin{tabular}{|c|c|c|c|c|c|c|c|c|c|c|c|c|c|}
\hline \multicolumn{5}{|c|}{ Entrada de simulación } & \multicolumn{9}{|c|}{ Salida de resultados } \\
\hline \multirow[t]{2}{*}{$\begin{array}{l}\text { Corr } \\
\text { ida }\end{array}$} & \multirow{2}{*}{$\begin{array}{c}\text { Ref } \\
\text { luj } \\
\text { o }\end{array}$} & \multirow{2}{*}{$\begin{array}{c}\text { Conver } \\
\text { sión } \\
\text { del AO }\end{array}$} & \multicolumn{2}{|c|}{$\begin{array}{l}\text { Flujo de MO } \\
(\mathrm{kmol} / \mathrm{h})\end{array}$} & \multicolumn{2}{|c|}{$\begin{array}{l}\text { Temperatura } \\
\left({ }^{\circ} \mathrm{C}\right)\end{array}$} & \multicolumn{2}{|c|}{$\begin{array}{l}\text { Flujo de TO } \\
(\mathrm{kmol} / \mathrm{h})\end{array}$} & \multirow{2}{*}{$\begin{array}{c}\text { Flujo } \\
\text { DO } \\
(\mathrm{kmol} / \\
\text { h) } \\
\text { Fondo }\end{array}$} & \multicolumn{2}{|c|}{$\begin{array}{l}\text { Flujo MOO } \\
(\mathrm{kmol} / \mathrm{h})\end{array}$} & \multicolumn{2}{|c|}{$\begin{array}{c}\text { Flujo Glicerol } \\
(\mathrm{kmol} / \mathrm{h})\end{array}$} \\
\hline & & & Domo & Total & $\begin{array}{c}\text { Dom } \\
\text { o }\end{array}$ & Fondo & Domo & Fondo & & Fondo & Domo & Fondo & Domo \\
\hline S1-1 & 0.9 & 81.409 & $2.7 \mathrm{E}-14$ & 178.55 & 64.4 & 315.7 & 18.59 & $4.7 \mathrm{E}-13$ & 16.78 & 32.12 & $1.9 \mathrm{E}-21$ & 32.51 & $9.2 \mathrm{E}-10$ \\
\hline S1-2 & 1 & 83.201 & $1.4 \mathrm{E}-14$ & 186.99 & 64.4 & 315.3 & 16.80 & $2.9 \mathrm{E}-13$ & 15.60 & 31.42 & $7.9 \mathrm{E}-22$ & 36.19 & $6.2 \mathrm{E}-10$ \\
\hline S1-3 & 1.1 & 84.804 & $7.5 \mathrm{E}-15$ & 194.79 & 64.4 & 315.2 & 15.20 & $1.9 \mathrm{E}-13$ & 14.50 & 30.62 & $3.6 \mathrm{E}-22$ & 39.68 & 4.3E-10 \\
\hline S1-4 & 1.2 & 86.247 & $4.3 \mathrm{E}-15$ & 202.01 & 64.4 & 315.3 & 13.75 & $1.3 \mathrm{E}-13$ & 13.48 & 29.76 & $1.8 \mathrm{E}-22$ & 43.00 & $3.1 \mathrm{E}-10$ \\
\hline S1-5 & 1.3 & 87.549 & $2.6 \mathrm{E}-15$ & 208.72 & 64.4 & 315.7 & 12.45 & $9.2 \mathrm{E}-14$ & 12.53 & 28.87 & $9.1 \mathrm{E}-23$ & 46.15 & $2.3 \mathrm{E}-10$ \\
\hline S1-6 & 1.4 & 88.727 & $1.6 \mathrm{E}-15$ & 214.94 & 64.4 & 316.39 & 11.27 & $6.7 \mathrm{E}-14$ & 11.64 & 27.95 & $5.0 \mathrm{E}-23$ & 49.13 & $1.8 \mathrm{E}-10$ \\
\hline S1-7 & 1.5 & 89.795 & $1.1 \mathrm{E}-15$ & 220.74 & 64.4 & 317.3 & 10.20 & $4.9 \mathrm{E}-14$ & 10.82 & 27.02 & $2.8 \mathrm{E}-23$ & 51.96 & $1.4 \mathrm{E}-10$ \\
\hline S1-8 & 1.6 & 90.765 & $7.1 \mathrm{E}-16$ & 226.13 & 64.4 & 318.6 & 9.24 & 3.7E-14 & 10.04 & 26.08 & $1.7 \mathrm{E}-23$ & 54.65 & $1.1 \mathrm{E}-10$ \\
\hline S1-9 & 1.7 & 91.652 & $4.8 \mathrm{E}-16$ & 231.19 & 64.4 & 326.7 & 8.35 & $2.8 \mathrm{E}-14$ & 9.32 & 25.13 & $1.0 \mathrm{E}-23$ & 57.21 & $8.9 \mathrm{E}-11$ \\
\hline
\end{tabular}


Tabla D2. Relación del rehervidor. Usando una razón de alimentación de $\mathrm{TO} / \mathrm{MeOH}$ de 1:6.5, alimentando la TO en la etapa 3 a $821^{\circ} \mathrm{C}$, el $\mathrm{MeOH}$ en la etapa 18 a $51^{\circ} \mathrm{C}, 20$ etapas totales, 3 de agotamiento, 3 de rectificación y 14 reactivas (4-17), una relación de reflujo 1.3, 10000L de catalizador.

\begin{tabular}{|c|c|c|c|c|c|c|c|c|c|c|c|c|}
\hline \multicolumn{3}{|c|}{ Entrada de simulación } & \multicolumn{10}{|c|}{ Salida de resultados } \\
\hline \multirow[t]{2}{*}{$\begin{array}{l}\text { Corrid } \\
\qquad \mathrm{a}\end{array}$} & \multirow{2}{*}{$\begin{array}{l}\text { Re } \\
\text { her } \\
\text { vid } \\
\text { or }\end{array}$} & \multirow{2}{*}{$\begin{array}{c}\text { Conver } \\
\text { sión } \\
\text { del AO }\end{array}$} & \multicolumn{2}{|c|}{$\begin{array}{c}\text { Flujo de MO } \\
(\mathrm{kmol} / \mathrm{h})\end{array}$} & \multicolumn{2}{|c|}{ Temperatura $\left({ }^{\circ} \mathrm{C}\right)$} & \multicolumn{2}{|c|}{$\begin{array}{l}\text { Flujo de TO } \\
(\mathrm{kmol} / \mathrm{h})\end{array}$} & \multicolumn{2}{|c|}{$\begin{array}{c}\text { Flujo MOO } \\
(\mathrm{kmol} / \mathrm{h})\end{array}$} & \multicolumn{2}{|c|}{$\begin{array}{l}\text { Flujo Glicerol } \\
(\mathrm{kmol} / \mathrm{h})\end{array}$} \\
\hline & & & Domo & Total & Domo & Fondo & Domo & Fondo & Fondo & Domo & $\begin{array}{c}\text { Fond } \\
\text { o }\end{array}$ & Domo \\
\hline S2-1 & 0.9 & 78.88 & $2.0 \mathrm{E}-14$ & 167.21 & 64.45 & 117.11 & 21.12 & $3.4 \mathrm{E}-13$ & 32.74 & $1.7 \mathrm{E}-21$ & 27.79 & $4.9 \mathrm{E}-10$ \\
\hline S2-2 & 1 & 80.00 & $1.5 \mathrm{E}-14$ & 172.16 & 64.45 & 120.71 & 20.00 & $2.9 \mathrm{E}-13$ & 32.49 & $1.2 \mathrm{E}-21$ & 29.83 & $4.5 \mathrm{E}-10$ \\
\hline S2-3 & 1.1 & 81.00 & $1.2 \mathrm{E}-14$ & 176.71 & 64.45 & 124.63 & 19.00 & $2.5 \mathrm{E}-13$ & 32.21 & $8.5 \mathrm{E}-22$ & 31.75 & 4.2E-10 \\
\hline S2-4 & 1.2 & 81.91 & $1.0 \mathrm{E}-14$ & 180.91 & 64.45 & 128.95 & 18.09 & $2.2 \mathrm{E}-13$ & 31.91 & $6.4 \mathrm{E}-22$ & 33.55 & $3.9 \mathrm{E}-10$ \\
\hline S2-5 & 1.3 & 82.74 & $8.3 \mathrm{E}-15$ & 184.81 & 64.45 & 133.78 & 17.26 & $2.0 \mathrm{E}-13$ & 31.59 & $4.8 \mathrm{E}-22$ & 35.24 & $3.6 \mathrm{E}-10$ \\
\hline S2-6 & 1.4 & 83.50 & $7.0 \mathrm{E}-15$ & 188.46 & 64.45 & 139.30 & 16.50 & $1.8 \mathrm{E}-13$ & 31.26 & $3.8 \mathrm{E}-22$ & 36.85 & $3.4 \mathrm{E}-10$ \\
\hline S2-7 & 1.5 & 84.21 & $5.9 \mathrm{E}-15$ & 191.90 & 64.45 & 145.77 & 15.79 & $1.6 \mathrm{E}-13$ & 30.92 & $3.0 \mathrm{E}-22$ & 38.39 & $3.2 \mathrm{E}-10$ \\
\hline S2-8 & 1.6 & 84.88 & $5.0 \mathrm{E}-15$ & 195.19 & 64.45 & 153.71 & 15.12 & $1.4 \mathrm{E}-13$ & 30.57 & $2.4 \mathrm{E}-22$ & 39.87 & $3.0 \mathrm{E}-10$ \\
\hline S2-9 & 1.7 & 85.53 & $4.3 \mathrm{E}-15$ & 198.42 & 64.45 & 164.18 & 14.47 & $1.3 \mathrm{E}-13$ & 30.20 & $1.9 \mathrm{E}-22$ & 41.34 & $2.8 \mathrm{E}-10$ \\
\hline S2-10 & 1.8 & 86.22 & 3.7E-15 & 201.90 & 64.45 & 180.99 & 13.78 & $1.2 \mathrm{E}-13$ & 29.78 & $1.5 \mathrm{E}-22$ & 42.95 & 2.7E-10 \\
\hline
\end{tabular}

Tabla D3. Temperatura de alimentación del MeOH. Usando la razón de alimentación de TO/MeOH de 1:6.5, alimentando la $\mathrm{TO}$ en la etapa 3 a $821^{\circ} \mathrm{C}$, el MeOH en la etapa 18, 20 etapas totales, 3 de agotamiento, 3 de rectificación y 14 reactivas (4-17), una relación de reflujo 1.7 y del rehervidor de 1.8, 10000L de catalizador.

\begin{tabular}{|c|c|c|c|c|c|c|c|c|c|c|c|c|c|}
\hline \multicolumn{3}{|c|}{ Entrada de simulación } & \multicolumn{11}{|c|}{ Salida de resultados } \\
\hline \multirow[t]{4}{*}{$\begin{array}{c}\text { Corri } \\
\mathrm{da}\end{array}$} & \multirow{2}{*}{$\begin{array}{l}\text { T de } \\
\text { alim } \\
\cdot \\
\left({ }^{\circ} \mathrm{C}\right)\end{array}$} & \multirow{2}{*}{$\begin{array}{c}\text { Conver } \\
\text { sión } \\
\text { del AO }\end{array}$} & \multicolumn{2}{|c|}{$\begin{array}{c}\text { Flujo de MO } \\
(\mathrm{kmol} / \mathrm{h})\end{array}$} & \multicolumn{2}{|c|}{$\begin{array}{l}\text { Temperatura } \\
\left({ }^{\circ} \mathrm{C}\right)\end{array}$} & \multicolumn{2}{|c|}{$\begin{array}{l}\text { Flujo de TO } \\
(\mathrm{kmol} / \mathrm{h})\end{array}$} & \multirow{2}{*}{$\begin{array}{c}\text { Flujo } \\
\text { DO } \\
(\mathrm{kmo} \\
\text { 1/h) }\end{array}$} & \multicolumn{2}{|c|}{$\begin{array}{c}\text { Flujo MOO } \\
(\mathrm{kmol} / \mathrm{h})\end{array}$} & \multicolumn{2}{|c|}{$\begin{array}{l}\text { Flujo Glicerol } \\
(\mathrm{kmol} / \mathrm{h})\end{array}$} \\
\hline & & & Domo & Total & $\begin{array}{c}\text { Dom } \\
\text { o }\end{array}$ & Fondo & Domo & Fondo & & Fondo & Domo & Fondo & Domo \\
\hline & $\mathrm{Me}$ & & & & & & & & Fond & & & & \\
\hline & $\mathrm{OH}$ & & & & & & & & o & & & & \\
\hline S3-1 & 36 & 89.469 & $9.2 \mathrm{E}-16$ & 218.95 & 64.4 & 160.37 & 10.53 & $4.3 \mathrm{E}-14$ & 11.07 & 27.31 & $2.6 \mathrm{E}-23$ & 51.09 & $1.1 \mathrm{E}-10$ \\
\hline S3-2 & 39 & 89.542 & $9.0 \mathrm{E}-16$ & 219.35 & 64.4 & 161.70 & 10.46 & 4.3E-14 & 11.01 & 27.24 & $2.5 \mathrm{E}-23$ & 51.28 & $1.1 \mathrm{E}-10$ \\
\hline S3-3 & 42 & 89.617 & $8.8 \mathrm{E}-16$ & 219.76 & 64.4 & 163.12 & 10.38 & $4.2 \mathrm{E}-14$ & 10.96 & 27.18 & $2.4 \mathrm{E}-23$ & 51.48 & $1.1 \mathrm{E}-10$ \\
\hline S3-4 & 45 & 89.693 & $8.6 \mathrm{E}-16$ & 220.18 & 64.4 & 164.62 & 10.31 & $4.2 \mathrm{E}-14$ & 10.90 & 27.11 & $2.3 \mathrm{E}-23$ & 51.69 & $1.1 \mathrm{E}-10$ \\
\hline S3-5 & 48 & 89.769 & $8.4 \mathrm{E}-16$ & 220.60 & 64.4 & 166.21 & 10.23 & $4.1 \mathrm{E}-14$ & 10.84 & 27.04 & $2.3 E-23$ & 51.90 & $1.1 \mathrm{E}-10$ \\
\hline S3-6 & 51 & 89.848 & $8.2 \mathrm{E}-16$ & 221.03 & 64.4 & 167.93 & 10.15 & $4.0 \mathrm{E}-14$ & 10.77 & 26.97 & $2.2 \mathrm{E}-23$ & 52.11 & $1.1 \mathrm{E}-10$ \\
\hline S3-7 & 54 & 89.928 & 8.0E-16 & 221.47 & 64.4 & 169.78 & 10.07 & 4.0E-14 & 10.71 & 26.89 & $2.1 \mathrm{E}-23$ & 52.33 & $1.1 \mathrm{E}-10$ \\
\hline S3-8 & 55 & 89.955 & $8.0 \mathrm{E}-16$ & 221.62 & 64.4 & 170.44 & 10.04 & $3.9 \mathrm{E}-14$ & 10.69 & 26.87 & $2.1 \mathrm{E}-23$ & 52.40 & $1.1 \mathrm{E}-10$ \\
\hline S3-9 & 57 & 90.010 & $7.9 \mathrm{E}-16$ & 221.92 & 64.4 & 171.80 & 9.99 & $3.9 \mathrm{E}-14$ & 10.65 & 26.81 & $2.1 \mathrm{E}-23$ & 52.55 & $1.1 \mathrm{E}-10$ \\
\hline
\end{tabular}


Tabla D4. Temperatura de alimentación del trioleína. Usando la razón de alimentación de TO/MeOH de 1:6.5, alimentando la $\mathrm{TO}$ en la etapa 3, el $\mathrm{MeOH}$ en la etapa 18 a $55^{\circ} \mathrm{C}, 20$ etapas totales, 3 de agotamiento, 3 de rectificación y 14 reactivas (4-17), una relación de reflujo 1.7 y del rehervidor 1.8, 10000L de catalizador.

\begin{tabular}{|c|c|c|c|c|c|c|c|c|c|c|c|c|c|}
\hline \multicolumn{7}{|c|}{ Entrada de simulación } & \multicolumn{5}{|c|}{ Salida de resultados } & & \\
\hline \multirow[t]{2}{*}{$\begin{array}{l}\text { Corr } \\
\text { ida }\end{array}$} & \multirow{2}{*}{$\begin{array}{l}\mathrm{T} \mathrm{de} \\
\text { alim. } \\
\left({ }^{\circ} \mathrm{C}\right) \\
\mathrm{AO}\end{array}$} & \multirow{2}{*}{$\begin{array}{c}\text { Conver } \\
\text { sión } \\
\text { del AO }\end{array}$} & \multicolumn{2}{|c|}{$\begin{array}{c}\text { Flujo de MO } \\
(\mathrm{kmol} / \mathrm{h})\end{array}$} & \multicolumn{2}{|c|}{$\begin{array}{l}\text { Temperatura } \\
\left({ }^{\circ} \mathrm{C}\right)\end{array}$} & \multicolumn{2}{|c|}{$\begin{array}{c}\text { Flujo de TO } \\
(\mathrm{kmol} / \mathrm{h})\end{array}$} & \multirow{2}{*}{$\begin{array}{c}\text { Flujo } \\
\text { DO } \\
(\mathrm{kmol} / \\
\mathrm{h}) \\
\text { Fondo }\end{array}$} & \multicolumn{2}{|c|}{$\begin{array}{c}\text { Flujo MOO } \\
(\mathrm{kmol} / \mathrm{h})\end{array}$} & \multicolumn{2}{|c|}{$\begin{array}{l}\text { Flujo Glicerol } \\
(\mathrm{kmol} / \mathrm{h})\end{array}$} \\
\hline & & & Domo & Total & $\begin{array}{c}\text { Dom } \\
\text { o }\end{array}$ & Fondo & Domo & Fondo & & Fondo & Domo & Fondo & Domo \\
\hline S4-1 & 700 & 89.711 & $8.8 \mathrm{E}-16$ & 220.28 & 64.4 & 171.5 & 10.29 & $4.2 \mathrm{E}-14$ & 10.88 & 27.09 & $2.4 \mathrm{E}-23$ & 51.74 & $1.2 \mathrm{E}-10$ \\
\hline S4-2 & 720 & 89.741 & $8.7 E-16$ & 220.44 & 64.4 & 171.3 & 10.26 & $4.2 \mathrm{E}-14$ & 10.86 & 27.06 & $2.3 \mathrm{E}-23$ & 51.82 & $1.1 \mathrm{E}-10$ \\
\hline$S 4-3$ & 740 & 89.775 & $8.6 \mathrm{E}-16$ & 220.63 & 64.4 & 171.2 & 10.23 & $4.1 \mathrm{E}-14$ & 10.83 & 27.03 & $2.3 \mathrm{E}-23$ & 51.91 & $1.1 \mathrm{E}-10$ \\
\hline S4-4 & 760 & 89.811 & $8.5 \mathrm{E}-16$ & 220.83 & 64.4 & 171.0 & 10.19 & $4.1 \mathrm{E}-14$ & 10.80 & 27.00 & $2.3 \mathrm{E}-23$ & 52.01 & $1.1 \mathrm{E}-10$ \\
\hline$S 4-5$ & 780 & 89.851 & $8.3 \mathrm{E}-16$ & 221.05 & 64.4 & 170.9 & 10.15 & $4.1 \mathrm{E}-14$ & 10.77 & 26.96 & $2.2 \mathrm{E}-23$ & 52.12 & $1.1 \mathrm{E}-10$ \\
\hline S4-6 & 800 & 89.895 & $8.2 \mathrm{E}-16$ & 221.29 & 64.4 & 170.7 & 10.11 & $4.0 \mathrm{E}-14$ & 10.74 & 26.92 & $2.2 \mathrm{E}-23$ & 52.24 & $1.1 \mathrm{E}-10$ \\
\hline S4-7 & 820 & 89.942 & $8.0 \mathrm{E}-16$ & 221.55 & 64.4 & 170.5 & 10.06 & 4.0E-14 & 10.70 & 26.88 & $2.1 \mathrm{E}-23$ & 52.37 & $1.1 \mathrm{E}-10$ \\
\hline S4-8 & 830 & 89.968 & $7.9 E-16$ & 221.69 & 64.4 & 170.4 & 10.03 & $3.9 \mathrm{E}-14$ & 10.68 & 26.85 & $2.1 \mathrm{E}-23$ & 52.44 & $1.1 \mathrm{E}-10$ \\
\hline S4-9 & 835 & 89.981 & $7.9 \mathrm{E}-16$ & 221.76 & 64.4 & 170.3 & 10.02 & $3.9 \mathrm{E}-14$ & 10.67 & 26.84 & $2.1 \mathrm{E}-23$ & 52.47 & $1.1 \mathrm{E}-10$ \\
\hline $\begin{array}{l}\text { S4- } \\
10\end{array}$ & 825 & 89.955 & $8.0 \mathrm{E}-16$ & 221.62 & 64.4 & 170.4 & 10.04 & $3.9 \mathrm{E}-14$ & 10.69 & 26.87 & $2.1 \mathrm{E}-23$ & 52.40 & $1.1 \mathrm{E}-10$ \\
\hline
\end{tabular}

Tabla D5. Variación de Cantidad de catalizador. Usando la razón de alimentación de TO/MeOH de 1:6.5, alimentando la $\mathrm{TO}$ en la etapa 3 a $830^{\circ} \mathrm{C}$, el $\mathrm{MeOH}$ en la etapa 18 a $55^{\circ} \mathrm{C}, 20$ etapas totales, 3 de agotamiento, 3 de rectificación y 14 reactivas (4-17), una relación de reflujo 1.7 y del rehervidor de 1.8 .

\begin{tabular}{|c|c|c|c|c|c|c|c|c|c|c|c|c|c|}
\hline \multicolumn{3}{|c|}{ Entrada de simulación } & \multicolumn{11}{|c|}{ Salida de resultados } \\
\hline \multirow[t]{2}{*}{ Corrida } & \multirow{2}{*}{$\begin{array}{l}\text { Catal } \\
\text { izado } \\
\text { r (L) }\end{array}$} & \multirow{2}{*}{$\begin{array}{c}\text { Conver } \\
\text { sión } \\
\text { del AO }\end{array}$} & \multicolumn{2}{|c|}{$\begin{array}{c}\text { Flujo de MO } \\
(\mathrm{kmol} / \mathrm{h})\end{array}$} & \multicolumn{2}{|c|}{$\begin{array}{l}\text { Temperatura } \\
\left({ }^{\circ} \mathrm{C}\right)\end{array}$} & \multicolumn{2}{|c|}{$\begin{array}{c}\text { Flujo de TO } \\
(\mathrm{kmol} / \mathrm{h})\end{array}$} & \multirow{2}{*}{$\begin{array}{c}\text { Flujo } \\
\text { DO } \\
(\mathrm{kmo} \\
1 / \mathrm{h}) \\
\text { Fond } \\
\mathrm{o}\end{array}$} & \multicolumn{2}{|c|}{$\begin{array}{c}\text { Flujo MOO } \\
(\mathrm{kmol} / \mathrm{h})\end{array}$} & \multicolumn{2}{|c|}{$\begin{array}{l}\text { Flujo Glicerol } \\
(\mathrm{kmol} / \mathrm{h})\end{array}$} \\
\hline & & & Domo & Total & $\begin{array}{c}\text { Dom } \\
\text { o }\end{array}$ & Fondo & $\begin{array}{c}\text { Dom } \\
\text { o }\end{array}$ & Fondo & & Fondo & Domo & Fondo & Domo \\
\hline S5-1 & 500 & 90.996 & $5.2 \mathrm{E}-18$ & 226.57 & 64.4 & 340.21 & 9.00 & $2.1 \mathrm{E}-14$ & 9.81 & 26.80 & $1.6 \mathrm{E}-25$ & 54.38 & $3.9 \mathrm{E}-13$ \\
\hline S5-2 & 600 & 91.134 & $7.0 \mathrm{E}-18$ & 227.83 & 64.4 & 339.96 & 8.87 & $2.2 \mathrm{E}-14$ & 9.72 & 26.14 & $2.3 \mathrm{E}-25$ & 55.28 & $6.3 \mathrm{E}-13$ \\
\hline S5-3 & 700 & 91.182 & $9.1 \mathrm{E}-18$ & 228.32 & 64.4 & 339.86 & 8.82 & $2.2 \mathrm{E}-14$ & 9.68 & 25.87 & $3.0 \mathrm{E}-25$ & 55.63 & $9.4 \mathrm{E}-13$ \\
\hline S5-4 & 800 & 91.204 & $1.1 \mathrm{E}-17$ & 228.54 & 64.4 & 339.82 & 8.80 & $2.2 \mathrm{E}-14$ & 9.66 & 25.75 & $3.8 \mathrm{E}-25$ & 55.79 & $1.3 \mathrm{E}-12$ \\
\hline S5-5 & 900 & 91.216 & $1.4 \mathrm{E}-17$ & 228.65 & 64.4 & 339.79 & 8.78 & $2.2 \mathrm{E}-14$ & 9.65 & 25.70 & $4.6 \mathrm{E}-25$ & 55.87 & $1.8 \mathrm{E}-12$ \\
\hline S5-6 & 1000 & 91.224 & $1.7 \mathrm{E}-17$ & 228.72 & 64.4 & 339.78 & 8.78 & $2.2 \mathrm{E}-14$ & 9.64 & 25.66 & $5.6 \mathrm{E}-25$ & 55.91 & $2.4 \mathrm{E}-12$ \\
\hline S5-7 & 1100 & 91.230 & $2.1 \mathrm{E}-17$ & 228.76 & 64.4 & 339.77 & 8.77 & $2.2 \mathrm{E}-14$ & 9.64 & 25.65 & $6.6 \mathrm{E}-25$ & 55.94 & $3.0 \mathrm{E}-12$ \\
\hline S5-8 & 1200 & 91.236 & $2.4 \mathrm{E}-17$ & 228.79 & 64.4 & 339.77 & 8.76 & $2.2 \mathrm{E}-14$ & 9.64 & 25.63 & 7.7E-25 & 55.96 & $3.8 \mathrm{E}-12$ \\
\hline S5-9 & 1500 & 91.247 & $3.8 \mathrm{E}-17$ & 228.86 & 64.4 & 339.76 & 8.75 & $2.3 \mathrm{E}-14$ & 9.64 & 25.61 & $1.2 \mathrm{E}-24$ & 56.01 & $6.7 \mathrm{E}-12$ \\
\hline S5-10 & 2000 & 91.261 & $7.0 \mathrm{E}-17$ & 228.94 & 64.4 & 339.74 & 8.74 & $2.4 \mathrm{E}-14$ & 9.63 & 25.58 & $2.0 \mathrm{E}-24$ & 56.05 & $1.3 \mathrm{E}-11$ \\
\hline S5-11 & 2500 & 91.270 & 7.0E-17 & 228.94 & 64.4 & 339.74 & 8.74 & $2.4 \mathrm{E}-14$ & 9.63 & 25.58 & $2.0 \mathrm{E}-24$ & 56.05 & $1.3 \mathrm{E}-11$ \\
\hline
\end{tabular}


Tabla D6. Etapas reactivas y alimentación de la trioleína. Usando la razón de alimentación de $\mathrm{TO} / \mathrm{MeOH}$ de 1:6.5, alimentando la $\mathrm{TO}$ a $830^{\circ} \mathrm{C}$, el MeOH en la etapa 18 a $55^{\circ} \mathrm{C}, 20$ etapas totales, una relación de reflujo 1.7 y del rehervidor de 1.8 y $1000 \mathrm{~L}$ de catalizador.

\begin{tabular}{|c|c|c|c|c|c|c|c|c|c|c|c|c|c|c|c|c|c|c|c|}
\hline \multirow{4}{*}{$\begin{array}{c}\text { Corri } \\
\mathrm{da}\end{array}$} & \multicolumn{11}{|c|}{ Entrada de simulación } & \multicolumn{8}{|c|}{ Salida de resultados } \\
\hline & \multicolumn{5}{|c|}{ Número de Etapas } & \multirow{3}{*}{$\begin{array}{c}\text { Etap } \\
\text { a } \\
\text { alim. } \\
\text { TO }\end{array}$} & \multirow{3}{*}{$\begin{array}{c}\text { Conver } \\
\text { sión } \\
\text { del AO }\end{array}$} & \multicolumn{2}{|c|}{$\begin{array}{c}\text { Flujo de MO } \\
(\mathrm{kmol} / \mathrm{h})\end{array}$} & \multicolumn{2}{|c|}{ Temperatura $\left({ }^{\circ} \mathrm{C}\right)$} & \multicolumn{2}{|c|}{$\begin{array}{c}\text { Flujo de TO } \\
(\mathrm{kmol} / \mathrm{h})\end{array}$} & \multicolumn{2}{|c|}{$\begin{array}{l}\text { Flujo DO } \\
(\mathrm{kmol} / \mathrm{h})\end{array}$} & \multicolumn{2}{|c|}{$\begin{array}{c}\text { Flujo MOO } \\
(\mathrm{kmol} / \mathrm{h})\end{array}$} & \multicolumn{2}{|c|}{$\begin{array}{c}\text { Flujo Glicerol } \\
(\mathrm{kmol} / \mathrm{h})\end{array}$} \\
\hline & \multicolumn{2}{|c|}{ Rxn } & \multirow{2}{*}{$\begin{array}{l}\text { Recti } \\
\text { ficac } \\
\text { ión }\end{array}$} & \multirow{2}{*}{$\begin{array}{l}\text { Agot } \\
\text { amie } \\
\text { nto }\end{array}$} & \multirow{2}{*}{$\begin{array}{l}\text { Tot } \\
\text { al }\end{array}$} & & & Domo & Total & Domo & Fondo & Domo & Fondo & Fondo & Domo & Fondo & Domo & Fondo & Domo \\
\hline & $\begin{array}{l}\text { To } \\
\text { tal }\end{array}$ & $\begin{array}{l}\text { Rang } \\
\text { o }\end{array}$ & & & & & & & & & & & & & & & & & \\
\hline S6-1 & 14 & $4-17$ & 3 & 3 & 20 & 2 & 90.077 & $1.43 \mathrm{E}-14$ & 222.2 & 64.45 & 165.27 & 9.919 & 0.003 & 10.46 & $4.5 \mathrm{E}-35$ & 27.11 & $1.8 \mathrm{E}-21$ & 52.51 & $5.8 \mathrm{E}-12$ \\
\hline$S 6-2$ & 14 & $4-17$ & 3 & 3 & 20 & 3 & 89.550 & $3.0 \mathrm{E}-17$ & 219.28 & 64.45 & 167.1 & 10.45 & 0.000 & 10.87 & 0 & 27.63 & $1.1 \mathrm{E}-24$ & 51.05 & 3.0E-12 \\
\hline S6-3 & 14 & $4-17$ & 3 & 3 & 20 & 4 & 89.550 & $4.5 \mathrm{E}-20$ & 219.28 & 64.45 & 167.1 & 10.45 & 0.000 & 10.87 & 0 & 27.63 & 4.7E-28 & 51.05 & $1.3 \mathrm{E}-12$ \\
\hline S6-4 & 14 & $4-17$ & 3 & 3 & 20 & 5 & 89.548 & $2.2 \mathrm{E}-26$ & 219.25 & 64.45 & 167.1 & 10.45 & 0.000 & 10.88 & 0 & 27.64 & $5.5 \mathrm{E}-35$ & 51.03 & $8.2 \mathrm{E}-16$ \\
\hline S6-5 & 14 & $4-17$ & 3 & 3 & 20 & 6 & 89.544 & $2.5 \mathrm{E}-34$ & 219.20 & 64.45 & 167.0 & 10.46 & 0.000 & 10.88 & 0 & 27.66 & 0.0 & 51.00 & $4.5 E-20$ \\
\hline S6-6 & 13 & $4-16$ & 3 & 4 & 20 & 2 & 90.088 & $1.4 \mathrm{E}-14$ & 222.25 & 64.45 & 165.2 & 9.91 & 0.003 & 10.45 & 0 & 27.11 & $1.8 \mathrm{E}-21$ & 52.53 & $5.8 \mathrm{E}-12$ \\
\hline S6-7 & 14 & $4-17$ & 3 & 3 & 20 & 2 & 90.090 & $1.4 \mathrm{E}-14$ & 222.27 & 64.45 & 165.2 & 9.91 & 0.003 & 10.45 & 0 & 27.09 & $1.8 \mathrm{E}-21$ & 52.54 & $5.8 \mathrm{E}-12$ \\
\hline S6-8 & 15 & $4-18$ & 3 & 2 & 20 & 2 & 90.056 & 1.4E-14 & 222.10 & 64.45 & 165.0 & 9.94 & 0.003 & 10.49 & 0 & 27.09 & $1.8 \mathrm{E}-21$ & 52.47 & $5.8 \mathrm{E}-12$ \\
\hline S6-9 & 15 & $3-17$ & 2 & 3 & 20 & 2 & 89.536 & 2.1E-09 & 219.36 & 64.45 & 162.4 & 10.46 & 0.004 & 11.03 & 0 & 27.19 & 3.8E-14 & 51.31 & $4.8 \mathrm{E}-08$ \\
\hline S6- & 16 & $2-17$ & 1 & 3 & 20 & 2 & 90.241 & $2.9 \mathrm{E}-04$ & 223.13 & 64.45 & 164.7 & 9.75 & 0.005 & 10.33 & $1.3 \mathrm{E}-20$ & 26.93 & 7.2E-07 & 52.98 & 0.0004 \\
\hline 10 & & & & & & & & & & & & & & & & & & & \\
\hline
\end{tabular}


Tabla D7. Razón de alimentación de los reactivos. Alimentando la $\mathrm{TO}$ en la etapa 2 a $830^{\circ} \mathrm{C}$, el $\mathrm{MeOH}$ en la etapa 18 a $55^{\circ} \mathrm{C}, 20$ etapas totales, 3 de agotamiento, 1 de rectificación y 16 reactivas (2-17), una relación de reflujo 1.7 y del rehervidor de 1.8 y $1000 \mathrm{~L}$ de catalizador.

\begin{tabular}{|c|c|c|c|c|c|c|c|c|c|c|c|c|c|c|}
\hline \multicolumn{12}{|c|}{ Entrada de simulación } & \multicolumn{3}{|c|}{ Salida de resultados } \\
\hline \multirow[t]{2}{*}{$\begin{array}{c}\text { Corrid } \\
\text { a }\end{array}$} & \multirow{2}{*}{$\begin{array}{c}\text { Razón } \\
\text { TO/MeOH } \\
(\mathrm{kmol} / \mathrm{h})\end{array}$} & \multirow[t]{2}{*}{$\begin{array}{c}\text { Conversión } \\
\text { del AO }\end{array}$} & \multicolumn{2}{|c|}{ Flujo de MO (kmol/h) } & \multicolumn{2}{|c|}{ Temperatura $\left({ }^{\circ} \mathrm{C}\right)$} & \multicolumn{2}{|c|}{ Flujo de TO $(\mathrm{kmol} / \mathrm{h})$} & \multicolumn{2}{|c|}{ Flujo DO (kmol/h) } & \multicolumn{2}{|c|}{ Flujo MOO (kmol/h) } & \multicolumn{2}{|c|}{$\begin{array}{c}\text { Flujo Glicerol } \\
(\mathrm{kmol} / \mathrm{h})\end{array}$} \\
\hline & & & Domo & Total & Domo & Fondo & Domo & Fondo & Fondo & Domo & Fondo & Domo & Fondo & Domo \\
\hline S7-1 & $1: 6.5$ & 90.885 & 0.0003 & 226.76 & 64.4 & 181.7 & 9.11 & 0.004 & 9.82 & $9.8 \mathrm{E}-21$ & 26.26 & $6.3 \mathrm{E}-07$ & 54.81 & 0.0004 \\
\hline$S 7-2$ & $1: 7$ & 91.674 & 0.0002 & 231.29 & 64.4 & 158.4 & 8.32 & 0.004 & 9.17 & $6.9 \mathrm{E}-21$ & 25.39 & $5.4 \mathrm{E}-07$ & 57.11 & 0.0003 \\
\hline S7-3 & $1: 10$ & 95.737 & 0.0001 & 256.68 & 64.4 & 117.2 & 4.26 & 0.001 & 5.54 & $9.0 \mathrm{E}-22$ & 19.44 & $2.1 \mathrm{E}-07$ & 70.75 & 0.0003 \\
\hline S7-4 & $1: 12$ & 97.305 & 0.0001 & 268.02 & 64.4 & 106.1 & 2.69 & 0.001 & 3.93 & $3.1 \mathrm{E}-22$ & 16.03 & $1.3 \mathrm{E}-07$ & 77.34 & 0.0002 \\
\hline S7-5 & $1: 14$ & 98.268 & 0.0001 & 275.90 & 64.4 & 98.8 & 1.73 & 0.000 & 2.82 & $1.3 \mathrm{E}-22$ & 13.27 & $8.2 \mathrm{E}-08$ & 82.18 & 0.0002 \\
\hline S7-6 & $1: 15$ & 98.596 & 0.0000 & 278.87 & 64.4 & 96.0 & 1.40 & 0.000 & 2.40 & 8.7E-23 & 12.11 & 6.7E-08 & 84.08 & 0.0002 \\
\hline S7-7 & 1:17 & 99.051 & 0.0000 & 283.39 & 64.4 & 91.5 & 0.95 & 0.000 & 1.78 & $4.3 \mathrm{E}-23$ & 10.20 & $4.8 \mathrm{E}-08$ & 87.07 & 0.0002 \\
\hline S7-8 & 1:19 & 99.330 & 0.0000 & 286.56 & 64.4 & 88.0 & 0.67 & 0.000 & 1.36 & $2.3 \mathrm{E}-23$ & 8.72 & $3.5 \mathrm{E}-08$ & 89.25 & 0.0002 \\
\hline S7-9 & $1: 20$ & 99.427 & 0.0000 & 287.79 & 64.4 & 86.6 & 0.57 & 0.000 & 1.19 & $1.7 \mathrm{E}-23$ & 8.11 & $3.0 \mathrm{E}-08$ & 90.13 & 0.0002 \\
\hline S7-10 & $1: 25$ & 99.684 & 0.0000 & 291.73 & 64.4 & 81.2 & 0.32 & 0.000 & 0.69 & $5.2 \mathrm{E}-24$ & 5.94 & $1.7 \mathrm{E}-08$ & 93.05 & 0.0001 \\
\hline S7-11 & $1: 30$ & 99.765 & 0.0000 & 293.70 & 64.4 & 77.8 & 0.24 & 0.000 & 0.46 & $2.0 \mathrm{E}-24$ & 4.69 & $1.02 \mathrm{E}-08$ & 94.62 & 0.0001 \\
\hline
\end{tabular}


Tabla D8. Relación de reflujo y del rehervidor. Usando la razón de alimentación de TO/MeOH de 1:15, alimentando la $\mathrm{TO}$ en la etapa 2 a $830^{\circ} \mathrm{C}$, el MeOH en la etapa 18 a $55^{\circ} \mathrm{C}, 20$ etapas totales, 3 de agotamiento, 1 de rectificación y 16 reactivas (2-17) y $1000 \mathrm{~L}$ de catalizador.

\begin{tabular}{|c|c|c|c|c|c|c|c|c|c|c|c|c|c|c|c|}
\hline \multicolumn{3}{|c|}{ Entrada de simulación } & \multicolumn{13}{|c|}{ Salida de resultados } \\
\hline \multirow[t]{2}{*}{$\begin{array}{c}\text { Corrid } \\
\mathrm{a}\end{array}$} & \multirow[t]{2}{*}{$\begin{array}{l}\text { Refl } \\
\text { ujo }\end{array}$} & \multirow{2}{*}{$\begin{array}{c}\text { Rehe } \\
\text { rvido } \\
\mathrm{r}\end{array}$} & \multirow[t]{2}{*}{$\begin{array}{c}\text { Conversión } \\
\text { del AO }\end{array}$} & \multicolumn{2}{|c|}{ Flujo de $\mathrm{MO}(\mathrm{kmol} / \mathrm{h})$} & \multicolumn{2}{|c|}{ Temperatura $\left({ }^{\circ} \mathrm{C}\right)$} & \multicolumn{2}{|c|}{$\begin{array}{c}\text { Flujo de TO } \\
(\mathrm{kmol} / \mathrm{h})\end{array}$} & \multicolumn{2}{|c|}{ Flujo DO (kmol/h) } & \multicolumn{2}{|c|}{$\begin{array}{c}\text { Flujo MOO } \\
(\mathrm{kmol} / \mathrm{h})\end{array}$} & \multicolumn{2}{|c|}{$\begin{array}{c}\text { Flujo Glicerol } \\
(\mathrm{kmol} / \mathrm{h})\end{array}$} \\
\hline & & & & Domo & Total & Domo & Fondo & Domo & Fondo & Fondo & Domo & Fondo & Domo & Fondo & Domo \\
\hline S8-1 & 1.7 & 1.8 & 98.596 & $4.5 \mathrm{E}-05$ & 278.87 & 64.4 & 96.0 & 1.40 & 0.0003 & 2.404 & $8.7 E-23$ & 12.11 & $6.7 \mathrm{E}-08$ & 84.08 & 0.0002 \\
\hline S8-2 & 1.7 & 2 & 98.723 & $4.2 \mathrm{E}-05$ & 280.07 & 64.4 & 97.1 & 1.28 & 0.0002 & 2.238 & $7.3 \mathrm{E}-23$ & 11.62 & $6.2 \mathrm{E}-08$ & 84.86 & 0.0002 \\
\hline S8-3 & 1.7 & 3 & 99.354 & 2.6E-05 & 286.85 & 64.4 & 108.5 & 0.65 & $9.1 \mathrm{E}-05$ & 1.318 & $2.2 \mathrm{E}-23$ & 8.57 & $3.4 \mathrm{E}-08$ & 89.46 & 0.0002 \\
\hline S8-4 & 1.7 & 3.5 & 99.481 & $2.2 \mathrm{E}-05$ & 288.50 & 64.4 & 115.4 & 0.52 & $6.6 \mathrm{E}-05$ & 1.101 & $1.4 \mathrm{E}-23$ & 7.74 & $2.8 \mathrm{E}-08$ & 90.64 & 0.0002 \\
\hline S8-5 & 1.7 & 4 & 99.561 & $1.9 \mathrm{E}-05$ & 289.65 & 64.4 & 123.5 & 0.44 & $5.1 \mathrm{E}-05$ & 0.953 & $1.1 \mathrm{E}-23$ & 7.13 & $2.4 \mathrm{E}-08$ & 91.48 & 0.0002 \\
\hline S8-6 & 1.7 & 5 & 99.655 & $1.6 \mathrm{E}-05$ & 291.17 & 64.4 & 148.8 & 0.35 & $3.3 \mathrm{E}-05$ & 0.761 & $6.4 \mathrm{E}-24$ & 6.27 & $1.8 \mathrm{E}-08$ & 92.62 & 0.0002 \\
\hline S8-8 & 1.8 & 4 & 99.614 & $1.6 \mathrm{E}-05$ & 290.49 & 64.4 & 121.0 & 0.39 & $3.8 \mathrm{E}-05$ & 0.847 & 7.7E-24 & 6.66 & $2.0 \mathrm{E}-08$ & 92.11 & 0.0001 \\
\hline S8-9 & 2 & 4 & 99.687 & $1.2 \mathrm{E}-05$ & 291.77 & 64.4 & 116.8 & 0.31 & $2.3 \mathrm{E}-05$ & 0.687 & $4.3 \mathrm{E}-24$ & 5.91 & $1.4 \mathrm{E}-08$ & 93.09 & 0.0001 \\
\hline S8-10 & 2.5 & 4 & 99.764 & $6.6 \mathrm{E}-06$ & 293.64 & 64.4 & 109.4 & 0.24 & 8.0E-06 & 0.462 & $1.4 \mathrm{E}-24$ & 4.72 & 7.0E-09 & 94.58 & $9.2 \mathrm{E}-05$ \\
\hline S8-11 & 3 & 4 & 99.778 & $4.2 \mathrm{E}-06$ & 294.58 & 64.4 & 104.5 & 0.22 & $3.5 \mathrm{E}-06$ & 0.353 & $6.0 \mathrm{E}-25$ & 4.05 & 4.1E-09 & 95.37 & $7.1 \mathrm{E}-05$ \\
\hline S8-12 & 3.5 & 4 & 99.770 & $2.8 \mathrm{E}-06$ & 295.09 & 64.4 & 101.0 & 0.23 & $1.8 \mathrm{E}-06$ & 0.294 & $3.1 \mathrm{E}-25$ & 3.64 & 2.7E-09 & 95.84 & $5.8 \mathrm{E}-05$ \\
\hline S8-13 & 4 & 4 & 99.752 & $2.1 \mathrm{E}-06$ & 295.37 & 64.45 & 98.34 & 0.25 & $1.1 \mathrm{E}-06$ & 0.259 & $2.1 \mathrm{E}-25$ & 3.37 & $1.9 \mathrm{E}-09$ & 96.13 & $4.8 \mathrm{E}-05$ \\
\hline S8-14 & 4.5 & 4 & 99.730 & $1.6 \mathrm{E}-06$ & 295.53 & 64.45 & 96.28 & 0.27 & $6.8 \mathrm{E}-07$ & 0.238 & $1.8 \mathrm{E}-25$ & 3.18 & $1.4 \mathrm{E}-09$ & 96.31 & 4.1E-05 \\
\hline S8-15 & 5 & 4 & 99.7047306 & $1.3 \mathrm{E}-06$ & 295.61 & 64.45 & 94.62 & 0.30 & 4.6E-07 & 0.22 & $1.65 \mathrm{E}-25$ & 3.06 & $1.11 \mathrm{E}-09$ & 96.42 & $3.6 \mathrm{E}-05$ \\
\hline
\end{tabular}


Tabla D9. Número de etapas totales y reactivas. Usando la razón de alimentación de $\mathrm{TO} / \mathrm{MeOH}$ de 1:15, alimentando la $\mathrm{TO}$ en la etapa 2 a $830^{\circ} \mathrm{C}$, el $\mathrm{MeOH}$ a $55^{\circ} \mathrm{C}, 3$ etapas de agotamiento, 1 de rectificación, una relación de reflujo de 3 y del rehervidor de 4 y $1000 \mathrm{~L}$ de catalizador.

\begin{tabular}{|c|c|c|c|c|c|c|c|c|c|c|c|c|c|c|c|c|c|}
\hline \multicolumn{5}{|c|}{ Entrada de simulación } & \multicolumn{13}{|c|}{ Salida de resultados } \\
\hline \multirow[t]{3}{*}{ Corrida } & \multicolumn{3}{|c|}{ Número de Etapas } & \multirow{3}{*}{$\begin{array}{c}\text { Etapa de } \\
\text { alimentació } \\
\mathrm{n} \mathrm{MeOH}\end{array}$} & \multirow[t]{3}{*}{$\begin{array}{c}\text { Conversión } \\
\text { del AO }\end{array}$} & \multicolumn{2}{|c|}{$\begin{array}{l}\text { Flujo de MO } \\
(\mathrm{kmol} / \mathrm{h})\end{array}$} & \multicolumn{2}{|c|}{ Temperatura $\left({ }^{\circ} \mathrm{C}\right)$} & \multicolumn{2}{|c|}{$\begin{array}{c}\text { Flujo de TO } \\
(\mathrm{kmol} / \mathrm{h})\end{array}$} & \multicolumn{2}{|c|}{ Flujo DO $(\mathrm{kmol} / \mathrm{h})$} & \multicolumn{2}{|c|}{$\begin{array}{c}\text { Flujo MOO } \\
(\mathrm{kmol} / \mathrm{h})\end{array}$} & \multicolumn{2}{|c|}{$\begin{array}{l}\text { Flujo Glicerol } \\
(\mathrm{kmol} / \mathrm{h})\end{array}$} \\
\hline & & $\mathrm{xn}$ & Total & & & Domo & Total & Domo & Fondo & Domo & Fondo & Fondo & Domo & Fond & Domo & Fond & Domo \\
\hline & Total & Rango & & & & & & & & & & & & o & & o & \\
\hline s9-1 & 17 & $2-18$ & 21 & 19 & 99.830 & $4.2 \mathrm{E}-06$ & 294.91 & 64.45 & 104.53 & 0.17 & $3.5 \mathrm{E}-06$ & 0.334 & $6.0 \mathrm{E}-25$ & 3.91 & $4.1 \mathrm{E}-09$ & 95.58 & $7.1 \mathrm{E}-05$ \\
\hline s9-2 & 18 & $2-19$ & 22 & 20 & 99.863 & $4.2 \mathrm{E}-06$ & 295.13 & 64.45 & 104.55 & 0.14 & $3.5 \mathrm{E}-06$ & 0.321 & $6.0 \mathrm{E}-25$ & 3.82 & 4.1E-09 & 95.72 & 7.1E-05 \\
\hline S9-3 & 19 & $2-20$ & 23 & 21 & 99.885 & $4.2 \mathrm{E}-06$ & 295.27 & 64.45 & 104.57 & 0.12 & $3.5 \mathrm{E}-06$ & 0.312 & $6.0 \mathrm{E}-25$ & 3.76 & $4.1 \mathrm{E}-09$ & 95.81 & $7.1 \mathrm{E}-05$ \\
\hline s9-4 & 20 & $2-21$ & 24 & 22 & 99.899 & $4.2 \mathrm{E}-06$ & 295.36 & 64.45 & 104.58 & 0.10 & $3.5 \mathrm{E}-06$ & 0.306 & $6.0 \mathrm{E}-25$ & 3.72 & 4.1E-09 & 95.87 & 7.1E-05 \\
\hline S9-5 & 21 & $2-22$ & 25 & 23 & 99.937 & $1.9 \mathrm{E}-06$ & 297.16 & 64.45 & 329.61 & 0.06 & $6.3 \mathrm{E}-07$ & 0.138 & 2.7E-25 & 2.38 & $1.7 \mathrm{E}-09$ & 97.42 & $5.8 \mathrm{E}-05$ \\
\hline
\end{tabular}




\section{Apéndice E. Columna de Destilación Reactiva con Condensador Total y dos corrientes de metanol}

\section{(CDR-CT2), para la reacción de transesterificación.}

Tabla E1. Variación de la etapa de alimentación de la corriente $1(500 \mathrm{kmol} / \mathrm{h})$ de $\mathrm{MeOH}$ y variación del flujo de la corriente 2 . Alimentando la TO en la etapa 2 a $830^{\circ} \mathrm{C}$, el $\mathrm{MeOH}$ en cada corriente a $55^{\circ} \mathrm{C}$, la corriente 2 en la etapa 23,25 etapas totales, 3 de agotamiento, 1 de rectificación y 21 reactivas $(2-22)$, una relación de reflujo de 3 y del rehervidor de 4 y 1000L de catalizador.

\begin{tabular}{|c|c|c|c|c|c|c|c|c|c|c|c|c|c|c|c|}
\hline \multicolumn{3}{|c|}{ Entrada de simulación } & \multicolumn{13}{|c|}{ Salida de resultados } \\
\hline \multirow[t]{2}{*}{$\begin{array}{c}\text { Corrid } \\
\text { a }\end{array}$} & \multirow{2}{*}{$\begin{array}{l}\text { Flujo } \\
\text { kmol/h } \\
\text { Corriente } \\
2\end{array}$} & $\begin{array}{l}\text { Etapa } \\
\text { Alimentació }\end{array}$ & \multirow[t]{2}{*}{$\begin{array}{c}\text { Conversión } \\
\text { del AO }\end{array}$} & \multicolumn{2}{|c|}{$\begin{array}{l}\text { Flujo de MO } \\
(\mathrm{kmol} / \mathrm{h})\end{array}$} & \multicolumn{2}{|c|}{ Temperatura $\left({ }^{\circ} \mathrm{C}\right)$} & \multicolumn{2}{|c|}{$\begin{array}{l}\text { Flujo de TO } \\
(\mathrm{kmol} / \mathrm{h})\end{array}$} & \multicolumn{2}{|c|}{$\begin{array}{l}\text { Flujo DO } \\
(\mathrm{kmol} / \mathrm{h})\end{array}$} & \multicolumn{2}{|c|}{$\begin{array}{c}\text { Flujo MOO } \\
(\mathrm{kmol} / \mathrm{h})\end{array}$} & \multicolumn{2}{|c|}{$\begin{array}{c}\text { Flujo Glicerol } \\
(\mathrm{kmol} / \mathrm{h})\end{array}$} \\
\hline & & $\begin{array}{l}\text { n } \mathrm{MeOH} \\
\text { Corriente } 1\end{array}$ & & Domo & Total & Domo & Fondo & Domo & Fondo & $\begin{array}{c}\text { Fond } \\
\text { o }\end{array}$ & Domo & $\begin{array}{c}\text { Fond } \\
\text { o }\end{array}$ & Domo & $\begin{array}{c}\text { Fond } \\
\text { o }\end{array}$ & Domo \\
\hline S1-1 & 500 & 6 & 99.783 & $9.3 \mathrm{E}-06$ & 294.04 & 64.45 & 151.81 & 0.217 & $2.0 \mathrm{E}-05$ & 0.420 & $4.0 \mathrm{E}-24$ & 4.464 & $1.1 \mathrm{E}-08$ & 94.90 & $8.6 \mathrm{E}-05$ \\
\hline S1-2 & 600 & 6 & 99.790 & $7.8 \mathrm{E}-06$ & 294.48 & 64.45 & 132.72 & 0.210 & $1.4 \mathrm{E}-05$ & 0.369 & $2.6 \mathrm{E}-24$ & 4.150 & $8.8 \mathrm{E}-09$ & 95.27 & $8.3 \mathrm{E}-05$ \\
\hline S1-3 & 700 & 6 & 99.791 & $6.5 \mathrm{E}-06$ & 294.84 & 64.45 & 121.89 & 0.209 & $9.6 \mathrm{E}-06$ & 0.328 & $1.7 \mathrm{E}-24$ & 3.876 & $7.1 \mathrm{E}-09$ & 95.59 & $7.9 \mathrm{E}-05$ \\
\hline S1-4 & 800 & 6 & 99.786 & $5.6 \mathrm{E}-06$ & 295.12 & 64.45 & 114.48 & 0.214 & $6.7 \mathrm{E}-06$ & 0.295 & $1.2 \mathrm{E}-24$ & 3.645 & $5.9 \mathrm{E}-09$ & 95.85 & $7.6 \mathrm{E}-05$ \\
\hline S1-5 & 500 & 10 & 99.791 & $9.3 \mathrm{E}-06$ & 294.07 & 64.45 & 151.82 & 0.209 & $2.0 \mathrm{E}-05$ & 0.419 & $4.0 \mathrm{E}-24$ & 4.466 & $1.1 \mathrm{E}-08$ & 94.91 & $8.6 \mathrm{E}-05$ \\
\hline S1-6 & 600 & 10 & 99.800 & $7.8 \mathrm{E}-06$ & 294.52 & 64.45 & 132.73 & 0.200 & $1.4 \mathrm{E}-05$ & 0.367 & $2.6 \mathrm{E}-24$ & 4.143 & $8.8 \mathrm{E}-09$ & 95.29 & $8.3 \mathrm{E}-05$ \\
\hline S1-7 & 700 & 10 & 99.803 & $6.5 \mathrm{E}-06$ & 294.90 & 64.45 & 121.90 & 0.197 & $9.6 \mathrm{E}-06$ & 0.325 & $1.7 \mathrm{E}-24$ & 3.862 & 7.1E-09 & 95.62 & $7.9 \mathrm{E}-05$ \\
\hline S1-8 & 800 & 10 & 99.800 & $5.6 \mathrm{E}-06$ & 295.19 & 64.45 & 114.49 & 0.200 & $6.7 \mathrm{E}-06$ & 0.291 & $1.2 \mathrm{E}-24$ & 3.625 & $5.9 \mathrm{E}-09$ & 95.88 & $7.6 \mathrm{E}-05$ \\
\hline S1-9 & 600 & 13 & 99.795 & $7.8 \mathrm{E}-06$ & 294.39 & 64.45 & 132.68 & 0.205 & $1.4 \mathrm{E}-05$ & 0.377 & $2.6 \mathrm{E}-24$ & 4.241 & $8.8 \mathrm{E}-09$ & 95.18 & $8.3 \mathrm{E}-05$ \\
\hline S1-10 & 700 & 13 & 99.803 & $6.5 \mathrm{E}-06$ & 294.81 & 64.45 & 121.88 & 0.197 & $9.6 \mathrm{E}-06$ & 0.332 & $1.7 \mathrm{E}-24$ & 3.939 & 7.1E-09 & 95.53 & $7.9 \mathrm{E}-05$ \\
\hline S1-11 & 800 & 13 & 99.803 & $5.6 \mathrm{E}-06$ & 295.13 & 64.45 & 114.48 & 0.196 & $6.7 \mathrm{E}-06$ & 0.296 & $1.2 \mathrm{E}-24$ & 3.684 & $5.9 \mathrm{E}-09$ & 95.82 & $7.6 \mathrm{E}-05$ \\
\hline S1-12 & 900 & 13 & 99.799 & $4.8 \mathrm{E}-06$ & 295.39 & 64.45 & 108.95 & 0.201 & $4.8 \mathrm{E}-06$ & 0.268 & $8.3 \mathrm{E}-25$ & 3.472 & $4.9 \mathrm{E}-09$ & 96.06 & $7.4 \mathrm{E}-05$ \\
\hline
\end{tabular}


Tabla E2. Variación de etapa de alimentación de la corriente $2(500 \mathrm{kmol} / \mathrm{h})$ de $\mathrm{MeOH}$ y variación del flujo de la corriente 1 . Alimentando la TO en la etapa 2 a $830^{\circ} \mathrm{C}$, el MeOH en cada corriente a $55^{\circ} \mathrm{C}$, la corriente 2 en la etapa 23,25 etapas totales, 3 de agotamiento, 1 de rectificación y 21 reactivas (2-22), una relación de reflujo de 3 y del rehervidor de 4 y $1000 \mathrm{~L}$ de catalizador.

\begin{tabular}{|c|c|c|c|c|c|c|c|c|c|c|c|c|c|c|c|}
\hline \multicolumn{3}{|c|}{ Entrada de simulación } & \multicolumn{13}{|c|}{ Salida de resultados } \\
\hline \multirow[t]{2}{*}{ Corrida } & \multirow{2}{*}{$\begin{array}{l}\text { Flujo } \\
\text { kmol/h } \\
\text { Corriente 1 }\end{array}$} & \multirow[t]{2}{*}{$\begin{array}{l}\text { Etapa Alimentación } \\
\text { MeOH Corriente } 1\end{array}$} & \multirow{2}{*}{$\begin{array}{c}\text { Conversi } \\
\text { ón del } \\
\text { AO }\end{array}$} & \multicolumn{2}{|c|}{ Flujo de $\mathrm{MO}(\mathrm{kmol} / \mathrm{h})$} & \multicolumn{2}{|c|}{ Temperatura $\left({ }^{\circ} \mathrm{C}\right)$} & \multicolumn{2}{|c|}{$\begin{array}{c}\text { Flujo de TO } \\
(\mathrm{kmol} / \mathrm{h})\end{array}$} & \multicolumn{2}{|c|}{ Flujo DO $(\mathrm{kmol} / \mathrm{h})$} & \multicolumn{2}{|c|}{$\begin{array}{c}\text { Flujo MOO } \\
(\mathrm{kmol} / \mathrm{h})\end{array}$} & \multicolumn{2}{|c|}{$\begin{array}{l}\text { Flujo Glicerol } \\
(\mathrm{kmol} / \mathrm{h})\end{array}$} \\
\hline & & & & Domo & Total & Domo & Fondo & Domo & Fondo & Fondo & Domo & Fondo & Domo & Fondo & Domo \\
\hline S2-1 & 500 & 6 & 99.783 & $9.3 \mathrm{E}-06$ & 294.04 & 64.45 & 151.81 & 0.217 & $2.0 \mathrm{E}-05$ & 0.4199 & $4.0 \mathrm{E}-24$ & 4.464 & $1.1 \mathrm{E}-08$ & 94.90 & $8.6 \mathrm{E}-05$ \\
\hline S2-2 & 600 & 6 & 99.794 & $7.8 \mathrm{E}-06$ & 294.77 & 64.45 & 132.83 & 0.206 & $1.4 \mathrm{E}-05$ & 0.3374 & $2.6 \mathrm{E}-24$ & 3.940 & $8.8 \mathrm{E}-09$ & 95.52 & 8.3E-05 \\
\hline S2-3 & 700 & 6 & 99.789 & $6.5 \mathrm{E}-06$ & 295.26 & 64.45 & 121.99 & 0.211 & $9.6 \mathrm{E}-06$ & 0.2815 & $1.7 \mathrm{E}-24$ & 3.545 & $7.1 \mathrm{E}-09$ & 95.96 & $7.9 \mathrm{E}-05$ \\
\hline S2-4 & 800 & 6 & 99.773 & $5.6 \mathrm{E}-06$ & 295.58 & 64.45 & 114.56 & 0.227 & $6.7 \mathrm{E}-06$ & 0.2441 & $1.2 \mathrm{E}-24$ & 3.251 & $5.9 \mathrm{E}-09$ & 96.28 & $7.6 \mathrm{E}-05$ \\
\hline S2-5 & 600 & 11 & 99.915 & $7.8 \mathrm{E}-06$ & 295.56 & 64.45 & 133.13 & 0.085 & $1.4 \mathrm{E}-05$ & 0.2903 & $2.6 \mathrm{E}-24$ & 3.604 & $8.8 \mathrm{E}-09$ & 96.02 & $8.3 \mathrm{E}-05$ \\
\hline S2-6 & 700 & 11 & 99.933 & $6.5 \mathrm{E}-06$ & 296.18 & 64.45 & 122.22 & 0.067 & $9.6 \mathrm{E}-06$ & 0.2290 & 1.7E-24 & 3.159 & $7.1 \mathrm{E}-09$ & 96.54 & $7.9 \mathrm{E}-05$ \\
\hline S2-7 & 800 & 11 & 99.943 & $5.6 \mathrm{E}-06$ & 296.65 & 64.45 & 114.75 & 0.057 & $6.7 \mathrm{E}-06$ & 0.1855 & $1.2 \mathrm{E}-24$ & 2.810 & $5.9 \mathrm{E}-09$ & 96.95 & $7.6 \mathrm{E}-05$ \\
\hline S2-8 & 900 & 11 & 99.948 & $4.8 \mathrm{E}-06$ & 297.00 & 64.45 & 109.18 & 0.052 & $4.8 \mathrm{E}-06$ & 0.1539 & $8.3 E-25$ & 2.533 & $4.9 \mathrm{E}-09$ & 97.26 & $7.4 \mathrm{E}-05$ \\
\hline S2-9 & 1000 & 11 & 99.950 & 4.1E-06 & 297.28 & 64.45 & 104.80 & 0.050 & $3.5 \mathrm{E}-06$ & 0.1307 & $6.0 \mathrm{E}-25$ & 2.309 & 4.1E-09 & 97.51 & 7.1E-05 \\
\hline S2-10 & 600 & 12 & 99.914 & $7.8 \mathrm{E}-06$ & 295.55 & 64.45 & 133.13 & 0.086 & $1.4 \mathrm{E}-05$ & 0.2906 & 2.6E-24 & 3.607 & $8.8 \mathrm{E}-09$ & 96.02 & $8.3 \mathrm{E}-05$ \\
\hline S2-11 & 700 & 12 & 99.933 & $6.5 \mathrm{E}-06$ & 296.18 & 64.45 & 122.22 & 0.067 & $9.6 \mathrm{E}-06$ & 0.2291 & $1.7 \mathrm{E}-24$ & 3.161 & $7.1 \mathrm{E}-09$ & 96.54 & $7.9 \mathrm{E}-05$ \\
\hline S2-12 & 800 & 12 & 99.943 & $5.6 \mathrm{E}-06$ & 296.65 & 64.45 & 114.75 & 0.057 & 6.7E-06 & 0.1855 & $1.2 \mathrm{E}-24$ & 2.811 & $5.9 \mathrm{E}-09$ & 96.95 & $7.6 \mathrm{E}-05$ \\
\hline S2-13 & 900 & 12 & 99.949 & $4.8 \mathrm{E}-06$ & 297.00 & 64.45 & 109.18 & 0.051 & $4.8 \mathrm{E}-06$ & 0.1539 & $8.3 E-25$ & 2.533 & $4.9 \mathrm{E}-09$ & 97.26 & $7.4 \mathrm{E}-05$ \\
\hline S2-14 & 1000 & 12 & 99.951 & $4.1 \mathrm{E}-06$ & 297.28 & 64.45 & 104.80 & 0.049 & $3.5 \mathrm{E}-06$ & 0.1305 & $6.0 \mathrm{E}-25$ & 2.309 & 4.1E-09 & 97.51 & 7.1E-05 \\
\hline S2-15 & 600 & 13 & 99.914 & $7.8 \mathrm{E}-06$ & 295.55 & 64.45 & 133.12 & 0.086 & $1.4 \mathrm{E}-05$ & 0.2911 & 2.6E-24 & 3.612 & $8.8 \mathrm{E}-09$ & 96.01 & $8.3 \mathrm{E}-05$ \\
\hline S2-16 & 700 & 13 & 99.932 & $6.5 \mathrm{E}-06$ & 296.17 & 64.45 & 122.22 & 0.068 & $9.6 \mathrm{E}-06$ & 0.2295 & 1.7E-24 & 3.165 & $7.1 \mathrm{E}-09$ & 96.54 & $7.9 \mathrm{E}-05$ \\
\hline S2-17 & 800 & 13 & 99.943 & $5.6 \mathrm{E}-06$ & 296.64 & 64.45 & 114.75 & 0.057 & 6.7E-06 & 0.1858 & $1.2 \mathrm{E}-24$ & 2.815 & 5.9E-09 & 96.94 & $7.6 \mathrm{E}-05$ \\
\hline S2-18 & 900 & 13 & 99.949 & $4.8 \mathrm{E}-06$ & 297.00 & 64.45 & 109.18 & 0.051 & $4.8 \mathrm{E}-06$ & 0.1540 & $8.3 E-25$ & 2.536 & 4.9E-09 & 97.26 & $7.4 \mathrm{E}-05$ \\
\hline S2-19 & 1000 & 13 & 99.951 & 4.1E-06 & 297.28 & 64.45 & 104.80 & 0.049 & $3.5 \mathrm{E}-06$ & 0.1305 & $6.0 \mathrm{E}-25$ & 2.311 & 4.1E-09 & 97.51 & $7.1 \mathrm{E}-05$ \\
\hline S2-20 & 800 & 14 & 99.943 & $5.6 \mathrm{E}-06$ & 296.63 & 64.45 & 114.75 & 0.057 & 6.7E-06 & 0.1864 & $1.2 \mathrm{E}-24$ & 2.822 & 5.9E-09 & 96.93 & $7.6 \mathrm{E}-05$ \\
\hline S2-21 & 900 & 14 & 99.949 & $4.8 \mathrm{E}-06$ & 297.00 & 64.45 & 109.18 & 0.051 & $4.8 \mathrm{E}-06$ & 0.1544 & $8.3 E-25$ & 2.542 & 4.9E-09 & 97.25 & $7.4 \mathrm{E}-05$ \\
\hline S2-22 & 1000 & 14 & 99.952 & $4.1 \mathrm{E}-06$ & 297.28 & 64.45 & 104.80 & 0.048 & $3.5 \mathrm{E}-06$ & 0.1307 & $6.0 \mathrm{E}-25$ & 2.316 & 4.1E-09 & 97.50 & $7.1 \mathrm{E}-05$ \\
\hline
\end{tabular}


Tabla E3. Relación de reflujo y del rehervidor. Alimentación del $\mathrm{MeOH}$ a $55^{\circ} \mathrm{C}$, la corriente $2(500 \mathrm{kmol} / \mathrm{h})$ en la etapa 23 y la corriente 1 en la etapa 11 , alimentación de la TO en la etapa 2 a $830^{\circ} \mathrm{C}, 25$ etapas totales, 3 de agotamiento, 1 de rectificación y 21 reactivas (2-22) y 1000L de catalizador.

\begin{tabular}{|c|c|c|c|c|c|c|c|c|c|c|c|c|c|c|c|c|}
\hline \multicolumn{4}{|c|}{ Entrada de simulación } & \multicolumn{13}{|c|}{ Salida de resultados } \\
\hline \multirow[t]{2}{*}{ Corrida } & \multirow{2}{*}{$\begin{array}{l}\text { Flujo } \\
\text { kmol/h } \\
\text { Corriente } \\
1\end{array}$} & \multirow[t]{2}{*}{ Reflujo } & \multirow[t]{2}{*}{ Rehervidor } & \multirow[t]{2}{*}{$\begin{array}{c}\text { Conversión } \\
\text { del AO }\end{array}$} & \multicolumn{2}{|c|}{$\begin{array}{l}\text { Flujo de MO } \\
(\mathrm{kmol} / \mathrm{h})\end{array}$} & \multicolumn{2}{|c|}{ Temperatura $\left({ }^{\circ} \mathrm{C}\right)$} & \multicolumn{2}{|c|}{$\begin{array}{c}\text { Flujo de TO } \\
(\mathrm{kmol} / \mathrm{h})\end{array}$} & \multicolumn{2}{|c|}{$\begin{array}{l}\text { Flujo DO } \\
(\mathrm{kmol} / \mathrm{h})\end{array}$} & \multicolumn{2}{|c|}{$\begin{array}{c}\text { Flujo MOO } \\
(\mathrm{kmol} / \mathrm{h})\end{array}$} & \multicolumn{2}{|c|}{$\begin{array}{l}\text { Flujo Glicerol } \\
(\mathrm{kmol} / \mathrm{h})\end{array}$} \\
\hline & & & & & Domo & Total & Domo & Fondo & Domo & Fondo & Fondo & Domo & Fondo & Domo & Fondo & Domo \\
\hline S3-1 & 600 & 3.5 & 4 & 99.929 & $5.3 \mathrm{E}-06$ & 296.06 & 64.45 & 124.24 & 0.071 & $7.3 \mathrm{E}-06$ & 0.241 & $1.3 \mathrm{E}-24$ & 3.25 & $5.7 \mathrm{E}-09$ & 96.44 & $6.7 \mathrm{E}-05$ \\
\hline S3-2 & 700 & 3.5 & 4 & 99.941 & $4.5 \mathrm{E}-06$ & 296.58 & 64.45 & 115.81 & 0.059 & $5.0 \mathrm{E}-06$ & 0.192 & $8.6 \mathrm{E}-25$ & 2.86 & 4.6E-09 & 96.89 & $6.4 \mathrm{E}-05$ \\
\hline S3-3 & 800 & 3.5 & 4 & 99.947 & $3.8 \mathrm{E}-06$ & 296.97 & 64.45 & 109.70 & 0.053 & $3.5 \mathrm{E}-06$ & 0.157 & $6.0 \mathrm{E}-25$ & 2.56 & $3.8 \mathrm{E}-09$ & 97.23 & $6.2 \mathrm{E}-05$ \\
\hline S3-4 & 900 & 3.5 & 4 & 99.948 & $3.3 \mathrm{E}-06$ & 297.26 & 64.45 & 104.99 & 0.052 & $2.5 \mathrm{E}-06$ & 0.132 & $4.2 \mathrm{E}-25$ & 2.32 & $3.2 \mathrm{E}-09$ & 97.50 & $6.0 \mathrm{E}-05$ \\
\hline $3-5$ & 600 & 4 & 4 & 99.937 & $3.8 \mathrm{E}-06$ & 296.41 & 64.45 & 118.38 & 0.063 & $4.2 \mathrm{E}-06$ & 0.207 & $7.3 \mathrm{E}-25$ & 2.99 & 4.0E-09 & 96.75 & $5.6 \mathrm{E}-05$ \\
\hline S3-6 & 700 & 4 & 4 & 99.945 & $3.2 \mathrm{E}-06$ & 296.86 & 64.45 & 111.33 & 0.055 & $2.9 \mathrm{E}-06$ & 0.166 & $4.9 \mathrm{E}-25$ & 2.64 & $3.2 \mathrm{E}-09$ & 97.13 & $5.4 \mathrm{E}-05$ \\
\hline S3-7 & 800 & 4 & 4 & 99.947 & $2.8 \mathrm{E}-06$ & 297.19 & 64.45 & 106.05 & 0.053 & $2.0 \mathrm{E}-06$ & 0.138 & $3.4 \mathrm{E}-25$ & 2.38 & 2.7E-09 & 97.43 & $5.2 \mathrm{E}-05$ \\
\hline S3-8 & 900 & 4 & 4 & 99.946 & $2.4 \mathrm{E}-06$ & 297.44 & 64.45 & 101.90 & 0.054 & $1.5 \mathrm{E}-06$ & 0.117 & $2.5 \mathrm{E}-25$ & 2.17 & $2.2 \mathrm{E}-09$ & 97.66 & $5.0 \mathrm{E}-05$ \\
\hline S3-9 & 600 & 4 & 4.5 & 99.942 & $3.3 \mathrm{E}-06$ & 296.65 & 64.45 & 124.37 & 0.058 & $3.1 E-06$ & 0.185 & $5.3 \mathrm{E}-25$ & 2.80 & $3.4 \mathrm{E}-09$ & 96.96 & $5.4 \mathrm{E}-05$ \\
\hline S3-10 & 700 & 4 & 4.5 & 99.946 & $2.8 \mathrm{E}-06$ & 297.05 & 64.45 & 115.91 & 0.054 & $2.1 \mathrm{E}-06$ & 0.150 & $3.6 \mathrm{E}-25$ & 2.49 & 2.7E-09 & 97.30 & $5.2 \mathrm{E}-05$ \\
\hline S3-11 & 800 & 4 & 4.5 & 99.946 & $2.4 \mathrm{E}-06$ & 297.34 & 64.45 & 109.79 & 0.054 & $1.5 \mathrm{E}-06$ & 0.125 & $2.5 \mathrm{E}-25$ & 2.25 & $2.3 \mathrm{E}-09$ & 97.57 & $5.0 \mathrm{E}-05$ \\
\hline S3-12 & 900 & 4 & 4.5 & 99.943 & $2.1 \mathrm{E}-06$ & 297.56 & 64.45 & 105.07 & 0.057 & $1.1 \mathrm{E}-06$ & 0.107 & $2.1 \mathrm{E}-25$ & 2.06 & $1.9 \mathrm{E}-09$ & 97.78 & $4.8 \mathrm{E}-05$ \\
\hline
\end{tabular}


Apéndice E

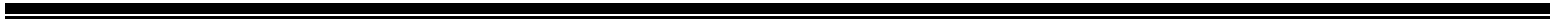

